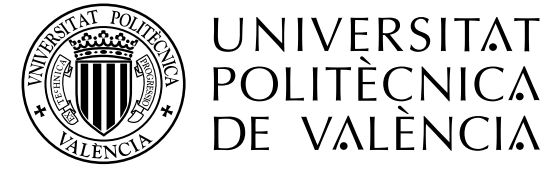

Programa de Doctorado en Ingeniería del Agua y Medioambiental

\title{
Assessment and implementation of evolutionary algorithms for optimal management rules design in water resources systems
}

CANDIDATE:

NÉSTOR LERMA ELVIRA

PhD Thesis

DIRECTORS:

PhD. JaVier Paredes Arquiola

PhD. JoAquín ANDReu Álvarez

September 2017 

Everything seems impossible until it is done NELSON MANDELA, 1918-2013 

Defendiendo esta tesis doctoral finaliza un ciclo importante de mi vida. Tras pasar por la guardería, el colegio, el instituto, estudiar una carrera, un máster y, por último, desarrollar una tesis doctoral, la vida de estudiante e investigador deja paso a una nueva etapa como profesional. Por ello, quiero expresar mi agradecimiento a todas aquellas personas que han hecho posible que yo esté ahora mismo donde estoy. No puedo nombrar a todas, pero si quiero reconocer el valor de las más destacadas.

A mis directores, D. Javier Paredes Arquiola y D. Joaquín Andreu Álvarez, por todo el tiempo que me han dedicado en mi carrera como investigador desde que empecé con el Proyecto Final de Carrera. Su opinión y conocimiento han sido muy valiosos para sacar adelante el trabajo realizado. En especial a Javier, que confió en mí desde el principio, me dio la oportunidad de trabajar con ellos $y$, además, me introdujo de lleno en la programación que es algo con lo que disfruto continuamente.

A mis compañeros y amigos de despacho, María, Andrea, Edgar, Antonio y Héctor (entre otros muchos que he conocido), por ayudarme, darme consejos y estar ahí durante todo este tiempo. En especial a María y Edgar, con los que en breve voy a empezar una nueva etapa profesional.

En el ámbito familiar, indiscutiblemente a mi madre, Cristina, por estar siempre ahi, cuando la he necesitado y cuando no, pendiente de mí y de mis estudios, pero sobre todo de mi felicidad. A mi hermano Carlos, por su apoyo a lo largo de los años, tanto en los estudios como en los momentos de diversión de la infancia, jugando e incluso peleándonos. A su mujer Cristina, por los buenos momentos que hemos pasado juntos desde hace ya más de 9 años, por su ayuda en cierta parte de mi investigación y por sus consejos.

Por último, aunque le considero indudablemente parte de la familia, requiere un agradecimiento muy especial mi pareja Laura. Ella ha estado ahi, en los buenos momentos y en los no tan buenos. Durante casi ya 10 años ha sido mi confidente, pero sobre todo mi amor, la que me ha hecho ver el lado positivo de las cosas y la que me ha animado cuando más lo necesitaba. Sin su apoyo no creo que hubiese acabado esta empresa, pero ahora que ya está se lo agradezco con todo mi corazón. 



\section{ACKNOWLEDGEMENTS}

The author of this thesis and his directors wish to thank the Spanish Ministry of Economy and Competitiveness for its financial support through the NUTEGES project (CGL2012-34978), the FPI fellowship (BES-2013-062954), and for the FPI stay (EEBB-I-16-10731). These financial supports have allowed the researcher to develop his research.

Another special mention is for the University of Cagliari (Sardinia, Italy) and the Basin Agency of Sardinia, who provided the data for the development of this study, as well as the Autonomous Region of Sardinia who funded the research project CRP 2_716.

Finally, the author expresses his gratitude to the Laboratory of Hydraulic Constructions of the Swiss Federal Institute of Technology in Lausanne (Switzerland) for the invitation of the 3 months stay and for the participation in the research project in the field of flood control. 



\section{ABSTRACT}

Water is an essential resource from an environmental, biological, economic or social point of view. In basin management, the irregular distribution in time and in space of this resource is well known. This issue is worsened by extreme climate conditions, generating drought periods or flood events. For both situations, optimal management is necessary. In one case, different water uses should be supplied efficiently using the available surface and groundwater resources. In another case, the most important goal is to avoid damages in flood areas, including the loss of human lives, but also to optimize the revenue of energy production in hydropower plants, or in other uses.

The approach presented in this thesis proposes to obtain optimal management rules in water resource systems. With this aim, evolutionary algorithms were combined with simulation models. The first ones, as optimization tools, are responsible for guiding the process iterations. In each iteration, a new management rule is defined in the simulation model, which is computed to comprehend the situation of the system after applying this new management. For testing the proposed methodology, four evolutionary algorithms were assessed combining them with two simulation models. The methodology was implemented in four real case studies.

This thesis is presented as a compendium of five manuscripts: three scientific papers published in journals (which are indexed in the Journal Citation Report), another under review also in an indexed journal, and the last manuscript from Conference Proceedings. In the first manuscript, the Pikaia optimization algorithm was combined with the network flow SIMGES simulation model for obtaining four different types of optimal management rules in the Júcar River Basin. In addition, the parameters of the Pikaia algorithm were also analyzed to identify the best combination of them to use in the optimization process. In the second scientific paper, the multiobjective NSGA-II algorithm was assessed to obtain a parametric management rule in the Mijares River basin. In this case, the same simulation model was linked with the evolutionary algorithm. The results of this optimization process were presented in different colored plots to facilitate the decision makers for the selection of the best management of the system. In the Conference manuscript, an in-depth analysis of the Tirso-FlumendosaCampidano system using different scenarios and comparing three water simulation models for water resources management was developed. The 
third published manuscript presented the assessment and comparison of two evolutionary algorithms for obtaining optimal rules in the TirsoFlumendosa-Campidano system using SIMGES model. The algorithms assessed were the SCE-UA and the Scatter Search. In this research paper, the parameters of both algorithms were also analyzed as it was done with the Pikaia algorithm. The management rules in the three first manuscripts were focused to avoid or minimize deficits in urban and agrarian demands and, in some case studies, also to minimize the water pumped. Finally, in the last document, two of the algorithms used in previous manuscripts were assessed, the mono-objective SCE-UA and the multi-objective NSGA-II. For this research, the algorithms were combined with RS MINERVE software to manage flood events in Visp River basin minimizing damages in risk areas and losses in hydropower plants.

Results reached in the five manuscripts demonstrate the validity of the approach. In all the case studies and with the different evolutionary algorithms assessed, the obtained management rules achieved a better system management than the base scenario of each case. These results usually mean a decrease of the economic costs in the management of water resources. However, comparing the four algorithms assessed, SCE-UA algorithm proved to be the most efficient due to the different stop/convergence criteria and its formulation. Nevertheless, NSGA-II is the most recommended due to its multi-objective search focus on the enhancement of different objectives with the same importance where the decision makers can make the best decision for the management of the system. 


\section{RESUMEN}

El agua es un recurso esencial desde el punto de vista ambiental, biológico, económico o social. En la gestión de cuencas, es bien conocido que la distribución del recurso en el tiempo y el espacio es irregular. Este problema se agrava debido a condiciones climáticas extremas, generando períodos de sequía o inundaciones. Para ambas situaciones, una gestión óptima es necesaria. En un caso, el suministro de agua a los diferentes usos del sistema debe realizarte eficientemente empleando los recursos disponibles, tanto superficiales como subterráneos. En el otro caso, el objetivo más importante es evitar daños en las zonas de inundación, incluyendo la pérdida de vidas humanas, pero al mismo tiempo, optimizar los beneficios de centrales hidroeléctricas, o de otros usos.

El enfoque presentado en esta tesis propone la obtención de reglas de gestión óptimas en sistemas reales de recursos hídricos. Con este objetivo, se combinaron algoritmos evolutivos con modelos de simulación. Los primeros, como herramientas de optimización, encargados de guiar las iteraciones del proceso. En cada iteración se define una nueva regla de gestión en el modelo de simulación, que se evalúa para conocer la situación del sistema después de aplicar esta nueva gestión. Para probar la metodología propuesta, se evaluaron cuatro algoritmos evolutivos combinándolos con dos modelos de simulación. La metodología se implementó en cuatro casos de estudio reales.

Esta tesis se presenta como un compendio de cinco publicaciones: tres de ellas en revistas indexadas en el Journal Citation Report, otra en revisión y la última como publicación de un congreso. En el primer manuscrito, el algoritmo de optimización Pikaia se combinó con el modelo de simulación SIMGES para obtener reglas de gestión óptimas en la cuenca del río Júcar. Además, se analizaron los parámetros del algoritmo para identificar la mejor combinación de los mismos en el proceso de optimización. El segundo artículo evaluó el algoritmo multi-objetivo NSGA-II para obtener una regla de gestión paramétrica en la cuenca del río Mijares. Los resultados de este proceso de optimización se presentaron en diferentes gráficos de colores para facilitar la selección de la mejor gestión por parte de los tomadores de decisiones. En el trabajo presentado en el congreso se desarrolló un análisis en profundidad del sistema Tirso-Flumendosa-Campidano utilizando 
diferentes escenarios y comparando tres modelos de simulación para la gestión de los recursos hídricos. En el tercer manuscrito publicado se evaluó y comparó dos algoritmos evolutivos (SCE-UA y Scatter Search) para obtener reglas de gestión óptimas en el sistema Tirso-Flumendosa-Campidano. En dicha investigación también se analizaron los parámetros de ambos algoritmos. Las reglas de gestión de estas cuatro publicaciones se enfocaron en evitar o minimizar los déficits de las demandas urbanas y agrarias y, en ciertos casos, también en minimizar el caudal bombeado, utilizando para ello el modelo de simulación SIMGES. Finalmente, en la última publicación se evaluó el algoritmo mono-objetivo SCE-UA y el multi-objetivo NSGA-II. Para esta investigación, los algoritmos se combinaron con el software RS MINERVE para gestionar los eventos de inundación en la cuenca del río Visp minimizando los daños en las zonas de riesgo y las pérdidas en las centrales hidroeléctricas.

Los resultados obtenidos en las cinco publicaciones demuestran la validez del enfoque. En todos los casos de estudio y, con los diferentes algoritmos evolutivos evaluados, las reglas de gestión obtenidas lograron una mejor gestión del sistema que el escenario base de cada caso. Estos resultados suelen representar una disminución de los costes económicos en la gestión de los recursos hídricos. Comparando los cuatro algoritmos, el SCE-UA demostró ser el más eficiente debido a los diferentes criterios de convergencia. No obstante, el NSGA-II es el más recomendado debido a su búsqueda multi-objetivo enfocada en la mejora, con la misma importancia, de diferentes objetivos, donde los tomadores de decisiones pueden seleccionar la mejor decisión para la gestión del sistema. 


\section{RESUM}

L'aigua és un recurs essencial des del punt de vista ambiental, biològic, econòmic o social. En la gestió de conques, és ben conegut que la distribució del recurs en el temps i l'espai és irregular. Este problema s'agreuja a causa de condicions climàtiques extremes, generant períodes de sequera o inundacions. Per a ambdúes situacions, una gestió òptima és necessària. En un cas, el subministrament d'aigua als diferents usos del sistema ha de realitzar-se eficientment utilitzant els recursos disponibles, tant superficials com subterranis. En l'altre cas, l'objectiu més important és evitar danys en les zones d'inundació, incloent la pèrdua de vides humanes, però al mateix temps, optimitzar els beneficis de centrals hidroelèctriques, o d'altres usos.

La proposta d'esta tesi és l'obtenció de regles de gestió òptimes en sistemes reals de recursos hídrics. Amb este objectiu, es van combinar algoritmes evolutius amb models de simulació. Els primers, com a ferramentes d'optimització, encarregats de guiar les iteracions del procés. En cada iteració es definix una nova regla de gestió en el model de simulació, que s'avalua per a conéixer la situació del sistema després d'aplicar esta nova gestió. Per a provar la metodologia proposada, es van avaluar quatre algoritmes evolutius combinant-los amb dos models de simulació. La metodologia es va implementar en quatre casos d'estudi reals.

Esta tesi es presenta com un compendi de cinc publicacions: tres d'elles en revistes indexades en el Journal Citation Report, una altra en revisió i l'última com a publicació d'un congrés. En el primer manuscrit, l'algoritme d'optimització Pikaia es va combinar amb el model de simulació SIMGES per a obtindre regles de gestió òptimes en la conca del riu Xúquer. A més, es van analitzar els paràmetres de l'algoritme per a identificar la millor combinació dels mateixos en el procés d'optimització. El segon article va avaluar l'algoritme multi-objectiu NSGA-II per a obtindre una regla de gestió paramètrica en la conca del riu Millars. Els resultats d'este procés d'optimització es van presentar en diferents gràfics de colors per a facilitar la selecció de la millor gestió per part dels decisors. En el treball presentat en el congrés es va desenvolupar una anàlisi en profunditat del sistema TirsoFlumendosa-Campidano utilitzant diferents escenaris i comparant tres models de simulació per a la gestió dels recursos hídrics. En el tercer 
manuscrit publicat es va avaluar i va comparar dos algoritmes evolutius (SCEUA i Scatter Search) per a obtindre regles de gestió òptimes en el sistema Tirso-Flumendosa-Campidano. En dita investigació també es van analitzar els paràmetres d'ambdós algoritmes. Les regles de gestió d'estes quatre publicacions es van enfocar a evitar o minimitzar els dèficits de les demandes urbanes i agràries $i$, en certs casos, també a minimitzar el cabal bombejat, utilitzant per a això el model de simulació SIMGES. Finalment, en l'última publicació es va avaluar l'algoritme mono-objectiu SCE-UA i el multi-objetiu NSGA-II. Per a esta investigació, els algoritmes es van combinar amb el programa RS MINERVE per a gestionar els esdeveniments d'inundació en la conca del riu Visp minimitzant els danys en les zones de risc i les pèrdues en les centrals hidroelèctriques.

Els resultats obtinguts en les cinc publicacions demostren la validesa de la metodología. En tots els casos d'estudi i, amb els diferents algoritmes evolutius avaluats, les regles de gestió obtingudes van aconseguir una millor gestió del sistema que l'escenari base de cada cas. Estos resultats solen representar una disminució dels costos econòmics en la gestió dels recursos hídrics. Comparant els quatre algoritmes, el SCE-UA va demostrar ser el més eficient a causa dels diferents criteris de convergència. No obstant això, el NSGA-Il és el més recomanat a causa de la seua cerca multi-objectiu enfocada en la millora, amb la mateixa importància, de diferents objectius, on els decisors poden seleccionar la millor opció per a la gestió del sistema. 


\section{CONTENTS}

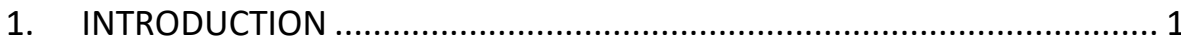

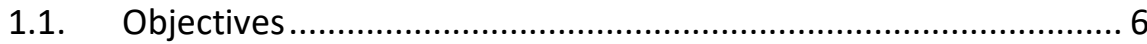

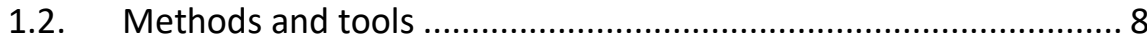

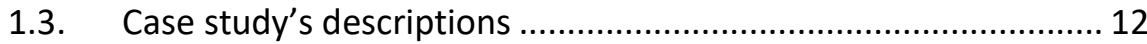

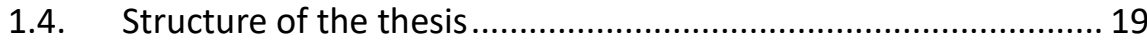

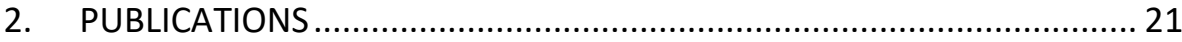

2.1. Development of operating rules for a complex multireservoir system by coupling genetic algorithms and network optimisation ......... 22

2.2. Evolutionary network flow models for obtaining operation rules in multi-reservoir water systems 23

2.3. Comparativa de herramientas para el desarrollo de Sistemas Soporte a la Decisión para los sistemas de recursos hídricos de Cerdeña, Italia 23

2.4. Assessment of evolutionary algorithms for optimal operating rules design in real water resource systems .................................................. 25

2.5. Optimization assessment of hydropower plants during floods in Visp basin (Switzerland) using evolutionary algorithms ......................... 26

3. GENERAL DISCUSSION OF THE RESULTS....................................... 27

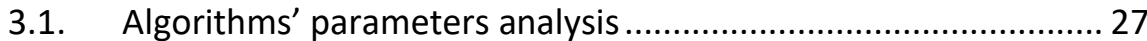

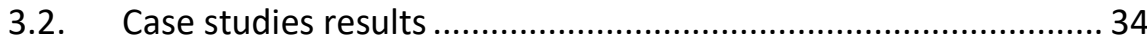




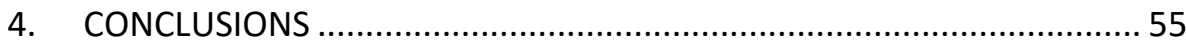

4.1. Algorithms parameters............................................................. 55

4.2. Methodology application ........................................................ 57

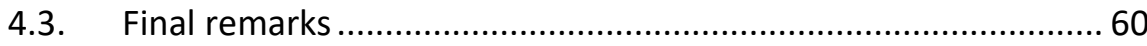

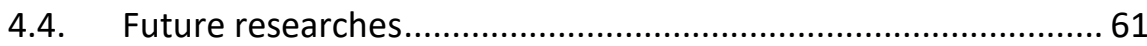

\section{ANNEXES}

REFERENCES

63

A.1. Development of operating rules for a complex multireservoir system by coupling genetic algorithms and network optimisation. 79

A.2. Evolutionary network flow models for obtaining operation rules in multireservoir water systems.

A.3. Assessment of evolutionary algorithms for optimal operating rules design in real water resource systems. 149

A.4. Optimization assessment of hydropower plants during floods in Visp basin (Switzerland) using evolutionary algorithms. 189

A.5. Comparativa de herramientas para el desarrollo de Sistemas Soporte a la Decisión para los sistemas de recursos hídricos de Cerdeña, Italia. 


\section{List of figures}

Figure 1: Proposed methodology to obtain optimal MRs in WRSs. 8

Figure 2: Location of the Júcar River basin (source: Lerma et al., 2013). .... 13

Figure 3: Topology of the simulation model developed for the Júcar River basin.

Figure 4: Location of the Mijares River basin (source: Lerma et al., 2014).. 14

Figure 5: Topology of the simulation model developed for the Mijares River basin. 15

Figure 6: Location of Tirso-Flumendosa-Campidano system in Sardinia (Italy). 16

Figure 7: Schematic of Tirso-Flumendosa-Campidano system (source: Lerma et al., 2015)

Figure 8: Case Study location. Visp basin in Valais Canton (Switzerland) (source Lerma et al., 2017). 18

Figure 9: Case study model in RS MINERVE software (source Lerma et al., 2017) 18

Figure 10: Schematic flow chart for research paper 1 22

Figure 11: Schematic flow chart for research paper 2 23

Figure 12: Schematic flow chart for the Conference manuscript. 24

Figure 13: Schematic flow chart for research paper 3 25

Figure 14: Schematic flow chart for research paper 4. 26

Figure 15 a-f: Results of the OF for different test developed for definition of the EA-parameters (adapted from Lerma et al., 2013) 28 
Figure 16: Performed test with SCE-UA algorithm (source: Lerma et al., 2015).

Figure 17: Performed test with Scatter Search algorithm (source: Lerma et al., 2015)

Figure 18: a-d. Evolution of the OF, volume stored, and restriction coefficient for the "April-September" MR (adapted from Lerma et al., 2013).

Figure 19: Pareto front 1; maximum deficits for the agricultural demands (for color-marker coding, see Table 3) (source: Lerma et al. (2014). 39

Figure 20: Pareto front 2; number years pumped versus deficit of the agricultural demands (for color-marker coding, see Table 3) (source: Lerma et al. (2014). 40

Figure 21: Restriction coefficient (for color-marker coding, see Table 3) (source: Lerma et al. (2014).

Figure 22: Obtained results using the SCE-UA algorithm (source: Lerma et al. (2015)).

Figure 23: Obtained results using the Scatter Search algorithm (source: Lerma et al. (2015)). 46

Figure 24: Result comparative using SCE-UA (b), NSGA-II (c) and without optimization (a). Where [Qmanagement Visp] = [Qnatural Visp]+[Upper river flow of Visp]+[Zer Turbine] (adapted from Lerma et al., 2017). 49

Figure 25: NSGA-II (orange) vs SCE-UA (blue) search space for the analyzed forecast (6). 3D view (i), OF1 vs OF2 (ii), OF1 vs OF3 (iii) and OF2 vs OF3 (iv) (adapted from Lerma et al., 2017). 51

Figure 26: Colored plots of the NSGA-II solutions for the forecast 6. 3D view (i), OF1 vs OF2 (ii), OF1 vs OF3 (iii) and OF2 vs OF3 (iv). From the worst solutions (red) to the best ones (green) (source Lerma et al., 2017). 52 


\section{List of tables}

Table 1: EAs and Simulation model used in each case study..................... 7

Table 2: OF and maximum deficits for 1 year and 10 years accumulated for the irrigation demands (adaptation of Lerma et al. (2013)). 36

Table 3: Color-marker coding adopted in Figures 7-11 (source: Lerma et al., 2014) 40

Table 4: Results of deficits and pumping without $M R$ and with the “Agreement 70" rule curve (source: Lerma et al. (2014)) 43

Table 5: Results of the current management system for the case study (source: Lerma et al. (2015)). 44

Table 6: OF values for the analyzed forecast (6) without optimization (a) and with SCE-UA (b) and NSGA-II (c) algorithms (adapted from Lerma et al., 2017). 



\section{INTRODUCTION}

Living beings need water to survive, a resource which is also essential from an environmental, economic or social point of view. When water is used for biological purposes, the main problem is its availability. Usually, this resource has an irregular distribution in time and in space. Moreover, extreme climate conditions can worsen these effects generating drought periods or flood events. In both cases, an optimal management of the resource is necessary. In the first case, the available surface and groundwater resource must be distributed between the different uses according to their priorities. In the second case, avoiding damages in flood areas is the most important goal, but also to optimize revenue due to the different water uses, like electricity production in hydropower plants.

In multi-reservoir water systems, there is a lack of application of optimization models (Labadie, 2004; Wurbs, 1993; Yeh, 1985). The necessarily high degree of simplification of these types of models, which remove them excessively far from reality, is one of the main reasons for this shortcoming (Akter and Simonovic, 2004; Moeini et al., 2011). Due to this simplification, it has consequently made water managers not trust the results of these models. Nevertheless, other authors consider that institutional limitations are the real cause, rather than technological or mathematical ones (Oliveira and Loucks, 1997).

Optimization techniques are employed for multi-reservoir systems in the majority of water allocation problems. Labadie (2004) and Rani and Moreira (2010) reviewed the state of the art of these techniques for this type of problem. These authors commented that the most favored technique for water allocation models has been linear programming, which is the most traditional (ReVelle, 1999). This technique has been used for optimizing resources management of river basin schemes (Zoltay et al., 2010), optimizing irrigation water allocation in complex agricultural systems (Reca et al., 2001a, 2001b) and developing decision support systems for urban water supply areas (Yamout and El-Fadel, 2005). Kuczera (1989 and 1993) explains that network flow programming, a computationally efficient form of linear programming, is more suitable than linear programming for solving large multi-reservoir models. 
A hydrologic-hydraulic network global analysis is important in numerous decision-making situations as water resources management, reservoir regulation, spillways design, hydropower plant operations optimization or the flood protection development (García et al., 2016). However, there is no general method for optimizing reservoir operations (Yeh, 1985). Linear programming, heuristic approaches, stochastic dynamic programming methods (Celeste and Billib, 2009; Mousavi et al., 2004; Tilmant et al., 2002), evolutionary optimization (Oliveira and Loucks, 1997) and other approaches are typical methods of optimizing reservoir operations. For using these methods, the water resource management problem requires a large number of control variables, which, typically, represent the sequences of releases from all reservoirs and for all time steps of the studied period (Koutsoyiannis and Economou, 2003).

In flood mitigation studies, system operators make decisions about storing and releasing water according to the possibilities given by reservoirs structures (Farhangi et al., 2012). A necessary task of flood management is to determinate an effective reservoir operation strategy keeping dam safety, maximizing the volume reservoir at the end of the flood event and, especially, minimizing downstream damage (Malekmohammadi et al., 2010; Uysal et al., 2016). In this field, Yeh (1985) used mathematical models for reservoir operations. Dias et al. (1985) optimized power generation requirements and flood control in multi-purpose reservoir. To solve this type of short-term optimal schedule problem, many other authors used network flow methods and linear programming (Lian and Jiang, 2005; Needham et al., 2000; Zeng et al., 2003), artificial neural networks (Naresh and Sharma, 2000), dynamic programming (Zhang and Zhang, 2003), nonlinear programming (Lyra and Ferreira, 1995; Piekutowski et al., 1994) or mathematical decomposition ( $\mathrm{Ni}$ et al., 1999).

Despite the growing use and development of optimization models (Labadie, 1997), simulation models are the most commonly used tool to analyze the integrated planning and management of water resources systems (WRSs). These models allow for more detailed representations of the systems than optimization models (Loucks and Sigvaldason, 1982) or typical optimization schemes such as linear, dynamic or stochastic dynamic programming models. 
These optimization techniques suffer from high dimensionality, and often unrealistic, simplifications concerning the operation of the real systems (Efstratiadis et al., 2004). For these reasons, in general, simulation models are used as support for performing river basin management. These types of models are characterized by their capacity and flexibility for representing very complex elements. However, they require the definition of system management through different management rules (MRs).

In many real water systems, their managers employ MRs to make decisions depending on the storage of the system and/or last inflows, among other indicators. The decisions are normally related to reducing the deficit demand, to increase the available resource, to minimize flood damages or to maximize hydropower plant revenue. These rules can be considered as trigger MRs because one or several actions (for example, reduce supply to demands, start pumping groundwater or start turbine tasks) are triggered when the system reaches a specific situation. Although the use of this kind of MRs is criticized because of its relative inefficiency (Karamouz et al., 2000), they perform the practical management of systems due to their comprehension and ease of application. These rules must be robust as well as simple; therefore, they must be implementable in real applications.

During the scientific history of water resources, the design and obtainment of MRs for multi-reservoir systems has been widely developed (Bhaskar and Whitlatch, 1980; Lund and Ferreira, 1996; Young, 1967). Results of optimization models for obtaining MRs can be done using simple statistics, tables and graphs (Lund and Ferreira, 1996), simple (Young, 1967) or multiple (Bhaskar and Whitlatch, 1980) linear regressions. Unfortunately, a regression analysis can produce poor results, limiting the use of the obtained MR (Labadie, 2004). On the other hand, empirical MRs like the space rule (Bower et al., 1962) or the New York City rule (Clark, 1956) have limited applicability.

In order to solve the issues of simulation and optimization models for obtaining optimal MRs, some authors propose coupling different techniques. For example, (Wurbs, 1993) suggests a modeling approach for combining efficient exploration of mathematical optimization models with adherence and flexibility of simulation models. In this sense, a typical technique for 
obtaining MRs is the iteration with basin simulation models. An optimization algorithm that varies the MRs according to the results of the simulation model runs can control these iterations. Nalbantis and Koutsoyiannis (1997) proposed another methodology introducing a parametric rule based in two parameters per reservoir. They defined and tested this rule by means of linear and nonlinear optimization methods, using a simulation model to evaluate the objective function. This approach has the advantage of using a parsimonious formulation with just two parameters per reservoir making searching most effective than other optimization approaches.

Among the possible optimization algorithms that exist for solving real problems, Evolutionary Algorithms (EAs) are characterized by avoiding local optimal better than gradient methods and by their flexibility for adaptation to any kind of problem. Moreover, these algorithms allow for several benefits compared with classical optimization techniques. EAs can be implemented without heavy a-priori model requirements and their optimization procedures can directly address alternatives when applied to MRs optimization due to the ability to manage discrete variables.

Evolutionary programming, evolutionary strategies and genetic algorithms are the three main paradigms of EAs. In general, these paradigms evolve a population of individuals by subjecting it to similar processes to those that act in the biological evolution (crosses and mutations). The population also suffers a selection process, which depends on survival of the fittest, and the less suitable, who will be discarded.

Nicklow et al. (2010) reviewed the state of the art evolutionary techniques applied to water resource planning and management. Cai et al. (2001) described strategies for solving large nonlinear water resources management models combining EA with linear programming, in which this approach was applied to a reservoir operation model with a nonlinear hydropower generation and to a long-term dynamic river basin planning model. Momtahen and Dariane (2007) used a direct search approach to optimize the parameters of reservoir operating policies with an EA as an optimization method. In the particular case of MRs, Oliveira and Loucks (1997), and later Ahmed and Sarma (2005), presented an approach for 
optimizing MRs for multi-reservoir systems using EAs. Elferchichi et al. (2009) also applied a real-coded EA to optimize the operation of reservoirs for an on-demand irrigation system, and this was later applied to the Sinista Ofanto irrigation scheme (Foggia, Italy). In flood problems, EAs have been applied to optimize a flood control reservoir (Chang and Chen, 1998), also for real-time flood management in river-reservoir systems (Malekmohammadi et al., 2010), or to obtain a daily energy demand in an economic and safe way (Hidalgo et al., 2015).

In real management problems, decision making can be complex and inflexible due to the inherent trade-offs among socio-political, technical, economic and environmental factors. Multiple conflicting objectives, which should be optimized simultaneously (Makropoulos et al., 2008), are involved for selecting the appropriate management strategies. For these reasons, Pareto front concept was defined. This front contains the solutions for which it is not possible to improve on the attainment of one objective without making at least one of the others worse. It has been demonstrated that, multi-objective EAs allow to reach the optimal Pareto front (Abd-Elhamid and Javadi, 2011; Cisty, 2010; Farmani et al., 2005a; Zhou et al., 2015).

Solving a number of complicated real-world problems in hydraulic, electrical, aeronautical or structural engineering, the efficiency of these algorithms has been illustrated (Farmani et al., 2007, 2006, 2005b; Hanne and Nickel, 2005; Molina-Cristóbal et al., 2005; Osman et al., 2005). However, there are limited applications in the policy analysis of water resources management (Farmani et al., 2009; Molina et al., 2011). In this field, multi-objective EAs have been applied in real studies, such us the control of Seawater Intrusion in Coastal Aquifers (Abd-Elhamid and Javadi, 2011; Kourakos and Mantoglou, 2011; Sedki and Ouazar, 2011), the optimal design of water distribution systems or reservoirs (Cisty, 2010; Haghighi et al., 2011; Hınçal et al., 2011; Louati et al., 2011; Nazif et al., 2010), to optimize the rule curves of a multipurpose reservoir system in Taiwan (Chen et al., 2007), the Conjunctive Use of Surface Water and Groundwater (Safavi et al., 2010), for hydrological studies (Dumedah et al., 2010; Gorev et al., 2011; Hassanzadeh et al., 2011), or for solving an optimal multi-objective dispatch of hydroelectric generating units (Villasanti et al., 2004). 


\subsection{Objectives}

This research thesis aims to develop a generalizable methodology to optimize the water management of WRSs. In the last years, various strategies have been defined by using a combination of optimization and simulation techniques. However, full integration of both techniques has not yet been achieved in order to close the gap between research and real-world application. Few of these strategies have been employed in real-world multi-reservoir and multiuse water systems (Sechi and Sulis, 2009). Moreover, although EAs have been applied successfully for many academic problems, additional research is required to enable them to be applied in real-life context (Maier et al., 2014).

These are the grounds that motivated this thesis, in which one of the goals is to achieve optimal management for real and complex WRSs. Moreover, this research assumes the technique, which will be presented later in this document, can be used for different types of problems. Two types of problems are assessed: 1) optimal water distribution between different end-uses using both surface and groundwater resource; and 2) avoiding damages in flood areas meanwhile revenue from different water uses is optimized during flood events. It is important to note that other problems could integrate into the proposed methodology. Furthermore, this research provides the methodologic basis for its application in other real and complex WRS for obtaining optimal MRs in drought and flood events.

The approach proposes the coupling between EAs and models for simulating water management. The methodology searches for optimal MRs in real cases and suggests alternatives for making decisions by decision makers. In this approach, which is applied to four real and complex systems, four different EAs are coupled with two simulation models. These last ones are characterized by their capacity and flexibility for representing very complex elements while EAs are characterized both by avoiding local optimal better than gradient methods and by their flexibility for adaptation to any kind of problem. Table 1 summarizes the different EAs and simulation models used in each real case study, which are described in the points 1.2 and 1.3 of this section. 
Table 1: EAs and Simulation models used in each case study.

\begin{tabular}{c|cc} 
REAL CASE STUDY & $\begin{array}{c}\text { EVOLUTIONARY } \\
\text { ALGORITHM }\end{array}$ & $\begin{array}{c}\text { SIMULATION } \\
\text { MODEL }\end{array}$ \\
\hline Júcar River Basin & PIKAIA & SIMGES \\
Mijares River Basin & NSGA-II & SIMGES \\
Tirso-Flumendosa- & SCE-UA & SIMGES \\
Campidano System & SCATTER SEARCH & WARGI \\
& & AQUATOR \\
& SCE-UA & \\
& NSGA-II & \\
\end{tabular}

Partial objectives were needed to archive the main one. The following points describe some of these goals:

- To develop the main optimization frame, which is able to apply the proposed methodology combining the EAs with SIMGES or RS MINERVE tools.

- To translate NSGA-II and Scatter Search algorithms from other languages to Visual Basic for Applications.

- To develop a new element in RS MINERVE software for regulating the system management.

- To compare three simulation models for water resources management in one of the real and complex systems analyzed.

- To build four simulation models, one for each case study.

- To determine which searching mechanisms and terminationconvergence criteria are best for real-life problems.

- To reach the best way to convey the results of the optimization process to decision makers. 


\subsection{Methods and tools}

This point of the thesis summarizes the methodology and all the involved tools, including the simulation models and the EAs. The proposed methodology was defined with the objective of being generalizable, mainly in terms of case studies, but also for simulation models and EAs. The methodology estimates optimal MRs for a real and complex multireservoir WRS. With this aim, an EA is responsible for controlling the iterative optimization process and, for each iteration, a river basin simulation model is used for evaluating the system management. The Optimization Frame (Figure 1) is responsible for managing the whole process. Although this methodology is defined specifically for this type of problem, it could be also generalizable for other types where a set of parameters should be optimized using a simulation model.

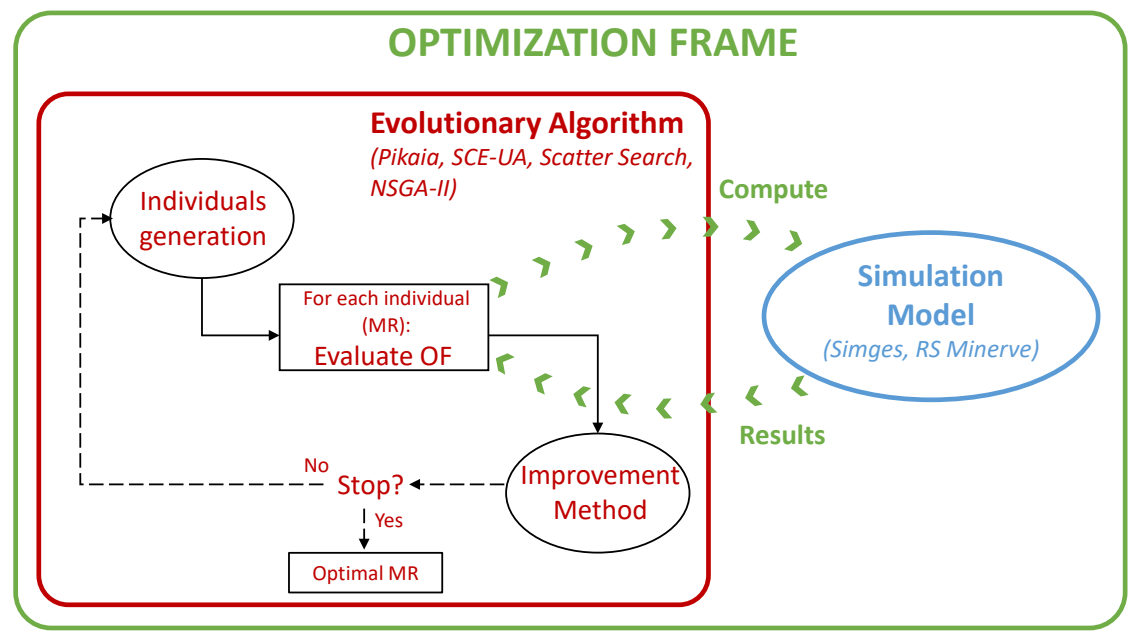

Figure 1: Proposed methodology to obtain optimal MRs in WRSs.

In the first step, the Optimization Frame user needs to define the decision variables, i.e. the MR parameters. The minimum and maximum thresholds of the decision variables are also required by the EA. Furthermore, some algorithm parameters, such as population size, the number of subgroups or the maximum number of iterations should be indicated to define the EA process. 
Every EA implements the optimization process as it is described in the four Annexes. In general, the EA generates several individuals that belong to a MR collection. In this case, each MR aptitude depends on how it affects the WRS management. For this reason, WRS management is computed for each MR, and the obtained results allow the EA to evaluate an objective function (OF). The results obtained by this model represent the situation of the water system under the proposed water management policies. Given the OF value for each individual, the algorithm obtains new values for the decision variables defining new MRs, and the process is repeated until the stop condition for each EA is fulfilled.

From all the EAs in the literature, four were selected to be assessed in this research. PIKAIA (Charbonneau and Knapp, 1995) in Annex 1, SCE-UA (Duan et al., 1992) in Annexes 3 and 4. This last algorithm was selected due to its demonstrated efficiency, which has been widely recognized in calibrating hydrological problems with a large number of parameters and with a high nonlinearity (Boyle et al., 2000; Duan et al., 1992; Kuczera, 1997; Luce and Cundy, 1994). Scatter Search (Glover, 1977) in Annex 3, where its use to design MRs is currently uncommon but has been successfully applied in distribution network calibration problems (Liberatore and Sechi, 2009) as well as a wide range of more general optimization problems (Adenso-Díaz et al., 2006; Campos et al., 2001; Martí, 2006; Scheuerer and Wendolsky, 2006). NSGA-II (Deb et al., 2002) in Annexes 2 and 4. This multi-objective algorithm was chosen due to the scarce or even non-existent studies on coupling network flow models and this type of algorithm. Furthermore, NSGA-II can be coupled to several other simulation models to provide optimized solutions by taking advantage of the power of those models (Farmani et al., 2009; Molina et al., 2011).

The water basin management models have been developed using the SIMGES module (Annexes 1 to 3 ) included in the Decision Support System Shell (DSSS) AQUATOOL (Andreu et al., 1996). Both, the simulation module and the DSSS, have been widely applied to river basins in Spain and abroad (CHJ, 1998; DICTUC, 2010; Jamieson, 1997; MIMAM, 2000; UNICA, 2012). SIMGES model is based on the conceptualization of a river 
basin as a set of interconnected elements that represent the real components of the WRS and their interactions. A large variety of elements are available, as reservoirs, river reaches, channels, aquifers, hydroelectricity generation facilities, groundwater pumping facilities, return flows, demands and intakes, etc.

In Annex 5, a comparative between SIMGES and other two simulation models (WARGI and AQUATOR) was carried out. WARGI (Water Resources System Optimization Aided by Graphical Interface) (Sechi and Zuddas, 2000) was developed by CRIFOR-CINSA (Centro di Ricerca e Formazione delle Reti del Centro Interdipartimentale CINSA) of the Cagliari University. AQUATOR is also a software for simulating complex water resources systems and was developed by Oxford Scientific Software. The conclusions of this study confirmed SIMGES as the simulation model with the best results, in terms of deficits of the demands, stored water in reservoirs and pumping. These better results could be reached because SIMGES module uses optimization techniques for each time step and allows the user to include more MRs in contrast of WARGI and AQUATOR.

RS MINERVE (García et al., 2016) is used to build the river basin model in Annex 4. RS MINERVE is a freeware software. This software is a hydrological-hydraulic tool to compute the water balance in a water system according to different predefined rules. RS MINERVE is used due to its application for studying basins in several projects and thesis in Switzerland, Spain, Peru, China, Brazil or Mexico (Astorayme et al., 2016, 2015; Deval et al., 2011; Drenkhan et al., 2016; García et al., 2014; Jordan et al., 2012; Perez et al., 2016; Rodrigues et al., 2016).

The basic description showed in these lines about the simulation models and the EAs assessed in this research, is included in the five manuscripts and it is fully developed in the Annexes of this document.

PIKAIA is a flexible and easy-to-use genetic algorithm. This EA is based on the search for an optimum using Darwinian evolutionary theory. Although its application has been more frequent in astrophysics, it has also been 
used in the calibration of water quality parameters with the QUAL2K model (Pelletier et al., 2006). The algorithm is based on six steps: initial population generation, fitness evaluation, selection, crossover, mutation, replacement and evaluation. It has two basic genetic operators: uniform crossover and mutation.

NSGA-II (Elitist Non-Dominated Sorting Genetic Algorithm) is a multiobjective EA with a specific operator to handle constraints. In this method, a fast, non-dominated sorting approach with a selection operator is used to create a mating pool by combining the parent and offspring populations and selecting the best solutions with respect to the fitness and the spread (Deb et al., 2002; Dumedah et al., 2010). The next generation is populated starting with the best non-dominated front and progresses through the rest of the fronts until the population size is reached, and if, in the final stage, there are more individuals in the nondominated front than there is available space, a crowded distance-based niching strategy is used to choose which individuals of that front are entered into the next population. The crowding distance value of a solution provides an estimate of the density of solutions surrounding that solution (Raquel and Naval, 2005). In this research, NSGA-II is used for the evaluation of the objective functions that allow knowing the aptitude of the operation rules.

The SCE-UA optimization mechanism (the Shuffled Complex Evolution) was developed at the University of Arizona. The basic operation of the SCE-UA algorithm, inspired by the principles of natural selection and genetics, is a combination of deterministic and random processes. The departing point is from different search points (individuals) that are organized by teams (complexes). Searching for the globally optimized solution, an evolutionary process (evolution) is designed. This process is based on different reproduction methods such as crossing, mutation or recombination, and team mixing (shuffle).

Finally, the Scatter Search algorithm is a metaheuristic procedure based upon formulations of strategies for generating candidate solutions. The concepts and principles of this method are based on the strategy of 
combining decision rules. The Scatter Search operates on a set of solutions, called the Reference Set, and combines them to create new solutions that improve the original ones. In this sense, the Scatter Search should be considered as an EA. However, contrary to other evolutionary methods, such as genetic algorithms, the Scatter Search algorithm is not based upon randomness over a relatively large group of solutions but is based upon systematic and strategic choices over a small group. Typically, genetic algorithms consider large population sizes (100 solutions as an order of magnitude), whereas the Scatter Search utilizes an equivalent set of only 10 solutions.

\subsection{Case study's descriptions}

All the case studies, to which the methodology was applied, are presented in this point. Three of them are representatives of Mediterranean climate. Júcar River basin and Mijares River basin are sited to the east of the Iberian Peninsula. The Tirso-Flumendosa-Campidano system is located in Sardinia Island, in the Mediterranean Sea. All three systems are also characterized, and for this reason representative of frequent drought events. However, the last system, Visp River basin is located in the Pennine Alps and is a typical case where flood events occur.

\section{Júcar River basin}

In the first journal manuscript, the proposed methodology is applied to the Júcar River basin. This basin is located in the east of Spain (Figure 2). Its area covers $22,378 \mathrm{~km}^{2}$ and the mainstream length is almost $550 \mathrm{~km}$. The water resources average is $1,200 \mathrm{hm}^{3} /$ year comprising both surface water and groundwater. These water resources are due to an average basin precipitation of $510 \mathrm{~mm} /$ year. 


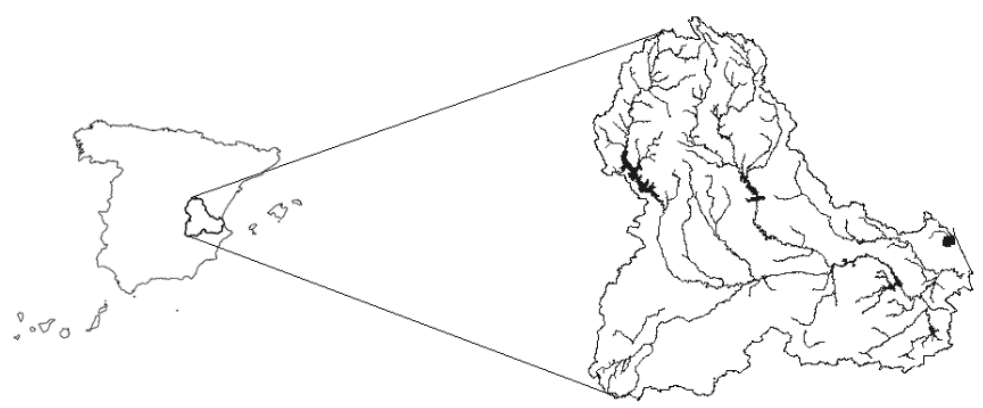

Figure 2: Location of the Júcar River basin (source: Lerma et al., 2013).

The management of this basin is complex due to the multiple uses of its resources. Although there are some important urban demands, agriculture use is the most important water consumption demand, with a value of $1,000 \mathrm{hm}^{3} /$ year. Mainly, this use occurs between April and September. The storage capacity of the main reservoirs is $2,000 \mathrm{hm}^{3}$ in total. Although these values may indicate that the basin resources are sufficient, the system suffers frequent over-annual droughts due to the Mediterranean climatology, with a strong winter-summer gradient and series of dry years between wet periods.

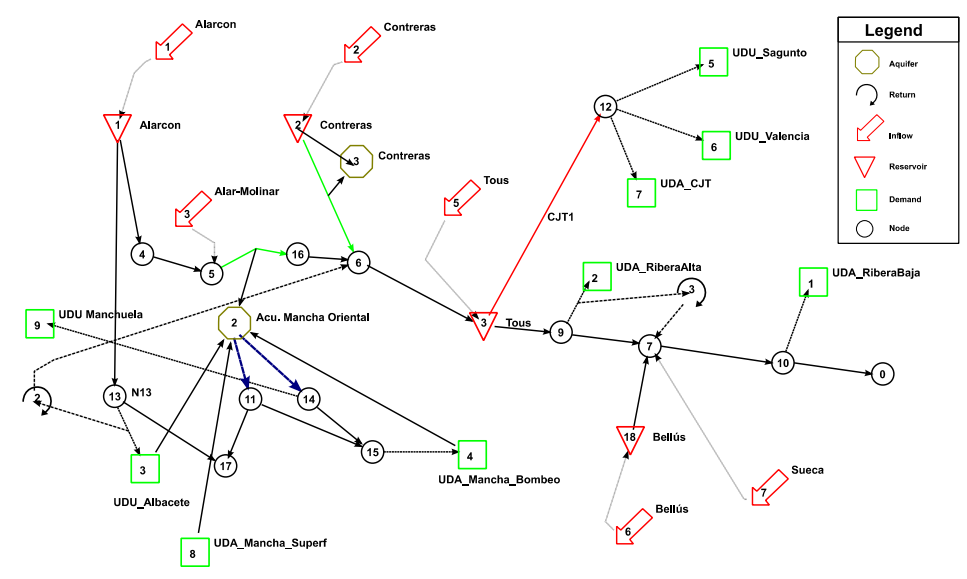

Figure 3: Topology of the simulation model developed for the Júcar River basin. 
Figure 3 shows the topology of the system, with the main reservoirs and demands. The last ones can be classified by their supply source into surface, groundwater and mixed supplies.

\section{Mijares River basin}

The second research paper was applied to the Mijares River basin, which is located in the eastern slope of Spain (Figure 4). The basin surface is $5,466 \mathrm{~km}^{2}$.

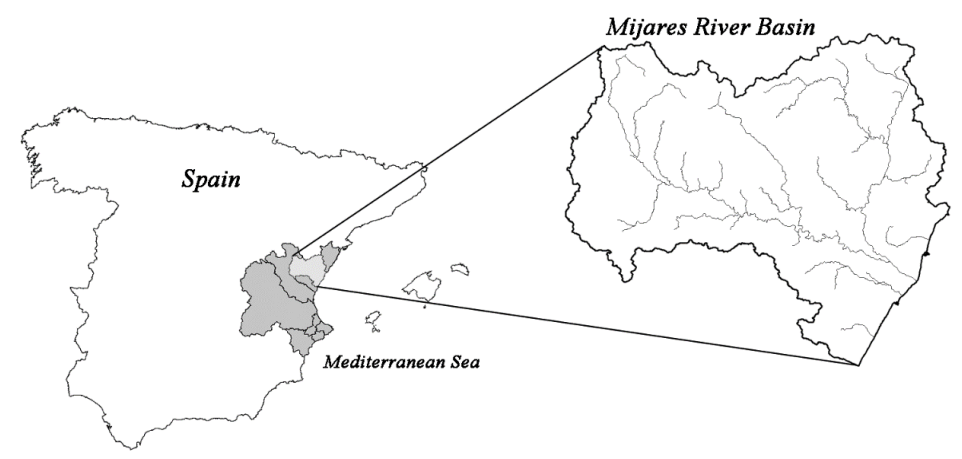

Figure 4: Location of the Mijares River basin (source: Lerma et al., 2014).

The basin is subdivided in two climatologically different geographical areas. The first one is characterized by a coastal climate with a Mediterranean coastline and, the second one, by a continental climate area located upstream of the Arenós reservoir. According to the Basin Water Plan (CHJ, 1998), the mean annual rainfall in Mijares River basin is $505 \mathrm{~mm}$, and the average temperature is 14.4 으. The maximum altitude is $2024 \mathrm{~m}$ above sea level. The average runoff is $380 \mathrm{Hm}^{3} /$ year and the length of the main river is approximately $156 \mathrm{~km}$.

The topology of the model for the Mijares water system is shown in Figure 5. It includes three reservoirs, Arenós $\left(95 \mathrm{Hm}^{3}\right)$, Sichar $\left(49 \mathrm{Hm}^{3}\right)$ and María Cristina $\left(19.7 \mathrm{Hm}^{3}\right)$. The urban demands are supplied from the exploitation of pumping wells and the use of springs. Regarding to agrarian demands, the irrigated land area is 48,509 ha. 


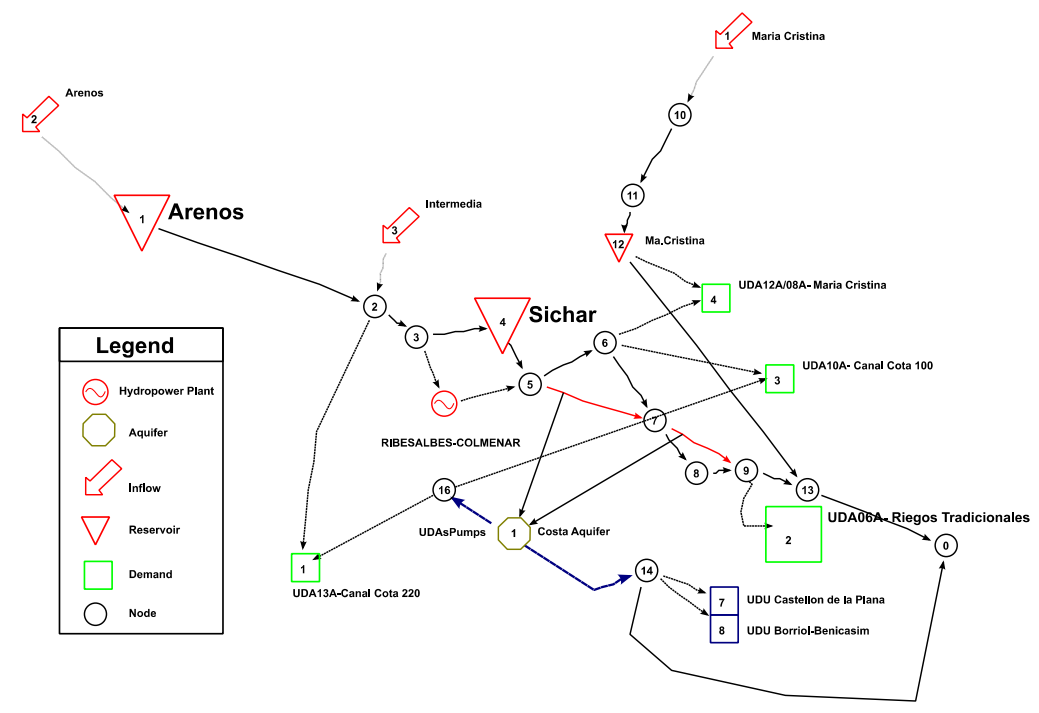

Figure 5: Topology of the simulation model developed for the Mijares River basin.

The water rights over surface water of the traditionally irrigated area in the low part of the basin are senior with respect to other more recent agricultural uses. The other agrarian demands in the basin represent modern irrigation, also called "mixed irrigation" due to the possibility of using both surface and ground water.

The current system management is based on a rule curve defined in 1970 ("Agreement 70 "). If the sum of the volume of the reservoirs is greater than this rule curve, then all the demands can use cheaper surface water. However, when the volume storage is lower than the curve, mixed irrigation demands have to pump water, and the remaining surface water is reserved for the traditionally irrigated area.

\section{Tirso-Flumendosa-Campidano system}

In the third journal manuscript (Annex 3), the proposed methodology is applied to the Tirso-Flumendosa-Campidano system, which is located on Sardinia Island (Italy) (Figure 6). This system is also studied in the Conference manuscript (Annex 5). The island has a Mediterranean climate 
and the system is characterized by irregular distribution of demand in time and by irregular distributions of water resources in both time and space. The average hydrological inflow of water resources to the system is approximately $750 \mathrm{hm}^{3} /$ year and the total system demand is 383.25 $\mathrm{hm}^{3} /$ year.

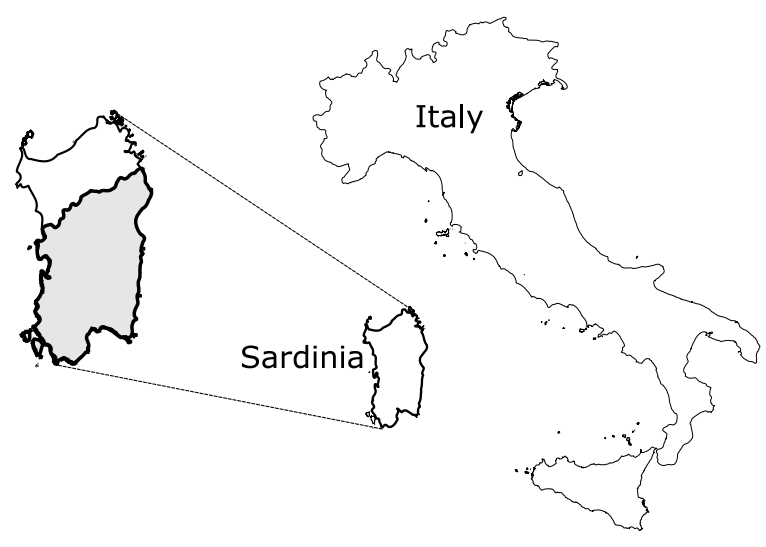

Figure 6: Location of Tirso-Flumendosa-Campidano system in Sardinia (Italy).

The water supply system is mainly characterized by the use of surface water that is stored and regulated by reservoirs. Groundwater is used only for small-localized requirements. However, the main problem of the system is to carry water to these places from areas with a high volume of resources. For this reason, as Figure 7 shows, the system has many pumping systems and pipelines that facilitate this transference of water, with a consequent economic cost. All these factors turn the TirsoFlumendosa-Campidano system into one of the most complex systems to manage in the region.

The Water Management Authority of Sardinia (ENAS), as a decisionmaker, advised the building of the river basin model. ENAS considered that the priority in the optimization process was two-fold: to reduce the demand deficits and to reduce the pumping costs, both with the same level of importance. 
Figure 7 illustrates the complexity of the Tirso-Flumendosa-Campidano system, with 23 reservoirs, 14 diversion dams, 23 pumps and 44 demands.

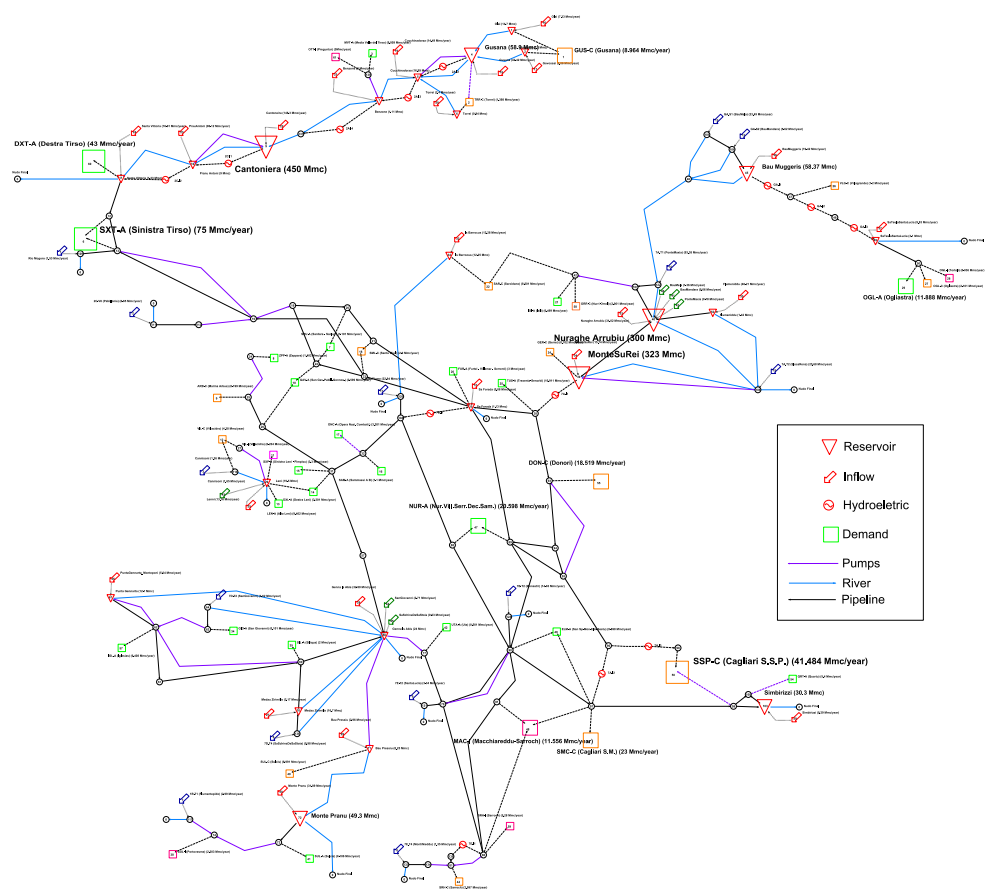

Figure 7: Schematic of Tirso-Flumendosa-Campidano system (source: Lerma et al., 2015).

\section{Visp River basin}

The case study of the last research paper (Annex 4) is Visp River basin, which is located in Upper Rhone River basin, Valais Canton, in Switzerland (Figure 8). The basin has an area of $778 \mathrm{~km}^{2}$, the length of the Visp River is around $40 \mathrm{~km}$ and its average discharge is about $17.2 \mathrm{~m}^{3} / \mathrm{s}$. The basin altitude varies from 450 masl to up to 4000 masl and $3 \%$ of the basin surface is occupied by glaciers. 


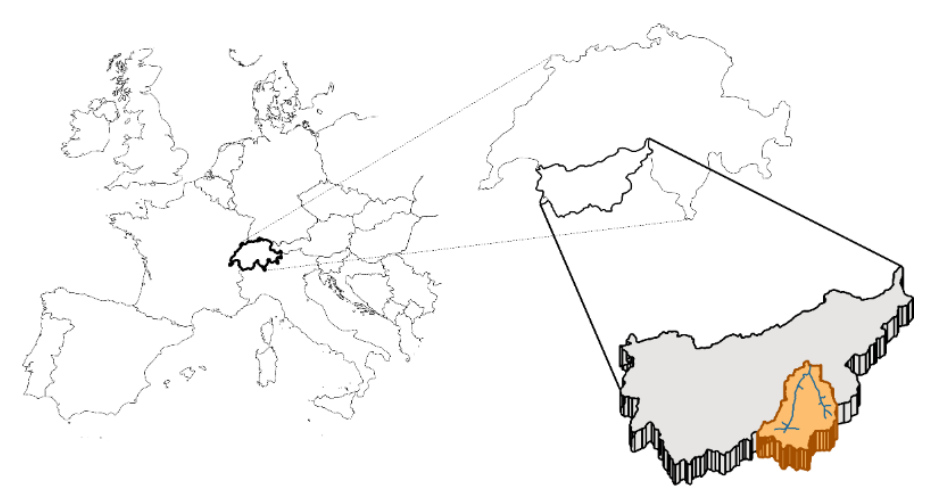

Figure 8: Case Study location. Visp basin in Valais Canton (Switzerland) (source Lerma et al., 2017).

Although the system is small compared with the Upper Rhone River basin $\left(5520 \mathrm{~km}^{2}\right)$, it has a real and complex regulation system with two reservoirs and their corresponding hydropower plants (Figure 9).

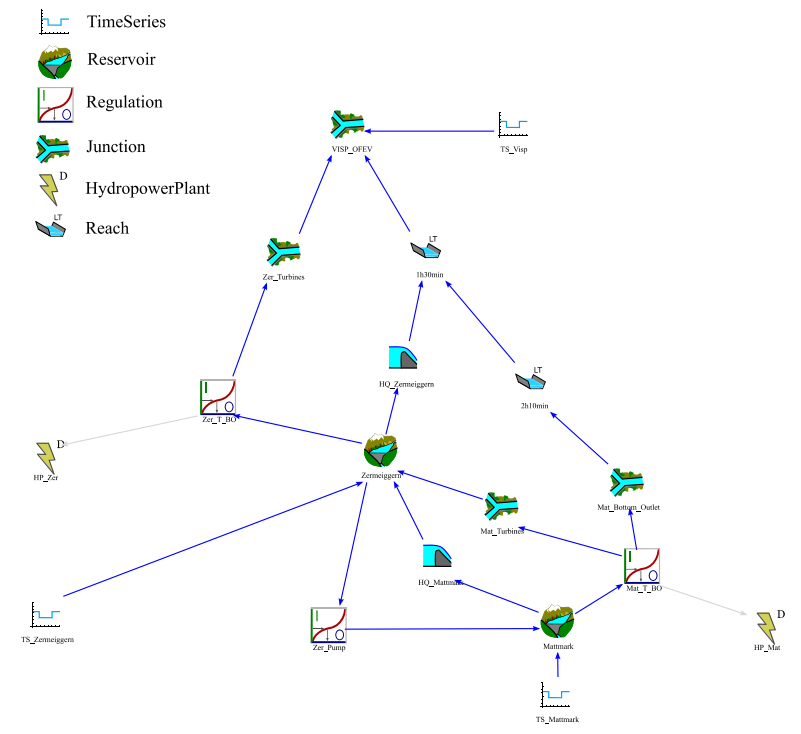

Figure 9: Case study model in RS MINERVE software (source Lerma et al., 2017).

The reservoirs are Mattmark $\left(100 \mathrm{Hm}^{3}\right)$ and Zermeiggern $\left(0.12 \mathrm{Hm}^{3}\right)$. The last one, as tank reservoir, is used as compensation basins for short time storage. Both reservoirs have a hydropower plant to turbine water in 
regular conditions. Due to the system configuration, Zermeiggern hydropower plant generates more energy than Mattmark hydropower plant. Moreover, each reservoir has a spillway, and only Mattmark has a bottom outlet system. As Figure 9 shows, the water from the spillways and the Mattmark bottom outlet goes to the downstream through the river network, taking into account a fixed transit time between the elements.

\subsection{Structure of the thesis}

This thesis is developed as a compendium of research papers. For this reason, the document is divided in two main parts. The first part contains four sections complying with the regulations established by the Doctoral School of the Polytechnic University of Valencia. It synthesizes the thesis. The second part contains five annexes with the author's version of the mentioned research papers.

This introduction is enclosed in the first section (of four sections), with the objectives of the thesis, the methodology, the tools, the case study's descriptions and the structure of the document. Second section cites the five research papers and a brief abstract of each one is presented. Next section shows the results reached in each research paper. Finally, in the last section the main conclusions and future research lines are presented. 



\section{PUBLICATIONS}

This thesis is a compendium of five scientific papers. Three of them published in peer review journals indexed in the Journal Citation Report, one more under reviewer in another indexed journal and the last one was included in a Conference Proceedings. The author version of each one is presented in the Annexes of this document. The citations of these manuscripts are exposed below. In the following points, a brief description of them are presented.

* Lerma, N., Paredes-Arquiola, J., Andreu, J., and Solera, A. 2013. Development of operating rules for a complex multi-reservoir system by coupling genetic algorithms and network optimization. Hydrol. Sci. J., 58 (4), 797-812.

* Lerma, N., Paredes-Arquiola, J., Molina, J. L. and Andreu, J. 2014. Evolutionary network flow models for obtaining operation rules in multi-reservoir water systems. Journal of Hydroinformatics, 16.1, pp. 33-49 DOI:10.2166/hydro.2013.151.

* Lerma Elvira, Néstor; Solera Solera, Abel; Andreu Álvarez, Joaquín, Paredes Arquiola, Javier; Sechi, Giovanni M. y Zucca, Riccardo 2014. Comparativa de herramientas para el desarrollo de Sistemas Soporte a la Decisión para los sistemas de recursos hídricos de Cerdeña, Italia. Aplicaciones de Sistemas Soporte a la Decisión en Planificación y Gestión Integradas de Cuencas Hidrográficas (ed. Solera Solera A. et al.), pp. 85-94, Ed. Marcombo, Barcelona.

* Lerma, N., Paredes-Arquiola, J., Andreu, J., Solera, A. and Sechi, G. M. 2015. Assessment of evolutionary algorithms for optimal operating rules design in real Water Resource Systems. Environmental Modelling \& Software, Volume 69, Pages 425-436, ISSN 1364-8152, http://dx.doi.org/10.1016/j.envsoft.2014.09.024.

* Lerma, N., García, J., Paredes-Arquiola, J. and Andreu, J. (under Review). Optimization assessment of hydropower plants during floods in Visp basin (Switzerland) using evolutionary algorithms. Journal of Flood Risk Management. 
2.1. Development of operating rules for a complex multireservoir system by coupling genetic algorithms and network optimisation

This research paper is developed in Annex 1 , which proposes a procedure for obtaining and assessing MRs under drought situations in multireservoir WRSs (Figure 10). In the proposed methodology, genetic algorithms, as EAs, and network flow optimization are combined. The Pikaia algorithm was used as the EA in this research due to the fact that it had been used in some other water resources fields. Furthermore, a module of the AQUATOOL Decision Support System, SIMGES, was linked with the mentioned algorithm (more information of Pikaia algorithm and SIMGES model is presented in Annex 1).

The objective of the paper was to obtain drought MRs in the Júcar River basin in Spain, as a real and complex WRS. The resource allocation among urban and agricultural demands and environmental requirements in drought periods is one of the main issues in this basin.

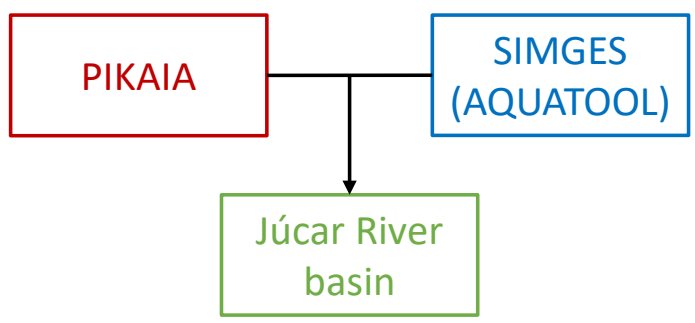

Figure 10: Schematic flow chart for research paper 1.

In the manuscript, the optimization of various operating rules was analyzed with the objective of minimizing short-term and long-term water deficits. This paper validated the usefulness of this approach in the assessment of MRs for complex multi-reservoir systems. Results show that simple MRs generate similar results than other ones whose definition is more sophisticated. 
2.2. Evolutionary network flow models for obtaining operation rules in multi-reservoir water systems

Annex 2 presents the second research paper, which proposes a methodology to obtain operation rules for integrated water resource management coupling NSGA-II, as evolutionary multi-objective optimization, with the SIMGES network flow simulation model (Figure 11).

The proposed methodology is implemented in the Mijares River basin (Spain), which is characterized by a very traditional water rights system, by severe drought events, and by a historical practice of conjunctive use of surface and ground water. The established MRs for the system aim to minimize the maximum deficit in the short term without compromising the maximum deficits in the long term.

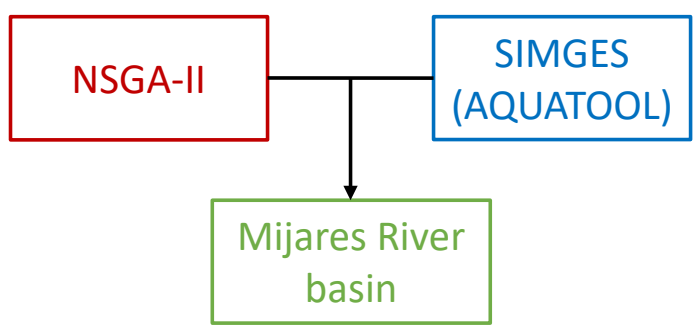

Figure 11: Schematic flow chart for research paper 2.

This research paper demonstrates the utility of the proposed methodology by coupling NSGA-II and SIMGES to find the optimal reservoir MRs in multi-reservoir water systems. Moreover, the NSGA-II results could be very useful for decision-making.

2.3. Comparativa de herramientas para el desarrollo de Sistemas Soporte a la Decisión para los sistemas de recursos hídricos de Cerdeña, Italia

"Comparative of tools for developing Decision Support Systems in Sardinia water resources systems, Italy." is the English translation of the 
Conference manuscript title. This research document is included in Annex 5 , which is focused on the comparative of three simulation models for water resources management: WARGI, SIMGES and AQUATOR.

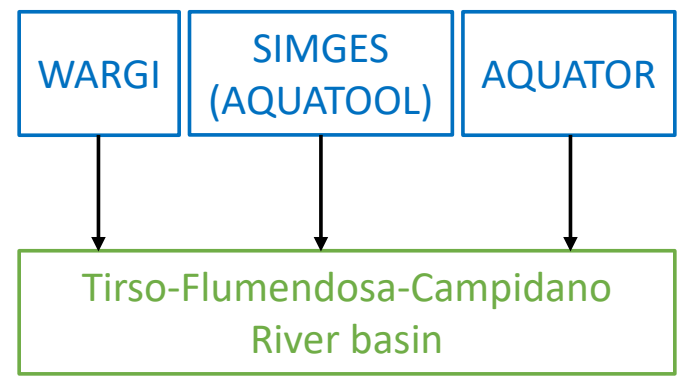

Figure 12: Schematic flow chart for the Conference manuscript.

An in-depth analysis of these simulation models was developed using the Tirso-Flumendosa-Campidano system as a case study (Figure 12), as part of an international research project (RAS, 2013). For this purpose, a model was developed describing the current situation and a set of 15 scenarios were defined. These scenarios included ecological flows (2), the possibility of an infrastructure failure (3), new demands and infrastructures currently building (1) and an increment of the demands requirement (9). For each one, the system management was modified trying to avoid deficits in the demands, as the main objective of ENAS (the Water Management Authority of Sardinia).

This research demonstrated that the three simulation models reached similar results in terms of deficits of demands, stored water in reservoirs and pumping. However, SIMGES obtained the best ones minimizing deficits. These results could be due to SIMGES uses of optimization techniques in each time step of the simulation process. Another reason is that in the SIMGES model, it can define many different types of MRs.

The model developed in this research and all the scenarios defined and analyzed allowed for the understanding of the management of the Italian system. This knowledge was necessary to apply the proposed methodology. Although in this Conference paper the methodology was 
summarized in one section, the following research paper (Annex 3) includes full details about the application of the methodology, the results reached and the conclusions obtained.

\subsection{Assessment of evolutionary algorithms for optimal} operating rules design in real water resource systems

The third research paper is developed in Annex 3. This one assesses two EAs to design optimal MRs for water resource systems. To achieve this goal, a parameter analysis of both algorithms is developed in a theoretical case and the proposed methodology is applied to a complex and real case, the Tirso-Flumendosa-Campidano system (Figure 13).

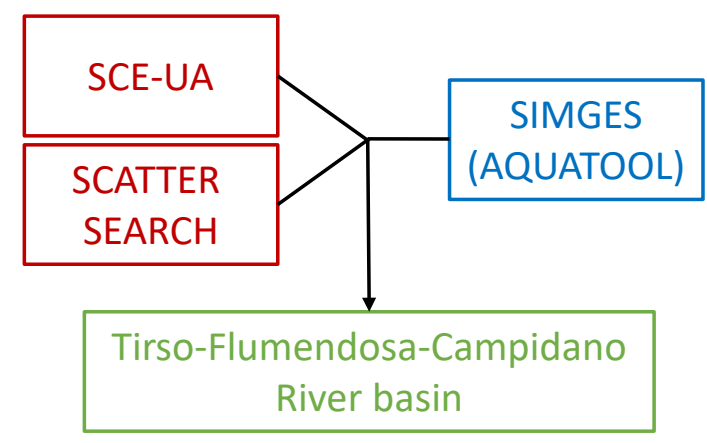

Figure 13: Schematic flow chart for research paper 3.

The algorithm's properties and performance by defining MRs are analyzed through these two applications. Moreover, both analyses allow knowing how an algorithm's termination/convergence criteria affect the results. As one more aim, the importance of decision-makers participating in the optimization process is assessed.

Results of both applications reflect the need for correctly defining the algorithm parameters to ensure an optimal result. Additionally, the former analyses demonstrate how the availability of more termination conditions makes the algorithm an efficient tool for obtaining optimal rules in less time. Finally, in the complex and real case application, the 
participation value of decision-makers in order to define objectives and to make decisions in the post-process was analyzed.

2.5. Optimization assessment of hydropower plants during floods in Visp basin (Switzerland) using evolutionary algorithms

The last research paper is presented in Annex 4, in which an optimization approach based on real forecasts is assessed using EAs with the main purpose of obtaining optimal management rules during floods in the Visp basin (Switzerland).

The proposed methodology was developed by coupling two EAs (SCE-UA and NSGA-II) and the hydrological-hydraulic tool RS MINERVE (Figure 14). The main goal of this research was to assess the algorithms validity for optimizing management rules in flood events and for identifying the advantages of both algorithms.

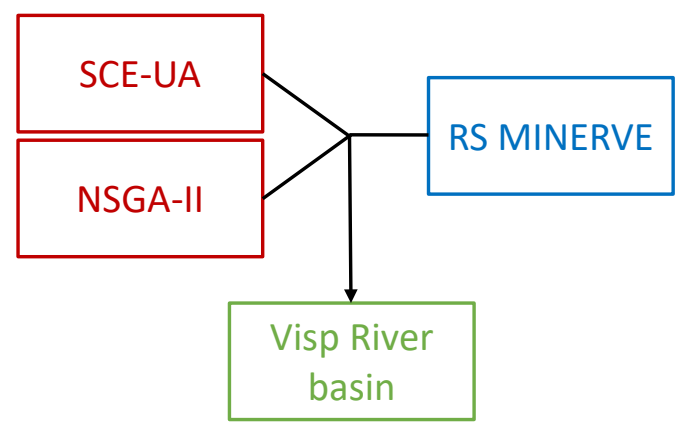

Figure 14: Schematic flow chart for research paper 4.

The achieved results indicate the importance of this methodology to significantly reduce the damage in flood areas and reduce energy losses in hydropower plants. 


\section{GENERAL DISCUSSION OF THE RESULTS}

In the following two sections, the results obtained in the five research papers are summarized. These results were reached after applying the methodology described in point 1.2. and in the Annexes. In the first one, the analyses of the algorithms parameters are presented. Their conclusions allow for the selection of the proper parameters of the algorithms to apply the methodology in the different case studies. The results achieved in these cases are exposed in the second section.

\subsection{Algorithms' parameters analysis}

According to Duan et al. (1994), the choice of the algorithm parameters influences in the effectiveness and efficiency of an algorithm. These parameters allow the user to decide how the algorithms should work and determine the algorithm's performance. Examples of these parameters are the population size, aspects related to the stopping criteria of the optimization process, the seed for the calculation of random numbers, the number and size of the subgroups in which the population is divided to evolve, etc. An analysis of them allows for identifying which parameters should be specially treated when defining them in new optimization processes.

\section{Pikaia algorithm}

In Annex 1, an analysis of Pikaia algorithm parameters was developed. The studied parameters were:

- the number of digits of codification,

- the initial population,

- the elitism consideration,

- the number of individuals,

- the crossover probability and

- the mutation method. 

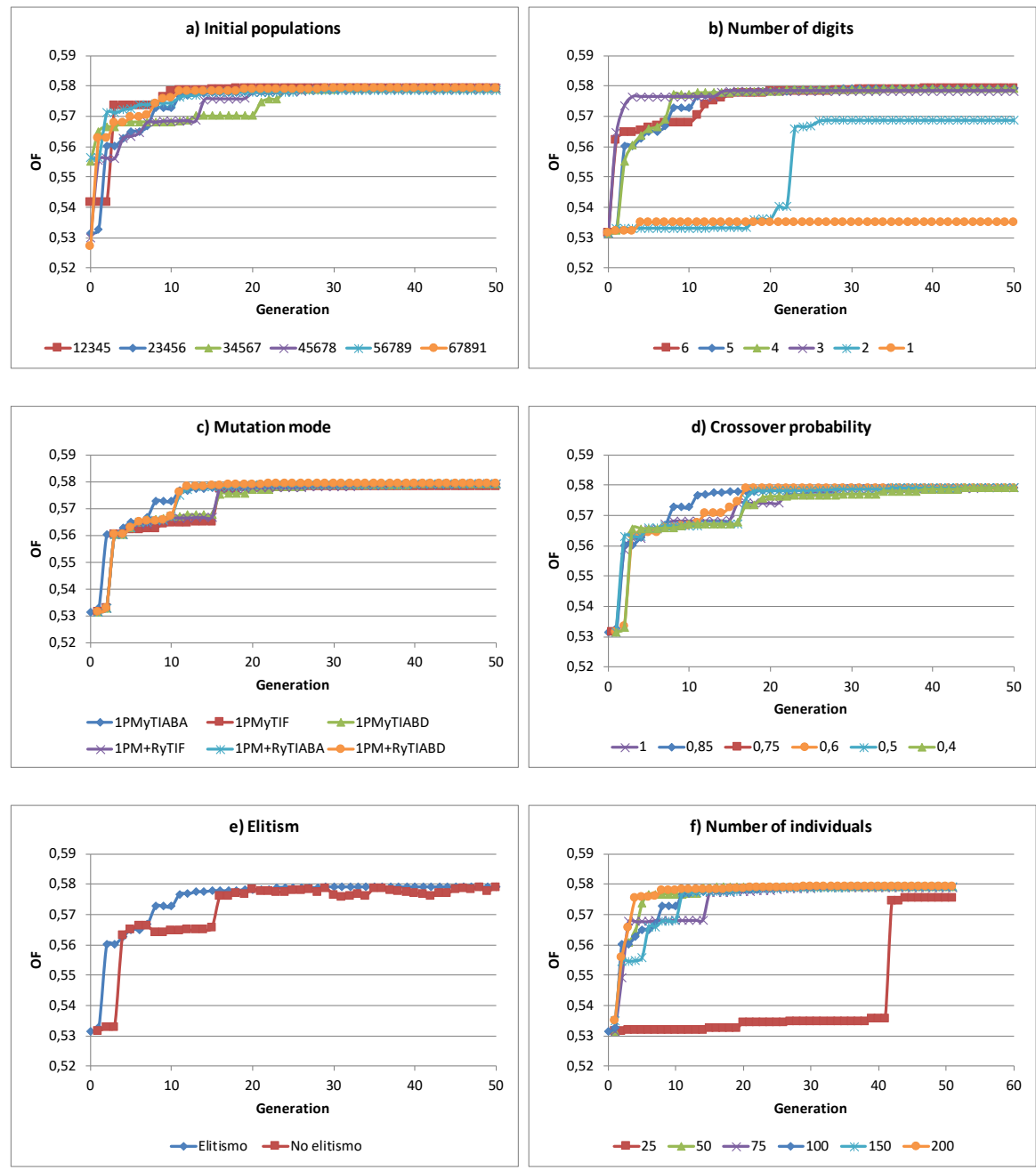

Figure 15 a-f: Results of the OF for different test developed for definition of the EAparameters (adapted from Lerma et al., 2013).

Figure 15 presents six plots with the analysis of each parameter. The results of the performed tests with the number of digits considered in the parameter codification revealed that the use of only one or two digits did not reach acceptable solutions compared to higher values. As the use of three digits does not affect at all the execution time, it is preferable to the use of the bigger number of digits. 
The initial population tests reflect that the first three initial populations achieved an optimum before or near generation 30 , whereas the last three initial populations obtained it by the $50^{\text {th }}$ generation. Even so, it is apparent that all initial population yielded almost the same results by generation 30 .

Slightly better results were obtained when elitism was taken into account. This test showed that the optimum was achieved at the $29^{\text {th }}$ generation, whereas it was obtained at generation 47 when elitism was not considered.

Regarding the number of individuals, all tests reached the same (or very similar) optimum values from the $20^{\text {th }}$ generation onwards, but the test with only 25 individuals did not reach an optimum comparable with the others. However, tests with 50, 100 and 200 individuals seemed to reach optimum values faster than the other tests.

Finally, an analysis of the different options related to mutation and crossover modes, showed that all generations above the $25^{\text {th }}$ generation presented the same (or very similar) optimum values.

This analysis concluded that from a minimum number of three codification digits and taking elitism into account, most of the other options yielded near optimum values by the $30^{\text {th }}$ generation.

\section{SCE-UA algorithm}

Annex 3 presents the analysis of SCE-UA algorithm parameters. The parameters studied were:

- Maximum number of function evaluation (MAXN),

- number of shuffling loops in which the criterion value must change by PECNTO before optimization is terminated (KSTOP),

- percentage by which the criterion value must change in KSTOP shuffling loops (PECNTO),

- number of complexes (NGS),

- considering initial parameters (IFLAG) and 
- random number (ISEED).

MAXN was not modified in the simple system used for this analysis. In other optimizations, which require a high number of decision variables, there will be a need for a high value of this parameter. The reason is that, in these situations, more iterations will be required to obtain an optimal MR. NGS was the first parameter in the analysis because, a priori, it seemed to affect the most to the obtained result. In a second step, KSTOP, PCENTO, ISEED and IFLAG were modified. Figure 16 shows the results of the analysis.

In the first step, 1 to 10,15 and 20 as values for NGS were tested. When NGS increases, a positive trend is observed in the number of evaluations of the OF (EVALS). For sizes smaller than 10 NGS, EVALS is below 1500; for sizes larger than $10 \mathrm{NGS}$, this number considerably increases, reaching more than 3000 OF evaluations. Regarding to the same parameter, the OF values range is quite narrow, between 0.537 and 0.539 , which means that different tests could reach quite similar results. For values above five of NGS, the OF values obtained are higher and thus represent better solutions. The optimal result of these tests is obtained with a NGS=7, requiring nearly 1500 evaluations and resulting in an OF value of 0.5385 .

With this solution, the KSTOP parameter was analyzed using the following values: 2, 5, 10, 15 and 20 . The results showed a high value of EVALS when KSTOP increases. This is normal because a hard stop criterion is defined for the algorithm. Regarding the OF values reached, for KSTOP values lower than 10 , the OF value was below 0.538 ; however, for KSTOP values of 10,15 and 20 resulted in the same OF value (0.5385).

The next parameter, PCENTO, was analyzed with values of $0.05,0.1,0.2$ and 0.5. In this case, when the PCENTO value increases (the term condition is less restrictive), EVALS is reduced along with the OF value.

ISEED parameter, which is related to the random number generation, was analyzed with four different values. The ISEED affects the obtained results without a clear criterion, i.e., there are ISEEDs with high OF values and 
high EVALS; others with low values for both of them; and still others with high OF values and low values of EVALS (the best scenario).
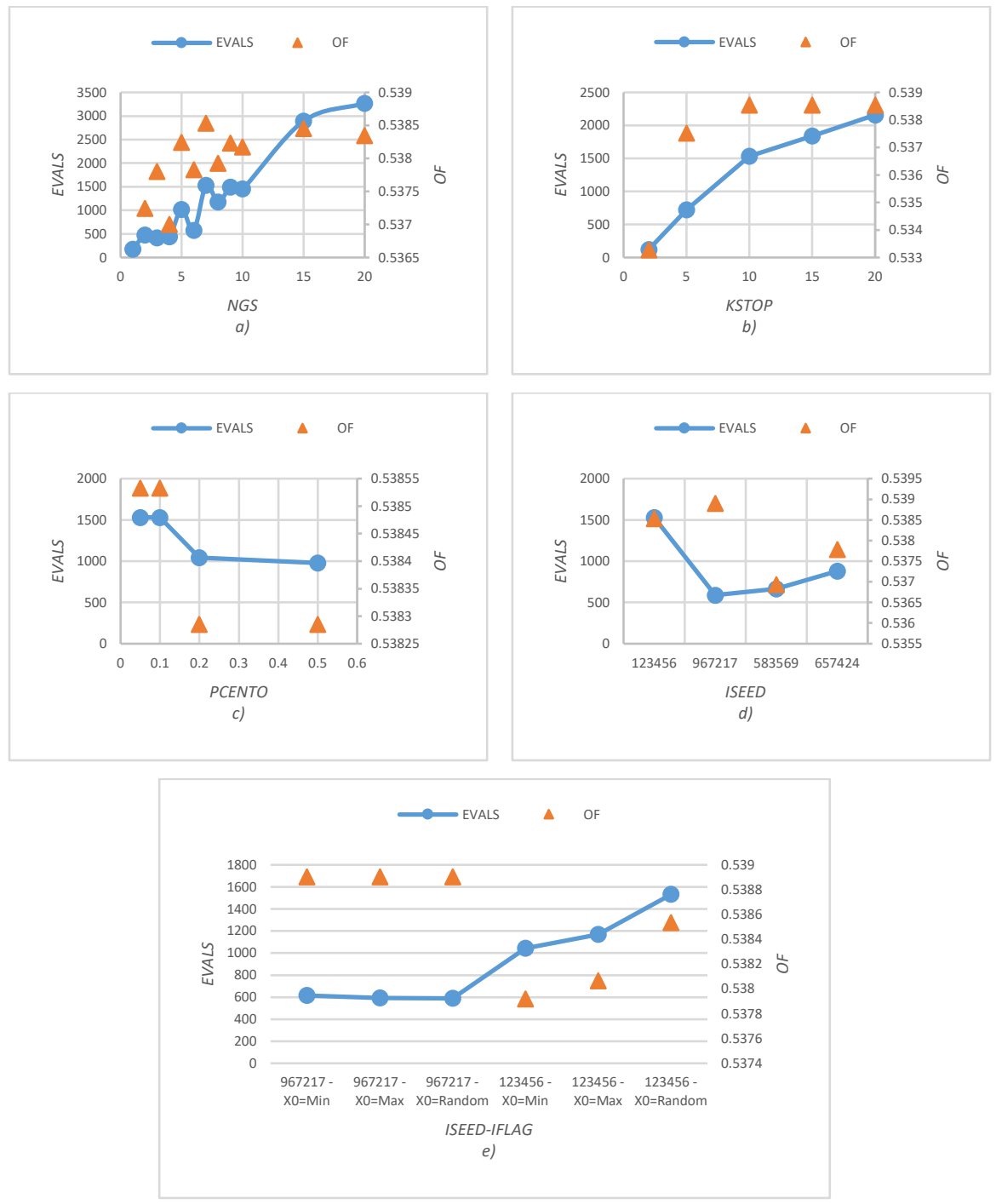

Figure 16: Performed test with SCE-UA algorithm (source: Lerma et al., 2015).

The last parameter analyzed was IFLAG, which allows the user to consider specific initial values (minimum and maximum in this case) or random values for the decision variables. For this group of tests, the ISEED used in 
the first ones and the ISEED with the best result originates in the last one, were used to evaluate the IFLAG behavior. The results showed how the initial values affect this behavior depending upon the ISEED. In the case of the ISEED with best results in previous tests, the initial value does not affect the result and the same EVALS and OF value are returned. By contrast, with the first ISEED, random initial values required a higher EVALS (compared to the minimum or maximum initial values) and higher values of the OF are obtained.

Once analyzed the five SCE-UA parameters, NGS is quite important, in which neither values lower than 3 nor values higher than 8 are recommended to obtain optimal results in an efficient way.

\section{Scatter Search algorithm}

In Annex 3, the analysis of Scatter Search parameters is presented. For this algorithm, the user only needs to define:

- number of iterations (ITER),

- $\quad$ the size of the population (SIZEPOP) and

- Reference Set (REFSET).

The analysis was divided into four groups, depending on SIZEPOP, which assumed values of 5, 10, 50 and 100. All results are represented in Figure 17. Results of the first group showed how the EVALS is higher when the ITER parameter increases for the three REFSET sizes (1,2 and 5) analyzed. The EVALS is significant (more than 5000) when REFSET takes a value of 5. However, in the case of ITER=1, only 164 EVALS were needed, but without finding any valid solution. Regarding to the OF values, the worst values are obtained with REFSET $=5$. The best result was obtained with REFSET $=1$ and 10 ITER (or more). 

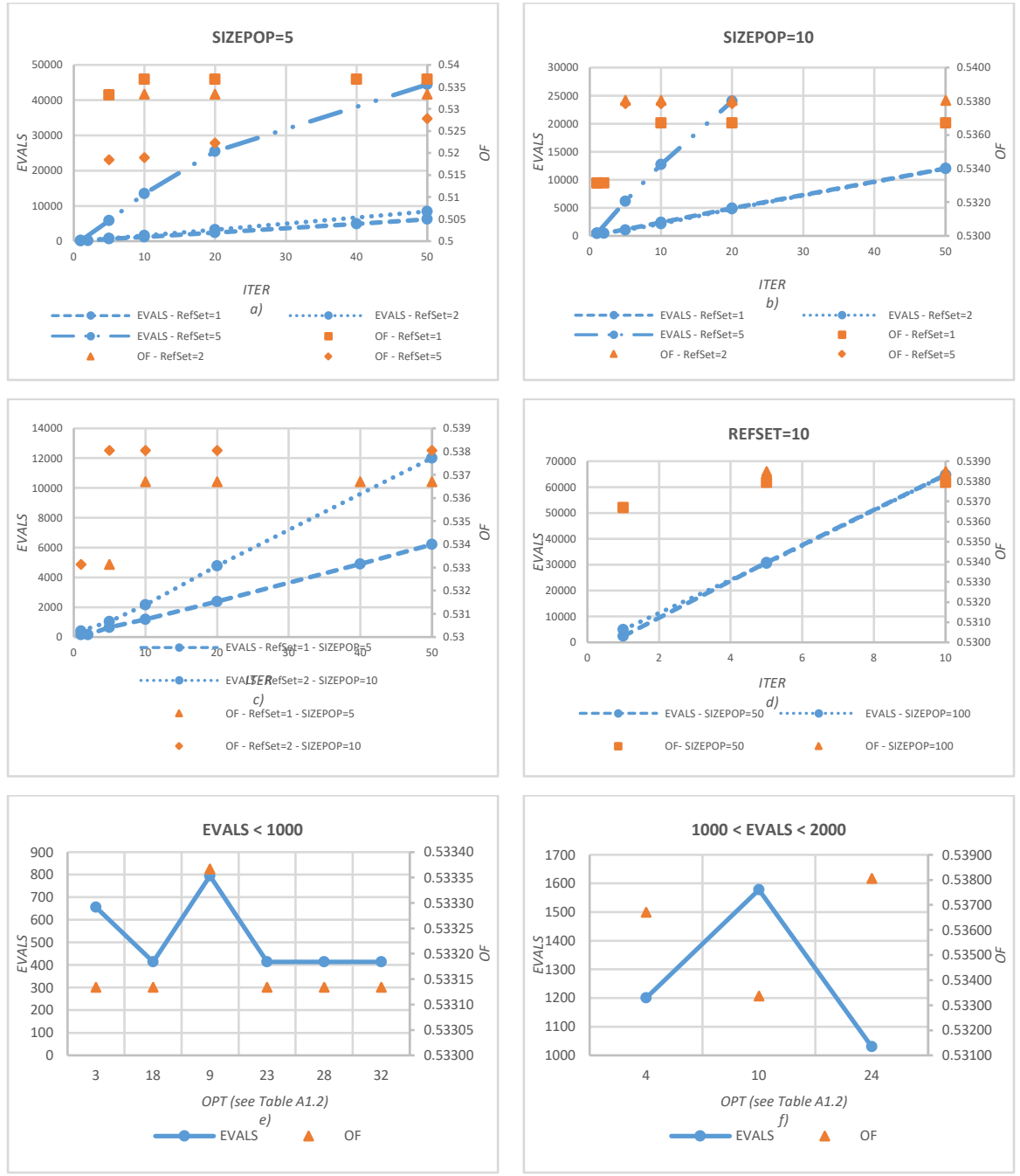

Figure 17: Performed test with Scatter Search algorithm (source: Lerma et al., 2015).

In the second group of tests (SIZEPOP=10), the trend is almost the same for values of REFSET equals to 1 and 2. In these cases more than 10,000 OF evaluations were needed for a value of ITER $=50$. Moreover, for REFSET $=5$, the increase in EVALS is larger, although slightly lower than that for SIZEPOP=5. However, the behavior of the OF value is not similar to previous tests. In these ones, for REFSET=1, the solutions obtained are less optimal than for the other two values. 
To summarize these two groups of tests, for the best combination of parameters, the proportion SIZEPOP/REFSET is maintained. In the first group, $S I Z E P O P=5$ and REFSET=1 were used, and for the second group, SIZEPOP $=10$ and REFSET $=2$.

In the last two groups of tests (SIZEPOP=50 and 100), a value of 10 has been chosen for REFSET size, a lower value than SIZEPOP to maintain the proportion of SIZEPOP to REFSET that was used in previous tests. The results reflect the need for a very high EVALS value (from 2,377 to more than 64,000$)$. With the lowest EVALS value, a worse OF value is reached than previous analysis. The best OF value was obtained only for EVALS values higher than 30,000 OF evaluations.

With this analysis, it can be concluded that parameters related to the population size and the Reference Set are the most influential during the optimization process in order to provide good solutions.

\subsection{Case studies results}

\section{Júcar River basin}

Results presented in this point are detailed in Annex 1 . In the research paper of this Annex, the Pikaia algorithm is combined with the network flow model SIMGES to obtain optimal MR in the Júcar River basin. The application of the methodology is summarized in the following lines (more details in Annex 1).

The OF to be minimized considers, in the first two terms, short-term and long-term deficits of the demands according to the Spanish Hydrologic Planning Instruction (IPH, 2008). In this document, the maximum deficit of one year as short-term deficit and the 10 consecutive years as longterm deficit are commonly used.

$$
f(x)=w_{1} \frac{\operatorname{Max}\left(\operatorname{Def}_{1, \operatorname{Trd}}\right)-50}{50}+w_{2} \frac{\operatorname{Max}\left(\operatorname{Def}_{10, \operatorname{Trd}}\right)-100}{100}+w_{3} \frac{\left(\sum_{t=1}^{\mathrm{n}} \mathrm{V}_{\mathrm{t}}\right)-\mathrm{n}^{*} 2000}{\mathrm{n}^{*} 2000}
$$

Both terms represent the deficit of Traditional demands. The Mixed demand deficits do not appear in the OF because it is assumed that the 
restriction coefficient for these demands with respect to surface water supply is twice that of the Traditional demands. The values of $50 \%$ and $100 \%$ were included in the function used for the reliability criteria, as they are the limits established by the IPH (2008) for agricultural demand satisfaction criteria. The last term of the equation was added to ensure the minimum reservoir volume among different possibilities. The weight $W_{3}$ was fixed with a sufficiently low value to ensure that deficits terms are always more important. This term is evaluated as the sum of the volumes in the different months that are decision variables; this value is reduced by the number of months multiplied by 2,000 (considered the upper volume limit).

In the optimization problem, the decision variables are the sum of the volumes of the three reservoirs of the system (Alarcón, Contreras and Tous) and a restriction coefficient for the demands. The volume of water stored in the reservoirs indicates the water reserve for scarcity periods. The restriction coefficient is applied to the Traditional demands, multiplying it by two for the Mixed demands as explained above.

In this study, three different MRs were analyzed:

- "April-September" MR: This rule makes a single decision in April and uses it until the end of the hydrological year. It is based on the fact that most of the demand is realized between the months of April and September.

- "4 months" MR: It is a parametric curve using decision variables for only four months and estimating the rest by linear interpolation.

- "12 months" MR: This last rule is based on the most general case, i.e., making decisions each month of the year.

Each MR results are compared with a situation denoted "basic". In this situation, the management is performed only according to the water distribution system priorities. Table 2 shows the best OFs and the maximum deficits in the demands for the three MR studied. These results are compared with the "basic" situation: 
- The reduction of the annual deficits versus the "basic" case was very high for the traditional demands (from 40\% to $9 \%$, approximately), but not so much for Mixed demands due to the pumping option in some of them.

- The results of the maximum ten-year deficit show a worse behavior in both types of demands. In Traditional demands, this deficit increased but it is under the IPH (2008) criteria. The worse value of this indicator was expected because the proposed $\mathrm{OF}$, is to diminish the annual deficit; therefore, the deficit must be distributed over time.

Table 2: OF and maximum deficits for 1 year and 10 years accumulated for the irrigation demands (adaptation of Lerma et al. (2013)).

\begin{tabular}{|c|c|c|c|c|}
\hline MR & OF & $\begin{array}{c}\text { DEFICITS (\% OF } \\
\text { ANNUAL } \\
\text { DEMAND) }\end{array}$ & $\begin{array}{l}\text { TRADITIONAL } \\
\text { DEMANDS }\end{array}$ & $\begin{array}{c}\text { MIXED } \\
\text { DEMANDS }\end{array}$ \\
\hline & & MaxDef1year & $40.84 \%$ & $34.90 \%$ \\
\hline & & MaxDef10years & $72.35 \%$ & $102.34 \%$ \\
\hline & & MaxDef1year & $9.37 \%$ & $22.20 \%$ \\
\hline & & MaxDef10years & $90.10 \%$ & $139.13 \%$ \\
\hline & & MaxDef1year & $9.43 \%$ & $22.27 \%$ \\
\hline & & MaxDef10years & $90.76 \%$ & $140.09 \%$ \\
\hline & & MaxDef1year & $9.31 \%$ & $23.51 \%$ \\
\hline & & MaxDef10years & $89.72 \%$ & $154.01 \%$ \\
\hline
\end{tabular}

Regarding to the pumps of some of the Mixed demands (La Mancha demands), the pumped flow decreased respect the "basic" situation due to the restrictions imposed with the MR proposed.

Taking into account all these results together, including the OF values, they demonstrated that the three MRs are quite similar and justified that defining very complex rules is not necessary. A simple MR like "AprilSeptember" is enough to achieve the objective of minimizing the annual deficits without compromising ten-year annual deficits. 
Finally, Figure 18 shows all the tested solutions for "April-September" MR. This figure is composed for four plots. The first one is a 3D plot representing the two decision variables (total volume and the restriction coefficients of the traditional demands) versus the OF. The other three plots are the corresponding 2D projections.

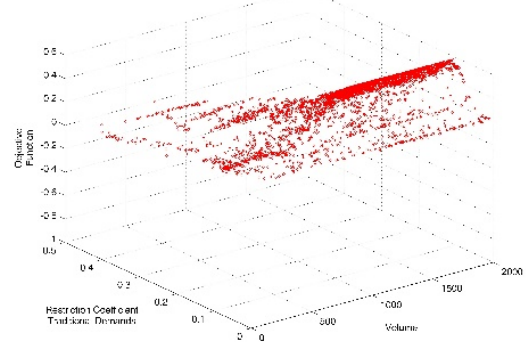

a)

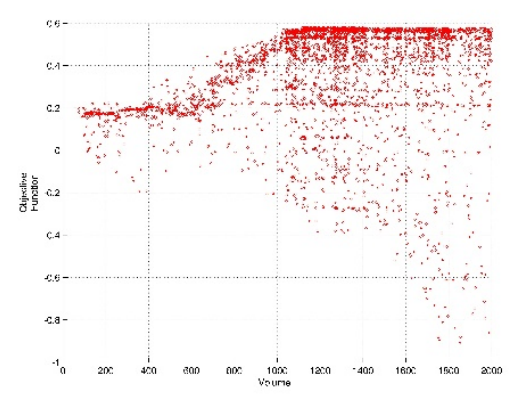

c)

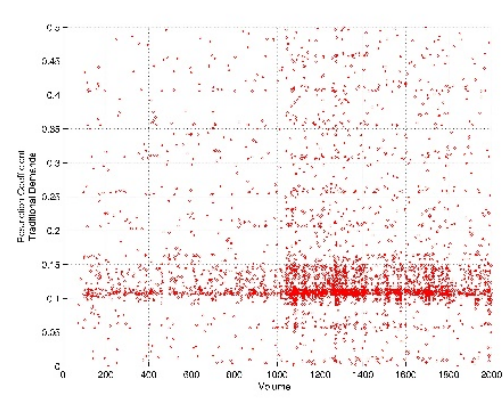

b)

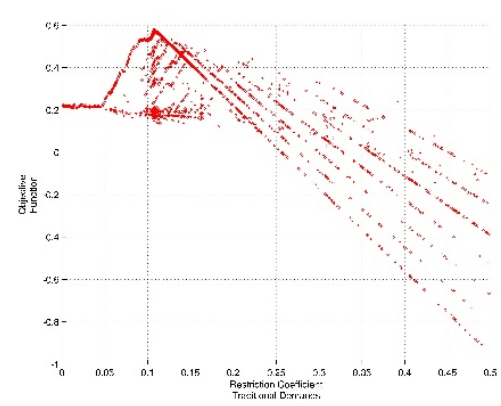

d)

Figure 18: $a-d$. Evolution of the OF, volume stored, and restriction coefficient for the "April-September" MR (adapted from Lerma et al., 2013).

The plots show the restriction coefficients for the traditional demands tend to cluster near to $10 \%$. Therefore, it is maintained as the optimal restriction value for any volume. Regarding this last decision variable, the best results are grouped near volumes above $1,000 \mathrm{Hm}^{3}$. The $2 \mathrm{D}$ plot representing both decision variables shows how the algorithm searched for combinations over the entire solution space. 
Confronting the volume versus the $\mathrm{OF}$, the highest concentration of points was reached at a value of the OF near 0.6, corresponding to volumes over $1,000 \mathrm{Hm}^{3}$. The most interesting result is the minimum volume where the maximum value of the OF is reached, which is approximately this threshold of $1,000 \mathrm{Hm}^{3}$. The figure also shows the restriction coefficient versus the OF. The greatest concentration of points is near a restriction of 5 to $20 \%$ and a value above 0.2 for the OF. The maximum value of the $\mathrm{OF}$ is achieved with a restriction coefficient of approximately $11 \%$.

\section{Mijares River basin}

In Annex 2, the multi-objective EA NSGA-II is combined with SIMGES to search optimal managements in the Mijares River basin. In this point, the application of the methodology and the results of the case study are presented (more details in Annex 2).

As a multi-objective algorithm, NSGA-II requires the definition of different OFs and not a weighted-combined OF, like the Pikaia algorithm. In this problem, there are three OFs to minimize, which take into account the maximum deficit of the demands as well as the resilience of the water system:

- $\mathrm{OF}_{1}=$ maximum annual deficit for agricultural demands (MaxDef1Year)

- $\mathrm{OF}_{2}=$ maximum ten consecutive years deficit for agricultural demands (MaxDef10Years)

- $\mathrm{OF}_{3}=$ years of pumping

Each individual of the algorithm is composed by 13 values and corresponds with the definition of a MR. These values represent a volume threshold in each month (12) and the restriction coefficient for the water supply (1). The volume level is between a minimum $\left(5 \mathrm{Hm}^{3}\right)$ and a maximum $\left(87 \mathrm{Hm}^{3}\right.$ ) value depending on the associated reservoirs (Sichar and Arenós), and the restriction coefficient varies between 0 and 1 (not applying and applying a total restriction). 
In this research, a complex MR composed by 13 decision variables was used to analyze the behavior of the multi-objective algorithm to search optimal and complex MR.

Apart from the OFs definition and the decision variables, in this case, the NSGA-II algorithm also requires the problem restrictions. Two constraints related to the deficit objective functions were defined:

- $\mathrm{C} 1 \rightarrow$ MaxDef1Year $<50 \%$

- $\quad$ C2 $\rightarrow$ MaxDef10Years $<100 \%$

Results reached for the algorithm are presented in Annex 2 in different figures. In this section, only the most relevant figures will be commented. In some of these figures, the Pareto front is represented linking the different OFs. In the other ones, the MR parameters are confronted.

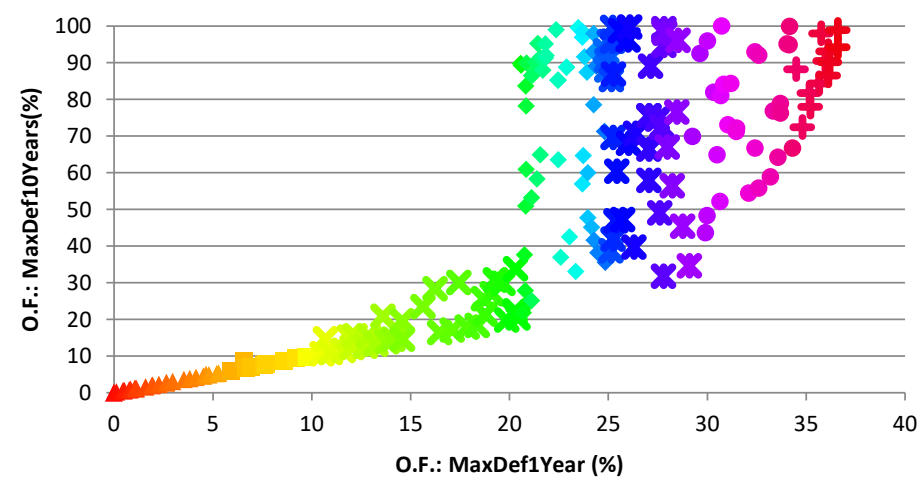

Figure 19: Pareto front 1; maximum deficits for the agricultural demands (for colormarker coding, see Table 3) (source: Lerma et al. (2014).

In Pareto front plots, each one contains two hundred points. These points represent the result for applying SIMGES to each combination of parameters obtained by NSGA-II in its last generation, i.e. the best solutions reached by the algorithm. To relate the solutions of one figure with the other ones, a color scale gradient was fixed, sorting the solutions according to the maximum annual deficit of the agricultural demands (abscissa of Figure 19). 
Table 3: Color-marker coding adopted in Figures 7-11 (source: Lerma et al., 2014).

\begin{tabular}{cc}
\hline Color (marker) & $\begin{array}{c}\text { Maximum annual deficit of the agricultural demands } \\
(\%)\end{array}$ \\
\hline Red $(\Delta)$-orange $(\square)$ & $0-5$ \\
Orange $(\square)$-yellow $(\square)$ & $5-10$ \\
Yellow $(\square)$-green $(\mathrm{X})$ & $10-20$ \\
Green $(\mathrm{X})$-cyan $(\diamond)$ & $20-25$ \\
Blue $(\Psi)$-purple $(\bullet)$ & $25-30$ \\
Purple $(\bullet)$-pink $(\bullet)$ & $30-35$ \\
Pink $(\bullet)$-dark red $(+)$ & $35-37$ \\
\hline
\end{tabular}

In Figure 19, the Pareto front corresponding to the short term (1 year) and the long term (10 years) of the deficit of agricultural demands is shown. The points of the figure represent a great variety of possible solutions generated by different MRs. The growing trend of this figure is due to the conditions of the basin. The optimal solution will not be the one with zero deficits, because the number of years pumped must also be taken into account.

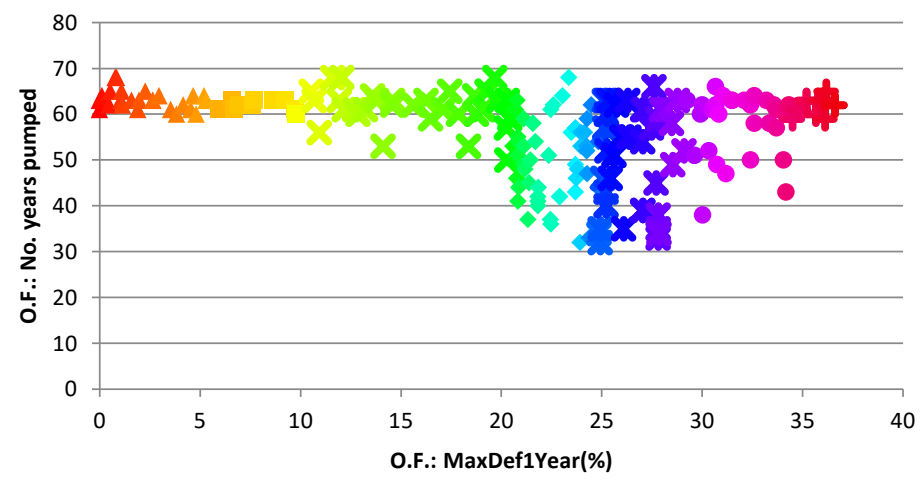

Figure 20: Pareto front 2; number years pumped versus deficit of the agricultural demands (for color-marker coding, see Table 3) (source: Lerma et al. (2014).

The number of years pumped is represented in Figure 20, sorted according to the annual deficit of the agricultural demands. This parameter was taken into account because pumping has an associated 
cost, which decreases when reducing the pumping time. The figure contains a second Pareto front. As this figure shows, at least 30 years of pumping is required according to the system. In this figure, three zones can be distinguished. The first one, with a low value of deficits $(<20 \%)$ and a high number of years pumping ( $>55)$. The second one, between 20 and $28 \%$ of deficits and a low number of year $(>30)$. The last zone is characterized by high deficits and years pumped, whereby the set of solutions is not indicated.

Figure 21 represents the restriction coefficient, MR parameter and the decision variable of the algorithm, depending on the maximum annual deficit of agrarian demands. The obtained restriction is higher than $92 \%$, although the largest set of solutions is between $96 \%$ and $100 \%$. This figure shows that a very high restriction has to be applied to reach the results obtained.

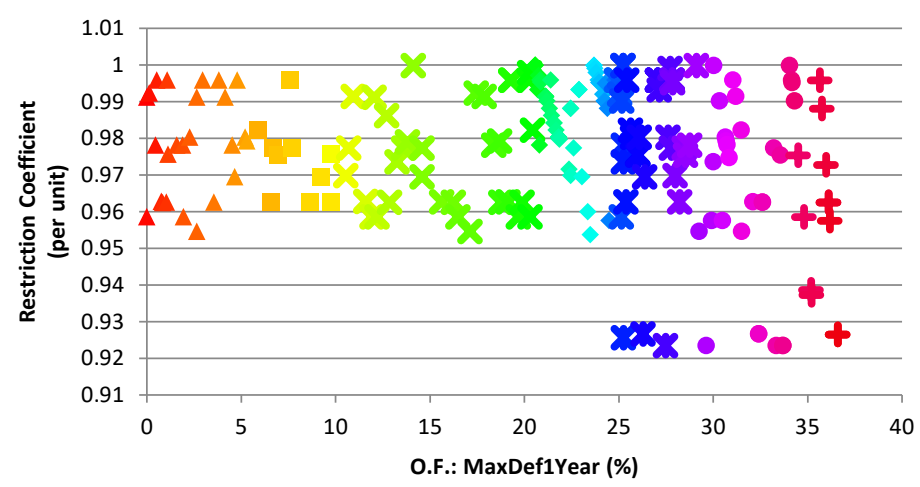

Figure 21: Restriction coefficient (for color-marker coding, see Table 3) (source: Lerma et al. (2014).

As mentioned above, the two hundred points represent the best solutions obtained by NSGA-II algorithm. Each point corresponds to a MR definition composed by thirteen values. Twelve of these are the threshold vale for each month of the year and the other is the coefficient of restriction. Because analyzing $200 \mathrm{MR}$ is not feasible, and given that some of them are not applicable to real management scenarios due to the complexity 
and variability of their definitions, four MRs were selected as representatives of the set of solutions.

The first MR selected (MR1) corresponds to solutions near $5 \%$ of the maximum annual and ten years deficits of the agricultural demands. These solutions imply a large number of years pumped and high values for the pumped volume. MR1 is defined with high levels of the sum of the volumes of the Arenós and Sichar reservoirs. When the system is below those levels, it indicates that the Mixed Irrigation is not supplied with the surface water, but has to pump water. Only Traditional Irrigation is supplied with surface water.

Second MR (MR2) is associated with annual maximum deficits between $20 \%$ and $25 \%$ of the agrarian demands and between $30 \%$ and $100 \%$ in the case of the maximum deficits of 10 years. MR2 allows a larger surface water to supply the Mixed Irrigation and, therefore, somewhat less by pumping. The next MR (MR3) is similar to MR2, differing mainly in the first months of the hydrological year, i.e., November to January. For these months, MR2 reserves supply more surface water for Traditional Irrigation. However, MR3 allows a greater surface water to supply Mixed Irrigation, and for this reason, Traditional Irrigation increases its deficits.

Finally, the last MR selected (MR4) corresponds to maximum annual deficits between $25 \%$ and $30 \%$ of the agricultural demands and between $30 \%$ and $100 \%$ in the case of the greatest deficits of 10 years. This MR is defined with low reservoir levels and is associated with a very small reserve for Traditional Irrigation, causing high deficits of traditional demands.

With the optimization carried out with NSGA-II and linked with SIMGES module, a great number of MR alternatives were reached. All these MRs obtained results below the maximum values of the IPH (2008) criteria. Thus, these solutions are better than not applying any MR (Table 4). The MR3 presented above is the closest to the operating rule included in the "Agreement 70" MR. 
Table 4: Results of deficits and pumping without MR and with the "Agreement 70 " rule curve (source: Lerma et al. (2014)).

\begin{tabular}{l|lcc} 
& & $\begin{array}{c}\text { WITHOUT MR } \\
\text { (\%) }\end{array}$ & $\begin{array}{c}\text { “AGREEMENT } \\
\text { 70” (\%) }\end{array}$ \\
\hline & $\begin{array}{l}\text { Maximum deficit of } \\
\text { one year }\end{array}$ & 37.12 & 23.35 \\
$\begin{array}{l}\text { Maximum deficit of } \\
\text { ten years } \\
\text { Maximum pumping } \\
\text { of one year } \\
\text { Maximum pumping } \\
\text { of ten years }\end{array}$ & 217.28 & 55.77 \\
& 87.4 & 97.85 \\
& & 73.3
\end{tabular}

\section{Tirso-Flumendosa-Campidano system}

SCE-UA and Scatter Search algorithms are assessed in Annex 3 to obtain optimal MR in the Tirso-Flumendosa-Campidano system. The application of the methodology is summarized in the following lines (more details in Annex 3).

In this study, an optimization problem is proposed to improve the defined system management protocols using the following OF:

$$
O F=\left(0.3 * N D C D * C_{N D}+0.2 * \frac{\sum D M A}{N D C D} * C_{D M A}\right)+0.5 * \sum C B * C_{C B}
$$

The optimization process minimizes the weighted sum of the number of demands with deficit (NDCD), the maximum annual deficit (DMA), and the pumping costs (CB). The main goal of the optimization for this case study is to design MRs that obtain the least number of demands with deficit. Moreover, it attempts to get the lowest possible value for their maximum annual deficits and the lowest pumping rate to reduce their associated economic costs. Typically, the problem with these goals is that, in this type of system, the reduction of deficit demands implies an increase in net pumping and, hence, the WRS operating cost. Therefore, the defined OF tries to minimize both aspects for optimal management. 
Each term of the equation includes a weight $(0.3 ; 0.2$ and 0.5$)$. These weights impose the priority of the system managers in the search for optimal managements. Moreover, each term includes some ratios coefficients $\left(\mathrm{C}_{\mathrm{ND}}, \mathrm{C}_{\mathrm{DMA}}\right.$ and $\mathrm{C}_{\mathrm{CB}}$ ) to make each one unitary.

The optimization problem also includes some restrictions detailed below:

- R1: Deficit in Urban Demands $\leq 1$

- R2: Maximum 1 Year Deficit (\%)<50\% Annual Demand

- R3: Maximum 2 Years Deficit (\%) $<75 \%$ Annual Demand

- R4: Maximum 10 Years Deficit $(\%)<100 \%$ Annual Demand

- R5: Maximum Pumping Cost $(€)<5,000,000 €$

Where R2 to R4 take into account the vulnerability criteria (IPH, 2008) used in Spain to verify the compliance of agrarian demands.

Table 5: Results of the current management system for the case study (source: Lerma et al. (2015)).

a)

\begin{tabular}{c|c} 
NUMBER OF DEMANDS WITH DEFICITS & 4 \\
AVERAGE ANNUAL COST OF PUMPING & $3,675,330.24 €$
\end{tabular}

b)

Demand Maximum annual deficit

\begin{tabular}{c|c}
\hline GIO-A & $86 \%$ \\
GUS-C & $47.04 \%$ \\
LEN-A & $80.2 \%$ \\
IGL-A & $2.9 \%$
\end{tabular}

The MR for this real case is defined by six parameters, which represent the thresholds of different reservoirs of the system. The decision makers of the WRS selected these parameters. Based on the above mentioned 
thresholds, the supply degree of the demands is affected and, at the same time, this affects to the volume pumped.

The initial situation of the system after its modeling with the collaboration of the Water Management Authority of Sardinia is presented in Table 5.

For each EA, a figure with all the MRs tested is displayed, representing the number of demands with deficit ( $x$-axis) and the average annual cost of pumping (y-axis).

SCE-UA algorithm optimization employed 1594 iterations to complete the process obtaining the best value for the OF equal to 0.57 . For this result, the total number of demands with deficits is three and the average annual pumping cost is $3,161,191.56 €$. Figure 22 shows the results of all iterations. In this figure, previous solution has the combination of the fewest number of demands with deficit and the lowest average annual cost of pumping. Regarding to the initial situation, the number of demands with deficits was reduced and the average annual cost of pumping also decreased from $3,675,330.24 €$ to $3,161,191.56 €$.

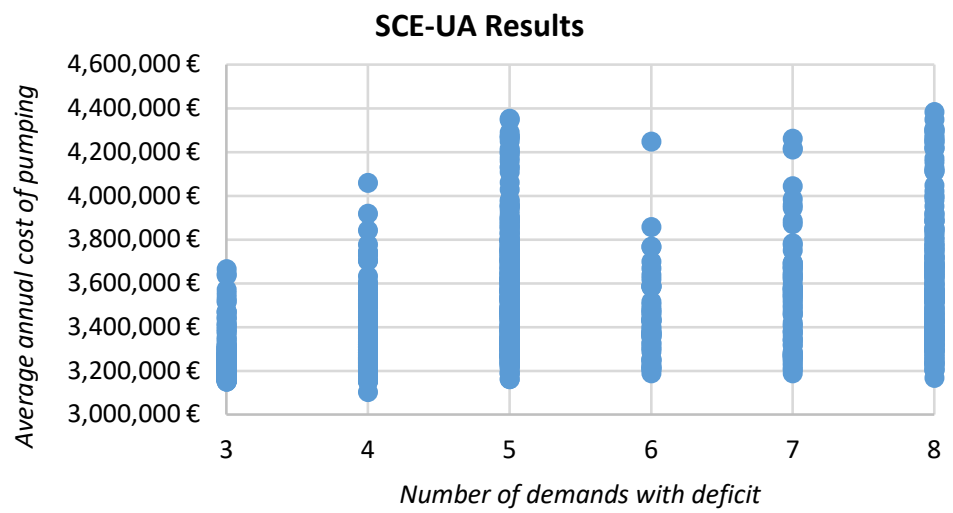

Figure 22: Obtained results using the SCE-UA algorithm (source: Lerma et al. (2015)). 


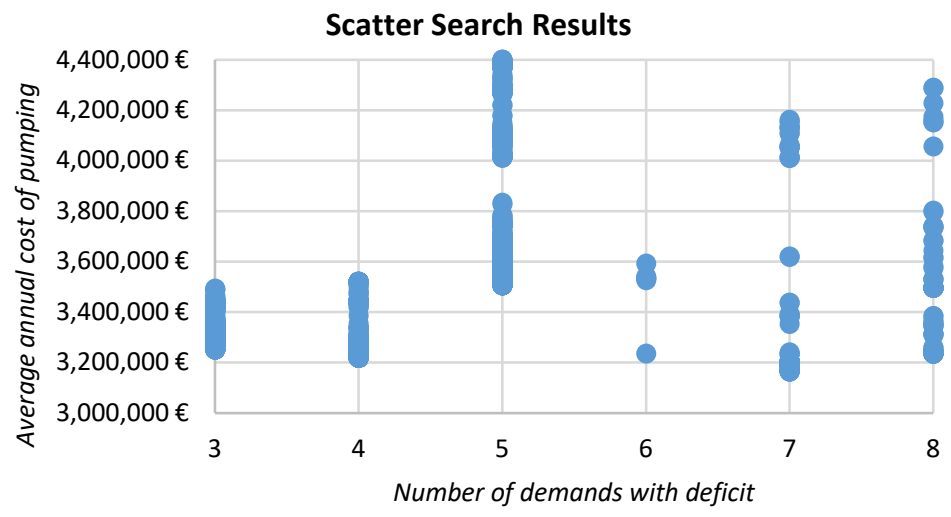

Figure 23: Obtained results using the Scatter Search algorithm (source: Lerma et al.

(2015)).

Scatter Search algorithm required 3,989 iterations (Figure 23), and the optimal solution obtained is one with three demands with deficit and having an average annual cost of pumping of $3,251,280.22 €$. The OF value reached is 0.579 .

The three demands that have deficits (in the best solution using both algorithms) show the same values of maximum annual deficit that are observed in the initial management system. However, with these best solutions the system suffers less deficits and the final cost of pumping decreases.

Comparing both algorithms, the number of iterations used by the SCE-UA algorithm is smaller than the Scatter Search algorithm. Considering the OF and the results obtained, the best solution reached by the algorithms is more optimal than the initial management system, in terms of water supply deficits and pumping costs. However, the SCE-UA obtains an average annual cost of pumping that is lower than Scatter Search alternative, i.e., the SCE-UA obtains a better solution. On the other hand, the Scatter Search algorithm has fewer parameters, which makes it flexible and able to provide good solutions. 
Figure 23 shows that the solutions found by the Scatter Search algorithm are focused on specific values for the average annual cost of pumping. However, in the SCE-UA plot (Figure 22) a major homogeneous distribution of the solutions is appreciated. Therefore, Scatter Search does not analyze or does not provide solutions for all the ranges of the average annual cost of pumping.

Regarding the decision-makers, they can use this methodology to select between alternatives for what they consider the most desirable for the interests of the system. For example, with the results reached with both algorithms, the decision-maker may choose an alternative with a greater number of demands with deficits, but with lower pumping costs. Nevertheless, in cases where there are more than two objectives to be considered, it is possible that only with the figures presented, it would not be sufficient to make a decision because they do not show all aspects of the WRS management needed for making objective decisions. For these cases, a collection of figures could be created to show all important aspects and relate different solutions across the figures using a color code (Lerma et al., 2014).

\section{Visp River basin}

In the last manuscript (Annex 4), the mono-objective SCE-UA algorithm and the multi-objective NSGA-II algorithm were assessed to obtain optimal MR during flood events using RS MINERVE software. The proposed approach was applied to the Visp basin (Switzerland). The following lines summarize the application of the methodology before presenting the results (more details in Annex 4).

To reach an optimal solution, minimizing damages in flood zones and losses in hydropower plants, three OFs were defined. However, SCE-UA, as mono-objective algorithm, is able to handle only one OF. The sum of the individual OFs represents a combined OF used in the optimizations with the last mentioned algorithm. Each OF represents an economical cost. One objective in these types of problems is to reduce the peak flow in the risk zone $\left(\mathrm{OF}_{1}\right)$. Sometimes, it will be necessary to stop the normal 
turbine process. For this reason, the second objective $\left(\mathrm{OF}_{2}\right)$ is defined to minimize the difference between the maximum revenue in normal conditions and the revenue obtained in the optimization. In other situations, a preventive turbine program is necessary to provide enough space in the reservoirs. To avoid an excessive turbined volume in these cases, the $\mathrm{OF}_{3}$ is defined to get more benefit storing the water in the reservoir at the end of the optimization period for future turbining.

- $\mathrm{OF}_{1}$ : flood damage in the risk zone. This OF is calculated according to the maximum flow $\left(Q_{\max }\right)$ in the risk zone. Its evaluation is based in a curve. If $Q_{\max }$ does not exceed a specific value, there is no economical cost. Between two specific values, an equation estimates the damage cost. Finally, if the $Q_{\max }$ exceed the second threshold, a constant cost is assigned (detailed expressions in Annex 4).

- $\mathrm{OF}_{2}$ : revenue in the hydropower plants and the pumping cost. To evaluate the second OF the difference between the maximum cumulated revenue (in optimal condition) and the optimized cumulated revenue is calculated. Furthermore, the cost of the pumping between reservoirs is also considered.

- $\mathrm{OF}_{3}$ : potential revenue of future uses of the stored water. This function is evaluated according to the maximum volumes of the reservoirs, their final volume and a unitary cost per cubic meter associated to the potential revenue.

Besides the OFs, two restrictions are considered in this optimization problem:

- In order to avoid the turbines from being activated and deactivated every ten minutes, a restriction is added preventing at least one hour in the same state (on or off).

- The other restriction is added directly into the model. The spillways curve in the reservoir is modified to consider the failure of this reservoir. In this case, the damage cost in the risk zone is not acceptable and the EA will discard this solution. 
A set of optimizations was conducted for each flood forecast available series (7) and for each EA (SCE-UA and NSGA-II). In Figure 24, the results achieved with both algorithms ( $b$ and $c$ ) and the results obtained without a specific flood management (a) are presented for one forecast series (forecast 6, more results in Annex 4). In order to compare the results, the NSGA-II results represent the solution with the minimum sum of three individual OFs.

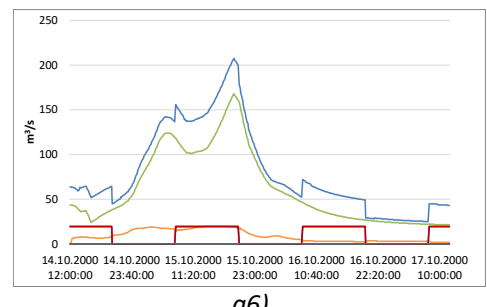

a6)
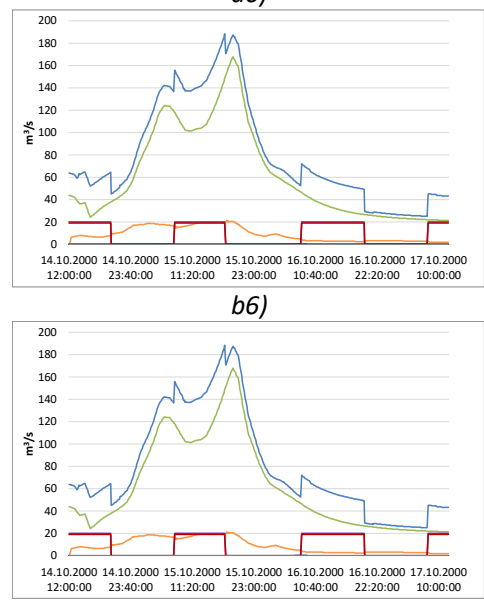

c6)

$\begin{array}{lll}\text { - Qmanagement Visp - Qnatural Visp } & \text { - Zer Spillway } & \text { - Matt Spillway } \\ \text {-Zer Turbine } & \text { - Matt Turbine } & \text { - Matt Bottom Outlet - Zer Pumping }\end{array}$

Figure 24: Result comparative using SCE-UA (b), NSGA-II (c) and without optimization (a). Where [Qmanagement Visp] = [Qnatural Visp]+[Upper river flow of Visp]+[Zer Turbine] (adapted from Lerma et al., 2017).

Results presented in Annex 4 demonstrated the optimization process efficacy. In the example exposed in this point, the EA optimizations acquire an optimal management, saving a significant amount of money 
compared to the situation without a specific flood management (Table 6). In this situation, the optimization tool demonstrates the importance of its use. Without the optimization, the cost amounts to CHF 162 Million. However, both algorithms obtain the same reduction of the cost, around CHF 161 Million. This reduction is due to the peak flood decreases from more than $200 \mathrm{~m}^{3} / \mathrm{s}$ to less than $190 \mathrm{~m}^{3} / \mathrm{s}$, making the damage cost in the flood zone disappear.

Comparing both EAs, their solution is the same in some of the forecast series used (just in terms of final cost; the decision variables could be different) and in other cases NSGA-II results are better than SCE-UA. This last algorithm has different stop criteria (e.g. maximum number of iterations or variation percentage of the OF) and the range of its time computation (equivalent to the OF evaluations) is normally less than NSGA-II. The computation time of NSGA-II algorithm is the same in the different optimizations because the number of individuals and the generations is equal in all of them. The value of these two parameters was fixed in order to the computation time will be similar for both algorithms.

Table 6: OF values for the analyzed forecast (6) without optimization (a) and with SCE-UA (b) and NSGA-II (c) algorithms (adapted from Lerma et al., 2017).

\begin{tabular}{|c|c|c|c|c|c|c|c|}
\hline & & $\mathrm{F}_{1}$ & & $\mathrm{OF}_{2}$ & $\mathrm{OF}_{3}$ & \multicolumn{2}{|c|}{$\sum o F_{k}$} \\
\hline a6) & $\mathrm{CHF}$ & $1,922,749$ & $\mathrm{CHF}$ & $-1,774$ & CHF 323,423 & CHF & $162,244,397$ \\
\hline b6) & $\mathrm{CHF}$ & - & $\mathrm{CHF}$ & 56,841 & CHF 314,389 & CHF & 371,230 \\
\hline c6) & $\mathrm{CHF}$ & - & $\mathrm{CHF}$ & 56,841 & CHF 314,389 & CHF & 371,230 \\
\hline
\end{tabular}

The evolution of the individuals of both algorithms is shown in Figure 25. The figure contains one 3D plot and its corresponding 2D projections (OF1 vs OF2, OF1 vs OF3 and OF2 vs OF3). The SCE-UA individuals were represented with blue points and NSGA-II individuals with orange triangles. 


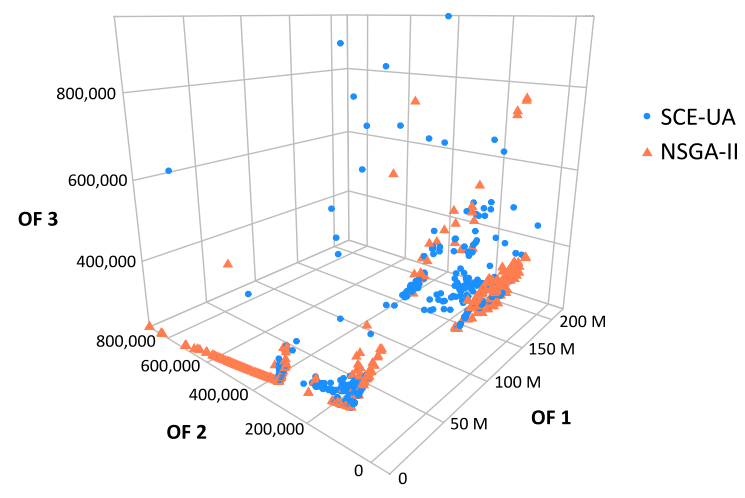

6-i)

ำ

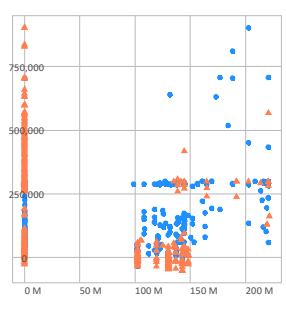

OF1

6-ii)

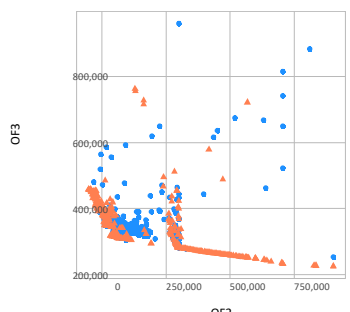

6-iv)

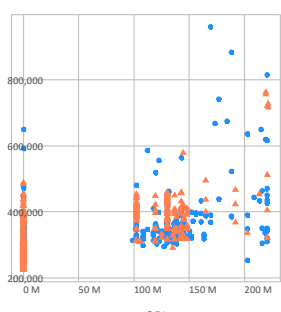

OF1

6-iii)

Figure 25: NSGA-II (orange) vS SCE-UA (blue) search space for the analyzed forecast (6). $3 D$ view (i), OF1 vs OF2 (ii), OF1 vs OF3 (iii) and OF2 vs OF3 (iv) (adapted from Lerma et al., 2017). 


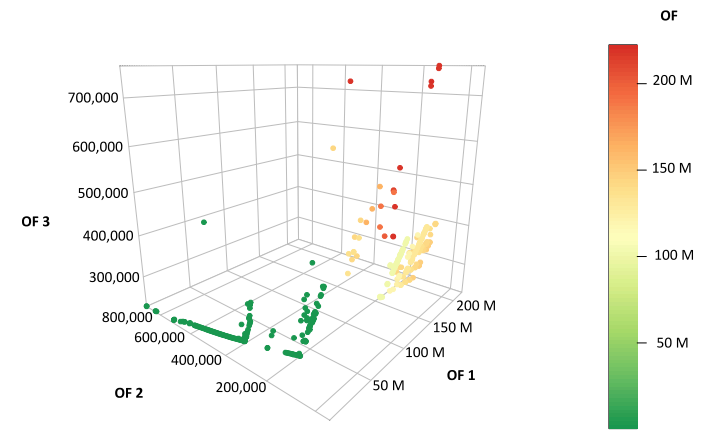

i)

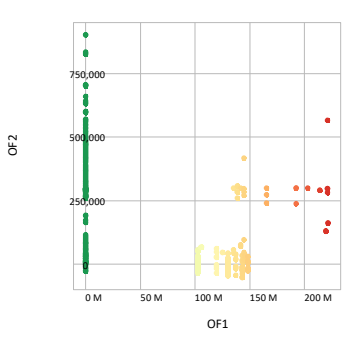

ii)

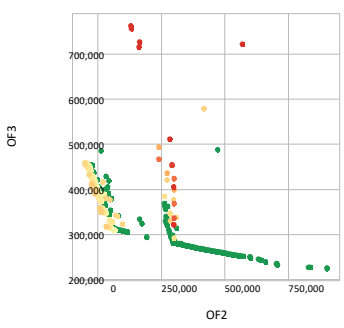

iv)

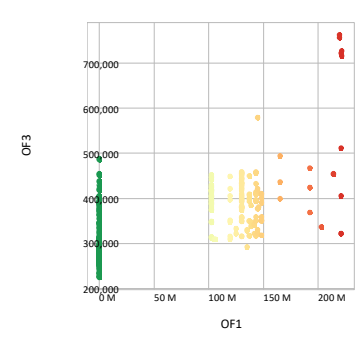

iii)

Figure 26: Colored plots of the NSGA-II solutions for the forecast 6. 3D view (i), OF1 vs OF2 (ii), OF1 vs OF3 (iii) and OF2 vs OF3 (iv). From the worst solutions (red) to the best ones (green) (source Lerma et al., 2017).

As it has been commented previously, NSGA-II is defined to find solutions that represent a Pareto front. For this reason, orange triangle points try to represent that front. In this sense, it seems that the optimal search of NSGAII, as a multi-objective algorithm, is better and more effective than the SCE- 
UA algorithm. Moreover, this Pareto front could be the best tool for decision makers to select the best management for the system according to the different objectives and priorities. It is due to the fact that the front contains only non-dominated solutions. When a management rule of the Pareto front is selected based on a specific OF (e.g. cost in flood zone), the two other OF values will be the minimum possible.

Figure 26 represents another alternative in case the solution set does not contain a defined Pareto front. The points of the plots included in this figure are colored according to the global OF value (sum of the individual OFs). These plots allow to identify quickly the best rules obtained in the optimization process (considering that the best rule is obtained by minimizing all individual functions). 



\section{CONCLUSIONS}

This thesis is a compendium of five research papers. All of them apply a methodology to obtain optimal MRs in WRS. The manuscript published in a Conference Proceedings is also focused in the comparative of three simulation models. In each manuscript, different EAs were assessed combining them with SIMGES module or RS MINERVE software. Moreover, in each one, the approach is applied to a different case study. The EAs assessed in the manuscripts were Pikaia, SCE-UA, Scatter Search and NSGAII. A parameter analysis of the first three algorithms was developed in order to estimate the best parameters in the search of optimal MRs in WRS. The case studies where the methodology was applied were to the Júcar River basin, Mijares River basin, the Tirso-Flumendosa-Campidano system and the Visp basin.

This section presents the conclusions reached in the different manuscripts that compose this thesis. The section is subdivided into four points. In the first point, the conclusions about the algorithms parameters analysis are presented. The second point details the main conclusions of the methodology application in the case studies. The third point summarizes the main conclusions reached in this study and the last point presents some future research lines.

\subsection{Algorithms parameters}

The parameters of three algorithms used in this thesis were analyzed in the research papers (Annex 1 and Annex 3). The conclusions obtained in these analyses are presented in the following lines and they will allow for selecting the proper parameters when some of these algorithms will be used to obtain optimal MRs in WRS.

\section{Pikaia algorithm}

For this algorithm, the initial population, the elitism, the number of digits of codification, the number of individuals, the crossover probability and the mutation method were analyzed. 
The analysis concluded that optimal values were reached taking into account the minimum number of three codification digits, including the elitism criteria, and a minimum population of 50 individuals. Less than three codification digits did not reach acceptable solutions and, furthermore, this parameter does not affect the execution time. Regarding the elitism criteria, when it was not considered, the optimal values were obtained just at the end of the optimization process. The tests with the number of individuals indicated that with a small number of individuals (25) the optimal solution is not so if compared with a population of 50,100 or 150 individuals.

The initial population tests, associated with the seed parameter, showed that all the initial populations considered reach almost the same optimal value and, for this reason, this parameter is not a key parameter in the optimization process. Finally, in the analysis with the mutation methods and the crossover modes, all the tests reached optimal values in the middle of the optimization process.

\section{SCE-UA algorithm}

Five parameters were studied in the SCE-UA algorithm. One of them affects the improvement of individuals (NGS), the other two (KSTOP and PCENTO) affect the stopping criteria, and the last two (ISEED and IFLAG) condition the initial values for the decision variables and generate new values as the individuals evolve.

Tests with NGS parameter showed that it is not convenient to choose either a low or a high value for this parameter. In the first case, because the optimizations reached worse values for the OF. And in the second case, because the number of evaluations, and therefore the execution time, increased. Therefore, NGS values between 3 and 8 would be appropriate.

Regarding the convergence/termination criteria, KSTOP and PCENTO parameters are important. In this sense, PCENTO is the most influential parameter. Choosing an incorrect value can make the algorithm finish prematurely and sub-optimal results could be reached. Or, on the 
contrary, the algorithm can take more time to complete the optimization than is strictly needed to reach the optimal solution.

Regarding ISEED and IFLAG, they have a certain random nature and better or worse results can be obtained depending on the practical case.

\section{Scatter Search algorithm}

In the analysis developed for the Scatter Search algorithm parameters, three of them were analyzed. Each one affected in some way the computation time.

Regarding to the SIZEPOP parameter, the tests indicated that the algorithm is not efficient for high values (more than 20 solutions) because a high computation time is required, obtaining similar results when lower population sizes are used (10 or fewer solutions).

The REFSET parameter is quite influential in optimized solutions. Considering SIZEPOP values less than or equal to 10 , it is observed that low values of REFSET are most appropriate because optimal solutions are reached with a lower number of evaluations.

For the last parameter (ITER), values near 10 but lower than 20 obtained results with a low number of evaluations and optimal values for the OF. This parameter controls the stop condition of the algorithm.

\subsection{Methodology application}

In Annex 1, the research paper presented an approach for obtaining MRs in a real and very complex WRS, the Júcar River basin system. The main goal was to obtain an optimal water allocation between the agricultural demands during drought periods.

The proposed approach in that research coupled the Pikaia EA with the SIMGES flow network model for obtaining optimal decision rule curves. The addressed problem had the objective of reducing the maximum annual deficits and the maximum accumulated deficits in the long term. 
Each iteration in the optimization process implied the computation of the simulation model with a new MR obtained by the EA. With the results of this model, for example the deficit of the demands, the OF was evaluated.

The research paper includes several tests (commented in the previous point) to define the most suitable parameters for the EA. Applying the methodology to the case study, three possible MRs were analyzed. Each one was based on different months for decision-making and application. For this case study, the research concluded that it is sufficient to make a decision in the month of April and apply it from then until September to obtain an optimal management. Moreover, this demonstrated that, in some cases, simple MRs could be used for the management of very complex WRSs.

The second research paper presented in this thesis showed the optimization of MRs based on the coupling of the NSGA-II multi-objective EA with the SIMGES flow network. This methodology was applied to the Mijares River basin, a water resources system characterized by severe droughts and the possibility of the conjunctive use of surface and groundwater resources.

Applying this approach to the case study, different types of MRs were tested. The optimization decision variables were the trigger volume of applying the MRs and the restriction coefficient for supplying demands. The methodology proposed required the use of the simulation model SIMGES, for Mijares basin, to estimate the deficits of the demands and pumps and therefore, to evaluate the OFs.

In this approach, a multi-objective point of view allowed to take into account the short and long terms of the deficit and the pumping resource. Moreover, this implementation helps users or managers of the water system to decide the best, or the most convenient, management for the river basin.

In the manuscript of Annex 3, two EAs were assessed as optimization tools to design optimal MRs in a WRS. In this research, each algorithm's parameter was analyzed and the approach was applied to the Tirso- 
Flumendosa-Campidano system, as a real case, using both EAs. The assessed algorithms were the SCE-UA and the Scatter Search.

In the real case study application, aspects related to the decision-makers were considered apart from checking the validity of the methodology. In this research, it was concluded that a correct representation of the results is needed for the post-process, where the decision-makers must have all the information necessary to make the best decisions that yield the most appropriate management protocols for the WRS.

Comparing both algorithms, the SCE-UA needed less iterations to reach an optimal solution in the real case study, and the solution obtained is better than the one obtained using the Scatter Search algorithm. Therefore, it was concluded that the SCE-UA algorithm is a more efficient algorithm for realistic problems and that it obtains better nearly globally optimized solutions than Scatter Search algorithm. However, the Scatter Search could be considered flexible and able to provide quality solutions in an expanded range of real-world applications.

In the last research paper (Annex 4), an approach to optimize the management in hydropower plants and reservoirs during flood events was presented. The mono-objective SCE-UA algorithm and the multiobjective NSGA-II algorithm were assessed combining them with the RS MINERVE precipitation-runoff model. The methodology was applied in Visp basin (Switzerland) using seven available forecast series.

The results obtained applying both algorithms according to the proposed methodology showed the efficacy of them in finding optimal solutions and to reduce the final cost of the flood. Comparing the EAs, both of them obtained the same results (in terms of final cost) in some of the forecast series tested and in other cases, NSGA-II achieved better solutions than SCE-UA.

The version of the SCE-UA algorithm used has different stop criteria, which give it some advantages. For example, the algorithm can reduce its computation time because the process stops when the solution is not 
improved in consecutives steps without having to wait to reach a specific number of iterations. Meanwhile, NSGA-II always took the same time because the number of iterations based on the number of individuals and generations was predefined. However, this last algorithm has the advantage of finding a Pareto front, as 3D plots showed. For decision makers, the $3 \mathrm{D}$ view, its $2 \mathrm{D}$ projections and the Pareto front can help to select the best management rule for the system according to the different objectives.

Finally, in Annex 5 (Conference manuscript) an in-depth analysis was developed comparing three simulation models: WARGI, SIMGES and AQUATOR. Although in the Conference manuscript, it merely described the methodology proposed in this thesis, it was completely applied to the research paper in Annex 3. To carry out the mentioned analysis, a model of the Tirso-Flumendosa-Campidano system was developed. Moreover, in this research 15 scenarios were defined, including future water demands and infrastructure failures. For each one, the management of the system was modified to try to minimize the demands with deficits. This process was supervised by ENAS (the Water Management Authority of Sardinia).

The results obtained for the three simulations models and for all the scenarios are similar in terms of deficits of the demands, stored water in reservoirs and pumping. However, SIMGES is the model that reaches the best results in terms of minimizing deficits in the demands. This was the main objective for ENAS. These SIMGES results are reached due to the optimization executed in each time step of the simulation process. Moreover, this model allows to define more types and more detailed MRs.

\subsection{Final remarks}

The proposed approach in this thesis combines an EA with a simulation model. The main goal of its application is to obtain optimal MRs in WRS in two main fields. The first one, for an optimal resources distribution between different uses and, the second one, for avoiding damages in flood areas and increase the hydropower plants revenues in flood events. 
The methodology was applied in four different real case studies. Both simulation models used in this research, SIMGES model (included in the DSSS AQUATOOL) and RS MINERVE, allowed their integration in the proposed methodology. The results reached in all the case studies demonstrate the validity of the approach. The obtained MR generated a more optimal system management than the base scenario of each case. Usually, it is translated into a decrease of the economic costs in the management of the water resources.

The four algorithms assessed in this study obtained an optimal management with respect to the base situation, as discussed above. However, SCE-UA algorithm is the most efficient due to the different stop/convergence criteria and its formulation. Nevertheless, NSGA-II is the most recommended if computation time is not a limitation. This algorithm is multi-objective and its search is focused on different objectives equally. Moreover, the decision makers can make the best decision for the system with the results of this algorithm and the proposed representation of them.

\subsection{Future researches}

In this point, future research lines are considered as a result of this thesis. The following lines correspond with some interesting features that would complete an extended research about this study topic.

The first two proposed future researches are linked with the algorithms used in the optimization process. In the bibliography, there are some other EAs that could be tested. Especially, multi-objective algorithms to compare them with the NSGA-II algorithm assessed in this thesis. This feature would enhance the conclusions reached in the four manuscripts presented.

Another interesting study about the algorithms could be to compare these EAs with other recent techniques that might be more efficient. These optimization processes require a high computation time and, sometimes, the decision should be made in a shorter time, e.g. during 
flood events. This is the main reason to research algorithms that are even more efficient that the tested EA in this thesis.

The last research paper, presented in Annex 4, was focused in the optimization of MR during flood events. Although the results reached were satisfactory, more studies in this field should be done. Moreover, if forecast series were more in line with reality, a combined optimizationsimulation process could be defined to obtain the MR in real time in these types of events.

The last feature proposed is related with the decision makers. They are responsible of making the best decision for the system. For this reason, developing a user interface to manage the optimization process and the results could be interesting. With the help of this tool, it would be possible to select a specific EA, the OFs and, at the end of the process, to show the results according to the different objectives as it was proposed in this thesis.

All these studies are proposed to obtain the best management of the water resources systems and, at the same time, to reduce the economic costs and to save water. 


\section{REFERENCES}

Abd-Elhamid, H.F., Javadi, A.A., 2011. A Cost-Effective Method to Control Seawater Intrusion in Coastal Aquifers. Water Resour. Manag. 25, 2755-2780. doi:10.1007/s11269-011-9837-7

Adenso-Díaz, B., García-Carbajal, S., Lozano, S., 2006. An empirical investigation on parallelization strategies for Scatter Search. Eur. J. Oper. Res. 169, 490-507. doi:10.1016/j.ejor.2004.08.011

Ahmed, J.A., Sarma, A.K., 2005. Genetic Algorithm for Optimal Operating Policy of a Multipurpose Reservoir. Water Resour. Manag. 19, 145-161. doi:10.1007/s11269-005-2704-7

Akter, T., Simonovic, S.P., 2004. Modelling uncertainties in short-term reservoir operation using fuzzy sets and a genetic algorithm. Hydrol. Sci. J. 49. doi:10.1623/hysj.49.6.1081.55722

Andreu, J., Capilla, J., Sanchís, E., 1996. AQUATOOL, a generalized decisionsupport system for water-resources planning and operational management. J. Hydrol. 177, 269-291. doi:10.1016/00221694(95)02963-X

Astorayme, M.A., García, J., Felipe, O., Suarez, W., Huggel, C., Molina, W., Sarango, D., 2016. Análisis comparativo de los modelos hidrológicos GR4J-SOCONT-HBV-SAC en la cuenca del río Chillón, Perú, in: XXVII Congreso Latinoamericano de Hidráulica -LADHI. International Association of Hydraulic Engineering and Research, IAHR. Lima, Perú, pp. 227-237.

Astorayme, M.A., García, J., Suarez, W., Felipe, O., Huggel, C., Molina, W., 2015. Hydrological modeling with a semi-distributed approach in the Chillon River Basin, Peru. RPGA 4, 109-124.

Bhaskar, N.R., Whitlatch, E.E., 1980. Derivation of monthly reservoir release policies. Water Resour. Res. 16, 987-993. doi:10.1029/WR016i006p00987 
Bower, B.T., Hufschmidt, M.M., Reedy, W.H., 1962. Operation procedures: Their role in the design and implementation of water resource systems by simulation analysis, in: Maass, A. (Ed.), Design of Water Resource Systems. Harvard University Press, Cambridge, pp. 443-458.

Boyle, D.P., Gupta, H. V., Sorooshian, S., 2000. Toward improved calibration of hydrologic models: Combining the strengths of manual and automatic methods. Water Resour. Res. 36, 3663-3674. doi:10.1029/2000WR900207

Cai, X., McKinney, D.C., Lasdon, L.S., 2001. Solving nonlinear water management models using a combined genetic algorithm and linear programming approach. Adv. Water Resour. 24, 667-676. doi:10.1016/S0309-1708(00)00069-5

Campos, V., Glover, F., Laguna, M., Martí, R., 2001. An Experimental Evaluation of a Scatter Search for the Linear Ordering Problem. J. Glob. Optim. 21, 397-414. doi:10.1023/A:1012793906010

Celeste, A.B., Billib, M., 2009. Evaluation of stochastic reservoir operation optimization models. Adv. Water Resour. 32, 1429-1443. doi:10.1016/j.advwatres.2009.06.008

Chang, F.-J., Chen, L., 1998. Real-Coded Genetic Algorithm for Rule-Based Flood Control Reservoir Management. Water Resour. Manag. 12, 185198. doi:10.1023/A:1007900110595

Charbonneau, P., Knapp, B., 1995. User's guide to PIKAIA 1.0. NCAR Technical Note 418+IA. Boulder: National Center for Atmospheric Research.

Chen, L., McPhee, J., Yeh, W.W.-G., 2007. A diversified multiobjective GA for optimizing reservoir rule curves. Adv. Water Resour. 30, 1082-1093. doi:10.1016/j.advwatres.2006.10.001

CHJ, 1998. Hydrological Plan of Júcar Basin (in Spanish). Ministry of Environment in BOE 191 11/aug/1998, Spain.

Cisty, M., 2010. Hybrid Genetic Algorithm and Linear Programming Method for Least-Cost Design of Water Distribution Systems. Water Resour. 
Manag. 24, 1-24. doi:10.1007/s11269-009-9434-1

Clark, E.J., 1956. Impounding reservoirs. Water Work. Assoc 48, 349-354.

Deb, K., Pratap, A., Agarwal, S., Meyarivan, T., 2002. A fast and elitist multiobjective genetic algorithm: NSGA-II. IEEE Trans. Evol. Comput. 6, 182-197. doi:10.1109/4235.996017

Deval, J., Luengo, J.A., Lorenzo, J.L., García, J., de Paz, M., 2011. Módulo nival en los modelos hidrológicos de la Confederación Hidrográfica del Cantábrico. Calibración y validación en Picos de Europa, Jornada Internacional del Agua. ISBN-13: 978-84-615-4023-5, Barcelona, Spain.

Dias, N.L.C., Pereira, M.V.F., Kelman, J., 1985. Optimization of flood control and power generation requirements in a multi-purpose reservoir. In Proceedings of the IFAC symposium on planning and operation of electric energy systems, Rio de Janeiro, Brazil, pp. 121-124.

DICTUC, 2010. Análisis integrado de gestión en Cuenca del Río Copiapó. Technical Report. División de Ingeniería Hidráulica y ambiental DICTUC para la Dirección General de Aguas, Chile.

Drenkhan, F., Huggel, C., García, J., Seidel, J., 2016. Objetivos del modelamiento hidrológico integrado bajo cambios hidroclimáticos y socioeconómicos en la Cordillera Blanca, Perú. XXVII Congreso Latinoamericano de Hidráulica -LADHI. International Association of Hydraulic Engineering and Research, Lima, Perú, pp. 4259-4268.

Duan, Q., Sorooshian, S., Gupta, V., 1992. Effective and efficient global optimization for conceptual rainfall-runoff models. Water Resour. Res. 28, 1015-1031. doi:10.1029/91WR02985

Duan, Q., Sorooshian, S., Gupta, V.K., 1994. Optimal use of the SCE-UA global optimization method for calibrating watershed models. J. Hydrol. 158, 265-284. doi:10.1016/0022-1694(94)90057-4

Dumedah, G., Berg, A.A., Wineberg, M., Collier, R., 2010. Selecting Model Parameter Sets from a Trade-off Surface Generated from the NonDominated Sorting Genetic Algorithm-Il. Water Resour. Manag. 24, 
Efstratiadis, A., Koutsoyiannis, D., Xenos, D., 2004. Minimizing water cost in water resource management of Athens. Urban Water J. 1, 3-15. doi:10.1080/15730620410001732099

Elferchichi, A., Gharsallah, O., Nouiri, I., Lebdi, F., Lamaddalena, N., 2009. The genetic algorithm approach for identifying the optimal operation of a multi-reservoirs on-demand irrigation system. Biosyst. Eng. 102, 334344. doi:10.1016/j.biosystemseng.2008.12.009

Farhangi, M., Bozorg-Haddad, O., Mariño, M.A., 2012. Evaluation of simulation and optimisation models for WRP with PIs. Proc. Inst. Civ. Eng. - Water Manag. 165, 265-276. doi:10.1680/wama.10.00046

Farmani, R., Abadia, R., Savic, D., 2007. Optimum Design and Management of Pressurized Branched Irrigation Networks. J. Irrig. Drain. Eng. 133, 528-537. doi:10.1061/(ASCE)0733-9437(2007)133:6(528)

Farmani, R., Henriksen, H.J., Savic, D., 2009. An evolutionary Bayesian belief network methodology for optimum management of groundwater contamination. Environ. Model. Softw. 24, 303-310. doi:10.1016/j.envsoft.2008.08.005

Farmani, R., Savic, D., Walters, G., 2005a. Evolutionary multi-objective optimization in water distribution network design. Eng. Optim. 37, 167183. doi:10.1080/03052150512331303436

Farmani, R., Walters, G., Savic, D., 2006. Evolutionary multi-objective optimization of the design and operation of water distribution network: total cost vs. reliability vs. water quality. J. Hydroinformatics 8 .

Farmani, R., Walters, G., Savic, D., 2005b. Trade-off between Total Cost and Reliability for Anytown Water Distribution Network. J. Water Resour. Plan. Manag. 131, 161-171. doi:10.1061/(ASCE)07339496(2005)131:3(161)

García, J., Claude, A., Paredes, J., Roquier, B., Boillat, J.-L., 2014. Integrated flood forecasting and management system in a complex catchment 
area in the Alps - Implementation of the MINERVE project in the canton of Valais, in: Schleiss, S.\& P. (Ed.), Swiss Competences in River Engineerig and Restoration. Taylor \& Francis Group, London, pp. 87-97. doi:doi:10.1201/b17134-12

García, J., Paredes, J., Foehn, A., Roquier, B., 2016. RS MINERVE - Technical manual v2.4.

Glover, F., 1977. Heuristics for integer programming using surrogate constraints. Decis. Sci. 8, 156-166. doi:10.1111/j.15405915.1977.tb01074.x

Gorev, N.B., Kodzhespirova, I.F., Kovalenko, Y., Álvarez, R., Prokhorov, E., Ramos, A., 2011. Evolutionary Testing of Hydraulic Simulator Functionality. Water Resour. Manag. 25, 1935-1947. doi:10.1007/s11269-011-9782-5

Haghighi, A., Samani, H.M. V., Samani, Z.M. V., 2011. GA-ILP Method for Optimization of Water Distribution Networks. Water Resour. Manag. 25, 1791-1808. doi:10.1007/s11269-011-9775-4

Hanne, T., Nickel, S., 2005. A multiobjective evolutionary algorithm for scheduling and inspection planning in software development projects. Eur. J. Oper. Res. 167, 663-678. doi:10.1016/j.ejor.2004.07.014

Hassanzadeh, Y., Abdi, A., Talatahari, S., Singh, V.P., 2011. Meta-Heuristic Algorithms for Hydrologic Frequency Analysis. Water Resour. Manag. 25, 1855-1879. doi:10.1007/s11269-011-9778-1

Hidalgo, I.G., Barros, R.S. De, Fernandes, J.P.T., Estrócio, J.P.F., Correia, P.B., 2015. Metaheuristic Approaches for Hydropower System Scheduling. J. Appl. Math. 2015, 6 pages. doi:doi:10.1155/2015/701851

Hınçal, O., Altan-Sakarya, A.B., Metin Ger, A., 2011. Optimization of Multireservoir Systems by Genetic Algorithm. Water Resour. Manag. 25, 1465-1487. doi:10.1007/s11269-010-9755-0

IPH, 2008. Instrucción de Planificación Hidrológica. Ministerio de Medio ambiente Rural y Marino, BOE 229 de 22/09/2008. 
Jamieson, D.G., 1997. Special Issue on Decision-Support Systems. J. Hydrol. $177,3-4$.

Jordan, F., García, J., Boillat, J.-L., Bieri, M., De Cesare, G., Schleiss, A., 2012. Prévision des crues sur le Yangtsé - Application du concept MINERVE, in: Wasser Energie Luft. Wasser Energie Luft, pp. 282-288.

Karamouz, M., Szidarovszky, F., Zahraie, B., 2000. Water Resources Systems Analysis, New York. Lewis Publishers, Boca Raton Florida.

Kourakos, G., Mantoglou, A., 2011. Simulation and Multi-Objective Management of Coastal Aquifers in Semi-Arid Regions. Water Resour. Manag. 25, 1063-1074. doi:10.1007/s11269-010-9677-x

Koutsoyiannis, D., Economou, A., 2003. Evaluation of the parameterizationsimulation-optimization approach for the control of reservoir systems. Water Resour. Res. 39, n/a-n/a. doi:10.1029/2003WR002148

Kuczera, G., 1997. Efficient subspace probabilistic parameter optimization for catchment models. Water Resour. Res. 33, 177-185. doi:10.1029/96WR02671

Kuczera, G., 1993. Network Linear Programming Codes for Water-Supply Headworks Modeling. J. Water Resour. Plan. Manag. 119, 412-417. doi:10.1061/(ASCE)0733-9496(1993)119:3(412)

Kuczera, G., 1989. Fast multireservoir multiperiod linear programing models. Water Resour. Res. 25, 169-176. doi:10.1029/WR025i002p00169

Labadie, J., 1997. Reservoir system optimization models, in: Water Resources Update. University Council on Water Resources, pp. 83-110.

Labadie, J.W., 2004. Optimal Operation of Multireservoir Systems: State-ofthe-Art Review. J. Water Resour. Plan. Manag. 130, 93-111. doi:10.1061/(ASCE)0733-9496(2004)130:2(93)

Lerma, N., García, J., Paredes-Arquiola, J., Andreu, J., 2017. Optimization assessment of hydropower plants during floods in Visp basin (Switzerland) using evolutionary algorithms. J. Flood Risk Manag. In 
Review.

Lerma, N., Paredes-Arquiola, J., Andreu, J., Solera, A., 2013. Development of operating rules for a complex multi-reservoir system by coupling genetic algorithms and network optimization. Hydrol. Sci. J. 58, 797812. doi:10.1080/02626667.2013.779777

Lerma, N., Paredes-Arquiola, J., Andreu, J., Solera, A., Sechi, G.M., 2015. Assessment of evolutionary algorithms for optimal operating rules design in real Water Resource Systems. Environ. Model. Softw. 69, 425436. doi:10.1016/j.envsoft.2014.09.024

Lerma, N., Paredes-Arquiola, J., Molina, J.-L., Andreu, J., 2014. Evolutionary network flow models for obtaining operation rules in multi-reservoir water systems. J. Hydroinformatics 16, 33. doi:10.2166/hydro.2013.151

Lian, X., Jiang, T., 2005. Daily scheduling model and implementation in three gorges cascaded hydroelectric system. Adv. Syst. Sci. Appl. 5, 313-319.

Liberatore, S., Sechi, G.M., 2009. Location and Calibration of Valves in Water Distribution Networks Using a Scatter-Search Meta-heuristic Approach. Water Resour. Manag. 23, 1479-1495. doi:10.1007/s11269-008-93376

Louati, M.H., Benabdallah, S., Lebdi, F., Milutin, D., 2011. Application of a Genetic Algorithm for the Optimization of a Complex Reservoir System in Tunisia. Water Resour. Manag. 25, 2387-2404. doi:10.1007/s11269011-9814-1

Loucks, D.P., Sigvaldason, O.T., 1982. Multiple reservoir operation in North America, in: Kaczmarck, Z., Kindler, J. (Eds.), The Operation of Multiple Reservoir Systems. IIASA Collab Proc Ser, pp. 1-103.

Luce, C.H., Cundy, T.W., 1994. Parameter identification for a runoff model for forest roads. Water Resour. Res. 30, 1057-1069. doi:10.1029/93WR03348

Lund, J.R., Ferreira, I., 1996. Operating Rule Optimization for Missouri River Reservoir System. J. Water Resour. Plan. Manag. 122, 287-295. 
doi:10.1061/(ASCE)0733-9496(1996)122:4(287)

Lyra, C., Ferreira, L.R.M., 1995. A multiobjective approach to the short-term scheduling of a hydroelectric power system. IEEE Trans. Power Syst. 10, 1750-1755. doi:10.1109/59.476038

Maier, H.R., Kapelan, Z., Kasprzyk, J., Kollat, J., Matott, L.S., Cunha, M.C., Dandy, G.C., Gibbs, M.S., Keedwell, E., Marchi, A., Ostfeld, A., Savic, D., Solomatine, D.P., Vrugt, J.A., Zecchin, A.C., Minsker, B.S., Barbour, E.J., Kuczera, G., Pasha, F., Castelletti, A., Giuliani, M., Reed, P.M., 2014. Evolutionary algorithms and other metaheuristics in water resources: Current status, research challenges and future directions. Environ. Model. Softw. 62, 271-299. doi:10.1016/j.envsoft.2014.09.013

Makropoulos, C.K., Natsis, K., Liu, S., Mittas, K., Butler, D., 2008. Decision support for sustainable option selection in integrated urban water management. Environ. Model. Softw. 23, 1448-1460. doi:10.1016/j.envsoft.2008.04.010

Malekmohammadi, B., Zahraie, B., Kerachian, R., 2010. A real-time operation optimization model for flood management in river-reservoir systems. Nat. Hazards 53, 459-482. doi:10.1007/s11069-009-9442-8

Martí, R., 2006. Scatter Search-Wellsprings and Challenges. Eur. J. Oper. Res. 169, 351-358. doi:10.1016/j.ejor.2004.08.003

MIMAM, 2000. Libro Blanco del Agua en España. Ministerio de Medio Ambiente. Dirección General de Obras Hidráulicas y calidad de las Aguas, Spain.

Moeini, R., Afshar, A., Afshar, M.H., 2011. Fuzzy rule-based model for hydropower reservoirs operation. Int. J. Electr. Power Energy Syst. 33, 171-178. doi:10.1016/j.ijepes.2010.08.012

Molina-Cristóbal, A., Griffin, I.A., Fleming, P.J., Owens, D.H., 2005. Multiobjective controller design: optimising controller structure with genetic algorithms. IFAC Proc. Vol. 38, 51-56. doi:10.3182/200507036-CZ-1902.00869 
Molina, J.-L., Farmani, R., Bromley, J., 2011. Aquifers Management through Evolutionary Bayesian Networks: The Altiplano Case Study (SE Spain). Water Resour. Manag. 25, 3883-3909. doi:10.1007/s11269-011-9893Z

Momtahen, S., Dariane, A.B., 2007. Direct Search Approaches Using Genetic Algorithms for Optimization of Water Reservoir Operating Policies. J. Water Resour. Plan. Manag. 133, 202-209. doi:10.1061/(ASCE)07339496(2007)133:3(202)

Mousavi, S.J., Mahdizadeh, K., Afshar, A., 2004. A stochastic dynamic programming model with fuzzy storage states for reservoir operations. Adv. Water Resour. 27, 1105-1110. doi:10.1016/j.advwatres.2004.07.007

Nalbantis, I., Koutsoyiannis, D., 1997. A parametric rule for planning and management of multiple-reservoir systems. Water Resour. Res. 33, 2165-2177. doi:10.1029/97WR01034

Naresh, R., Sharma, J., 2000. Hydro system scheduling using ANN approach. IEEE Trans. Power Syst. 15, 388-395.

Nazif, S., Karamouz, M., Tabesh, M., Moridi, A., 2010. Pressure Management Model for Urban Water Distribution Networks. Water Resour. Manag. 24, 437-458. doi:10.1007/s11269-009-9454-x

Needham, J.T., Jr., D.W.W., Lund, J.R., Nanda, S.K., 2000. Linear Programming for Flood Control in the lowa and Des Moines Rivers. http://dx.doi.org/10.1061/(ASCE)0733-9496(2000)126:3(118). doi:10.1061/(ASCE)0733-9496(2000)126:3(118)

Ni, E., Guan, X., Li, R., 1999. Scheduling hydrothermal power systems with cascaded and head-dependent reservoirs. IEEE Trans. Power Syst. 14, 1127-1132.

Nicklow, J., Reed, P., Savic, D., Dessalegne, T., Harrell, L., Chan-Hilton, A., Karamouz, M., Minsker, B., Ostfeld, A., Singh, A., Zechman, E., 2010. State of the Art for Genetic Algorithms and Beyond in Water Resources Planning and Management. J. Water Resour. Plan. Manag. 136, 412- 
Oliveira, R., Loucks, D.P., 1997. Operating rules for multireservoir systems. Water Resour. Res. 33, 839-852. doi:10.1029/96WR03745

Osman, M.S., Abo-Sinna, M.A., Mousa, A.A., 2005. An effective genetic algorithm approach to multiobjective resource allocation problems (MORAPs). Appl. Math. Comput. 163, 755-768. doi:10.1016/j.amc.2003.10.057

Pelletier, G.J., Chapra, S.C., Tao, H., 2006. QUAL2Kw - A framework for modeling water quality in streams and rivers using a genetic algorithm for calibration, Environmental Modelling \& Software. doi:10.1016/j.envsoft.2005.07.002

Perez, G., García, J., Rubio, H., Fluixá, J., 2016. Gestión de recursos hídricos con un modelo semi-distribuido en la cuenca del río Fuerte, México. XXVII Congreso Latinoamericano de Hidráulica -LADHI. International Association of Hydraulic Engineering and Research, IAHR, Lima, Perú, pp. 2931-2940.

Piekutowski, M.R., Litwinowicz, T., Frowd, R.J., 1994. Optimal short-term scheduling for a large-scale cascaded hydro system. IEEE Trans. Power Syst. 9, 805-811. doi:10.1109/PICA.1993.291004

Rani, D., Moreira, M.M., 2010. Simulation-Optimization Modeling: A Survey and Potential Application in Reservoir Systems Operation. Water Resour Manag. 24, 1107-1138. doi:10.1007/s11269-009-9488-0

Raquel, C.R., Naval, P.C., 2005. An effective use of crowding distance in multiobjective particle swarm optimization, in: Proceedings of the 2005 Conference on Genetic and Evolutionary Computation - GECCO '05. ACM Press, New York, New York, USA, p. 257. doi:10.1145/1068009.1068047

RAS, 2013. Decision support system models development for multi-use water resource systems in water scarcity conditions using mixed simulationoptimization techniques. Final Report of the RAS Project. In Press., Italy. 
Reca, J., Roldán, J., Alcaide, M., López, R., Camacho, E., 2001a. Optimisation model for water allocation in deficit irrigation systems: I. Description of the model. Agric. Water Manag. 48, 103-116. doi:10.1016/S03783774(00)00126-8

Reca, J., Roldán, J., Alcaide, M., López, R., Camacho, E., 2001b. Optimisation model for water allocation in deficit irrigation systems: II. Application to the Bémbezar irrigation system. Agric. Water Manag. 48, 117-132. doi:10.1016/S0378-3774(00)00127-X

ReVelle, C., 1999. Optimizing reservoir resources : including a new model for reservoir reliability. Wiley.

Rodrigues, V.A., Lucas, M.E., García, J., Fluixá, J., Timoteo, M., Ranzini, M., 2016. Evaluación de los procesos hidrológicos y ciclo del agua en bosques tropicales con un modelo semi-distribuido. XXVII Congreso Latinoamericano de Hidráulica -LADHI. International Association of Hydraulic Engineering and Research, IAHR, Lima, Perú, pp. 2582-2589.

Scheuerer, S., Wendolsky, R., 2006. A scatter search heuristic for the capacitated clustering problem. Eur. J. Oper. Res. 169, 533-547. doi:10.1016/j.ejor.2004.08.014

Sechi, G.M., Sulis, A., 2009. Water System Management through a Mixed Optimization-Simulation Approach. J. Water Resour. Plan. Manag. 135, 160-170. doi:10.1061/(ASCE)0733-9496(2009)135:3(160)

Sechi, G.M., Zuddas, P., 2000. WARGI: Water Resources System Optimisation Aided By Graphical Interface. WIT Trans. Ecol. Environ. 40, 109-120. doi:10.2495/HY000101

Sedki, A., Ouazar, D., 2011. Simulation-Optimization Modeling for Sustainable Groundwater Development: A Moroccan Coastal Aquifer Case Study. Water Resour. Manag. 25, 2855-2875. doi:10.1007/s11269-011-9843-9

Tilmant, A., Faouzi, E.H., Vanclooster, M., 2002. Optimal operation of multipurpose reservoirs using flexible stochastic dynamic programming. Appl. Soft Comput. 2, 61-74. doi:10.1016/S1568- 
4946(02)00029-7

UNICA, 2012. Decision support system models development for multi-use water resource systems in water scarcity conditions using mixed simulation-optimization techniques. Technical Report. University of Cagliari, Italy.

Uysal, G., Akkol, B., Topcu, M.I., Sensoy, A., Schwanenberg, D., 2016. Comparison of Different Reservoir Models for Short Term Operation of Flood Management. 12th Int. Conf. Hydroinformatics 154, 1385-1392. doi:10.1016/j.proeng.2016.07.506

Villasanti, C.M., von Lucken, C., Baran, B., 2004. Dispatch of hydroelectric generating units using multiobjective evolutionary algorithms, in: IEEE/PES Transmision and Distribution Conference and Exposition: Latin America (IEEE Cat. No. 04EX956). IEEE, pp. 929-934. doi:10.1109/TDC.2004.1432507

Wurbs, R.A., 1993. Reservoir-System Simulation and Optimization Models. J. Water Resour. Plan. Manag. 119, 455-472. doi:10.1061/(ASCE)07339496(1993)119:4(455)

Yamout, G., El-Fadel, M., 2005. An Optimization Approach for Multi-Sectoral Water Supply Management in the Greater Beirut Area. Water Resour. Manag. 19, 791-812. doi:10.1007/s11269-005-3280-6

Yeh, W.W.-G., 1985. Reservoir Management and Operations Models: A Stateof-the-Art Review. Water Resour. Res. 21, 1797-1818. doi:10.1029/WR021i012p01797

Young, G., 1967. Finding reservoir operating rules. J. Hydraul. Div. ASCE 93 $(6,297-321$.

Zeng, Y., Lu, Z., Jiang, T., 2003. The model and application of daily optimal operation in three gorges cascaded hydroelectric systems. Adv. Syst. Sci. Appl. 3, 417-422.

Zhang, G., Zhang, Y., 2003. Hydrothermal generation scheduling with a stochastic dual dynamic programming algorithm. Adv. Syst. Sci. Appl. 3, 
383-389.

Zhou, J., Zhang, Y., Zhang, R., Ouyang, S., Wang, X., Liao, X., 2015. Integrated optimization of hydroelectric energy in the upper and middle Yangtze River. Renew. Sustain. Energy Rev. 45, 481-512. doi:10.1016/j.rser.2015.01.022

Zoltay, V.I., Vogel, R.M., Kirshen, P.H., Westphal, K.S., 2010. Integrated Watershed Management Modeling: Generic Optimization Model Applied to the Ipswich River Basin. J. Water Resour. Plan. Manag. 136, 566-575. doi:10.1061/(ASCE)WR.1943-5452.0000083 

ANNEXES 



\section{A.1. Development of operating rules for a complex multireservoir system by coupling genetic algorithms and network optimisation. ${ }^{1}$}

N. Lerma, J. Paredes-Arquiola, J. Andreu, and A. Solera.

Instituto de Ingeniería del Agua y Medio Ambiente. Universitat Politècnica de València. Caminos de Vera s/n. 46022, Valencia. Spain.

\section{Email: neslerel@upv.es}

Abstract: An alternative procedure for assessment of Operation Rules (ORs) under drought situations is proposed in this paper. The definition of ORs for multireservoir water resources systems (WRSs) is a topic that has been widely studied by means of optimisation and simulation techniques. A traditional approach is to link optimisation methods with simulation models. The objective of this paper is to obtain drought ORs for a real and complex WRS: the Júcar River basin in Spain. One of the main issues in this basin is the resource allocation among agricultural demands in periods of drought. To deal with this problem we present a method based on the combined use of Genetic Algorithms (GA) and Network Flow Optimisation (NFO). The GA used was PIKAIA, which has previously been used in other water resources related fields. This algorithm was linked to the SIMGES simulation model, a part of the AQUATOOL Decision Support System (DSS). Several tests were developed for defining the parameters of the GA. The optimisation of various ORs was analysed with the objective of minimising short-term and long-term water deficits. Results show that simple ORs produce similar results than more

\footnotetext{
${ }^{1}$ Lerma, N., Paredes-Arquiola, J., Andreu, J., and Solera, A. 2013. Development of operating rules for a complex multi-reservoir system by coupling genetic algorithms and network optimization. Hydrol. Sci. J., 58 (4), 797-812.

This is the authors accepted manuscript of an article published as the version of record in Hydrological Sciences Journal 2013 http://www.tandfonline.com/ http://dx.doi.org/10.1080/02626667.2013.779777.
} 
sophisticated ones. This paper demonstrates the usefulness of this approach in the assessment of ORs for complex multireservoir systems.

Key words water resources system, genetic algorithms, Pikaia, operating rules, decision support system, Aquatool, simulation, optimisation, agricultural demands, drought, deficits

\section{Développement de règles de fonctionnement d'un système complexe multi-réservoirs par couplage d'algorithmes génétiques et d'une optimisation en réseau}

\section{Résumé}

Une méthode alternative pour l'évaluation des règles de fonctionnement (ORs) dans des situations de sécheresse est proposée dans cet article. La définition des ORs pour des systèmes multi-réservoirs de ressources en eau (WRSs) est un topique qui a largement été étudié par le moyen de techniques d'optimisation et de simulation. L'approche traditionnelle est de relier les méthodes d'optimisation avec les modèles de simulation. L'objectif de cet article est d'obtenir les ORs de sécheresse pour un WRS réel et complexe: le bassin de la rivière Jucar en Espagne. L'une des problématiques principales de ce bassin est la répartition des ressources entre les différents besoins agricoles en période de sécheresse. Pour faire face à ce problème, une méthode basée sur l'utilisation combinée d'algorithmes génétiques (GA) et optimisation de réseaux de flux (NFO) est présentée. L'algorithme génétique utilisé est Pikaia, qui a déjà été employé dans d'autres domaines liés aux ressources en eau. Cet algorithme a été introduit par exemple dans le modèle de simulation SIMGES, qui est un module du système d'aide à la décision AQUATOOL (DSS). Plusieurs tests ont été développés pour définir les paramètres du GA. Les optimisations de différents ORs ont été analysées dans le but de minimiser les déficits en eau à court et à long terme. Les résultats montrent que les ORs simples produisent des résultats semblables aux ORs plus sophistiqués. Cet article démontre l'utilité de cette approche dans l'évaluation des ORs pour les systèmes complexes multi-réservoirs.

Mots clés: système de ressources en eau, algorithme génétique, Pikaia, règles de fonctionnement, système d'aide à la décision, Aquatool, simulation, optimisation, besoins agricoles, sécheresse, déficits. 


\section{INTRODUCTION}

Several authors have noted the lack of application of optimisation models to the practical management of multireservoir WRSs (Yeh 1985, Wurbs 1993, Labadie 2004). One of the main reasons for this shortcoming is the necessarily high degree of simplification of these models that removes them excessively far from reality, with the result that water managers lack sufficient confidence in their results to base decisions on model prescriptions. Nevertheless, Oliveira and Loucks (1997) argue that this fact is more likely due to institutional limitations than to technological or mathematical difficulties.

As pointed out by Yeh (1985), there is no general method for optimising reservoir operations; it ranges from simulation to optimization models. Typical methods of optimising reservoir operations are: Linear Programming, Heuristic Approaches, Stochastic Dynamic Programming methods (Mousavi 2004, Celeste and Billib 2009, Tilmanta 2002), Evolutionary Optimisation (Oliveira and Loucks 1997) and other approaches. These methods, used in optimal control of reservoir systems, require a large number of control variables, which are typically the sequences of releases from all reservoirs and for all time steps of the control period (Koutsoyiannis and Economou 2003).

Simulation models are generally preferred instead of typical optimisation schemes (such as linear, dynamic or stochastic dynamic programming models); the latter suffer both, from the high dimensionality, and the exaggerated and often unrealistic simplifications that are unavoidably made, concerning the operation of the real-world system (Efstratiadis et al. 2004). Simulation models allow for a more detailed representation of the system than optimisation models (Loucks and Sigvaldason 1982). Thus, in general, river basin management is performed with the support of simulation models that are characterised by their flexibility and capacity for representing very complex elements. However, these models require the establishment of predetermined ORs or a definition of system management. 
The design of Operating Rules (ORs) for multireservoir systems is a topic that has been studied deeply in the history of water resources management. ORs can be obtained from the results of optimisation models using linear regression (Young 1967), multiple linear regression (Bhaskar and Withlach 1980 ) and the use of simple statistics or tables and diagrams (Lund and Ferreira 1996). Unfortunately, regression analysis may yield poor correlation results, invalidating the ORs so obtained (Labadie 2004).

It is desirable to use a modelling approach combining adherence and flexibility of simulation models with the efficient exploration of mathematical optimization models (Wurbs 1993). Labadie (2004) and Rani and Moreira (2010) reviewed the state-of-the-art regarding the optimization techniques used for multi-reservoir systems, which represent the majority of water allocation problems. Both authors said that the most favored technique for water allocation models has been linear programming. This technique is the most traditional (ReVelle 1999) and has been used for optimizing resources management of whole river basin schemes (Zoltay et al. 2010), developing decision support systems for urban water supply areas (Yamout and El-Fadel 2005), and optimizing irrigation water allocation in complex agricultural schemes (Reca et al. 2001a, b). Network flow programming is a computationally efficient form of linear programming and, as was shown by Kuczera (1989) and Kuczera (1993), is more suitable than linear programming for solving large multi-reservoir multi-period models.

Moreover, the combination of nonlinear algorithms with linear or network flow programming is a specific and very efficient in water resources models. For example, Cai et al. (2001) described strategies for solving large nonlinear water resource management models combining GA with linear programming, in which a GA/LP approach was applied to a reservoir operation model with a nonlinear hydropower generation and to a long-term dynamic river basin planning model. Another methodology was proposed by Nalbantis and Koutsoyiannis (1997) introducing a parametric rule based in two parameters per reservoir. They proposed and tested a multireservoir parametric rule where parameters are estimated by means of linear and nonlinear optimization methods, using simulation to evaluate the objective function for each trial set of parameter values. The advantage of this 
approach is the parsimonious formulation with just two parameters per reservoir making searching most effective than other optimisation approaches. Efstratiadis et al. (2004) make use of the aforementioned operation rules to represent the system parameterization, an NFP method to solve the simulation problem and an evolutionary algorithm to determine the optimal parameters.

However, even with these methodologies, and despite potential for the use of optimization in the search for efficient alternatives, full integration between simulation and optimization has not yet been achieved to close the gap between research and real-world application.

Although various strategies have been defined for using optimization and simulation techniques in combination, few of these have been employed in real-world multireservoir and multiuse water systems (Sechhi et al. 2009). In many real water systems, especially systems affected by droughts, managers employ OR based on taking decisions depending on the storage of the system and/or last inflows. The decisions are normally related to reduction of the demand or increment of the resource. In particular, ORs for drought mitigation are developed defining some thresholds values (Rossi et al. 2011). These ORs can be considered Trigger ORs (TORs) because one or several actions are triggered when the system reaches a specific situation. Although some authors have criticised the use of this kind of ORs because of their relative inefficiency (Karamouz et al. 2000), the practical management of systems is usually performed with these kinds of rules due to their ease of application and comprehension. Additionally, there are several aspects of these curves that give them special relevance. First, a great number of multireservoir systems are managed by the division of reservoirs into layers (Pool-Based Rule systems). For example, many of the reservoirs built by the US Corp of Engineers are managed on the basis of defined layers or storage zones divided by reservoir curves (Lund and Ferreira 1996). Moreover, TORs have other advantages: they are easy to understand for both users and basin managers, they can be implemented into a legal framework, and they are extremely useful as triggers for decision making during periods of drought. Typically, these decisions concern restrictions on transfers, restrictions on nonpriority demands, and the initiation of special measures such as drought 
wells. Historically, these curves have been widely used in WRS planning and management.

A typical technique for obtaining TORs is the iteration with basin simulation models. These iterations can be controlled by an optimisation algorithm that varies the ORs according to the results of the simulation model runs. Among the possible optimisation algorithms than can be used, Genetic Algorithms (GAs) are characterised by their flexibility for adaptation to any kind of problem and by avoiding local optima better than gradient methods. Nicklow et al. (2010) recently reviewed the state of the art of GAs and evolutionary techniques applied to water resource planning and management. In the particular case of ORs, Oliveira and Loucks (1997), and later Ahmed and Sarma (2005), presented an approach for optimising ORs for multireservoir systems using GAs. Among recent application cases, Chen et al. (2007) applied a multiobjective GA to optimise the rule curves of a multipurpose reservoir system in Taiwan; Elferchichi et al. (2009) also applied a real-coded GA to optimise the operation of reservoirs in an on-demand irrigation system, and this was later applied to the Sinista Ofanto irrigation scheme (Foggia, Italy).

In this paper we propose a methodology for obtaining TORs for a real and very complex WRS. The novelty of the approach resides in the combination of short term and long term reliability and vulnerability indicators in a multiobjective function for the definition of the parameters of a TOR. The engineering interest is demonstrating that the coupled simulation optimization model based on SIMGES and a GA (PIKAIA) is able to solve the problem in a robust way for complex real cases. This methodology is applied to the Júcar River basin in Spain. This basin is a complex system with intensive use of its resources, principally for irrigation demands, although other uses such as hydropower production and urban supply were also considered. To deal with this problem we present a method for the development of TORs for multireservoir systems by coupling GA with Network Flow optimization (NFO) basin simulation models. 


\section{METHODOLOGY}

Analysis of reservoirs management under drought conditions has received increasing attention in the last years, specially the optimization of the rule curves and the operational procedures (Hsu et al. 2004, Chang et al. 2005, Cañon et al. 2009). Reservoir ORs under drought conditions are based on proactive measures, to be adopted before drought impacts occur (Rossi et al. 2011).

The proposed methodology, depicted in Figure P1. 1, is based on the estimation of TORs of the rule curve type for a complex multireservoir system with a basin simulation model through an iterative process. The optimisation search model used is PIKAIA (Charbonneau and Knapp 1995), a flexible and easy-to-use GA. For the evaluation of the objective function (OF), a basin management simulation model is required. This model represents the system situation in a proposed operational mode. The basin simulation model was developed with the SIMGES program (Andreu et al. 1996), which is part of the AQUATOOL DSS (Andreu et al. 1996). In the following, the characteristics of the optimisation algorithm, the simulation model and the coupling method are briefly explained.

\subsection{Trigger Operation Rules}

Generally, ORs are a set of guidelines to define releases from the reservoir that serves as a protocol for the operators. The difference between operation rules that are pre-specified and rules that are determined through optimization is that this are typically characterised as parametric, given that their parameters are handled as control variables to an optimization problem. There are many types from simple to very complex and usually relate outflows from reservoir with the storages volume and/or past or future hydrological variables. Among the best known are the Rule curves specifying the target storage at the end of each month. These rules have been widely used in practice for its simplicity. Different adaptations of ORs Curves, as parametric, have been developed and its usefulness has been tested (Koutsoyiannis and Economou 2003). 


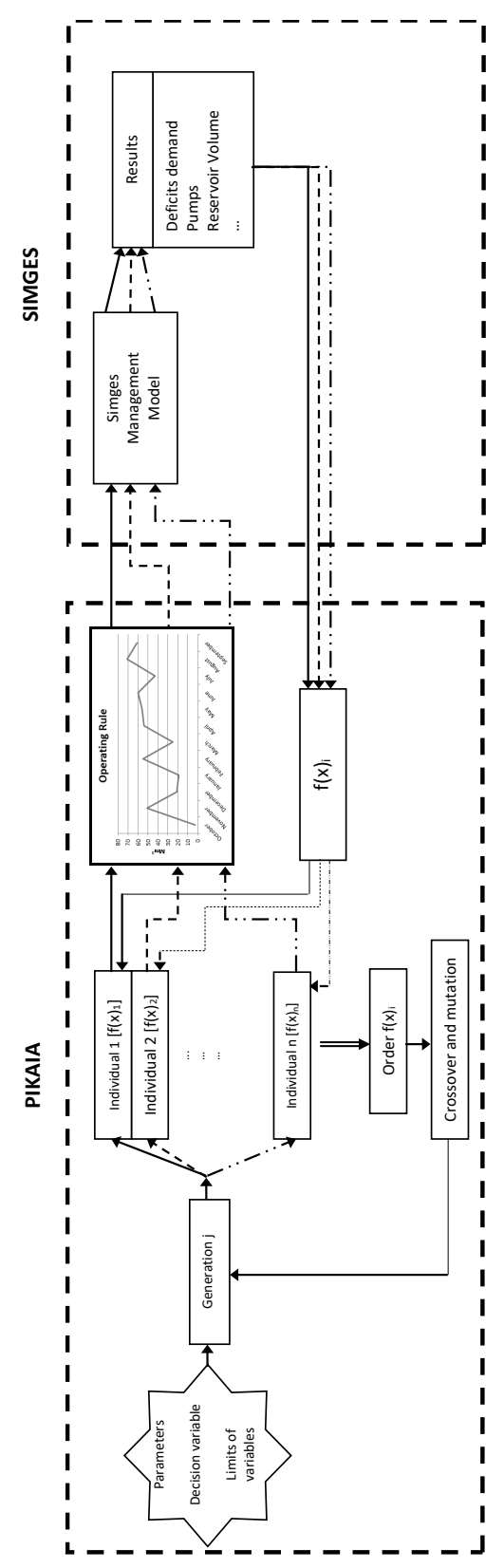

Figure P1. 1: Scheme of the methodological approach applied for the coupling of Pikaia GA and SIMGES water management simulation model. 
Other ORs related to Rule Curves, but where the curve is not a goal to be achieved but a threshold at which a decision is made are, as defined previously, TOR. These types of ORs are formed by a curve of an indicator and an action. The indicator can be the storage in one or more reservoirs, the inflows of last months in a system or the level of an aquifer. The action is related to a decision to be made that affects water supply of demands or alternative resources. This type of operation rules is applied in situations of drought in real systems. For example, in Spain, in the development of the Drought Special Plans (GPEASAS 2005) many systems based their Plans in defining this kind of ORs.

\subsection{The PIKAIA algorithm}

PIKAIA is a GA that, as all GA, is based on the search for an optimum using Darwinian evolutionary theory. Although its application has been more frequent in astrophysics, it has also been used in the calibration of water quality parameters with the QUAL2K model (Pelletier et al. 2006). The algorithm is based on six steps: initial population generation, fitness evaluation, selection, crossover, mutation, replacement and evaluation. It has two basic genetic operators: uniform crossover and mutation.

PIKAIA is based on a decimal codification as other GA packages, for example GENOCOP or GEATbx. There are three reproduction plans: complete generational replacement, random elimination and worst individual elimination. Elitism is also available and is a default option.

The mutation rate can be dynamically controlled by modifying the aptitude difference between the best individuals and the median of the population (also a default option). Selection is based on stochastic sample selection and individual arrangement, making use of the roulette-wheel algorithm (the probability of choosing an individual is proportional to its aptitude). The mutation modes implemented in PIKAIA are one-point mutation with: fixed rate, adjustable rate based on fitness, or an adjustable rate based on distance. PIKAIA has been used the version adapted for Microsoft Excel by Pelletier et al. (2006). 


\subsection{The SIMGES simulation model}

The proposed method requires multiple iterations of a representative simulation model of the studied WRS. For this purpose, we used SIMGES module of the DSS AQUATOOL. Both, the simulation module and the DSS, have been widely applied to river basins in Spain and abroad (CHJ 1998, MIMAM 2000, DICTUC 2010, UNICA 2012, Jamieson 1997). SIMGES model is based on the conceptualization of a river basin as a set of interconnected elements that represent the real components of the WRS and their interactions. A large variety of elements is available, as reservoirs, river reaches, channels, aquifers, hydroelectricity generation facilities, groundwater pumping facilities, return flows, demands and intakes, etc.

In the simulation process, for every time step (one month in this case) SIMGES model translates different water resources elements such as inflows, demands, rivers, reservoirs, into a Network Flow Optimization (NFO) problem. The NFO is composed by arcs and nodes where each arc is defined by a maximum, a minimum, and a flow cost. The minimum value is zero where using the Out of Kilter algorithm (Ford and Fulkerson 1962). The consideration of the different elements of the system is achieved by means of artificial arcs and nodes. For example, environmental, for minimum flows, are considered two virtual arcs one having the capacity equal to the desirable environmental flow and a negative cost and the other without cost and a high upper limit.

The arcs are defined by their initial and final nodes, the maximum and minimum flows passing through them, and the cost of circulating a single unit of flow. In this case, costs are not real costs, but pseudo-costs designed to reflect priorities, physical infeasibilities, preferences, etc. This problem is expressed mathematically as follows:

$$
\operatorname{Min} \sum_{i=1}^{m} \sum_{j=1}^{m} c_{i j} x_{i j}
$$


Subject to:

$$
\begin{array}{cc}
\sum_{j=1}^{m} x_{i j}-\sum_{k=1}^{m} x_{k i}=0 & \forall i=1, \ldots, m \\
x_{i j} \geq l_{i j} \quad \forall i=1, \ldots, m & \forall j=1, \ldots, m \\
x_{i j} \leq u_{i j} \quad \forall i=1, \ldots, m & \forall j=1, \ldots, m
\end{array}
$$

where $x_{i j}$ is the flow circulating through the arc from node $i$ to node $j, c_{i j}$ is the cost for each circulated flow unit, and $l_{i j}$ and $u_{i j}$ are the lower and upper flow limits, respectively, of the arc starting at node $i$ and ending at node $j$. Actually, the model allows flows lower than the minimum flow limit but does not allow flows greater than the maximum limit. Under these assumptions, the optimisation problem can be efficiently solved using the Out-of-Kilter algorithm (Ford and Fulkerson 1962).

Although the pure mathematical form is the one presented previously, the setting of the arcs, nodes and costs makes that the practical objective function of the model is composed by different terms, one for each element of the system. Depending on the type of element, its contribution to the objective function is different. The equivalent objective function defined in SIMGES model and simplified for reservoirs and demands is the following:

$$
\begin{aligned}
\text { Min } F=\sum_{i=1}^{I}( & \left.\sum_{n=1}^{m}\left(V_{n, i}\left(C_{n}+p n_{i}\right)\right)+\left(S p_{i} C_{s p}\right)\right)+\sum_{j=1}^{J} D R_{j}\left(C_{d r}+p n_{j}\right) \\
& +\sum_{k=1}^{K} D D_{k}\left(C_{D D}+p n_{k}\right)
\end{aligned}
$$

Where $I$ is the total number of reservoirs in the model; $V_{n, \mathrm{i}}$ is the volume of the reservoir $i$ in the pool $n ; m$ is the number of pools in a reservoir; $C_{n}$ is the cost/benefit of storage water into the pool $\mathrm{n} ; \mathrm{pn}_{\mathrm{i}}$ is the priority number assigned to the reservoir $\mathrm{I} ; \mathrm{Sp}_{\mathrm{i}}$ is the spill of the reservoir $\mathrm{I}$; and $\mathrm{C}_{\mathrm{sp}}$ is the cost of spills in the reservoirs; $J$ is the total number of conduits (either river reaches, or channels, or pipes) in the model; $D R_{j}$ is the Deficit of the minimum 
flow established for conduit $\mathrm{j}$; $\mathrm{C}_{\mathrm{dr}}$ is the cost of deficit of a minimum flow; $\mathrm{pn}_{\mathrm{j}}$ is the priority number of the conduit $\mathrm{j} ; \mathrm{K}$ is the number of demands in the model; $D_{k}$ is the deficit of a demand $k ; C_{D D}$ is the cost associated to deficits of demands and $\mathrm{pn}_{\mathrm{k}}$ is the priority number of demand $\mathrm{k}$.

As it can be seen, the above equation is comprised of costs and priorities. The costs, set by default and previously calibrated, allow for the rational behaviour of the model between different types of items: for example, supplying water to demands before storing in the reservoirs. Although this "rational behaviour" usually is not changed, a user can modify it altering these costs. On the other hand, priorities also set behaviour between elements of the same type. For example, the priorities identified in the demands establish the order of supplying demands. Priorities between environmental flows and between hydroelectric plants also have to be set. The same system of priorities combined with a definition of pools or zones is used for reservoirs. In each reservoir different pools have to be defined and a priority. Releases start from the reservoirs of less priority and all reservoirs are maintained in the same zone whenever possible.

Along with the pools and priority system, the management of reservoirs is defined with ORs. In SIMGES there are ORs that allow modelling decision making based on indicators, as TORs defined previously. Some examples of indicators are the stored volume in one or more reservoirs and the accumulated in stream flow during various months at one or more points of the system. The resulting decisions include the restriction to a certain percentage of one or more demands, turbine flow, environmental flow or pumping from an aquifer. Environmental aspects are also considered in the form of ecological flows to be satisfied.

An important feature of SIMGES is the joint consideration of surface water and groundwater. The program allows to model different types of aquifers and surface and ground connections. Among the models that can be used to represent aquifers are: deposit or reservoir, single cell with discharge through spring, aquifer hydraulically connected to a surface stream, connected to two surface streams, and also distributed heterogeneous aquifer of irregular shape (Andreu and Sahuquillo 1987). 
It has to be noticed that the NFO, as formulated above, is used every time step (i.e., one month in the case study) as a mechanism to find a set of flows through the system, storage in reservoirs, and water assignment to demands that fulfils the physical restrictions and fits as best as possible to the ORs and priorities. Therefore, SIMGES is not an optimization model, but rather a simulation model that uses NFO every time step for the mentioned purpose. In fact, NFO has to be solved several times in every time step (i.e., month) in order to deal with nonlinearities in some processes (e.g., evaporation from reservoirs), aquifer simulation (which is made apart, after each NFO optimization), and the resulting surface-groundwater interaction.

\subsection{Simulation and Optimization Models coupling}

The methodology used is based on the construction of an optimisation model with the following characteristics: the Objective Function (OF) considers the short-term and long term deficits of the demands:

$$
f(x)=w_{1} \text { MaxShortTermDef } f_{t}+w_{2} \text { MaxLongTermDe } f_{t}
$$

Where MaxShortTermDef $f_{t}$ represents the maximum annual deficit of several demands, and MaxLongTermDef ${ }_{t}$ represents the accumulated deficit in a period of time (several years, 10 years in the case of study). Both terms are weighted by $w_{1}$ and $w_{2}$ to incorporate the importance of each concept.

As illustrated schematically in Figure P1. 1, in the PIKAIA optimisation model, each individual operating condition consists of a proposed TOR and a restriction coefficient, and each evaluation of the OF requires a run of the basin management simulation model with that TOR. The simulation model estimates, among other things, the deficit in demands due to the proposed TOR. The results files with the series of deficits are then read to calculate the OF that is included into the optimisation model.

\section{THE JÚCAR RIVER BASIN.}

The Júcar River basin is located at the eastern end of the Iberian Peninsula (Figure P1. 2). It covers an area of $22,378 \mathrm{~km}^{2}$, and the length of the main 
stream is almost $550 \mathrm{~km}$. Its management is complex due to the high degree of use of its resources. The average basin precipitation of $510 \mathrm{~mm} /$ year implies a water resources average of $1,200 \mathrm{hm}^{3} /$ year including surface water and groundwater. Agriculture is the major water consumption demand, at $1,000 \mathrm{hm}^{3} /$ year, mainly between April and September. The storage capacity is $2,000 \mathrm{hm}^{3}$. Although the average values may indicate that its resources are sufficient, the Mediterranean climatology, with a strong winter-summer gradient and series of dry years between wet periods, causes the system to suffer frequent over-annual droughts.

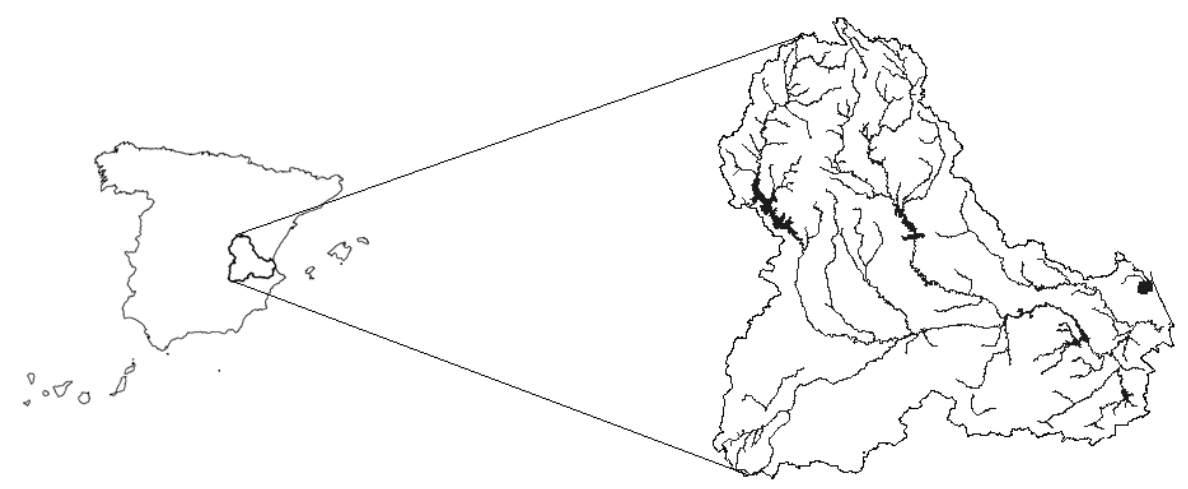

Figure P1. 2: Location of the Júcar River Basin.

The topology of the system is illustrated in Figure P1. 3, which shows the main elements located along the Júcar River itself and its main tributary, the Cabriel River; these include the principal reservoirs, the demands and other elements. The demands can be classified by their supply source into surface, groundwater, and mixed supplies. The majority of the demand is for irrigation, although there are some important urban demands. The agricultural demands are shown in Figure P1. 4.

The practical management of the system depends on the negotiations occurring in the meetings of the "Comisiones de Desembalse" (Reservoir Withdrawal Commission, RWC). Currently, there are no defined ORs. These are meetings among basin agency technicians, users and other stakeholders at different times of the year (almost monthly frequency). The most important one occurs in April, when the water assignments for the irrigation 
demands are defined for the rest of the hydrologic year. The assignments are defined according to the system state, although there are a series of principles that must be maintained:

- Water storage is preferably performed first in Alarcón, then in Contreras, and finally in Tous. In this way, the upstream storage priority is held above the downstream as long as the probability of spills from the Alarcón reservoir is minimal. Moreover, the Contreras reservoir suffers from a high filtration rate to the underlying aquifer.

- Although all agricultural demands face supply restrictions during droughts, the priority for surface water supply of traditional demands over mixed demands is taken into account. The demands for the Ribera Alta, the Ribera Baja and the Mancha Oriental (MO) aquifer are considered to have a higher priority than the demands from the Júcar-Turia Canal Irrigation system and part of the mixed irrigation schemes from the Mancha Aquifer. Conjunctive use of surface and groundwater is performed with intensities depending on the surface water reserves.

- Environmental flows have been defined at several points along the basin. By law, these must be maintained at all times, except when the drinking water supply is threatened.

The model developed for the Júcar River represents the current situation of the system and simplifies some aspects that did not affect the objective of this study. Six inflows elements were considered, for which the values were obtained by naturalised streamflows. Even though the available series covers the period from 1940 to 2008, only the period corresponding to the last 28 years was used because the longest periods of drought were concentrated in this time, allowing the running time to be reduced without loss of validity. 


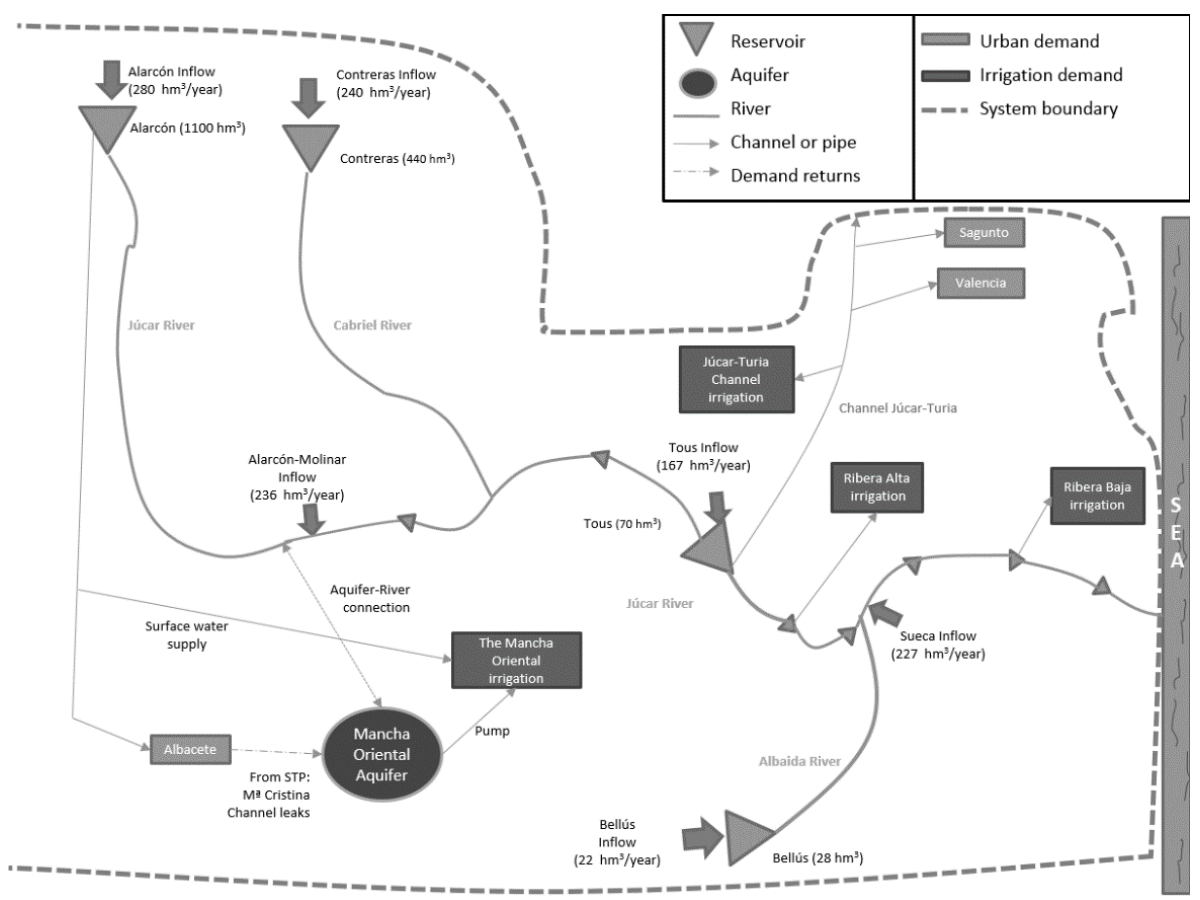

Figure P1. 3: Simplified scheme of the Júcar Water Resources System.

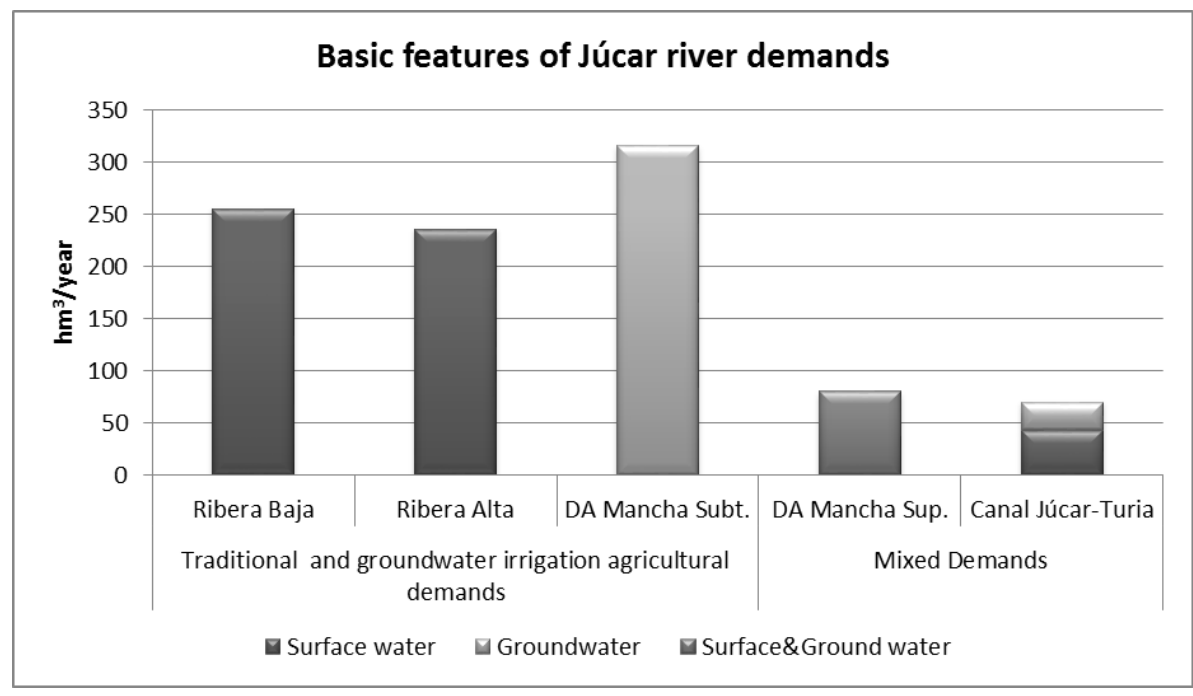

Figure P1. 4: Basic features of Júcar river basin demands. 
Also, only the four most important reservoirs were taken into account (Alarcón, Contreras, Tous and Bellús). None of the other existing reservoirs were considered, as they do not play any role in the regulation of the system and are only used for hydropower production. The demands were aggregated to a level sufficient to represent each different irrigation scheme. In the system schema we identified nine aggregated demands: four urban demands (Valencia, Sagunto, Albacete and the Manchuela) and five agricultural demands (Ribera Alta, Ribera Baja, La MO and the Júcar-Turia Canal). Among the aquifers existing in the basin, the La MO aquifer was considered (another aquifer was introduced to take into account the groundwater infiltration at the Contreras reservoir). MO aquifer is important because the demands from La Mancha are mainly supplied from it, and because there is a very strong relationship with the Jucar river, affecting the flows in the river. SIMGES includes a broad spectrum of approaches for modelling groundwater: reservoir type, aquifer with discharge through spring, aquifer hydraulically connected to a surface stream, connected to two streams and a distributed model. The aquifer model approaches are documented in the user-manual (Andreu et al. 1996). In the NFO after initial values for the decisions are obtained by the optimization algorithm simulations of aquifers are performed and this gives values for the surfacewater groundwater relationships which are updated within the networks (Andreu et al. 1996). Environmental flows defined at several points along the basin were considered in the model by placing them and certain streams of the Júcar River, with flows ranging from 0.5 to $6 \mathrm{~m}^{3} / \mathrm{s}(1.3$ to 15.3 $\mathrm{hm}^{3} /$ month).

\subsection{Specific methodology for the Júcar basin}

The OF that is defined for Júcar Basin is an adaptation of equation (1) and is as follows:

$$
f(x)=w_{1} \frac{\operatorname{Max}\left(\operatorname{Def}_{1, T r d}\right)-50}{50}+w_{2} \frac{\operatorname{Max}\left(\operatorname{Def}_{10, T r d}\right)-100}{100}+w_{3} \frac{\left(\sum_{t=1}^{n} V_{t}\right)-n * 2000}{n * 2000}
$$

The first two terms, as discussed in section 2.4 correspond to the deficit in the short and long term, respectively. In the Spanish Hydrologic Planning 
Instruction (IPH 2008) maximum deficit of one year as short-term deficit and the 10 consecutive years as long-term deficit are commonly used.

The $w_{1}$ and $w_{2}$ represent the selected weights associated with the maximum deficits for one and 10 consecutive years, summing to one. Max(Def $f_{1, \text { Trd }}$ ) represents the maximum deficit in one year for all the traditional demands as a percentage of the whole demand. $\operatorname{Max}\left(\operatorname{Def}_{10, \text { Trd }}\right)$ represents the maximum deficit for 10 consecutive years of all the traditional demands as a percentage of the annual demand. It has to be noted that in equation (5), and also in the rest of the paper, all deficits are expressed in terms of percentage of a value equal to the annual demand.

The values of $50 \%$ and $100 \%$ were included in the function used for the reliability criteria as they are the limits established by the IPH-2008 for agricultural demand satisfaction criteria. Therefore, in Spanish law the reliability criteria for agricultural demand was defined so that a demand is satisfied when the maximum annual deficit is less than $50 \%$ of the annual demand, the maximum consecutive two-year deficit is below $75 \%$ of the annual demand, and the maximum consecutive ten-year deficit is below $100 \%$ of the annual demand. The expected results will be negative values as long as the desired deficits are lower than 50 and $100 \%$.

The last term in equation (5) is added to ensure that the algorithm searches the minimum reservoir volume among different possibilities. The factor $w_{3}$ is the weight associated with this term, and here, its value was fixed at 0.01 , a sufficiently low value to ensure that deficits are always more important. The rest of the term is the sum of the volumes in the different months that are considered to be decision variables; this value is reduced by the number of months multiplied by 2,000 (considered the upper volume limit). Similarly, to the deficits, the term is divided by the number of months multiplied by 2,000 for a standardized result.

The mixed demand deficits do not appear in the OF because it is assumed that the restriction coefficient for these demands with respect to surface water supply is twice that of the traditional demands. This is an established factor traditionally applied in Júcar River management and accepted by all 
stakeholders, since they can resource to groundwater. The weights chosen for the OF were $w_{1}=0.667$ and $w_{2}=0.333$. The reason to choose these particular values was the desire to diminish large annual deficits and so avoid damage to the agricultural areas due to drought. Even so, a series of preliminary simulations was performed, and the results obtained for different weight values were the same or similar than those for the values finally chosen.

The decision variables for the optimisation problem are the sum of the volumes of the three reservoirs (Alarcón, Contreras and Tous) and a restriction coefficient for the demands. The volume of water stored in the three reservoirs indicates the water reserve for scarcity periods. The upper limit of this variable is considered to be $2000 \mathrm{hm}^{3}$ and the lower $75 \mathrm{hm}^{3}$ due to dead and environmental volume. On the demand side, the restriction coefficient is applied to the traditional demands, multiplying it by two for the mixed demand as explained above. The value of this coefficient ranges between zero and unity.

\section{SELECTION OF PARAMETERS FOR THE GA}

A characteristic of GA is that there are several options available to define the search process. This section describes the results of the various tests performed on the PIKAIA algorithm that permitted the definition of the best parameters for the TORs. The studied parameters were the initial population, the number of digits of codification, the mutation method, the crossover probability, the elitism and the number of individuals.

As discussed below, there are several possibilities for proposing TORs depending on when each decision is made and for how long that decision is applied. The rule known as "Decision making from April until September" was chosen for analysing the GA parameter selection, as it is the most similar to the actual basin management process.

Figure P1. 5 (a-f) represents the OF (in positive values) obtained by the best individual in each generation of the different tests conducted. The results of the tests performed with different initial population (Figure P1. 5-a) reflect 
that the first three initial population obtained an optimum before or near generation 30, whereas the last three initial population obtained it by the last generation. Even so, it is apparent that all initial population yielded almost the same results by generation 30 . The analysis of the number of digits considered in the parameter codification, with results depicted in Figure P1. 5-b, revealed that the use of only one or two digits did not yield acceptable solutions compared to the other options. Therefore, we concluded that a minimum of three digits is necessary to provide good results. As the use of three digits does not affect the execution time, it is preferable to the use of the maximum number of digits.

On analysis of the different options related to mutation and crossover modes, with the results compiled in Figure P1. 5-c and 5-d, we observed that all generations above the $25^{\text {th }}$ presented the same (or very similar) optimum values. Regarding the mutation methods, for which the names of the simulations are listed in Table P1. 1, tests 1 and 5 appear to display the most efficient paths in the search for the optimum. With regard to the OF, although all the tests reached nearly the same value, actually the last one result obtained the best value, with a difference in the fifth decimal position.

\begin{tabular}{|l|l|}
\hline Code & Explanation \\
\hline 1PMyTIABA & one-point, adjustable rate based on fitness \\
\hline 1PMyTIF & one-point mutation, fixed rate \\
\hline 1PMyTIABD & one-point, adjustable rate based on distance \\
\hline 1PM+RyTIF & one-point+creep, fixed rate \\
\hline 1PM+RyTIABA & one-point+creep, adjustable rate based on fitness \\
\hline 1PM+RyTIABD & one-point+creep, adjustable rate based on distance \\
\hline
\end{tabular}

Table P1. 1: Explanation of different simulations developed to define GA-parameters.

As presented in Figure P1. 5-e, slightly better results were obtained when elitism was taken into account. This test showed that the optimum was obtained at the $29^{\text {th }}$ generation, whereas it was obtained at generation 47 if elitism was not considered. 

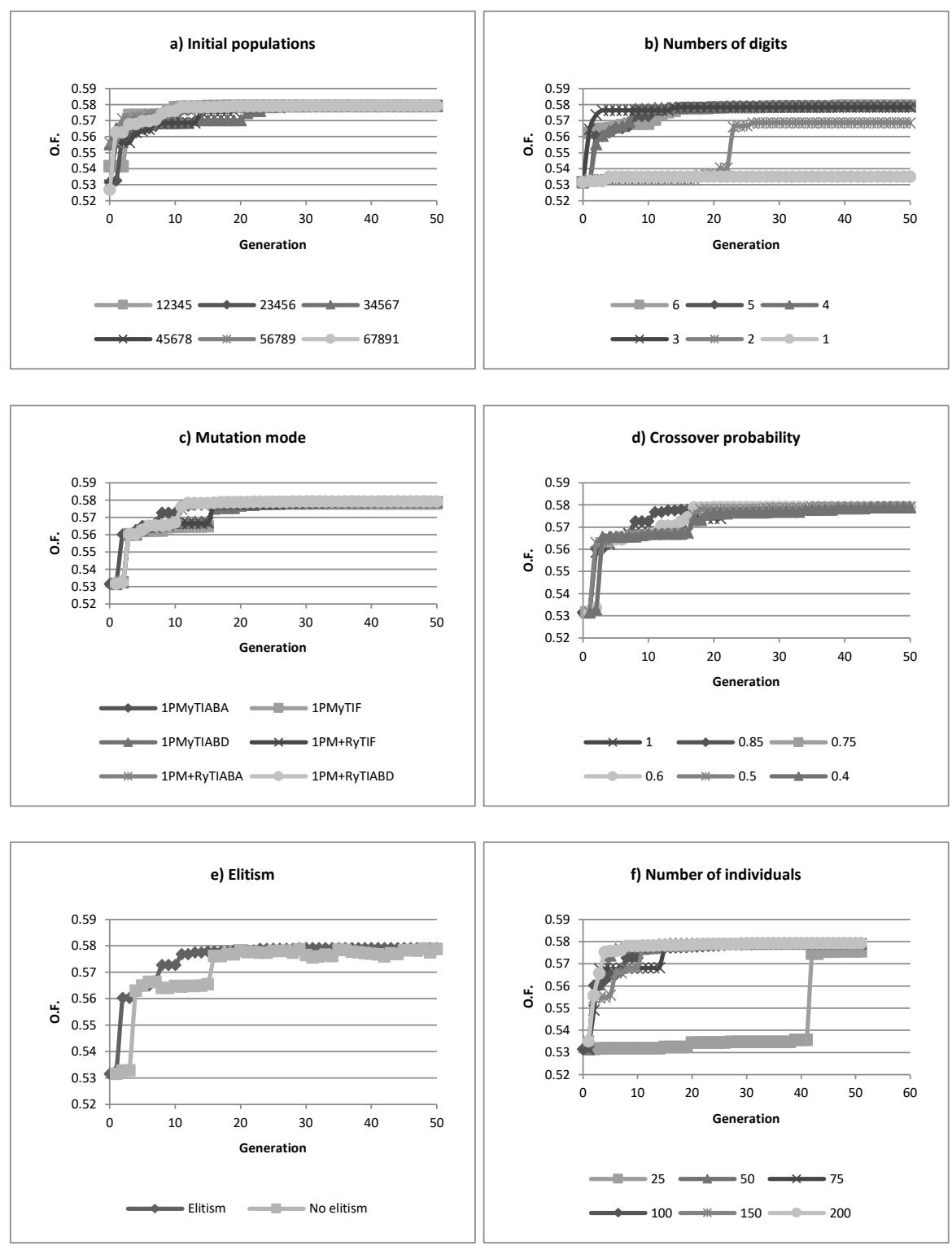

Figure P1. 5 a-f: Results of the Objective Function for different test developed for definition of the GA-parameters.

Finally, with regard to the number of individuals, as shown in Figure P1. 5-f, all tests reached the same (or very similar) optimum values from the $20^{\text {th }}$ 
generation onwards, but the test with 25 individuals did not reach an optimum comparable with the others. Simulations with 50, 100 and 200 individuals seemed to reach optimum values faster than the others.

Given this analysis, we concluded that from a minimum number of three codification digits and taking elitism into account, most of the other options yielded near optimum values by the $30^{\text {th }}$ generation. This implies that, for the particular problem of the Júcar River basin, the search is quite robust regarding the different options considered by the PIKAIA algorithm. It remains to be determined if this holds true for different systems and for different types of ORs.

\section{ANALYSIS OF THE RESULTS AND ASSESSMENT OF TORS}

Once the search parameters of the GA optimisation algorithm were defined, different TORs search possibilities were studied. Among the aspects analysed were different decision curves and restriction values. In all the cases, the decision indicator was considered to be the stored volume at the three main reservoirs.

Three different types of TORs were analysed. First we studied the rule of making a single decision in April and using it until the end of the hydrological year. This TOR has been named "April-September" OR. It is based in the fact that most of the demand is realised between the months of April and September, which coincides with the irrigation period. Moreover, in stream flows are always reduced in the summer. The second proposed rule is a parametric curve using decision variables for only four months and estimating the rest by linear interpolation. It has been named " 4 months" OR. Finally, " 12 months" OR is based on the most general case, i.e., making decisions each month of the year. This implies 13 decision variables, taking into account the restriction coefficient as one of them. In all the cases it has been considered a restriction coefficient of the mixed demands double than the one for the traditional demands.

The "April-September" OR is the one that most resembles the current system management because the resource allocation decisions in the Júcar River 
basin are now made during the meeting of the RWC that takes place at the end of March or the beginning of April. At these meetings, it is decided how much water will be supplied during the coming irrigation campaign. Therefore, attempting to imitate this form of management, the decision variables here are the total stored volume in the month of April and the restriction coefficients of the traditional agricultural demands, with the objective of simultaneously minimizing the one- and ten-year deficits.

For the "4 months" OR the decision variables were the total stored volume in the reservoirs in October, March, April and September. The selection was based on the fact that October and September correspond to the beginning and the end, respectively, of the hydrological year. April is when the bulk of the irrigation campaign starts, and March falls in between winter and spring. Previous tests using January instead of March yielded slightly worse results. The remaining months were calculated by linear interpolation. Once again, volume and restriction coefficient were the decision variables.

Decision variables of the "12 months" OR were the volume of each month of the year with a complete possibility of variation between the operational volume and the maximum storage capacity of all three reservoirs. The restriction coefficient was also considered to be a decision variable. While in the other TORs the optimisation process lasts a couple of hours, for the " 12 months" OR a simulation with 150 individuals and 1,200 generations took approximately 136 hours (almost 6 days) on an Intel ${ }^{\circledR}$ Core $^{\text {TM }}$ Duo CPU E 7300 running at $2.66 \mathrm{GHz}$. This technique has been applied on a real system whose management is complicated. However, in the case of much bigger systems, the computation time can be very high and therefore constitute a drawback. This is due to the high computational burden involved in GA.

Once the optimisation procedure has been performed for the three possibilities three optimal TORs ("April-September", "4 Months", and "12 Months") were obtained (Figure P1. 6). WRS simulation model was run for each TOR and the results are compared with a situation denoted "basic" OR. The management of the "basic" OR is performed only according to the water distribution order between demands and the water storage order of reservoirs in each month. The order between the demands is imposed by a 
system of priorities. This rule, commonly called the "blind rule", does not consider saving water for coming months during dry periods. This situation is used as a reference because it essentially represents a blind policy or the option of reactive rather than proactive management.

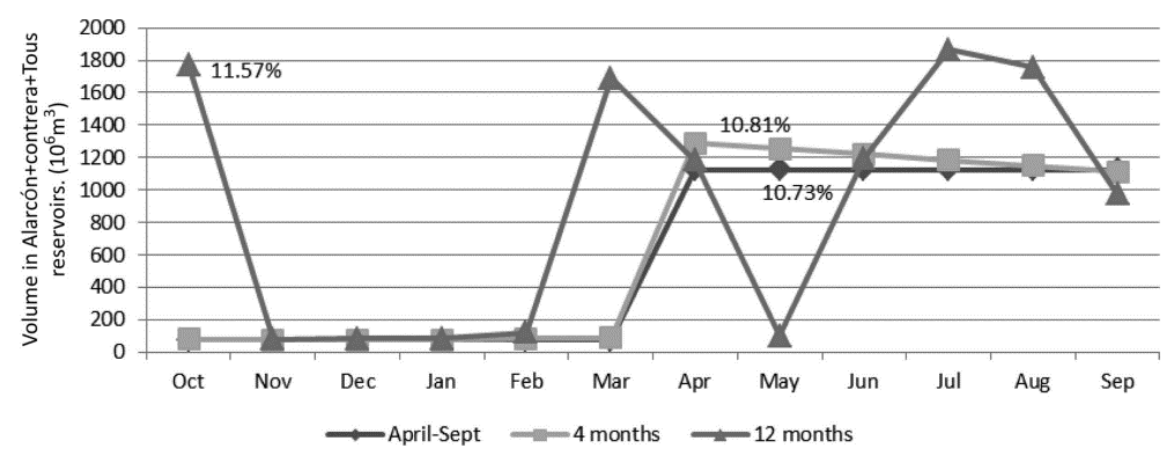

Figure P1. 6: Definition of the three ORs obtained from the optimization process.

In Figure P1. 6 it can be seen that the curve for "April-September" was fairly similar to the "4 months" parametric curve. However, the optimisation over twelve months yielded a curve with the highest provision in March instead of April. Moreover, this curve presents a very low value in May. This is because this month has very low effect in the results due to high values of flows in dry years in the month of May. Notice that curves with irregular shapes are not practical and do not inspire confidence. However, test of this curve changing the May value presents similar results.

A summary of the results comparing the three TORs and the "basic" simulation can be found in Table P1. 2 and Figures P1.7 to P1.9. The evolution of the total stored volume in the three main regulation reservoirs is shown in Figure P1. 7; the stored volume significantly increased with ORs compared with the situation without a rule. However, the volume evolution was almost the same among the scenarios with different rules. 


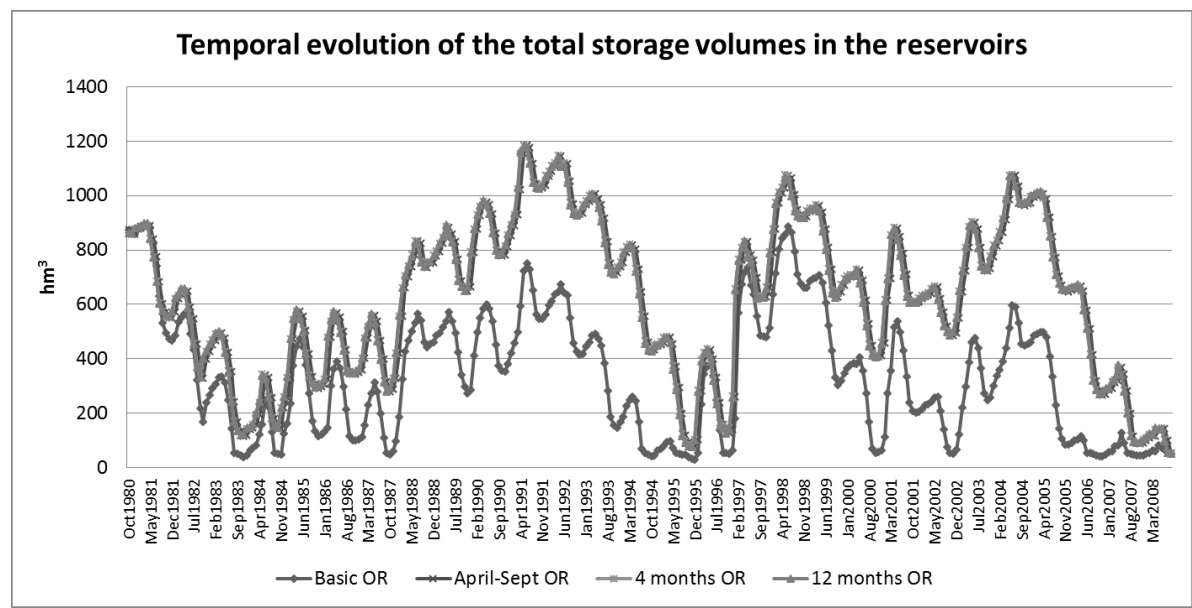

Figure P1. 7: Temporal evolution of total volume stored in the three reservoirs (Alarcón, Contreras and Tous) for the optimized ORs and the "basic" OR.

With respect to the maximum deficits occurring in the demands, see Table P1. 2, the reduction of the annual deficits versus the "basic" case was very high for the traditional demands and in the Júcar-Turia Canal. Nevertheless, the two demands from La Mancha worsened the situation due to their pumping possibilities. The results of the maximum ten-year deficit are not as clear as for the annual deficits. Regarding the "basic" OR, the situation was generally worsened for the demands in the zone of La Mancha but improved for the remaining areas. It must be emphasised that the 12-month curve yielded the worst result for this indicator, increasing the deficit for the demands of La Mancha and the Júcar-Turia Canal compared with any other alternative, including the "basic" OR. However, the deterioration of this indicator was expected because the proposed OF, and the objective of the TOR, is to diminish the annual deficit; therefore, the deficit must be distributed over time.

For example, the demand from the Ribera Alta presents the greatest benefit with any TOR. As presented in Table P1. 2 and Figure P1. 8, which shows the percentages of annual demand, the maximum deficit for one year in the demand of the Ribera Alta dropped from $58 \%$ without an OR to $7-8 \%$ when applying the TORs obtained. Moreover, the ten-year deficit also decreased. The demand of the Ribera Baja reflects the same behaviour. 


\begin{tabular}{|c|c|c|c|c|c|}
\hline \multirow[t]{9}{*}{ O.R. } & $\begin{array}{l}\text { Restriction } \\
\text { Coefficient }\end{array}$ & O.F. & Deficits (\% of annual Demand) & $\begin{array}{l}\text { Traditional } \\
\text { demands }\end{array}$ & $\begin{array}{l}\text { Mixed } \\
\text { Demands }\end{array}$ \\
\hline & & & MaxDef1year & $40.84 \%$ & $34.90 \%$ \\
\hline & & & MaxDef10years & $72.35 \%$ & $102.34 \%$ \\
\hline & & & MaxDef1year & $9.37 \%$ & $22.20 \%$ \\
\hline & & & MaxDef10years & $90.10 \%$ & $139.13 \%$ \\
\hline & & & MaxDef1year & $9.43 \%$ & $22.27 \%$ \\
\hline & & & MaxDef10years & $90.76 \%$ & $140.09 \%$ \\
\hline & & & MaxDef1year & $9.31 \%$ & $23.51 \%$ \\
\hline & & & MaxDef10years & $89.72 \%$ & $154.01 \%$ \\
\hline
\end{tabular}

Table P1. 2: Maximum Deficits for 1 year and 10 years accumulated for the irrigation demands obtained from the simulation model testing optimized ORs. Deficits are in \% of annual demand.

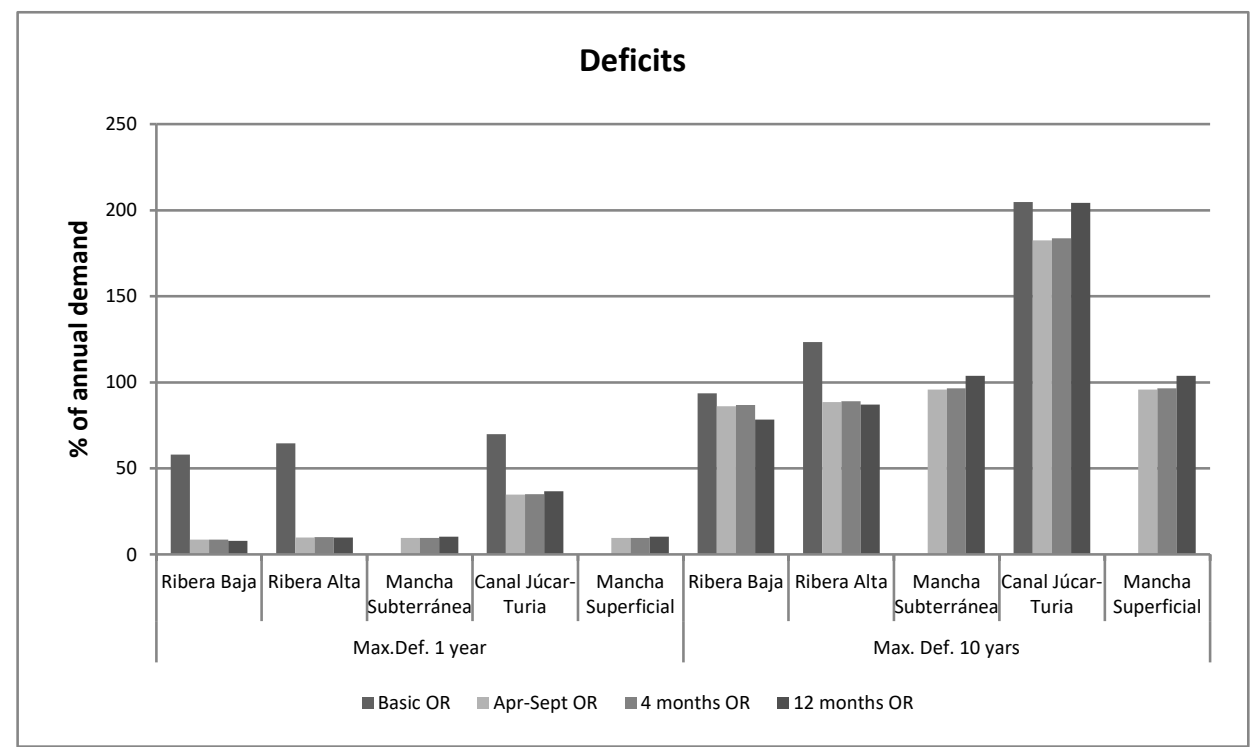

Figure P1. 8: Agricultural demands Deficits obtained from the simulations of the different optimized ORs. Deficits are in \% of annual demand. 
The irrigation demands from La Mancha, ranging from almost no deficit in their demand to approximately $10 \%$ in the annual deficits and $100 \%$ in the ten-year deficits. This indicates, as it does for the other demands, that the restriction associated with the defined TOR is applied, at least during one month each year. For the demands of La Mancha, these demands worsen slightly their results with respect to the "basic" OR, but getting with this a significant improvement for the demands of the Ribera Alta and Baja, as discussed above.

The demand of the Júcar-Turia Canal made a reduction in the maximum annual deficit by one-half when any of the three TORs was applied, whereas the maximum accumulated deficit for 10 years decreased slightly for the first two TORs defined (April-September and the 4-month parametric curve) and was unaffected by the 12-month rule.

Moreover, Figure P1. 9 summarizes the results related to pumping from groundwater in the La Mancha Oriental zones. As observed with all three TORs, the pumped flow was decreased thanks to the imposed restriction with respect the "basic" situation. The mean monthly pumping decreased from 28 to $22 \mathrm{hm}^{3} /$ month, and the maximum went from 95 to $70 \mathrm{hm}^{3} / \mathrm{month}$. The maximum annual pumping changed from 393 to $320 \mathrm{hm} /$ year, corresponding to a decrease of approximately $20-30 \%$.

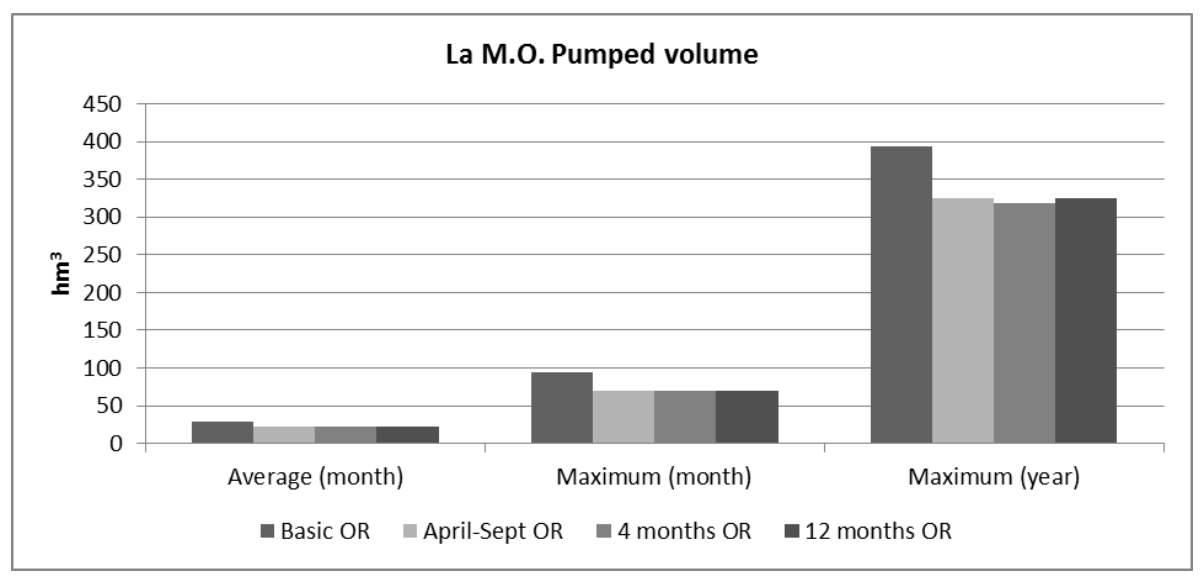

Figure P1. 9: Results for the groundwater abstraction in M. Oriental aquifer for the different optimized ORs. 
Taken together, these results demonstrate that the three TORs are quite similar, justifying, in this case, that it is not necessary to define very complex rules; i.e., decisions made in April and applied for the rest of the irrigation campaign are sufficient to achieve the objective of minimizing the annual and ten-year deficits.

Finally, Figure P1. 10-a shows the three-dimensional evolution of the two decision variables (total volume and the restriction coefficients of the traditional demands) versus the OF with the results obtained using PIKAIA. This particular case corresponds to the "April-September" OR. Notice that the OF axis represents values of opposite sign; i.e., values near 1 correspond to the best results. Here, the maximum and minimum imposed volumes are 2,000 and $75 \mathrm{hm}^{3}$, respectively. In the cases where the restriction coefficients for the traditional demands are between 0 and $50 \%$, the solutions tend to cluster near a restriction of $10 \%$. Therefore, it adopts a profile with a marked gradient towards this value, which is maintained as the optimal restriction value for any volume. Figure P1. 10-b, illustrates the relationship between the two decision variables, i.e., volume versus restriction coefficient. Here, it can be seen how the best results are grouped in the vicinity of volumes above $1,000 \mathrm{hm}^{3}$ and restriction values between 5 and $15 \%$. Simultaneously, a narrower band is observed near the same restriction values for volumes below $1,000 \mathrm{hm}^{3}$.

The remaining space is filled with dispersed points, indicating that the algorithm searched for combinations over the entire solution space. Figure P1. 10-c plots the evolution of the volume versus the OF. Unlike in the previous case, the two zones in this space contain no points because, for these volumes and for any of their combinations with the restriction coefficient, specific values of the OF were not reached. In this case, the highest concentration of points was reached for a value of the OF of 0.6, corresponding to volumes over $1,000 \mathrm{hm}^{3}$. 


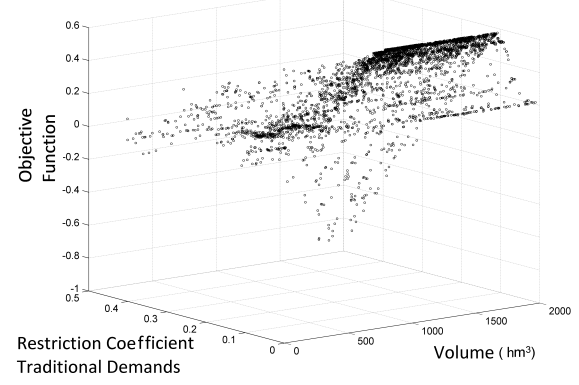

a)

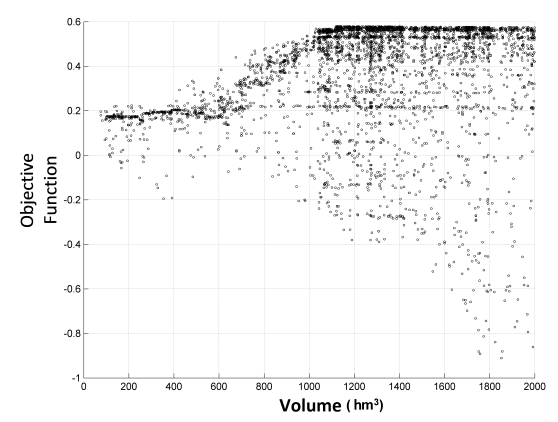

c)

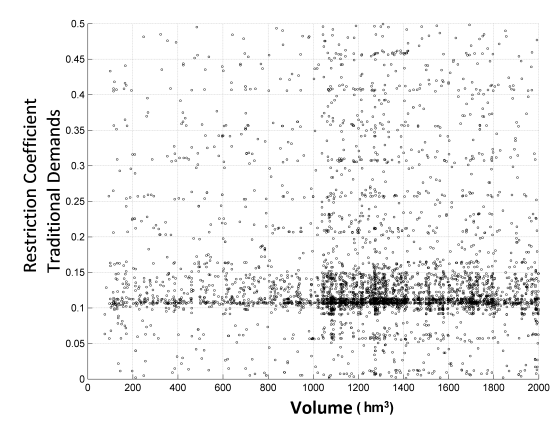

b)

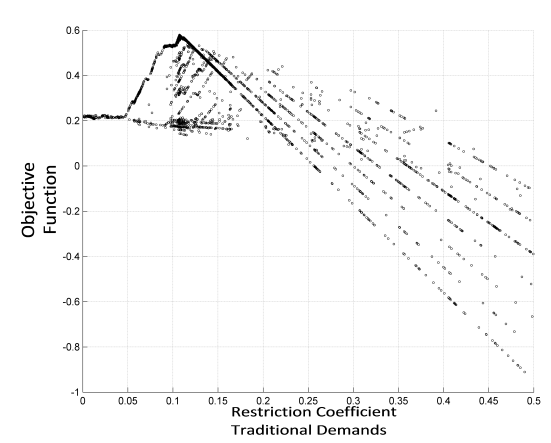

d)

Figure P1. 10: a-d. Evolution of the objective function, volume stored, and restriction coefficient for the "April-September" OR.

The most interesting result is the minimum volume for which the maximum value of the $O F$ is reached, which is approximately $1,000 \mathrm{hm}^{3}$. We also observed that it is impossible to obtain values of the OF above 0.2 or below -0.2 with volume values lower than $400 \mathrm{hm}^{3}$. Finally, Figure P1. 10-d shows the other decision variable, the restriction coefficient, versus the OF. This figure is the one with the most number of blank spaces, implying that the OF is highly related to the restriction applied. The greatest concentration of points is near a restriction of 5 to $20 \%$ and a value above 0.2 for the OF. The maximum value of the $\mathrm{OF}$ is achieved with a restriction coefficient of approximately $11 \%$ (10.7\%, as stated previously). The blank spaces indicate that, for example, for a restriction of $25 \%$, it is impossible to find a 
combination with any storage value that yields a value of the OF less than zero.

\section{CONCLUSIONS}

This study presents a new approach for obtaining TORs in a real and very complex WRS. This approach has been applied to the Jucar Basin System. The main problem of the basin is water allocation between the agricultural demands during periods of drought.

The approach proposed is based on the coupling of GAs with NFO based basin simulation models. This has allowed obtaining optimal decision rule curves for water allocation among various demands in periods of scarcity. The GA chosen was PIKAIA, used previously in the optimisation of water quality model parameters. The basin simulation model was developed in the AQUATOOL DSS environment using the SIMGES program, which uses NFO as a tool for river basin water allocation simulations. The problem addressed had the objective of reducing the weighted sum of the maximum annual deficits and the maximum accumulated deficits in the long term. Each evaluation of the OF implies a run of the simulation model with a new TOR and the estimation of the deficit of the demands.

Prior to the application of the approach, several tests were run to define the most suitable parameters for the GA. Next, three possible TORs were analysed, each based on different periods for decision making and application. For the case of the Júcar River, it was concluded that it is sufficient to make a decision in the month of April and apply it from then until September, using a restriction coefficient of $10.7 \%$ for surface water supply when the total volume stored at the three regulation reservoirs falls below $1,125 \mathrm{hm}^{3}$. This demonstrates that, in some cases, simple ORs can be used for the management of very complex WRSs.

Acknowledgements: The authors wish to thank to the Confederación Hidrográfica del Júcar (Spanish Ministry of the Environment) for the data provided in developing this study and the Spanish Ministry of Science and Innovation (Comisión Interministerial de Ciencia y Tecnología, CICYT) for 
funding the projects INTEGRAME (contract CGL2009-11798) and SCARCE (program Consolider-Ingenio 2010, project CSD2009-00065). The authors also thank the European Commission (Directorate-General for Research and Innovation) for funding the project DROUGHT-R\&SPI (program FP7-ENV2011, project 282769) and Seventh Framework Programme of the European Commission for funding the project SIRIUS (FP7-SPACE-2010-1, project 262902). And last, but not least, to the reviewers for their valuable comments, which have improved this paper.

\section{References}

- Ahmed, J.A. and Sarma, A.K., 2005 Genetic algorithm for optimal operating policy of a multipurpose reservoir. Water Resources Management 19, 145-161.

- Andreu, J. and Sahuquillo, A., 1987 Efficient aquifer simulation in complex systems, Journal of Water Resources Planning and Management, 113(1), 110-129.

- Andreu, J., Capilla, J. and Sanchís, E., 1996 AQUATOOL: A generalized decision support-system for water-resources planning and operational management Journal of Hydrology 177, 269-291.

- Cañon J., González J. and Valdés J., 2009 Reservoir operation and water allocation to mitigate drought effects in crops: a multilevel optimization using the drought frequency index. Journal of Water Resources Planning and Management 135(6):458-465.

- Celeste, A. B. and Billib, M., 2009 Evaluation of stochastic reservoir operation optimization models. Advances in Water Resources 32, 1429-1443.

- Chang F.J., Chen L. and Chang L., 2005 Optimizing the reservoir operating rule curves by genetic algorithms. Hydrological Processes 19:2277-2289.

- Bhaskar, N.R. and Whitlach, Jr. E. E., 1980 Deriving of monthly reservoir release policies Water Resources Research 16 (6), 987-993.

- Cai, X., McKinney, D. C. and Lasdon, L. S., 2001 Solving nonlinear water management models using a combined genetic algorithm and linear programming approach Advances in water Reseources 24, 667-676. 
- Charbonneau, P. and Knapp, B., 1995 A User's guide to PIKAIA 1.0, NCAR Technical Note 418+lA. Boulder: National Center for Atmospheric Research.

- Chen, L., McPhee, J. and Yeh, W-G., 2007 A diversified multiobjective GA for optimising reservoir rule curves Advances in Water Resources 30, 1082-1093.

- CHJ, 1998. Plan Hidrológico de la Cuenca del Júcar. Confederación Hidrográfica del Júcar. Ministerio de Medio Ambiente. España.

- DICTUC, 2010. Análisis integrado de gestión en Cuenca del Río Copiapó. Informe Técnico (Technical Report). División de Ingeniería Hidráulica y ambiental DICTUC para la Dirección General de Aguas. Chile.

- Elferchichi, A., Gharsallah, O., Nouri, I., Lebdi, F. and Lamaddalena, N., 2009 The genetic algorithm approach for identifying the optimal operation of a multi-reservoir on-demand irrigation system Biosystems Engineering 102, 334-344.

- Efstratiadis, A., Koutsoyiannis, D. and Xenos, D., 2004 Minimising water cost in the water resource management of Athens, Urban Water Journal, 1(1), 3-15.

- Ford, C. R. and Fulkerson, D. R., 1962 Flow in networks Princeton University Press. Princeton NJ, 194.

- GPEASAS, 2005 Guía Para La Redacción De Planes Especiales De Actuación En Situación De Alerta Y Eventual Sequía. Ministerio de Medio Ambiente. Dirección General del Agua.

- Hsu, S.Y., Tung, C. P., Chen, C.J. and Wang, C., 2004 Application to reservoir operation rule-curves. Proc of world water and environmental resources congress 2004. ASCE Conference Proc 138:304-314.

- IPH, 2008. Instrucción de Planificación Hidrológica. Ministerio de Medio ambiente Rural y Marino, BOE 229 de 22/09/2008.

- Jamieson, D.G., 1997 Special Issue on Decision-Support Systems (DSS). Journal of Hydrology. Vol 177, Nos. 3-4.

- Karamouz, M., Szidarousky, F. and Zahraire, B., 2000 Water Resources system Analysis Lewis Publishers CRC Press Boca Raton Florida, 579. 
- Koutsoyiannis, D. and A. Economou., 2003 Evaluation of the parameterization-simulationoptimization approach for the control of reservoir systems, Water Resources Research, 39 (6), 1170, doi:10.1029/2003WR002148.

- Kuczera, G., 1989 Fast Multireservoir Mulltiperiod Linear Programming Models. Water Resources Research 25:169- 176.

- Kuczera, G., 1993 Network linear programming codes for water-supply headworks modeling. Journal of Water Resources Planning and Management 119:412-417.

- Labadie, J., 2004 Optimal Operation of Multireservoirs Systems: Stateof-the-Art Review Journal of Water Resources Planning and Management 130 N2 March 1.

- Loucks, D.P. and Sigvaldason, O. T., 1982 Multiple reservoir operation in North America In The Operation of Multiple Reservoir Systems Edited by Z. Kaczmarck and J. Kindler IIASA Collab Proc Ser CP-82-53, 1-103.

- Lund, J. and Ferreira, L., 1996 Operating rule optimisation for Missouri River reservoir system Journal of Water Resources Planning and Management 122 (4), 287-295.

- MIMAM, 2000. Libro Blanco del Agua en España. Ministerio de Medio Ambiente. Dirección General de Obras Hidráulicas y calidad de las Aguas. España.

- Mousavi, S. J., Mahdizadehb, K. and Afsharc, A., 2004 A stochastic dynamic programming model with fuzzy storage states for reservoir operations. Advances Water Resources, 1005-1110.

- Nalbantis, I. and Koutsoyiannis, D., 1997 A parametric rule for planning and management of multiple -reservoir systems. Water Resources Research 33, 2165-2177.

- Nicklow, J., Reed, P., Savic, D., Harrell, L., Chan-Hilton, A., Karamouz, M., Minsker, B., Ostfeld, A., Singh, A. and Zechman, E., 2010 State of the art for genetic algorithms and beyond in water resources planning and management Journal of Water Resources Planning and Management 136 (4), 412-432.

- Oliveira, R. and Loucks, D. P., 1997 Operating rules for multiresservoir systems. Water Resources Research 33 (4), 839-852. 
- Pelletier, P. J., Chapra, S. C. and Tao, K., 2006 Qual2Kw - A framework for modeling water quality in streams and rivers using a genetic algorithm for calibration Environmental Modelling and Software 21, 419-465.

- Rani, D. and Moreira, M., 2010 Simulation-optimization modeling: a survey and potential application in reservoir systems operation. Water Resources Management 24:1107-1138.

- Reca, J., Roldán, J., Alcaide, M., López, R. and Camacho, E. 2001a Optimisation model for water allocation in deficit irrigation systems I. Description of the model. Agricultural Water Management 48:103116.

- Reca, J., Roldán, J., Alcaide, M., López, R. and Camacho, E. 2001b Optimisation model for water allocation in deficit irrigation systems II. Application to the Bembézar irrigation system. Agricultural Water Management 48:117-132.

- ReVelle, C., 1999 Optimizing reservoir resources : including a new model for reservoir reliability. New York. John Wiley \& Sons cop.

- Rossi, G., Caporali, A. and Garrote L., 2011. Definition of risk indicators for reservoirs management optimization. Water Resources Management 26:981-996. DOI 10.1007/s11269-011-9842-x.

- Sechi, G. M. and Sulis, A., 2009 Water system management through a mixed optimization-simulation approach, Journal of Water Resources Planning and Management, 135(3), 160-170.

- Tilmanta, A., Faouzib, E. H. and Vanclooster, M., 2002 Optimal operation of multipurpose reservoirs using flexible stochastic dynamic programming. Applied Soft Computing. Volume 2, Issue 1, 61-74.

- UNICA, 2012 Decision support system models development for multiuse water resource systems in water scarcity conditions using mixed simulation-optimization techniques. Technical Report. University of Cagliari. Italy.

- Wurbs, R., 1993 Reservoir-system simulation and optimisation models Journal of Water Resources Planning and Management 119 (4), 455472. 
- Yamout, G. and El-Fadel, M., 2005 An optimization approach for multisectoral water supply management in the greater Beirut area. Water Resources Management 19:791-812.

- Yeh, W., 1985 Reservoir management and operations models: A stateof-the-art review Water Resources Research 21 (12), 1797-1818.

- Young, G., 1967 Finding reservoir operating rules Journal of the Hydraulic Division, ASCE 93 (6), 297-321.

- Zoltay, V., Vogel, R., Kirshen, P. and Westphal, K., 2010 Integrated watershed management modeling: generic optimization model applied to the Ipswich river basin. Journal of Water Resources Planning and Management 136:566-575. 



\section{A.2. Evolutionary network flow models for obtaining operation rules in multi-reservoir water systems. ${ }^{2}$}

Néstor Lerma ${ }^{(1)}$, Javier Paredes-Arquiola ${ }^{(1)}$, Jose-Luis Molina ${ }^{(2)}$, Joaquín Andreu (1)

(1) Universitat Politècnica de València. Research Institute of Water and Environmental Engineering, (IIAMA). Ciudad Politécnica de la Innovación, Camino de Vera, 46022 Valencia, Spain.e-mail: neslerel@upv.es;

(2) Salamanca University. Polytechnic School of Engineering. Department of Hydraulic Engineering. Av. de los Hornos Caleros, 50, 05003 Ávila. e-mail: jlmolina@usal.es

\section{Abstract}

Obtaining Operation Rules (OR) for multi-reservoir water systems through optimization and simulation processes has been an intensely studied topic. However, an innovative approach for the integration of two approaches, network flow simulation models and Evolutionary Multi-objective Optimization (EMO), is proposed for obtaining the operation rules for Integrated Water Resource Management (IWRM). This paper shows a methodology based on the coupling of an EMO algorithm (NSGA-II) with an existing water resources allocation simulation network flow model (SIMGES). The implementation is made for a real case study, the Mijares River basin (Spain), which is characterized by severe drought events, by a very traditional water rights system, and by its historical implementation of the conjunctive use of surface and ground water. The established operation rules aim to minimize the maximum deficit in the short term without compromising the

\footnotetext{
2 Lerma, N., Paredes-Arquiola, J., Molina, J. L. and Andreu, J. 2014. Evolutionary network flow models for obtaining operation rules in multi-reservoir water systems. Journal of Hydroinformatics, 16.1, pp. 33-49 DOI:10.2166/hydro.2013.151.
}

Adapted from J. Hydro volume 16(1), 33-49, with permission from the copyright holders, IWA Publishing. 
maximum deficits in the long term. This research proves the utility of the proposed methodology by coupling NSGA-II and SIMGES to find the optimal reservoir operation rules in multi-reservoir water systems.

water resources system, genetic algorithms, NSGA-II, operating rules, decision support system shell, AQUATOOL, SIMGES, simulation, optimization, agricultural demands, drought, deficits

\section{Introduction}

Several authors have noted the absence of the application of optimization models to the real management of multi-reservoir water systems (Yeh, 1985; Wurbs, 1993; and Labadie, 2004). The applicability of most reservoir operation models is limited because of the 'high degree of abstraction' necessary for the efficient application of optimization techniques (Akter and Simonovic, 2004; Moeni et al., 2011). On the other hand, other authors such as Oliviera \& Loucks (1997) maintain that this is because of institutional limitations rather than technological or mathematical ones.

Decision making in environmental and hydrological projects can be complex and inflexible because of the inherent trade-offs among economic, sociopolitical, environmental and technical factors. The selection of the appropriate management strategies often involves multiple conflicting objectives that should be 'optimized' simultaneously (Makropoulos et al., 2008). Thus, there exists the concept of Pareto optimal solutions, i.e., solutions for which it is not possible to improve on the attainment of one objective without making at least one of the others worse. Evolutionary Multi-objective Optimization (EMO) algorithms offer a means of finding the optimal Pareto front (Farmani et al., 2005a; Cisty, 2010; Abd-Elhamid and Javadi, 2011). The decision maker can consequently be provided with a set of non-dominated solutions to select a final design solution from that set. Although the efficiency of these algorithms in solving a number of complicated real-world problems in electrical, hydraulic, structural or aeronautical engineering has been illustrated (Molina-Cristobal et al., 2005; Hanne and Nickel, 2005; Osman et al., 2005; Farmani et al., 2005b, 2006 and 2007; Murugan et al., 2009), there have been limited applications in the 
policy analysis of water resources management (Farmani et al., 2009; Molina et al., 2011). There are recent applications of EMO algorithms related to other water resources research studies, such as the optimal design of water distribution systems or reservoirs (Cisty, 2010; Nazif et al., 2010; Haghighi et al., 2011; Hınçal et al., 2011; Louati et al., 2011), the Conjunctive Use of Surface Water and Groundwater (Safavi et al., 2010), the control of Seawater Intrusion in Coastal Aquifers (Kourakos and Mantoglou, 2011; Abd-Elhamid and Javadi, 2011; Sedki and Ouazar, 2011), or hydrological studies (Dumedah et al., 2010; Hassanzadeh et al., 2011; Gorev et al., 2011). In this work, an evolutionary multi-objective optimization algorithm, NSGA-II (Deb et al., 2002), is coupled with the flow network model SIMGES (Andreu et al., 1996) and used to assist in the selection of the best operation rules in multireservoir water systems.

Despite the development and growing use of optimization models (Labadie, 1997), most reservoir planning and operation studies are based on simulation modelling and thus require the intelligent specification of Operation Rules (OR). Lund and Guzman (1996) review the derived singlepurpose operating rules for reservoirs in series and in parallel for different purposes, with the derived rules supported by conceptual or mathematical deduction. Obtaining OR from the results of optimization models can be done using simple (Young, 1967) or multiple (Bhaskar and Withlach, 1980) linear regressions and the use of simple statistics, tables and graphs (Lund and Ferreira, 1996). Unfortunately, a regression analysis can produce poor results, limiting the use of the obtained OR (Labadie, 2004). On the other hand, empirical OR like the space rule (Bower et al., 1962) or the New York City rule (Clark, 1956) have limited applicability.

In many real systems, the typical OR is defined by a volume target for a reservoir that had to be maintained. Another typical OR is defined by a curve (variable monthly and constant year by year) for a reservoir or a group of reservoirs that defines a threshold to trigger an action, for example, "reduce demands" or "start pumping groundwater". These types of OR are commonly called Rule Curves (RC), and although they are not always the most efficient rules, they are considered the most practical and accepted by users. 
This paper aims to show the findings of RC for multi-reservoir water systems by means of the coupling of an EMO (NSGA-II) (Deb et al., 2002) with the simulation flow network model SIMGES (Andreu et al., 1996). The proposed method is applied to the Mijares River basin water system (Spain), which is characterized by strong drought events, by a very traditional water rights system, and by its historical implementation of the conjunctive use of surface and ground water.

The paper is structured as follows. First, a theoretical background on reservoir operation rules and EMO is developed. Next, the case study is presented, followed by a description of the integrated methodology in which the implementation of the SIMGES and EMO methods is described. The results are then discussed, and several conclusions are drawn.

\section{Reservoirs operation rules and Evolutionary Multi-objective Optimization (EMO)}

Traditionally, reservoir operation is based on heuristic procedures, RC and subjective judgments by the operator. This provides general operation strategies for reservoir releases according to the current reservoir level, hydrological conditions, water demands, and the time of year (HakimiAsiabar, 2010; Moeni et al., 2011). Therefore, in practice, reservoir operators usually follow RC, which stipulate the actions that should be taken depending on the current state of the system (Alcigeimes and Billib, 2009). Rule curves, or guide curves, are used to denote the operating rules that define the ideal or target storage levels and provide a mechanism for release rules to be specified as a function of water storage (Mohan and Sivakumar, 2007; HakmiAsiabar et al., 2010). Moreover, RC can be defined as a trigger indicator to start different measures, or actions, for water management. Obtaining RC from the results given by optimization models by linear regressions is a complex task (Young, 1967). Revelle et al. (1969) proposed a linear decision rule; Lund y Ferreira (1996) used tables and statistics of the results from an optimization model to obtain the OR of the Missouri River water system. A common technique for obtaining $\mathrm{OR}$ and $\mathrm{RC}$ is based on an iteration method for river basin simulation models. These iterations are controlled by an optimization algorithm that varies the operation rules depending on the 
results. For example, Cai et al. (2001) described strategies for solving large nonlinear water resource management models combining genetic algorithm (GA) with linear programming, in which a GA/LP approach was applied to a reservoir operation model with hydropower generation and to a long-term dynamic river basin planning model. Simulation models are the most widespread tool for the analysis and planning of water systems. These models are characterized by their flexibility and by the possibility of including very complex elements in the modelling. They allow a more detailed representation of the systems than the optimization models (Loucks $y$ Sigvaldason, 1982). Thus, in general, river basin management decisions are made with the support of simulation models.

Quantitative compromises for the objectives and constraints presented in the methodology section are developed in this study using a multi-objective evolutionary algorithm (MOEA), Non-Dominated Sorting Genetic Algorithm II (e-NSGA-II) (Deb et al., 2002). The concept of Pareto optimality is used to define the multi-objective compromises for a system. A solution is Pareto optimal (or non-dominated) if no other solution in the solution space gives a better value for one objective without also degrading the performance of at least one other objective. MOEAs are heuristic search algorithms that change the approximation to the Pareto optimal set using crossover, selection, and mutation operators to mimic natural selection in the populations of organisms in nature. The evolutionary algorithm search process is an iterative process of selection that preserves and reproduces high-quality solutions and that varies to introduce innovation in order to improve the population of solutions. There are many examples demonstrating that MOEAs can solve complex nonlinear and non-convex multi-objective problems (a detailed review is given by Coello-Coello et al., 2007). Examples of applications in water resources engineering include groundwater monitoring design (Cieniawski et al., 1995; Reed and Minsker, 2004; Kollat and Reed, 2006), groundwater remediation (Beckford et al., 2003; Chan Hilton and Culver, 2005; Singh and Minsker, 2008), and water resources systems management (Suen and Eheart, 2006). Furthermore, in the last years, there have been new advances and improvements for the NSGA-II MOEA. e-NSGA-II represents an improvement over the original NSGA-II developed by Deb et al. (2002) by incorporating epsilon-dominance archiving 
(Laumanns and Ocenasek, 2002) and adaptive population sizing (Harik et al., 1997). Epsilon-dominance archiving helps to reduce the computational demand of solving high-dimensional optimization problems (Kollat and Reed, 2007) by allowing the user to control the resolution at which the objectives are evaluated and ranked. However, the use of NSGA-II to couple flow network models, which is the application of this research (SIMGES), is a new topic in the literature. The studies on coupling network flow models and EMO algorithms like NSGA-II are scarce or even non-existent in the literature. NSGA-II algorithm can be coupled to several other simulation models to provide optimized solutions by taking advantage of the power of those models (Farmani et al., 2010, Molina et al., 2011).

Most of the OR optimization problems have a multi-objective nature. Consequently, a multi-objective analysis is necessary for identifying the best solutions and simultaneously considering several objectives that are frequently in conflict (trade-offs). Many studies have used multi-objective techniques to address the multi-reservoir optimization problem. Classical multi-objective approaches such as the weighting approach or the constrain method were used for this purpose (Croley and Rao, 1979; Liang et al., 1996; Wang et al., 2005; Yeh and Becker, 1982). More recent applications use evolutionary multi-objective techniques for the same purpose. Reddy and Kumar (2007) developed a multi-objective differential evolutionary algorithm and applied it to the Hirakud reservoir project (India). Kim et al. (2006) applied the NSGA-II algorithm to the Han River basin multi-reservoir system. Chen et al. (2007) developed a macro evolutionary, multi-objective genetic algorithm for optimizing the rule curves of a water resources system in Taiwan. Malekmohammadi et al. (2011) presented an approach for incorporating flood control and water supply objectives for a cascade system of reservoirs by coupling the NSGA-II algorithm with an ELECTRE-TR1 postprocessor. Janga et al. (2006) presented a multi-objective evolutionary algorithm to derive operation rules to the multi-purpose Bhadra reservoir system (India). Furthermore, Chang et al. (2009) applied the NSGA-II algorithm in other reservoir systems in Taiwan to optimize state curves. Lin et al. (2008) modified the algorithm SCE-UA to use it as a multi-objective tool for getting the optimal water policy for the hydroelectric system of Huanren (NE China). 


\section{Case study: Mijares River basin}

The Mijares River Basin is located in the eastern slope of the Iberian Peninsula (Figure P2. 1). The water system comprises a surface of $5,466 \mathrm{~km}^{2}$. The total population of the zone is 363,578 inhabitants, and the urban supply is made from the exploitation of pumping wells and the use of springs. The total cropped surface is 124,310 ha, of which 43,530 ha (35\%) corresponds to irrigated land, whereas the rest $(65 \%)$ is occupied by dry-land farming. Citruses constitute the predominant crop, with a percentage of approximately $87 \%$ of the irrigated area. The length of the main river branch is approximately $156 \mathrm{~km}$, with an average runoff of $380 \mathrm{Mm}^{3} /$ year.

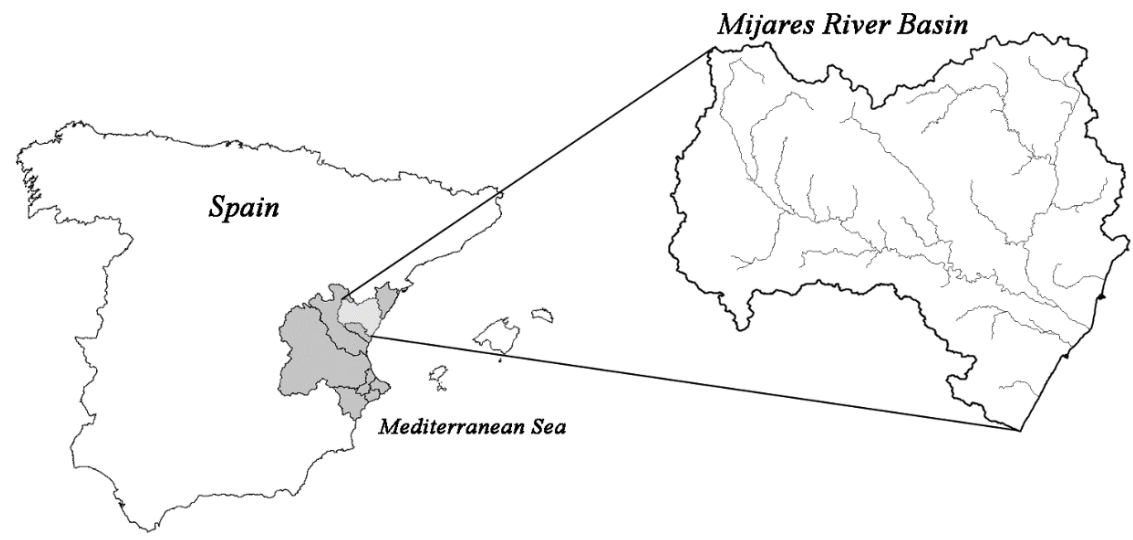

Figure P2. 1: Location of the Mijares River Basin.

Two climatologically different geographical areas can be distinguished: a coastal climate with a Mediterranean coastline and a continental climate area located upstream of the Arenós reservoir. The mean annual rainfall of the area is $505 \mathrm{~mm}$, and the average temperature is $14.4{ }^{\circ} \mathrm{C}$ according to the Basin Water Plan (CHJ, 1998). The maximum altitude is $2024 \mathrm{~m}$ above sea level.

Regarding the storage infrastructure of the basin, there are three main reservoirs: the largest in terms of capacity is the Arenós reservoir $\left(95 \mathrm{Mm}^{3}\right)$; located downstream is the Sichar reservoir $\left(49 \mathrm{Mm}^{3}\right)$; and finally, located in the tributary "Rambla de la Viuda" is the María Cristina reservoir $\left(19.7 \mathrm{Mm}^{3}\right)$. 


\begin{tabular}{|c|c|c|c|c|}
\hline & & \multicolumn{3}{|c|}{ Mixed Irrigated areas } \\
\cline { 4 - 5 }$\left(\mathrm{Mm}^{3} /\right.$ year $)$ & Traditional Irrigated area & Channel 100 & Channel 220 & $\begin{array}{c}\text { María } \\
\text { Cristina }\end{array}$ \\
\hline Surface water & 65 & & & \\
\hline Groundwater & & & & \\
\hline
\end{tabular}

Table P2. 1: Values of the water demand for the irrigated areas of the basin.

The topology of the model for the Mijares water system is shown in Figure P2. 2. The model includes a main course that represents the Mijares River where the Arenós and Sichar reservoirs are located. The other river considered is the tributary "Rambla de la Viuda", in which the María Cristina reservoir is located. The different sources of runoff considered are the runoff of the basin upstream of the Arenós reservoir, the runoff from the mid basin of the Mijares River between the Arenós and Sichar reservoirs, and the runoff from the "Rambla de la Viuda" river flowing to the María Cristina reservoir. The irrigation demand can be grouped into four main zones: "traditional", "channel 220", "channel 100" and "María Cristina". The main features of these demands are shown in Table P2. 1. The urban supply comes from the Plana de Castellón aquifer, which is located mainly beneath the coastal plain and recharged by precipitation, infiltration from irrigation, and Mijares riverbed infiltration.

One of the main issues of the basin is the allocation of the resource between the agricultural demands. The traditionally irrigated area in the low part of the basin is more than a millennium old, so its water rights are predominant over other agricultural uses. On the other hand, the irrigation of the mid part of the basin represents modern irrigation (Channel 220, Channel 100, and María Cristina), also called "mixed irrigation" because of the possibility of using both surface and ground water. In this situation, it is necessary to establish an OR in order to protect the rights of traditional irrigation over surface water by imposing the use of ground water for modern irrigation. Current management is based on a RC defined in 1970, called "Agreement 70" (Figure P2. 3). The indicator of this RC is the storage of the Sichar and Arenós reservoirs. If the sum of the volume of both reservoirs is greater than the defined RC, then all the demands can use cheaper surface water. On the other hand, when the volume storage goes down, the RC mixed irrigation 
demands have to pump water, and the remaining surface water is reserved for the traditionally irrigated area.

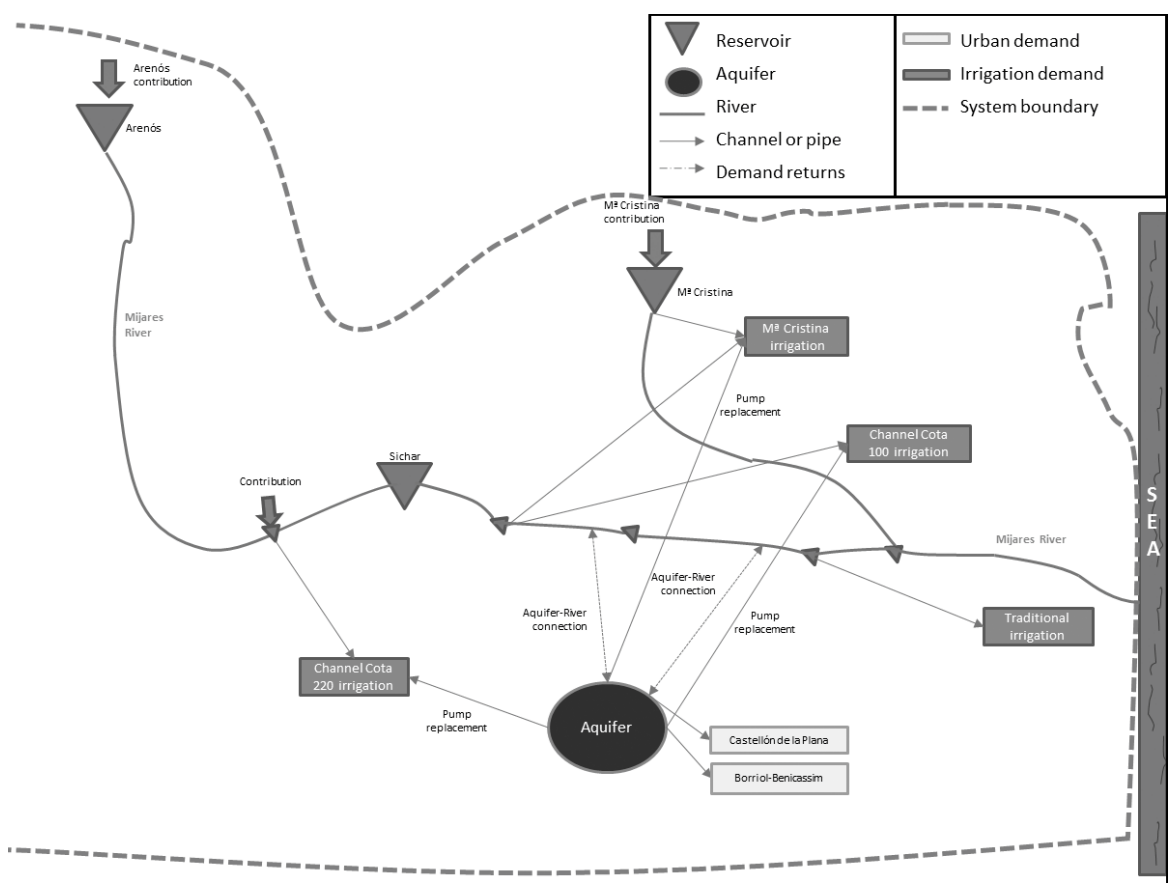

Figure P2. 2: Topology of the simulation model developed for the Mijares River Basin.

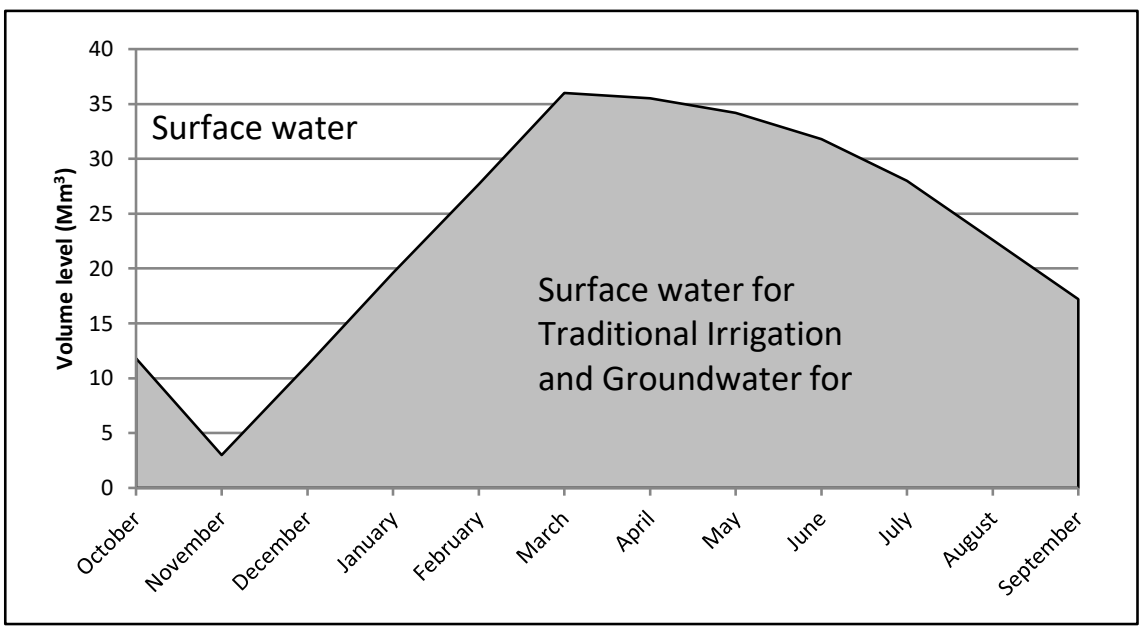

Figure P2. 3: Rule Curve of "Agreement 70". 


\section{$4 \quad$ Methodology.}

The methodology estimates the RC for a complex multi-reservoir water system through the iterative use of a river basin simulation model. A popular EMO algorithm that is usually applied in water resources engineering called NSGA-II has been used. NSGA-II is an EMO algorithm with a specific operator to handle constraints. Furthermore, the simulation of a water basin management model is required. The results obtained by this model represent the situation of the water system under the proposed water management policies. The water basin management model has been developed using the SIMGES module (Andreu et al., 1996) included in the Decision Support System Shell (DSSS) AQUATOOL (Andreu et al., 1996). The combination of nonlinear algorithms together with linear programming is common in water resources models.

\subsection{Implementation of the Simulation Model: SIMGES}

The method requires multiple iterations of a simulation model that accurately represents the water system. For this purpose, the simulation module SIMGES included in the DSSS AQUATOOL has been used. SIMGES is based on the conceptualization of river basins by networks comprising arc and nodes. Nodes usually represent the most important elements of the water system, such as divergence and confluence points, reservoirs, and demands. On the other hand, arcs represent any water conveyance element (natural or artificial). Furthermore, an internal combination of arcs and nodes within the model allows modelling other types of elements such as hydroelectric plants and water returns in the internal flow network. Arcs are defined by the initial and final nodes, by the maximum and minimum flows, and by the cost that produces each resource unit that flows through it. Mathematically, the simulation model is based on the resolution for each time step (monthly in this case) of an internal conservative flow network.

The equivalent objective function defined in the SIMGES model and simplified for our problem is the following: 
$\operatorname{Min} F=\sum_{i=1}^{I}\left(\sum_{n=1}^{m}\left(V_{n, i, t}\left(C_{n}+p n_{i}\right)\right)+\left(S p_{i, t} C_{s p}\right)\right)+\sum_{j=1}^{J} D R_{j, t}\left(C_{d r}+\right.$ $\left.p n_{j}\right)+\sum_{k=1}^{K} D D_{k, t}\left(C_{D D}+p n_{k}\right)$

where $t$ is the index for time; $i$ is the index for reservoir; $/$ is the total number of reservoirs in the model; $V_{n, \text { i }}$ is the volume of reservoir $i$ in pool $n ; m$ is the number of pools in a reservoir; $C_{n}$ is the cost/benefit of the storage water into pool $n ; \mathrm{pn}_{\mathrm{i}}$ is the priority number assigned to reservoir $\mathrm{I} ; \mathrm{Sp}_{\mathrm{i}}$ is the spill of reservoir l; $C_{s p}$ is the cost of spills in the reservoirs; $D R_{j}$ is the deficit of the minimum flow established for river or channel $j$; $C_{d r}$ is the cost of deficit of a minimum flow; $J$ is the number of rivers and channels; $\mathrm{pn}_{\mathrm{j}}$ is the priority number of river $j ; \mathrm{DD}_{\mathrm{k}}$ is the deficit of demand $k ; \mathrm{K}$ is the number of demands in the model; $C_{D D}$ is the cost associated with the deficits of the demands; and $\mathrm{pn}_{\mathrm{k}}$ is the priority number of demand $k$.

As usual, restrictions are related to physical constraints or other types of constraints such as legal or environmental constraints. Moreover, other constraints such as the balance in each junction or diversion are taken into account. Figure P2. 4 shows a diagram of SIMGES which takes into account the above aspects and data water system (demands, inflows, etc.) to translate this problem into an internal network flow optimization problem that is resolved using the Out-of-Kilter algorithm (Ford and Fulkerson, 1962).

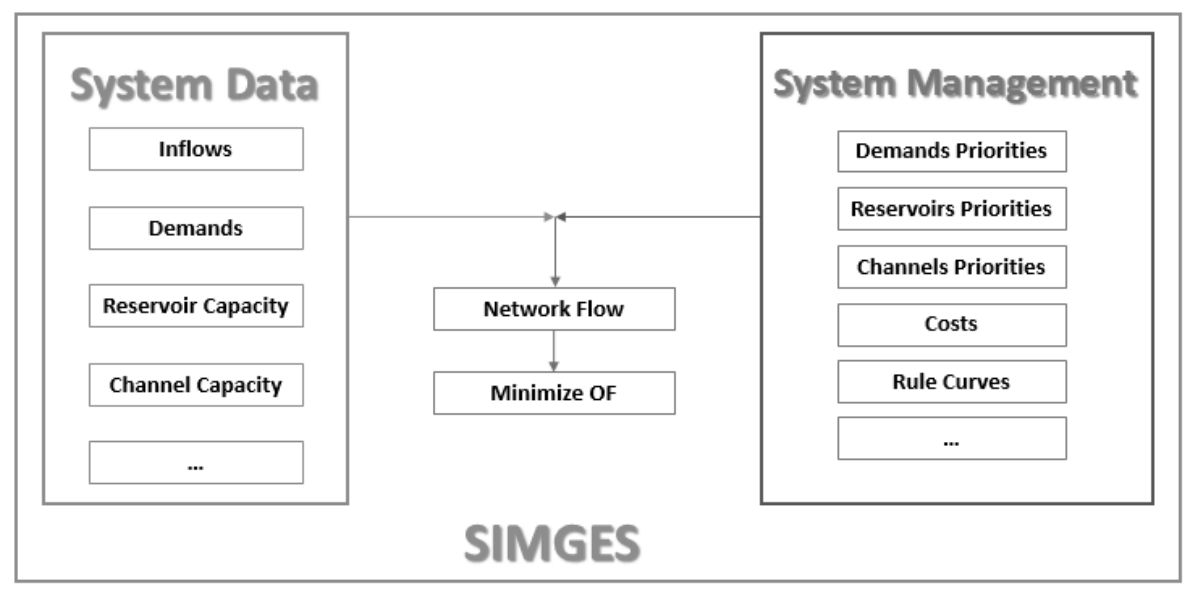

Figure P2. 4: Flowchart of SIMGES. Interaction between data and management system. 
The water management within the simulation model is defined in several ways. Firstly, among the water demands, a priority system that sets demands in order of priority (hierarchical order) is established. Similarly, a hierarchical system is established to define the releases among the reservoirs. Furthermore, the reservoirs are divided into zones such that the model tries to keep all reservoirs in the same zone and starts releasing depending on the priority. Finally, there are operation rules that allow the triggering of decisions based on indicators. These indicators can be the volume stored in one or several reservoirs or the cumulative runoff of several months. The decision can represent the application of a restriction on the demands, expressed as a percentage of one or several demands, on the flow through the turbines, on the ecological flow, or on the activation of pumping from the aquifer.

The model developed for the Mijares River basin (Figure P2. 2) represents quite well the current situation of the system. Three runoff inflow elements are considered (one for each reservoir), with historical monthly data obtained from re-naturalized monthly flows for the period 1940-2008. Additionally, the three existing reservoirs have been taken into account (Arenós, Sichar and María Cristina). The demands are considered at the correct aggregation level to represent the different irrigators. Six demands have been considered in the model: two urban demands, Castellón de la Plana and Borriol-Benicassim, and the four above-mentioned agricultural demands. SIMGES allows modelling the surface-groundwater interaction in a very complete way with several types of aquifers and river reaches connected to the aquifers. There are requirements for the ecological flows established in several parts of the basin. Within the model, the flows are considered in two specific river reaches, with a constant flow of $0.5 \mathrm{~m}^{3} / \mathrm{s}(1.3$ $\mathrm{Mm}^{3} /$ month).

\subsection{NSGA-II Implementation}

NSGA-II (Deb et al., 2002) (Elitist Non-Dominated Sorting Genetic Algorithm) is an EMO algorithm with a specific operator to handle constraints. In this method, a fast, non-dominated sorting approach with a selection operator is used to create a mating pool by combining the parent and offspring 
populations and selecting the best solutions with respect to the fitness and the spread (Deb et al., 2002; Dumedah et al., 2010). The next generation is populated starting with the best non-dominated front and progresses through the rest of the fronts until the population size is reached, and if, in the final stage, there are more individuals in the non-dominated front than there is available space, a crowded distance-based niching strategy is used to choose which individuals of that front are entered into the next population. The crowding distance value of a solution provides an estimate of the density of solutions surrounding that solution (Raquel and Naval, 2005). In this research, NSGA-II is used for the evaluation of the objective functions that allow knowing the aptitude of the operation rules.

Through this algorithm, the descendant population $\mathrm{Q}_{t}($ size $\mathrm{N}$ ) is created using the parent population $\mathrm{P}_{\mathrm{t}}$ (size $\mathrm{N}$ ). Then, both populations are combined to form $R_{t}$ with a size of $2 \mathrm{~N}$. After this, by means of non-dominated sorting, the population $\mathrm{R}_{\mathrm{t}}$ is classified in different Pareto fronts. Although this process requires more effort, it is necessary because dominance testing between the parent and descendant populations is developed. Once the sorting process is over, the new population is generated from the configurations of the nondominated Pareto fronts. This new population is first built with the best nondominated Pareto front $\left(F_{1}\right)$, and then the process continues with the solutions from the second front $\left(F_{2}\right)$, the third front and so on $\left(F_{3}\right)$. Because the population $\mathrm{R}_{\mathrm{t}}$ has a size of $2 \mathrm{~N}$ and there are only $\mathrm{N}$ configurations that form the descendant population, not all of the front configurations belonging to the $R_{t}$ population will be placed in the new population. Those fronts that cannot be placed are ignored.

When the last front is under consideration, the solutions that belong to this front can exceed future solutions to be placed in the descendant population (Figure P2. 5). In this case, it is useful to use strategies that allow those configurations to be selected at a scarcely populated area that is far away from the other solutions. This will fill up the rest of the positions of the descendant population instead of choosing configurations randomly. 


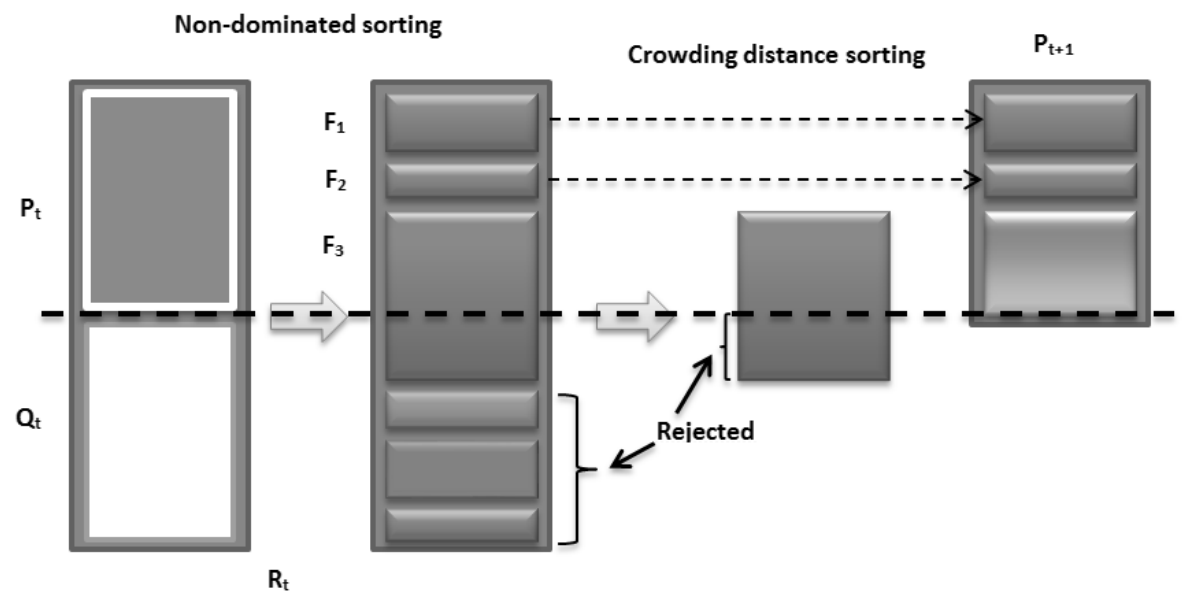

Figure P2. 5: Schematic diagram of the mechanism for promoting individuals of NSGA-II.

These strategies are irrelevant for the first generational cycles of the algorithm because there are many fronts that persist to the next generation. However, as the process moves forward, several configurations become part of the first generation, and this front may have more than $\mathrm{N}$ genes or individuals. Thus, it is important that the non-rejected configurations are chosen through a methodology that guarantees diversity. When the population as a whole converges to the Pareto front, the algorithm assures that the solutions are separated from each other.

Initially, a parent population $\mathrm{P}_{0}$ is created in the NSGA-II algorithm (randomly or by an initialization technique). The population is sorted according to the non-dominance of the different levels (sorting of Pareto fronts $F_{1}, F_{2} \ldots$ ). For each solution, a flair function is assigned according to its dominance level (1 for the best level), which decreases throughout the process. Sorting by Tournament (using a Crowding Tournament Operator), crossing and mutation are used to create the population of descendants $Q_{0}$ with a size $N$. The main phases followed by NSGA-II are described as follows:

1. A combination of parents and descendants to create $R_{t}=P_{t} \cup Q_{t}$. Developing the non-dominated sorting to $R_{t}$ and identifying fronts $F_{i}, i=1$, $2 \ldots$, etc. 
2. To make $P_{t+1}=\varnothing$, and $i=1$. While $\left|P_{t+1}\right|+\left|F_{i}\right|<N$, make $\left|P_{t+1}\right|=\left|P_{t+1}\right| \cup$ $\left|\mathrm{F}_{\mathrm{i}}\right|$ and $\mathrm{i}=\mathrm{i}+1$.

3. Sorting by crowding $\left(\mathrm{F}_{\mathrm{i}}{ }^{\prime}<\mathrm{C}\right.$, described below) and including at $\mathrm{P}_{\mathrm{i}}$ the $\mathrm{N}$ $\left|P_{t+1}\right|$ most widespread solutions using the crowding distance values associated with the front $\mathrm{F}_{\mathrm{i}}$.

4. Creating the descendant population $Q_{i+1}$ from $P_{i+1}$ using selection by Crowding Tournament, crossing and mutation.

\subsection{Coupling of methods: the multi-objective optimization model}

NSGA-II is used to define and test RC for the water allocation model developed with SIMGES. Each individual is composed of 13 values representing the value of the $\mathrm{RC}$ in each month of the year (12) and the restriction coefficient (1). The indicator of this $\mathrm{RC}$ is the storage of the Sichar and Arenós reservoirs. This $\mathrm{RC}$ is imposed in the water allocation model, and a run is performed. The results of this run are used to estimate the objective functions, which will be explained later. The value of this objective functions is translated to the multi-objective algorithm to define the aptitude of the RC proposed.

NSGA-II (Deb et al., 2002) is used to examine the SIMGES model and inspect it for inconsistencies or errors and to generate optimal trade-offs between conflicting objectives considering alternative management scenarios simultaneously. Consistency checks can help provide some confidence in the representation of the decision maker's preferences. In checking for consistency, it is important to detect errors in the decision-making utility function. For utility functions implying a complex preference structure, there is a greater need and opportunity for meaningful consistency checks (Castelletti and Soncini-Sessa, 2007).

Attempting to achieve the multiple goals simultaneously requires identifying a compromise in the Pareto optimality. EMO algorithms employ a population-based search to find many Pareto efficient solutions in a single run. Once the probability of all the linked nodes has been updated by compiling the SIMGES model, the objective function values are returned to the optimization tool, and the process is repeated. Consistency is critical to 
be able to identify a preferred alternative with confidence. In the proposed method, the first step in the consistency check occurs after the evolutionary algorithm has generated a set of non-dominated policy or management options. Usually, solutions generated by the evolutionary algorithm are a good indicator of shortcomings of the network flow model structure. For example, if changes in a node should have an effect on the utility function and this has been ignored intentionally or unintentionally in the SIMGES model, the results generated by EMO will exploit this weakness in the flow network and generate solutions that should have corresponded to higher utility function values.

The objective functions of the problem take into account the maximum deficit of the demands as well as the resilience of the water system. For that, three objective functions are proposed.

The problem can be mathematically expressed as follows:

Given three objective functions:

$$
\begin{aligned}
& x=f(B) \\
& y=g(b) \\
& z=h(b)
\end{aligned}
$$

where

$$
\begin{aligned}
& x=\text { maximum annual deficit for agricultural demands (MaxDef1Year) } \\
& \text { (Minimized) } \\
& y=\text { maximum ten consecutive years deficit for agricultural demands } \\
& \text { (MaxDef10Years) (Minimized) } \\
& z=\text { years of pumping (Minimized) }
\end{aligned}
$$

These objective functions are optimized by coupling NSGA-II algorithm and SIMGES. Results from this optimization running represent the outcome of SIMGES model. For this reason, these three functions are restricted by the solutions of equation (1). On the other hand, $\beta$ represents a combination of 
$\mathrm{n}$ non-ranked and non-weighted management options, which are the decision nodes of the SIMGES model and represent the RC. They also represent the genes of the chromosome of the algorithm.

$$
B=(g 0, g 2 \ldots g n)
$$

These $n$ input variables, representing RC, denote the set of feasible parameters over which the model produces a realistic output. Thus, there are $\mathrm{j}$ optimized solutions placed at the Pareto front expressed as $\mathrm{j}$ combinations of the different operation rules belonging to each input variable.

$$
\begin{aligned}
& B_{a}=x_{a}, y_{a}, z_{a} \\
& B_{b}=x_{b}, y_{b}, z_{b} \\
& \cdot \\
& \cdot \\
& B_{j}=x_{j}, y_{j}, z_{j}
\end{aligned}
$$

Each $B$ (the RC) is represented by the volume threshold in each month of the $\mathrm{OR}$ and the restriction coefficient corresponding to each of them. These variables (volume threshold and restriction coefficient) are discretized at certain intervals. The volume level is between a minimum $\left(5 \mathrm{Mm}^{3}\right)$ and a maximum $\left(87 \mathrm{Mm}^{3}\right)$ value depending on the associated reservoirs (Sichar and Arenós), and the restriction coefficient varies between 0 and 1 or, in other words, between not applying and applying a total restriction (100\%).

Two constraints related to the deficit objective functions were defined:

MaxDef1Year $<50 \%$

MaxDef10Years $<100 \%$ 


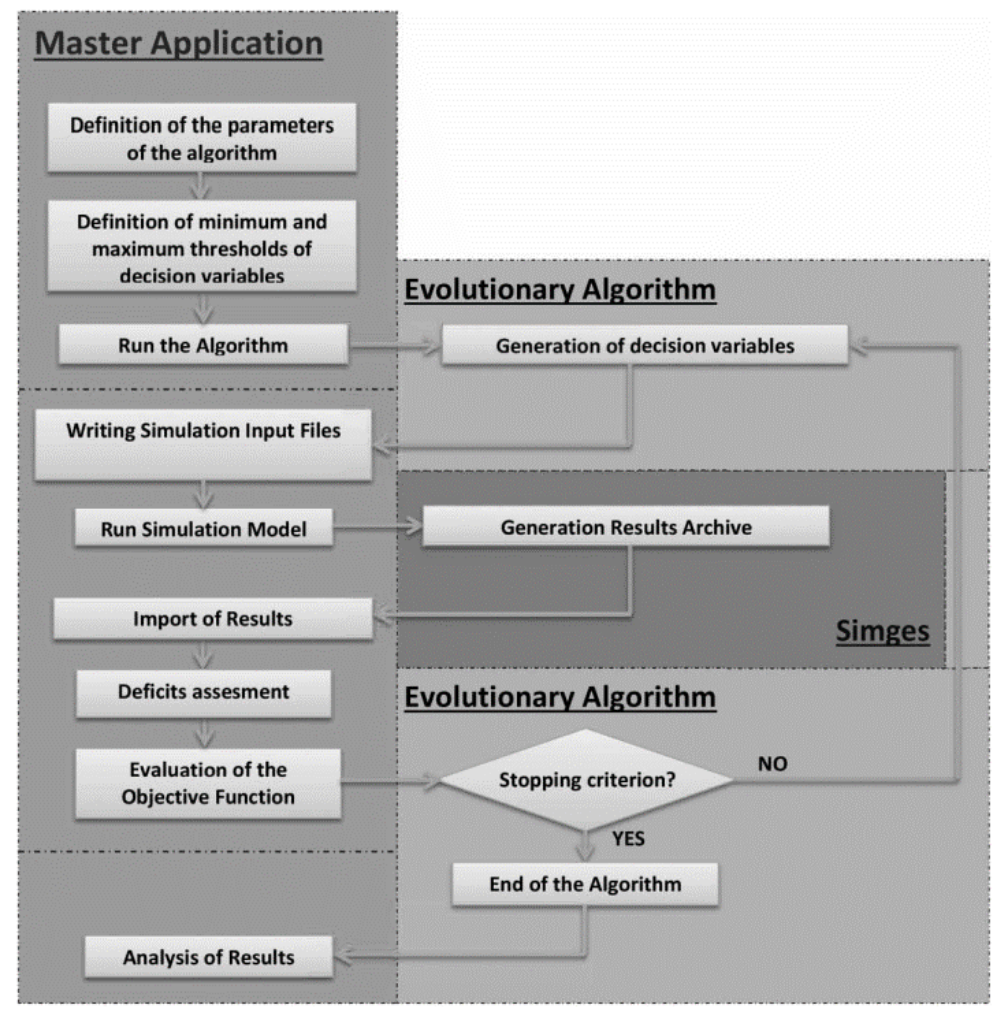

Figure P2. 6: Schematic model coupling.

Each evaluation of the objective functions requires running the simulation model under this operation rule. To do this, the process is as follows (Figure P2. 6): first, the parameters of the EMO and the minimum and maximum thresholds of the decision variables are defined in a Master Application that is responsible for controlling the whole process. After this, the Mater Application runs NSGA-II, which defines the first individual (set of decision variables), and with these variables, the data files needed for SIMGES are created. SIMGES is run, and the Master Application imports the results and calculates deficits. The aquifer pumping allows the OFs to be evaluated, and this value is returned to the optimization model to create the next individual.

Regarding EMO, the initial population for the optimization was 200, with a crossover probability of 0.9 , a single-point binary crossover, a bitwise mutation probability of 0.005 and a seed for a random number generator of 
0.123457 . This setting was the most suitable for handling the problem after developing a deep test with different configurations.

\section{$5 \quad$ Results and Discussion.}

The results drawn from this analysis are shown in the different figures representing, on the one hand, the Pareto front that links the different objective functions and, on the other hand, the operation rule parameters that are the decision variables of the algorithm. The results presented herein correspond to different tests conducted with the NSGA-II algorithm for the different OR proposed.

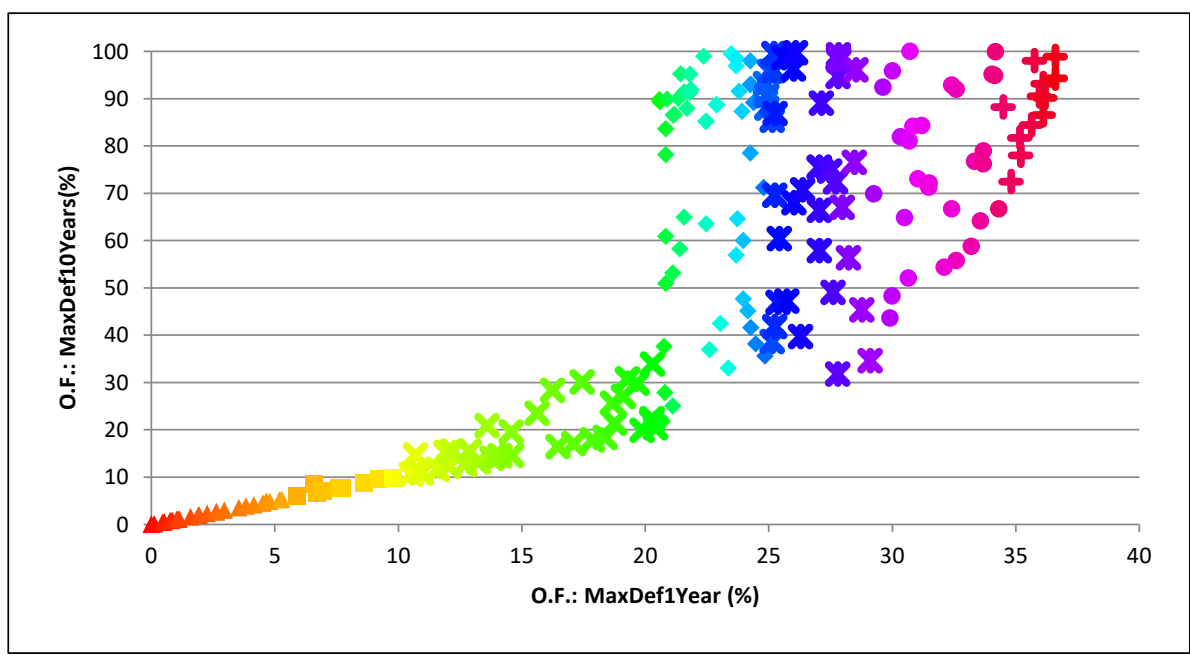

Figure P2. 7: Pareto front 1; maximum deficits for the agricultural demands (for colourmarker coding, see Table P2. 2).

Two hundred points are represented in Figures P2.7 to P2.10. Each of these points represents the result applying SIMGES for each combination of parameters obtained using NSGA-II to define the RC mentioned at the beginning of the previous point (4.3). These two hundred points represents an optimized solution for the OFs defined in equations (2), (3) and (4), RC's parameters or interesting variables (maximum pumping of the Mixed Irrigation), drawn from the last population found by NSGA-II algorithm. Thus, this is how RC's are obtained. To relate the solutions of one figure with the 
rest of the figures, a color scale gradient has been fixed, sorting the solutions according to the maximum annual deficit of the agricultural demands (abscissa of Figure P2. 7). Table P2. 2 shows the color coding adopted in Figures P2.7 to P2.11. For example, the points (in any figure) with colors between orange and yellow are related with OR that provide a maximum annual deficit of the agricultural demands between 5 and $10 \%$.

\begin{tabular}{cc}
\hline Colour (marker) & $\begin{array}{c}\text { Maximum annual deficit of the agricultural demands } \\
(\%)\end{array}$ \\
\hline Red $(\Delta)$-orange $(\square)$ & $0-5$ \\
Orange $(\square)$-yellow $(\square)$ & $5-10$ \\
Yellow $(\square)$-green $(\mathrm{X})$ & $10-20$ \\
Green $(\mathrm{X})$-cyan $(\diamond)$ & $20-25$ \\
Blue $(\Psi)$-purple $(\bullet)$ & $25-30$ \\
Purple $(\bullet)$-pink $(\bullet)$ & $30-35$ \\
Pink $(\bullet)$-dark red $(+)$ & $35-37$ \\
\hline
\end{tabular}

Table P2. 2: Colour-marker coding adopted in Figures 7-11.

Figure P2. 7 shows the Pareto front corresponding to the short term (1 year) and the long term (10 years) of the deficit of agricultural demands. Notice that an inferior front can be distinguished by the dispersing point over this line. This OR represents a great variety of possible solutions with deficits ranging from 0 to $36 \%$ for the short term deficit and up to $100 \%$ of the long term deficit (in percentage over the annual demand). 


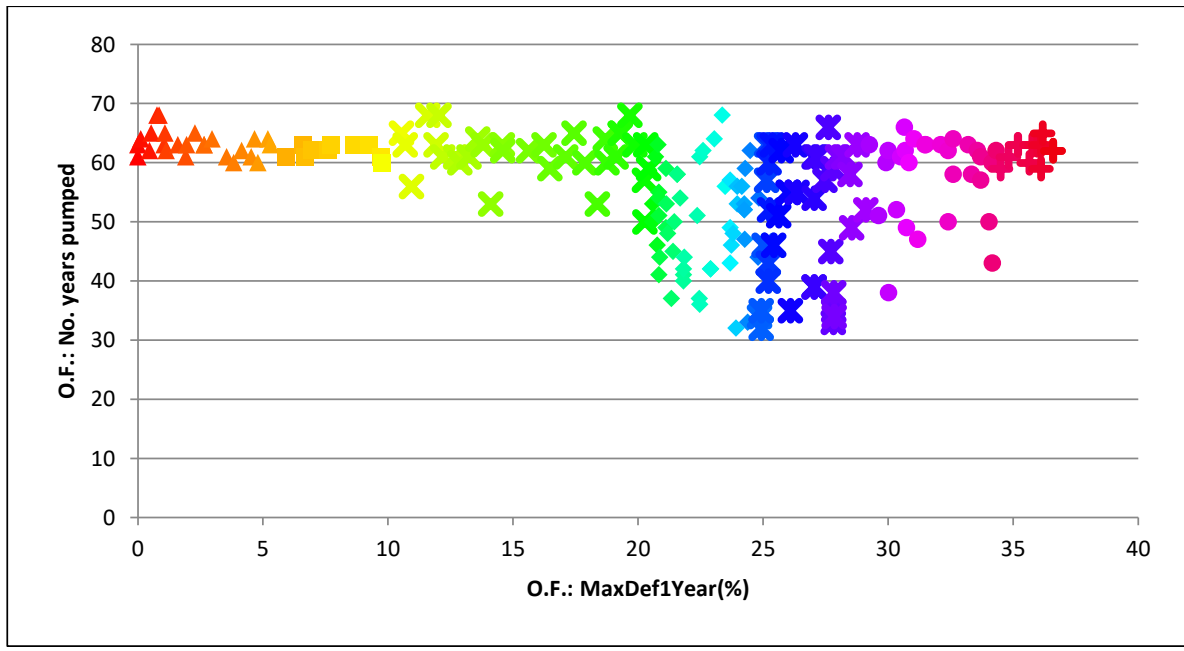

Figure P2. 8: Pareto front 2; number years pumped versus deficit of the agricultural demands (for colour-marker coding, see Table P2. 2).

The growing trend of this figure is due to the conditions of the basin. First storages in the reservoirs and, on the other hand, the fact that agricultural uses with more demand can be supplied with groundwater. Therefore, the set of demands that can receive groundwater can achieve a state of no deficit. From this situation and as shown in the figure, increasing the annual deficit implies that the growth also accumulated 10 years of deficit. The optimal solution is not the one with zero deficits, and the number of years pumped must also be taken into account.

Figure P2. 8 shows the number of years pumped, sorted according to the annual deficit of the agricultural demands. Notice that this figure indicates the number of years of pumping required for achieving specific deficits. This parameter (the number of years) was taken into account because pumping has an associated cost, which decreases while reducing the pumping time. It is possible to distinguish three zones in the figure, the first one approximately between 0 and $20 \%$ of the annual deficit in which the pump is above 55 years. Therefore, to result in fewer deficits, it is necessary to pump up to 68 years, which is the number of years simulated. The second zone is associated with annual deficits between 20 and $28 \%$, with ten years of accumulated deficits ranging between 20 and $100 \%$, hence the high values of these deficits. By not 
restricting the demand, constant pumping is not necessary, and the number of years pumped decreases to 35 . This lower value of years pumped means that no matter which operating rules apply, it is always necessary to pump at least 35 of the 68 years of the simulation because the surface water is not enough to supply the whole water demand of the basin. Finally, the third zone corresponds to a large number of years pumped, but this time, the zone is associated with high values of the maximum deficits, whereby this set of solutions are not indicated, neither or both deficits as pumped years.

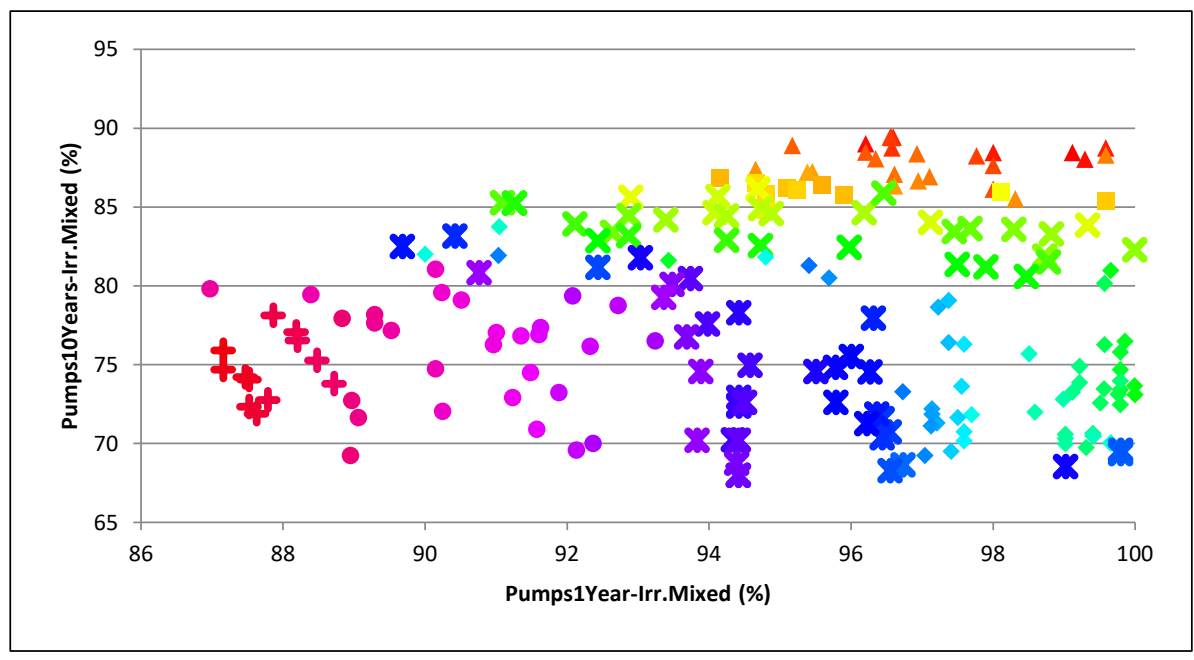

Figure P2. 9: Maximum pumping of 1 and 10 years for the mixed irrigation (for colour-marker coding, see Table P2. 2).

In addition to the number of years pumped, it is important to represent the maximum annual pumping of the Mixed Irrigation facing the maximum long term pumping of the same demand (Figure P2. 9). The figure shows a scatter cloud of points and much more restrictive intervals of variation of the pumping than for the deficits of the agricultural demands. The annual pumping is between 87 and $100 \%$ of the maximum annual pumping and of ten years of pumping and between 67 and $90 \%$ of the accumulated ten years of pumping. Very high values for both indicators imply that water is scarce and requires high pumping for agricultural areas of channel 100, channel 220 and María Cristina (Mixed Irrigation) to not suffer deficits. 
Looking at the color distribution discussed above, it can be seen that the first stage (between 0 and $15 \%$ of the annual deficits) of the Pareto front for the deficits is associated with a change of ten years of pumping between 90 and $84 \%$. The rest of the Pareto front (between 15 and $35 \%$ of the annual deficits) corresponds to a variation of annual pumping between 100 and $87 \%$. Thus, there is an area that varies depending on ten years of pumping and another area that depends on the annual pumping.

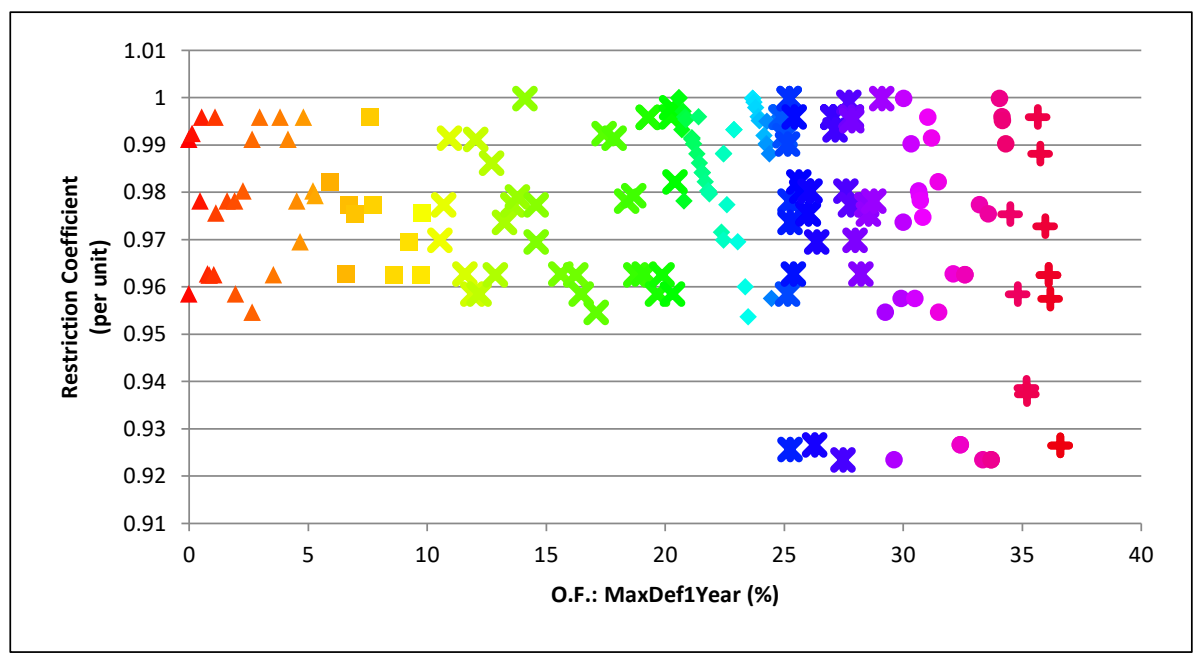

Figure P2. 10: Restriction coefficient (for colour-marker coding, see Table P2. 2).

Figure P2. 10 represents the coefficient of restriction, the OR parameter, and the decision variable algorithm depending on the maximum deficit agrarian demands. The obtained restriction is around $100 \%$, more specifically between 92 and 100\%, although the largest set of solutions is between 96 and $100 \%$. The figure reveals that a very high restriction has to be applied regardless of the results obtained. However, the restriction also influences the volume level (the other parameter of the operating rules) in these results to be obtained.

In Figures P2.7 and P2.8, the 200 points shown in each figure (last population found by NSGA-II) represent two Pareto fronts, the first between the short term (1 year) and the long term (10 years) of the deficit of agricultural 
demands and the second between the short term deficit and the number of pumping years.

As mentioned above, there are 200 results that provide different combinations of objective functions. These results translate into $200 \mathrm{RC}$ that the NSGA-II algorithm obtains. Each of these RC is a curve defined with thirteen values, twelve corresponding to the months of a year and another to the coefficient of restriction. Because representing and analyzing 200 curves is not feasible, and given that some curves are not applicable to real management scenarios because of the complexity and variability of their definitions, four curves have been selected to represent various parts of the Pareto front (Figure P2. 11).

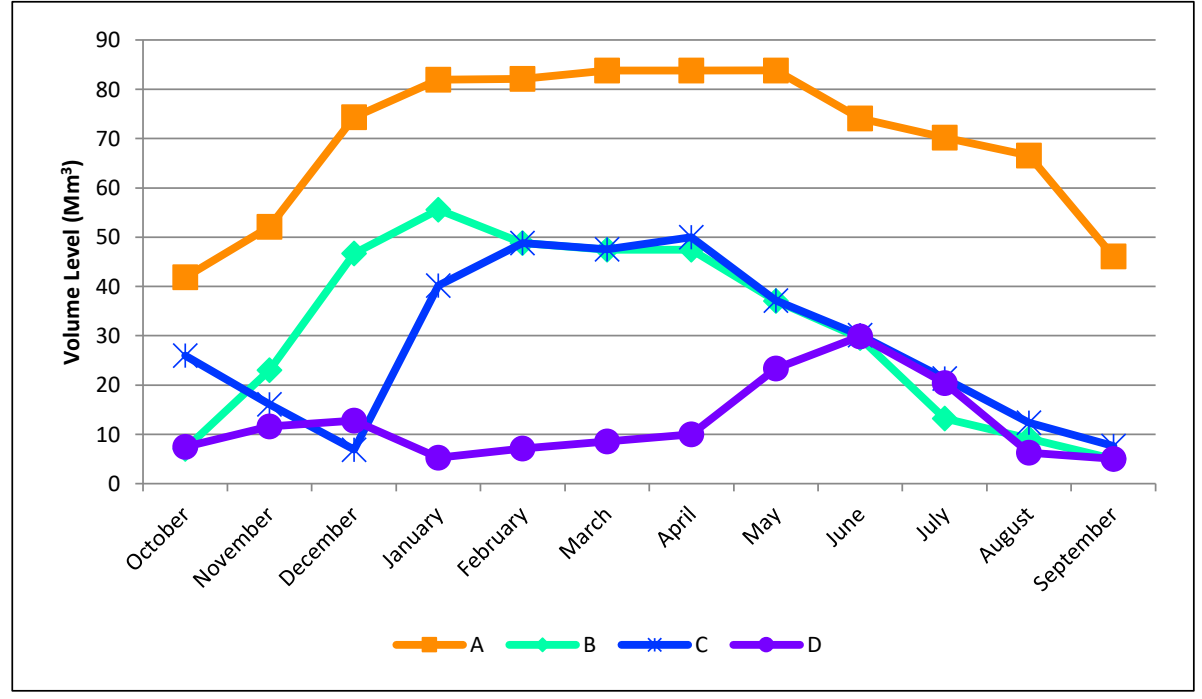

Figure P2. 11: Curves at the volume level, parameter of the operation rule (for colour-marker coding, see Table P2. 2).

Curve "A" (orange) corresponds to solutions close to the origin of Pareto front reference 1 (Figure P2. 7), i.e., the maximum annual deficits and ten years of claims of $5 \%$ of the agricultural environment. This implies, as already explained, a large number of years pumped (Figure P2. 8) and high values of these pumps (Figure P2. 9). To achieve these results, the OR are defined with fairly high levels (compared with the other three curves). Thus, when the sum 
of the volumes of the Arenós and Sichar reservoirs are below those levels, which indicates that the RC of the Mixed Irrigation are not supplied with the water surface, only traditional irrigation has to be taken into account, and Mixed Irrigation have to pump water. Curve "B" (cyan) is associated with annual maximum deficits between 20 and $25 \%$ of the agrarian demands and between 30 and $100 \%$ in the case of the maximum deficits of 10 years. This curve is defined with a level lower than curve "A", allowing a larger surface to supply the Mixed Irrigation and, therefore, somewhat less by pumping. Curve "C" (dark blue) is similar to "B", differing mainly in the first months of the hydrological year, i.e., November to January. Those months can be seen as the curve "B" reserve supplying more water to the surface for Traditional Irrigation. However, curve "C" allows for a greater surface to supply Mixed Irrigation, and for this reason, Traditional Irrigation, and therefore the agrarian demands, increase deficits. Finally, curve "D" (violet) corresponds to maximum annual deficits between 25 and $30 \%$ of the agricultural demands and between 30 and $100 \%$ in the case of the greatest deficiencies of 10 years. This RC is defined with low levels and is associated with a very small reserve for Traditional Irrigation, causing high deficits of traditional demands.

\begin{tabular}{|c|l|c|c|}
\hline \multicolumn{2}{|l|}{} & $\begin{array}{c}\text { Without OR } \\
(\%)\end{array}$ & $\begin{array}{c}\text { “Agreement } \\
\text { 70” RC (\%) }\end{array}$ \\
\hline & $\begin{array}{l}\text { Maximum deficit of } \\
\text { one year }\end{array}$ & 37.12 & 23.35 \\
\cline { 2 - 4 } & $\begin{array}{l}\text { Maximum deficit of } \\
\text { ten years }\end{array}$ & 217.28 & 55.77 \\
\hline & $\begin{array}{l}\text { Maximum pumping } \\
\text { of one year }\end{array}$ & 87.4 & 97.85 \\
\cline { 2 - 4 } & $\begin{array}{l}\text { Maximum pumping } \\
\text { of ten years }\end{array}$ & 59.64 & 73.3 \\
\hline
\end{tabular}

Table P2. 3: Results of deficits and pumping without OR and with the RC "Agreement 70".

Table P2. 3 shows the results (deficit and pumping) of the water system without OR and with RC "Agreement 70". The results without OR are not in the solutions of the NSGA-II algorithm because it has a maximum deficit of 
ten years of the traditionally irrigated area, which is larger than the limit established in official studies developed by the Jucar Basin Authority. The results with "Agreement 70" RC follow a similar behavior to the green points of the figures, and this curve (Figure P2. 3) corresponds to curve " $\mathrm{C}$ " (Figure P2. 11) but with a slightly lower level.

\section{Conclusions}

This paper shows the optimization of operating rules based on the coupling of an EMO with a flow network model. This approach allows a set of rule curves of a reservoir to be obtained for the allocation of water between demands during a drought. The EMO used was the NSGA-II algorithm. The simulation model was developed with the program SIMGES of the Decision Support System Shell AQUATOOL based on network flow algorithms. The problem that arises is aimed at reducing the highest annual deficits and the maximum long-term deficits while taking into account the cost of additional pumping. The optimization decision variables are the trigger volume of applying the OR and the restriction coefficient. The coupling methodology is based on the evaluation of the objective function, which represents a run of the simulation model for watershed management to estimate the demand deficits and pumps.

This methodology has been applied to the Mijares River basin, a system that is characterized by severe droughts, a well-established system of rights between users, and the possibility of the joint use of surface and groundwater resources. From applying this approach, different types of operating rules have been tested to provide results in terms of deficits and similar pumps. A multi-objective point of view allowed taking into account the short and long terms of the deficit and the pumping resource. Moreover, this implementation helps users or managers of the water system on deciding the best or most convenient management for the river basin.

\section{Acknowledgements}

The authors wish to thank the Confederación Hidrográfica del Júcar (Spanish Ministry of the Environment) for the data provided in developing this study, 
the Spanish Ministry of Science and Innovation (Comisión Interministerial de Ciencia y Tecnología, CICYT) for funding the projects INTEGRAME (contract CGL2009-11798) and SCARCE (program Consolider-Ingenio 2010, project CSD2009-00065) and the Generalitat Valenciana for the Gerónimo Forteza grant (FPA/2012/006). The authors also thank the European Commission (Directorate-General for Research \& Innovation) for funding the project DROUGHT-R\&SPI (program FP7-ENV-2011, project 282769) and the Seventh Framework Programme of the European Commission for funding the project SIRIUS (FP7-SPACE-2010-1, project 262902).

\section{References}

- Abd-Elhamid H.F., Javadi A.A.: A cost-effective method to control seawater intrusion in coastal aquifers, Water Resour Manag, 2011.

- Akter T, Simonovic S.P.: Modelling uncertainties in short-term reservoir operation using fuzzy sets and a genetic algorithm, Hydrol Sci J, 49,6,1079-81, 2004.

- Alcigeimes B. C. and Billib M.: Evaluation of stochastic reservoir operation optimization models, Advances in Water Resources, 32, 1429-1443, 2009.

- Andreu, J., Capilla, J., and Sanchís, E.: AQUATOOL: A generalized decision support-system for water-resources planning and operational management, Journal of Hydrology, 177, 269-291, 1996.

- Beckford, O., A. B. Chan Hilton, and X. Liu: Development of an enhanced multi-objective robust genetic algorithm for groundwater remediation design, in World Water and Environmental Resources Congress 2003: Proceedings of the Conference [CD-ROM], edited by P. A. Debarry, Am. Soc. of Civ. Eng., Reston, Va, 2003.

- Bhaskar, N. R. and Whitlach Jr., E. E.: Deriving of monthly reservoir release policies, Water Resources Res., 16, 6, 987-993, 1980.

- Bower, B. T., Hufschmidt M. M. and Reedy W. H.: Operation procedures: Their role in the design and implementation of water resource systems by simulation analysis, in Design of Water Resource Systems, chap. 11, edited by A. Maass et al., 443-458, Harvard University Press, Cambridge, Mass, 1962.

- Cai, X., McKinney D.C., and Lasdon L.S.: Solving nonlinear water management models using a combined genetic algorithm and linear 
programming approach, Advances in water Reseources, 24, 667-676, 2001.

- Castelletti A. and Soncini-Sessa R.: Bayesian Networks and participatory modelling in water resource management, Environ Model Software, 22, 1075-1088, 2007.

- Chang, L-C. and Chang, F-J.: Multi-objective evolutionary algorithm for operating parallel reservoir system, Journal of Hydrology, 377, 12-20, 2009.

- Chan Hilton, A. B. and Culver, T. B.: Groundwater remediation design under uncertainty using a robust genetic algorithm, Journal of Water Resources Planning and Management, ASCE, 131, 1, 25-34, 2005.

- Chen L., McPhee J., and Yeh W W-G.: A diversified multiobjective GA for optimizing reservoir rule curves, Advances in Water Resources, 30, 1082-1093, 2007.

- CHJ. Plan Hidrológico del Júcar. Confederación Hidrográfica del Júcar. Ministerio de Medio Ambiente. España, 1998.

- Cieniawski, S. E., Eheart, J. W., and Ranjithan, S.: Using genetic algorithms to solve a multiobjective groundwater monitoring problem, Water Resources Research, 31, 2, 399-409, 1995.

- Cisty, M.: Hybrid genetic algorithm and linear programming method for least-cost design of water distribution systems, Water Resour Manage 24, 1-24, 2010.

- Clark, E. J.: Impounding reservoirs, J. Am. Water Works Assoc., Vol. 48(4), 349-354, 1956.

- Coello-Coello, C. A., Lamont, G. B., and Van Veldhuizen, D. A.: Evolutionary algorithms for solving multi-objective problems, New York: Springer, 2007.

- Croley, T. E. and Rao, K. N. R.: Multi-objective risks in reservoir operation, Water Resources Research, 15, 4, 1807-1814, 1979.

- Deb K., Pratap A., Agarwal S. and Meyarivan, T. A.: Fast and Elitist Multiobjective Genetic Algorithm: NSGA-II, IEEE Transactions On Evolutionary Computation, 6, 2, April 2002.

- Dumedah G., Berg A.A., Wineberg M., Collier R.: Selecting model parameter sets from a trade-off surface generated from the nondominated sorting genetic algorithm-II, Water Resour Manag, 24, 4469-4489, 2010. 
- Farmani R., Savic D., Walters G.A.: Evolutionary multi-objective optimisation in water distribution network design, J Eng Optim, 37, 2, 167-183, 2005a.

- Farmani R., Walters G.A., Savic D.: Trade-off between total cost and reliability for Anytown water distribution network, J Water Resour Plann Manag, 131, 3, 161-171, 2005 b.

- Farmani R., Walters G.A., Savic D.: Evolutionary multi-objective optimization of the design and operation of water distribution network: total cost vs. reliability vs. water quality, Journal of Hydroinformatics 8, 3, 165-179, 2006.

- Farmani R., Abadia R., Savic D.: Optimum design and management of pressurised branched irrigation networks, J Irrigat Drain, 133, 6, 538547, 2007.

- Farmani R., Henriksen H.J., Savic D.: An evolutionary Bayesian belief network methodology for optimum management of groundwater contamination, Environ Model Software 24, 303-310, 2009.

- Ford, C.R. and Fulkerson, D.R.: Flow in networks, Princeton University Press, Princeton, NJ, 194, 1962.

- Gorev N.B., Kodzhespirova I.F., Kovalenko Y., Álvarez R., Prokhorov E. and Ramos A.: Evolutionary testing of hydraulic simulator functionality, Water Resour Manage 25, 1935-1947, 2011.

- Haghighi A., Samani HMV, Samani ZMV: GA-ILP method for optimization of water distribution networks, Water Resour Manage, 25, 1791-1808, 2011.

- Hakimi-Asiabar M., Ghodsypour S.H., and Kerachian R.: Aplied soft computing 10. 1151-1163, 2010.

- Hanne T., Nickel S.: A multiobjective evolutionary algorithm for scheduling and inspection planning in software development projects, Eur J Oper Res, 167, 3, 663-678, 2005.

- Harik, G. R., Lobo, F. G., and Goldberg, D. E.: The compact genetic algorithm (IlliGAL Report No. 97006). Urbana, IL: University of Illinois at Urbana-Champaign, Illinois Genetic Algorithms Laboratory, (1997).

- Hassanzadeh Y., Abdi A., Talatahari S., Singh V.P.: Meta-heuristic algorithms for hydrologic frequency analysis, Water Resour Manage, 25, 1855-1879, 2011.

- Hınçal O., Altan-Sakarya A.B., Ger A.M.: Optimization of multireservoir systems by genetic algorithm, Water Resour Manage 25, 1465-1487, 2011. 
- Janga Reddy, M. and Nagesh Kumar, D.: Optimal Reservoir Operation Using Multi-Objective Evolutionary Algorithm, Department of Civil Engineering, Indian Institute of Science, Bangalore 560012, India, 2006.

- Kim T, Heo J-H.: Application of implicit stochastic optimization in the Han River basin. In: Proceedings of the fourth international conference on hydroscience and -engineering. Seoul, Korea: Korean Society of Water Resources, 2000.

- Kollat, J. B., and Reed, P. M.: Comparison of Multi-Objective Evolutionary Algorithms for Long-Term Monitoring Design, Advances in Water Resources, 29, 6, 792-807, 2006.

- Kourakos G., Mantoglou A.: Simulation and multi-objective management of coastal aquifers in semiarid regions, Water Resour Manage, 25, 1063-1074, 2011.

- Lin, J-Y., Cheng, C-T. and Lin, T.: A Pareto Strength SCE-UA Algorithm for Reservoir Optimization Operation, Fourth International Conference on Natural Computation. IEEE Computer Society, 406-412, 2008.

- Labadie, J.: Reservoir system optimization models, Water Resources Update, University Council on Water Resources, 108(Summer), 83110, 1997.

- Labadie JW.: Optimal operation of multireservoir systems: state-ofthe-art review, J Water Resour Plan Manage, 130, 2, 93-111, 2004.

- Laumanns M., and Ocenasek J.: Bayesian Optimization Algorithms for Multi-objective Optimization, In: Guervós J., Adamidis P., Beyer H., Martín J., Schwefel H. (eds.): Parallel Problem Solving from Nature PPSN VII, 7th International Conference, Granada, Spain, September 711. Lecture Notes in Computer Science, Vol. 2439, Springer: 298-307, 2002.

- $\quad$ Liang, Q., Johnson, L. E., and Yu, Y.S.: A comparison of two methods for multiobjective optimization for reservoir operation. Water Resources Bulletin, 32, 2, 333-340, 1996.

- Louati M.H., Benabdallah S., Lebdi F., Milutin D.: Application of a genetic algorithm for the optimization of a complex reservoir system in Tunisia, Water Resour Manage, 2011.

- Loucks D. P. and Sigvaldason O. T.: Multiple reservoir operation in North America. In The Operation of Multiple Reservoir Systems, edited 
by Z. Kaczmarck and J. Kindler, IIASA Collab. Proc. Ser., CP-82-53, pp 1103, 1982.

- Lund, J., and Ferreira, I.: Operating rule optimization for Missouri River reservoir system. J. Water Resour. Plan. Manage, 122, 4, 287-295, 1996.

- Lund, J.R., and Guzman, J.: Developing seasonal and long-term reservoir system operation plans using HEC-PRM, Tech. Rep. No. RD40, Hydrologic Engineering Center, U.S. Army Corps of Engineers, Davis, Calif, 1996.

- Makropoulos C.K., Natsis K., Liu S., Mittas K., Butler D.: Decision support for sustainable option selection in integrated urban water management. Environ Model Software, 23, 1448-1460, 2008.

- Malekmohammadi B., Zahraie B., and Kerachian R.: Expert systems with applications, 38, 7851-7863, 2011.

- Moeini R., Afshar A. and Afshar M.H.: Fuzzy rule-based model for hydropower reservoirs operation, Int J Electr Power Energy Syst, 33, 2, 171-178, 2010.

- Mohan S. and Sivakumar S.: Development of multi-objective reservoir systems operation using DP-based neuro-fuzzy model: a case study in PAP systems, in: $4^{\text {th }}$ INWEPF Steering Meeting and Symposium, INWEPF, India, 2007.

- Molina-Cristobal A., Griffin I.A., Fleming P.J., Owens D.H.: Multiobjective Controller Design: Optimising Controller Structure with Genetic Algorithms. In Proceedings of the 2005 IFAC World Congress on Automatic Control, Prague, Czech Republic, 2005.

- Molina J.L., Farmani R. and Bromley J.: Aquifers Management through Evolutionary Bayesian Networks: The Altiplano Case Study (SE Spain), Water Resour Manage, 25, 3883-3909, 2011.

- Murugan P., Kannana S. and Baskarb S.: NSGA-II algorithm for multiobjective generation expansion planning problem, Elec Power Syst Res, 79, 622-628 2009.

- Nazif S., Karamouz M., Tabesh M. and Moridi A.: Pressure management model for urban water distribution networks, Water Resour Manage, 24, 437-458, 2010.

- Oliviera R. and Loucks D.P.: Operating rules for multiresservoir systems, Water Resour Res, 33, 4, 839-852, 1197. 
- Osman M.S., Abo-Sinna M.A., Mousa A.A.: An effective genetic algorithm approach Multiobjective Resource Allocation Problems (MORAPs), Appl Math Comput, 163, 2, 755-768, 2005.

- Raquel, C.R. and Naval, P.C.: An effective use of crowding distance in multiobjective particle swarm optimization, Proceedings of the Conference on Genetic and Evolutionary Computation, Jun. 25-29, ACM, New York, USA, 257-264, 2005.

- Reddy, M. Janga and Kumar, D.: Multiobjective differential evolution with application to reservoir system optimization, Journal of Computing in Civil Engineering, 21, 2, 136-146, 2007.

- Reed, P. and Minsker, B.S.: Striking the Balance: Long-Term Groundwater Monitoring Design for Conflicting Objectives, Journal of Water Resources Planning and Management, 130, 2, 140-149, 2004.

- Revelle, C., Joeres, E., Kirby, W.: The linear decision rule in reservoir management and design. I. Development of the stochastic model, Water Resources Research, 5, 4, 767-777, 1969.

- Safavi H.R., Darzi F., Mariño M.A.: Simulation-optimization modelling of conjunctive use of surface water and groundwater, Water Resour Manage, 24, 1965-1988, 2010.

- Sedki A., Ouazar D.: Simulation-optimization modeling for sustainable groundwater development: a moroccan coastal aquifer case study, Water Resour Manage, 2011.

- Singh, A., and Minsker, B. S.: Uncertainty-Based Multiobjective Optimization of Groundwater Remediation Design," Water Resources Research, 44, W02404, doi:10.1029/2005WR004436, 2008.

- Suen J.P. and Eheart J.W.: Reservoir management to balance ecosystem and human needs: incorporating the paradigm of the ecological flow regime, Water Resources Research, 42, 3, W03417, 2006.

- Wang, Y. C., Yoshitani, J. and Fukami, K.: Stochastic multiobjective optimization of reservoirs in parallel Hydrological Processes, 19, 35513567, 2005.

- Wurbs R.A.: Reservoir-system simulation and optimization models, J Water Resour Plan Manage, 119, 4, 455-72, 1993.

- Yeh WW-G.: Reservoir management and operations models: a stateof-the-art review, Water Resour Res, 21, 12, 1797-818, 1985.

- Yeh, W. W.-G., and Becker, L.: Multiobjective analysis of multreservoir operations. Water Resources Research, 18, 5, 1326-1336, 1982. 
- Young, G.: Finding reservoir operating rules, J. Hydraul. Div. Am. Soc. Civ. Eng., 93, 6, 297-321, 1967. 



\section{A.3. Assessment of evolutionary algorithms for optimal operating rules design in real water resource systems. $^{3}$}

Néstor Lerma ${ }^{1}$, Javier Paredes-Arquiola ${ }^{1}$, Joaquín Andreu ${ }^{1}$, Abel Solera ${ }^{1}$, Giovanni M. Sechi

${ }^{1}$ Research Institute of Water and Environmental Engineering, (IIAMA), Universitat Politècnica de València. Camino de Vera $S / N, 46022$, Valencia (Spain).nestorlerma@upv.es

${ }^{2}$ Department of Civil, Environmental and Architectural Engineering (DICAAR). Università di Cagliari. Via Marengo 2, 09131 Cagliari (Italy).

\section{Abstract}

Two evolutionary algorithms (EAs) are assessed in this paper to design optimal operating rules (ORs) for Water Resource Systems (WRS). The assessment is established through a parameter analysis of both algorithms in a theoretical case, and the methodology described in this paper is applied to a complex, real case. These two applications allow us to analyse an algorithm's properties and performance by defining ORs, how an algorithm's termination/convergence criteria affect the results and the importance of decision-makers participating in the optimisation process. The former analysis reflects the need for correctly defining the important algorithm parameters to ensure an optimal result and how the greater number of

${ }^{3}$ Lerma, N., Paredes-Arquiola, J., Andreu, J., Solera, A. and Sechi, G. M. 2015. Assessment of evolutionary algorithms for optimal operating rules design in real Water Resource Systems. Environmental Modelling \& Software, Volume 69, Pages 425-436, ISSN 1364-8152, http://dx.doi.org/10.1016/j.envsoft.2014.09.024

Elsevier offered the reuse of its content for a thesis or dissertation. 
termination conditions makes the algorithm an efficient tool for obtaining optimal ORs in less time. Finally, in the complex real case application, we discuss the participation value of decision-makers toward correctly defining the objectives and making decisions in the post-process.

Keywords: Evolutionary Algorithms, Water Resource System, Decision-Makers, AQUATOOL, SIMGES, Management, Optimisation, Operating Rules

\section{Introduction}

Over the last two decades, Evolutionary algorithms (EAs) have been applied extensively to a number of areas of water resources, such as water distribution systems (Goldberg and Kuo 1987; Savic and Walters, 1997), urban drainage and sewage systems (Guo et al. 2008), water supply and sewage treatment systems (Murthy and Vengal 2006), hydrologic and fluvial models (Muleta and Nicklow 2005) and subterranean systems (Dougherty and Marryott 1991), as highlighted in a review by Nicklow et al. (2009). However, while EAs have been applied successfully to many academic problems, additional research is required to enable them to be applied in real-life context (Maier et al., 2014). For example, there is a need to determine which searching mechanisms and termination/convergence criteria are best for real-life problems and the best way to convey the results of the optimisation process to decision makers (Maier et al., 2014). Consequently, these issues are the focus of this paper.

Simulation models are the most commonly used tool to analyse the integrated planning and management of WRS. These models allow for more detailed representations of the systems than do the optimisation models (Loucks and Sigvaldason, 1982). Moreover, the applicability of optimisation models to system management for most real reservoirs is limited due to the "high level of abstraction" needed for the efficient implementation of optimisation techniques (Akter and Simonovic, 2004; Moeni et al. 2010).

Normally, simulations of water management systems use operating rules (ORs) to model the efficient management of water resources. Designing and obtaining ORs for multi-reservoir systems is a complex task and has been 
widely developed during the scientific history of water resource studies (Young, 1967; Bhaskar and Withlach, 1980; Lund and Ferreira, 1996). On the other side, ORs must be implementable in real applications and therefore need to be robust as well as simple to be defined by a set of indicators and parameters.

A common technique used to design ORs is based upon iterative simulations of water management models. In this case, the goal is to find an OR that optimises system management. Therefore, the iterative process to find such an OR can be controlled by an optimisation algorithm that is responsible for varying the $O R$ parameters based upon the results obtained from the simulation. EAs afford several benefits compared with classical optimisation techniques because they can be implemented without heavy a-priori model requirements, and thanks to their ability to manage discrete variables, EA optimisation procedures can directly address alternatives when applied to OR optimisation. To this end, EAs present effective an optimisation algorithm for searching for optimal rules in WRSs. For example, Oliviera and Loucks (1997), and later Ahmed and Sarma (2005), presented an approach for the optimisation of ORs in multi-reservoir systems using EAs. Other cases are reported by Cai et al. (2001) to solve nonlinear models of water management using a combination of an EA and linear programming; by Momtahen and Dariane (2007), who used a direct search approach to optimize the parameters of reservoir operating policies with a EA as an optimization method; or by Elferchichi et al. (2009), who applied an EA to optimise reservoir operations in the Sinistra Ofanto (Foggia, Italy) irrigation system. Furthermore, in the literature were used another metaheuristic approaches such as Guo et al. (2013), who incorporated a multi-population mechanism into a non-dominated sorting particle swarm optimization to obtain optimal rules for a water-supply reservoir; or as in Hossain and Shafie (2014) where a nonlinear reservoir release optimization problem was resolved by comparing evolutionary methods and swarm intelligences.

The main purpose of this paper is to test EAs and scattered search approaches to design ORs that optimise WRS management. The EAs used are the SCE-UA (Duan et al. 1992) and the Scatter Search (Glover, 1997), which are combined with the SIMGES network flow simulation model to design 
optimal ORs. In addition, an analysis of the parameters of both algorithms is carried out, which allows us to determine which termination/convergence criteria are most appropriate for realistic problems, apart from showing the most influential parameters that affect the optimisation process. On the other hand, the previous analysis and the use of one of these EAs in a real complex case demonstrate which of the two studied algorithms is the best for solving this type of problem. Finally, a method of transmitting the optimisation results is presented to make the decision-making easier. To analyse the parameters, a simple theoretical model representing a fictitious WRS is used. In the application for a real complex WRS, the TirsoFlumendosa-Campidano system located on Sardinia Island (Italy) is used.

\section{Materials and Methods}

We propose a connection between EAs (SCE-UA or Scatter Search) and a traditional water allocation model (SIMGES) in the water resources field to design optimal ORs for real WRSs. The approach developed is detailed in Figure P3. 1. Decision variables, OR parameters, are defined by the user and are sought by the EA to design optimal ORs for the WRS to which it is applied. Moreover, some algorithm-specific parameters, such as population size, the number of subgroups or the maximum number of iterations should be indicated to the $E A$, apart from the decision variables, to allow optimisation. Every EA implements the optimisation process as outlined below; the EA generates several individuals (or solutions) that belong to an OR collection. In our case, each OR aptitude depends on how it affects the WRS management. For this reason, WRS management is simulated through the SIMGES network flow for each OR, and the obtained results allow the EA to evaluate the objective function (OF). Given the value for each individual (or solution) of that $\mathrm{OF}$, the algorithm obtains new values for the decision variables defining the $O R$, and the process is repeated until the stop condition for each EA is fulfilled. 


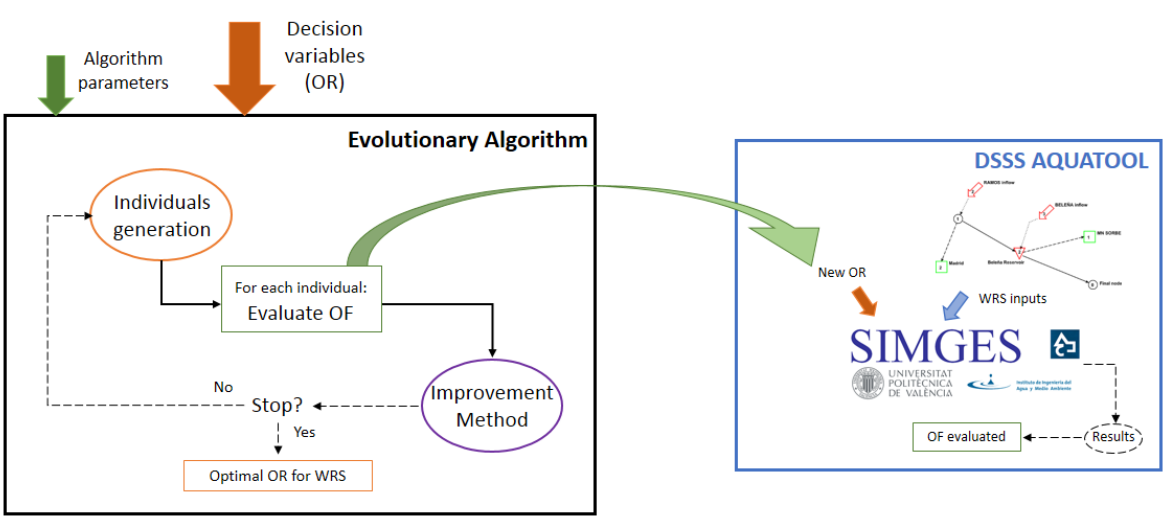

Figure P3. 1: Methodology. EA combined with the network flow SIMGES.

Both algorithms have been repeatedly used in different areas of research. The SCE-UA algorithm is implemented in this study due to its demonstrated efficiency, which has been widely recognised in calibrating hydrological problems with a large number of parameters and with a high nonlinearity (Duan et al., 1992; Luce and Cundy, 1994; Kuczera, 1997; Boyle et al., 2000). On the contrary, the use of the Scatter Search application to design OR is currently uncommon but has been successfully applied in distribution network calibration problems (Liberatore and Sechi, 2009) as well as a wide range of more general optimisation problems (Martí, 2006; Campos et al, 2001; Scheuerer and Wendolsky, 2006; Adenso-Díaz et al., 2006). However, we have chosen the second algorithm because, unlike most conventional EAs such as the SCE-UA, thanks to the adoption of search and selection techniques, the population is much smaller than when using other EAs.

\subsection{SCE-UA algorithm}

The SCE-UA optimisation mechanism (the Shuffled Complex Evolution) was developed by Duan et al. (1992) at the University of Arizona. As mentioned above, its efficiency has been successfully tested to calibrate problems of hydrological models with a large number of parameters and with a high nonlinearity. The basic operation of the SCE-UA algorithm, inspired by the principles of natural selection and genetics, is a combination of deterministic and random processes. The departing point is from different search points 
(individuals) that are organised by teams (complexes). Searching for the globally optimised solution, an evolutionary process (evolution) is designed. This process is based on different reproduction methods such as crossing, mutation or recombination, and team mixing (shuffle). An extended SCE-UA technical details can be found in Duan et al. (1992).

\subsection{Scatter Search algorithm}

The Scatter Search algorithm (Glover, 1997) is a metaheuristic procedure based upon formulations of strategies for generating candidate solutions, and thanks to the adoption of search and selection techniques, the point population used is much smaller than is necessary for other techniques. The concepts and principles of this method are based on the strategy of combining decision rules. The Scatter Search operates on a set of solutions, called the Reference Set, and combines them to create new solutions that improve the original ones. In this sense, the Scatter Search should be considered as an EA. However, contrary to other evolutionary methods, such as genetic algorithms, the Scatter Search algorithm is not based upon randomness over a relatively large group of solutions but is based upon systematic and strategic choices over a small group. Typically, genetic algorithms consider large population sizes (100 solutions as an order of magnitude), whereas the Scatter Search utilises an equivalent set of only 10 solutions.

It is worth noting that the Reference Set retains the "good" solutions, but the meaning of good is not restricted to the quality of the solution; the diversity given to the Reference Set is also taken into account. The optimisation path is guided by the gradual inflow of data on the admissible solutions level and in its neighbourhood. Indeed, Scatter Search can acquire information both from the points "visited" and from those generated separately through flexible management of the problem's data set.

One of the most interesting characteristics of the Scatter Search is that it integrates the combination of solutions with the local search. This local search can contain a memory structure, although it is not needed. In most cases, it is simply implementing a conventional local search. 
Figure P3. 2 shows the baseline method diagram. The detailed process that is followed by the Scatter Search starts with the generation of a collection $P$ of several solutions. This group of solutions is improved through local search, although if the obtained solution does not improve the results, the initial solution is maintained. Once group $P$ is generated and improved, the Reference Set is applied, following given criteria, including the quality of the solutions and how different they are to each other (quality and diversity). The Reference Set solutions are evaluated and ordered from best to worst with respect to the fitness values.

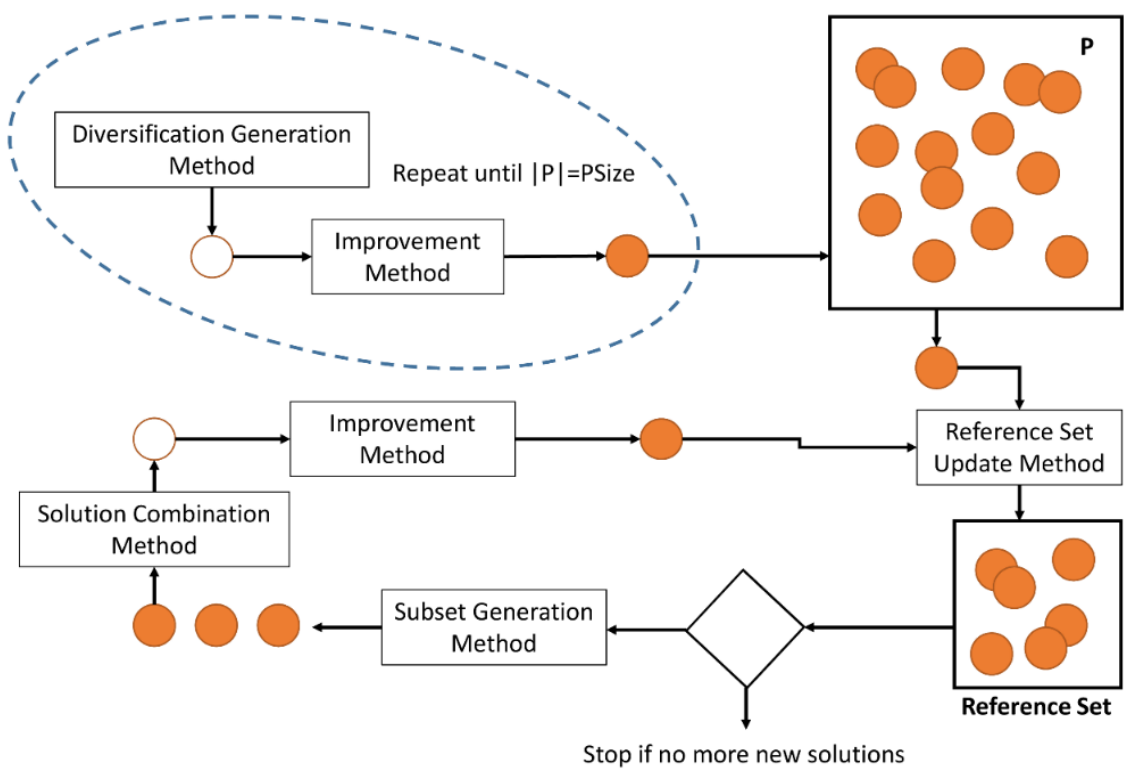

Figure P3. 2: Flowchart of Scatter Search algorithm (Adaptation of Martí and Laguna, 2003).

The Reference Set is divided into subgroups. A simple method to generate these subgroups consists of creating all couples that can be formed with the elements of the Reference Set, but these subgroups can be formed by threeperson groups or by any other solution sizes. Once these subgroups are designed, the solutions are combined to find new solutions. These new solutions are obtained from combinations that can be either immediately introduced to the Reference Set (dynamic actualisation), or temporarily stored in a list until all the combinations are formed to analyse which 
solutions are finally chosen for that Set (static actualisation). Note that the algorithm stops when it attempts to combine solutions, and the Reference Set is empty.

\subsection{Water allocation model}

To design an optimal OR, we combined EAs with the water allocation model SIMGES (Andreu et al., 1996), which is responsible for evaluating the management of WRS. SIMGES is a module of the Decision Support System Shell (DSSS) AQUATOOL (Andreu et al., 1996). The DSSS AQUATOOL includes different modules, apart from SIMGES, for evaluating the water quality of water bodies and for evaluating probabilities for drought analysis and drought risk assessment. This DSSS and its SIMGES model have both been extensively used for water basins in Spain (Júcar, Segura, Tajo, etc.) (CHJ, 1998; MIMAM, 2004; Andreu et al., 1996) and in other countries (e.g., Argentina, Chile, Brazil, Italy, Bosnia, Cyprus, Algeria). Generally, a DSSS facilitates the negotiation of socially conflicting decisions by users and stakeholders (as the implementation of environmental flows) and helps decision-makers in their task.

The SIMGES model transforms the WRS into an internal network flow optimisation problem that is solved for every time step (step-by-step) to find a flow solution compatible with the physical constraints, system priorities and other management constraints. An OF is used to solve this network flow, evaluated as a sum of different terms that depend on the type of element (reservoir, demand, arcs, etc.). A simplified OF example $\left(F_{r d}\right)$, for the case of reservoirs and demands, is shown in Equation 1. $F_{r d}$ is minimised to optimise the water allocation problem.

$$
F_{r d}=\sum_{i=1}^{R}\left(\sum_{j=1}^{L}\left(V_{j, i}\left(C_{j}+P R_{i}\right)\right)+S p_{i} C_{s p}\right)+\sum_{k=1}^{D} D D_{k}\left(C_{D D}+P D_{k}\right)
$$

where $R$ is the number of reservoirs in the network flow, $V_{j, i}$ is the volume at level $j$ for reservoir $I, L$ is the number of levels in a reservoir, $C_{j}$ is the benefit/cost of water storage at level $j$ and $P R_{i}$ is the priority number for reservoir $i$. The last part of the reservoir term is defined by $S p_{i}$, which is the 
probability of a spill to the reservoir $i$, and $C_{s p}$, which is the cost of spills to the reservoirs. The second term of $F_{r d}$ is associated with demands. $D$ is the total number of demands, and $D D_{k}$ is the deficit of demand $k$. The cost associated with the deficits of demand is $C_{D D}$, and $P D_{k}$ is the priority of demand $k$. Eq. 1 is composed of costs (set by default and previously calibrated) and priorities that the user can change.

Furthermore, the SIMGES model allows a user to define ORs to model decision-making based upon specific indicators. Examples of some of these indicators are the stored volume in one or more reservoirs and the accumulated in-stream flow during several months at one or more points within the system. The application of these ORs includes the restriction to a certain percentage of one or more demands, environmental flow or the pumping system. This type of $O R$ is used to anticipate droughts to avoid dramatic failures of the WRS.

\subsection{Optimization problem's statement}

The optimization problem carried out in this paper to obtain optimal operating rules involves different statements like the EA's parameters, the OR to optimise, the OF or the problem restrictions.

Both algorithms analysed in this manuscript have several parameters that affect the performance of the optimization process, and for each algorithm, these parameters are analysed in section 3. Moreover, the aim of the optimization is to find an optimal OR, which is defined by some parameters such as the volume stored in a reservoir or the restriction coefficient to supply more or less amount of water to a demand. Depending on the case analysed (theoretical - section 3 or real - section 4) the OR may be defined with different amounts of parameters. The OR's parameters are the decision variables of the EA and they will be defined in the appropriate section.

Furthermore, the algorithms use an OF to optimise the problem. Scatter Search and SCE-UA are single-objective algorithms. For this reason, in the real case studied in the document, the OF is a combination of several objectives. 
The main objectives will be related, for each case, to the demands (deficits) or to the pumping system (economic cost).

In addition, WRS usually have legal restrictions such as reliability criteria of the demands or economic bounds. These type of restriction are considered in the theoretical and real cases.

\section{Parameter analysis}

In this section, an analysis of the aforementioned EA is carried out. This analysis studies the influence of the SCE-UA and the Scatter Search parameters when used as a tool to design optimal ORs in WRS. According to Duan et al., (1994), the effectiveness and efficiency of an algorithm are influenced by the choice of the algorithmic parameters. Typically, these algorithms have a higher or lower number of parameters and provide a certain flexibility, i.e., these parameters determine the algorithm performance and allow the user to decide how the algorithms should work. Examples of these parameters are aspects related to the stopping criteria of the optimisation process (maximum number of iterations, variation percentage of the OF or the decision variables, etc.), population size, number and size of the subgroups in which the population is divided to evolve, seed for the calculation of random numbers, etc.

This analysis aims to determine which parameters are the most influential ones to the OR optimisation process. This will allow us to identify which parameters should be specially treated when defining them in new optimisation processes, and eventually, it will enable us to conduct several optimisation processes by modifying those parameters for the specific problem to obtain optimal results.

To this end, a group of optimisations (OPT) is carried out, modifying parameters in each group. Each optimisation is implemented following the methodology described in the previous section. A fairly simple WRS has been used, which is likely a naïve simplification of reality. This system is modelled through SIMGES and is composed of a reservoir, two demands and two inflows to the system (Figure P3. 3). The demand with greater priority 
(demand 1) and, therefore, the one that should be supplied first, is the one located downstream of reservoir 1 . Given the system conditions, it is not possible to supply both demands completely; however, it is possible to supply enough for demand 1 at the expense of not providing any water to the other demand (demand 2) during some time period. This result is typically unacceptable; thus, we look for an $O R$ in which the imposed reliability level for demand 1 is assured while maintaining the maximum possible volume of water supplied to demand 2 , as the system allows. In general, for this type of problem, the OF is defined to minimise the deficit of the demands or to maximise the water supplied to them. For this simple case, it is assumed that the supply to demand 1 meets the vulnerability criterion if the maximum annual deficit does not reach $50 \%$ of the target annual assignment.

\section{Restriction:}

Maximum Annual Deficit (\%)

$$
\leq 50 \% \text { Target Annual Assignment }
$$

To obtain this water allocation, an OR is defined in the system for the stored volume in the reservoir. If the stored volume in the reservoir is above a certain threshold (to be optimised), a certain percentage (to be optimised) of the assignment of demand 2 is supplied. Therefore, a simple OR is considered for this analysis and is defined using two parameters (EA decision variables).

OR (decision variables):

$$
\text { DV1 }=\text { Threshold of the Stored Volume (Reservoir 1) (Eq. 3) }
$$

$$
\text { DV2 = Restriction coefficient: Assignment percentage (Demand 2) (Eq. 4) }
$$




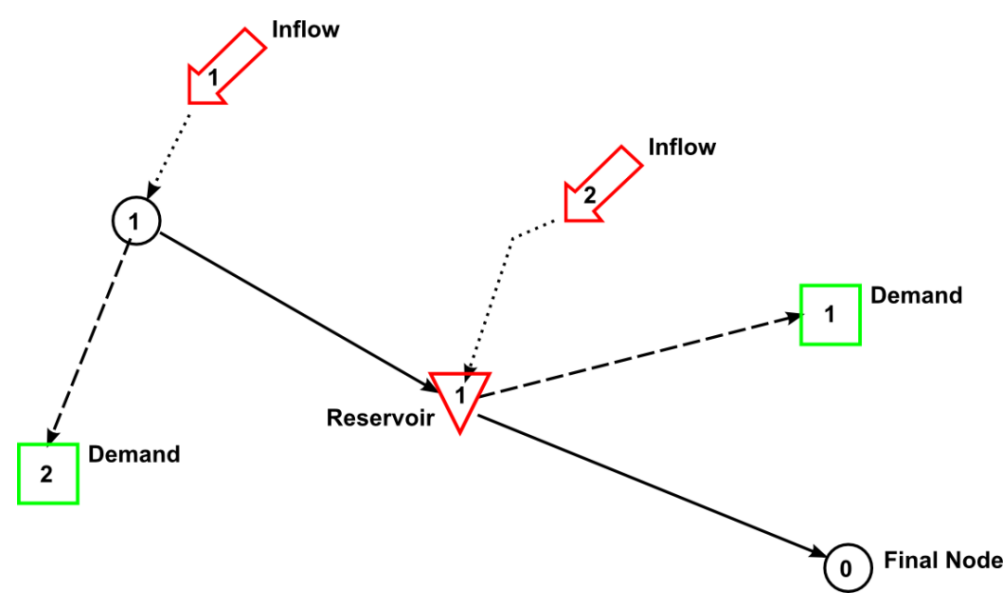

Figure P3. 3: Diagram of the example used for the analysis of the algorithms.

Once this simple example and the purpose for analysis are explained, we will discuss how the EA must maximise the resources supplied to demand 2 . With this intention, an OF is defined and evaluated using the following expression, as long as the vulnerability criterion for demand 1 is assured:

$$
O F=\frac{\text { Annual average supply of Demand } 2}{\text { Annual assignment of Demand } 2}
$$

The best value for this OF term (Eq. 5) is 1 , when demand 2 is completely supplied, and 0 is the worst value, representing the case in which no water resources are supplied to demand 2 .

\subsection{The SCE-UA parameter analysis}

The basic parameters that the SCE-UA optimisation process depends upon are specified in Table P3. 1. The maximum number of OF evaluations (MAXN), as will be seen in the several optimisations carried out, has not been necessary to modify its value, at least in the simple system used for this analysis. In complex optimisations requiring a high number of decision variables, there will be a need for a large number of iterations and thus a 
large number of evaluations of the OF as well. In these cases, it is advisable to adjust the MAXN to limit the maximum algorithm process time. The influence of the other five parameters is not trivial, which is why they were also analysed.

This analysis is formed using five groups of optimisations, one for each parameter in Table P3. 1 (except for MAXN, as previously mentioned). In the first group, 12 optimisations have been carried out in which the NGS parameter has been modified. This NGS has been the first parameter in the analysis because, a priori, it seems to affect the obtained result the most. In the second and subsequent groups, KSTOP, PCENTO, ISEED and IFLAG have been modified.

\begin{tabular}{|l|c|c|}
\hline Description & Parameter & Initial Values \\
\hline Maximum number of function evaluation & MAXN & 10000 \\
\hline $\begin{array}{l}\text { Number of shuffling loops in which the } \\
\text { criterion value must change by PECNTO } \\
\text { before optimisation is terminated }\end{array}$ & KSTOP & 10 \\
\hline $\begin{array}{l}\text { Percentage by which the criterion value must } \\
\text { change in KSTOP shuffling loops }\end{array}$ & PECNTO & 0.1 \\
\hline Number of complexes (sub-populations) & NGS & 3 \\
\hline Random number & ISEED & 123456 \\
\hline Considering initial parameters & IFLAG & 1 \\
\hline
\end{tabular}

Table P3. 1: Parameter description and initial values considered in the SCE-UA analysis.

In the first group of optimisations, some parameter values are defined (Table P3. 1), based upon several simulations that have been performed with the SCE-UA algorithm for the calibration of different types of parameters.

Table A1.1 summarises all the optimisation processes carried out in the SCEUA analysis, showing the value of each parameter, the number of OF evaluations reached in each trial (EVALS) and the OF value.

The numbers of subgroups (NGS) in which the SCE-UA sample is divided to find new improved individual in the first OPT are 1-10, 15 and 20. A great number of possibilities have been analysed, focusing on divisions below 10 NGS, and two higher NGS values are subsequently tested. Figure P3. 4a shows the evolution of EVALS and the OF according to the NGS. If we consider 
first EVALS obtained, an increasing trend is observed when the NGS increases. For sizes smaller than 10 NGS, EVALS is below 1500; for sizes larger than 10 NGS, this number substantially increases, reaching more than 3000 OF evaluations. However, in the first $10 \mathrm{OPT}$, the evolution is not completely linear; for example, a lower EVALS is obtained with 6 NGS than with 5 NGS.

EVALS alone does not allow us to correctly analyse the algorithm because it does not show us how optimal the identified solution is in reality. For that reason, the figure also shows the OF value, which represents the fitness reached in each OPT. It is worth noting that the range of OF values is quite narrow (Figure P3. 4a), between 0.537 and 0.539, which means that different OPT could reach quite similar results. Similarly, as often occurs with the evolution of EVALS, the OF does not follow a linear, positive trend. It is observed that the OF value is lowest when NGS=1 (not shown in Figure P3. 4 a because it requires an OF value of 0.534 ), 2, or even 4 . For values above 5 NGS, the OF values obtained are higher and thus represent better solutions. The optimal result of this group of OPT is obtained with an NGS=7, requiring nearly 1500 evaluations and resulting in an OF value of 0.5385 .

With this solution, the KSTOP parameter is analysed. This parameter has been modified using the following values: 2, 5, 10 (GROUP=1), 15 and 20 . Figure P3. 4b shows the results obtained. In this figure, an increasing trend of EVALS is observed when KSTOP increases. This is normal because a hard stop criterion is defined for the algorithm. For the KSTOP value that is double the value analysed in GROUP $=1$ (that is, $K S T O P=20$ ), the EVALS required is lower than double that required for a KSTOP=10, which shows that it does not follow a completely linear evolution. For the lowest values of KSTOP, the increase for EVALS is greater than the increase for higher KSTOP values. Regarding the OF values reached, for KSTOP values lower than 10, the OF value was below 0.538 ; however, for KSTOP, the values of 10,15 and 20 resulted in the same OF value (0.5385).

With the same parameters as in OPT $=7$, the PCENTO parameter is analysed. In this OPT group, the values adopted for PCENTO were 0.05, 0.1 (GROUP=1), 0.2 and 0.5 . Figure P3. $4 \mathrm{C}$ shows the results for this parameter. Contrary to the two previous parameters analysed, when the PCENTO value increases 
(the term condition is less restrictive), EVALS is reduced along with the OF value. For values of 0.05 and 0.1 for PCENTO, the same result is reached, both for EVALS and the OF value. Similarly, for the values of 0.2 and 0.5 , the OF reaches the same value, and EVALS is nearly the same; however, because the algorithm ends earlier, the results are worse than in the other case.
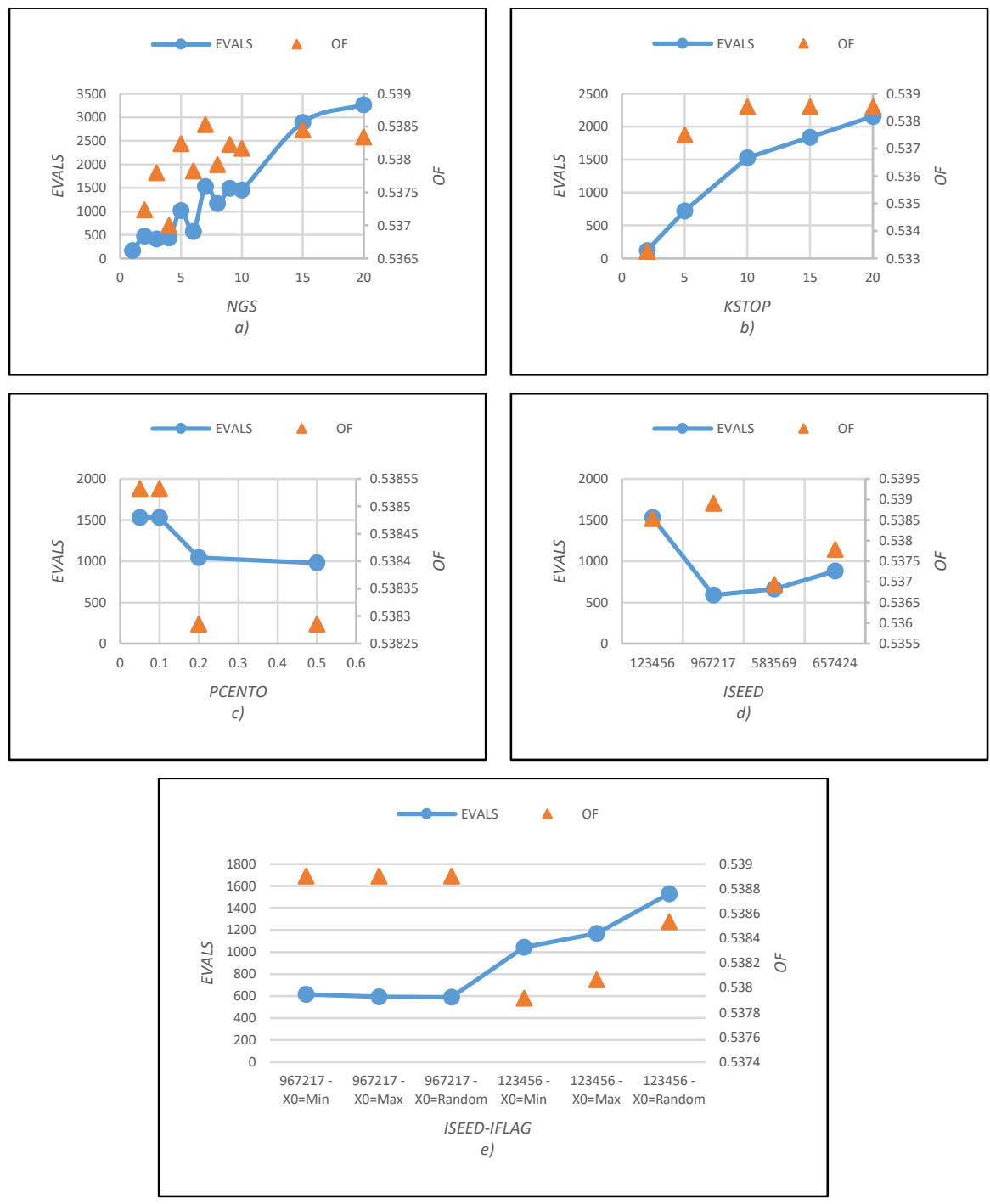

Figure P3. 4: Performed test with SCE-UA algorithm. 
The next parameter studied is the ISEED, which is related to the random number generation upon which the algorithm is based. Apart from the ISEED analysed in GROUP=1 (123456), three others have been considered, as shown in Figure P3. 4d. The ISEED affects the obtained results without a clear criterion, i.e., there are ISEEDs with high OF values and high EVALS; others with low values for both of them; and still others with high OF values and low values of EVALS (the best scenario). In these OPT, the optimal result is reached with a seed of 967217, an OF value of 0.5389 and 589 OF evaluations.

The last parameter analysed is IFLAG, which allows the user to consider initial values (XO) or random values for the decision variables. For this group of OPT, the ISEED of GROUP=1 has been used, and the ISEED with the best result originates from GROUP $=4$. The minimum, the maximum or a random value for each decision variable have been considered as the initial value for both ISEED parameters. Figure P3. 4e shows how the initial values affect the result, depending upon the ISEED. In the case with the best results for ISEED (GROUP=4), the initial value does not affect the result, and in all cases, the same EVALS and OF value are returned. By contrast, with the ISEED from $G R O U P=1$, for which random initial values and a higher EVALS are required (compared to the minimum or maximum initial values), higher values of the OF are obtained.

\subsection{The Scatter Search parameter analysis}

The difference for SCE-UA is that the Scatter Search only needs to define (in the basic configuration) the size of the population (SIZEPOP), Reference Set (REFSET), and number of iterations (ITER).

For this algorithm and in the WRS field, we do not have initial values from experience, and only the explanation in section 2.2 is considered, where it is discussed that this algorithm often works with a small SIZEPOP, typically of 10 individuals, and a small value for the REFSET.

In contrast of the SCE-UA algorithm analysis, and for the reasons mentioned above, a higher number of optimisations have been conducted for this 
algorithm to analyse its parameters (see Table A1.2). Nevertheless, they have been collected in 4 GROUPS, depending on SIZEPOP. In the first group, a value of 5 is adopted, and the size of REFSET and ITER vary. Figure P3. 5a shows EVALS and the OF value reached in each OPT. On the one hand, it is observed that EVALS increases as the ITER parameter increases for three REFSET sizes (1, 2 and 5). These values for REFSET have been chosen because they were lower than the value for SIZEPOP, and in an extreme case, they have the same value. For the three values of REFSET, it is observed that EVALS increases, which is even more important for the REFSET $=5$ case. Note that in those OPT, a very high EVALS (more than 5000) is needed to reach the stopping point for the algorithm, except in the case of ITER=1, in which the algorithm ends with 164 OF evaluations without finding any valid solution. For REFSET values of 1 and 2, the trend is almost the same, reaching the requirement of more than 8000 OF evaluations in the case where ITER=50. However, for ITER values below 20, this number is reduced to less than 3300 OF evaluations, with nearly 1600 evaluations for ITER $=10$ and almost half that value for ITER=5. Figure P3. $5 \mathrm{a}$ also shows the OF values, which are between 0.52 and 0.537. It is worth noting that for REFSET=5, in which a high EVALS value was required, the OF result is worse than that obtained with REFSET equal to 1 and 2 . The best result $(\mathrm{OF}=0.5367)$ was obtained with $\mathrm{REFSET}=1$ and 10 ITER (or more).

The second GROUP of OPT has been carried out with SIZEPOP $=10$. In this case, the initial values of REFSET have been kept, to see if they are affected by the increasing of SIZEPOP.

Figure P3. 5b and Figure P3. 5a are similar in regard to EVALS. For values of 1 and 2 for REFSET, the trend is almost the same in either case, reaching more than 10000 OF evaluations for a value of ITER=50. Moreover, for REFSET=5, the increase in EVALS is larger, although slightly lower than that for SIZEPOP $=5$. However, the OF value does not similarly evolve, in this group of OPT; for REFSET=1, the solutions obtained are less optimal than those for the other two values, which obtained almost identical values for the OF (0.5378) using values for ITER greater than 5 . 

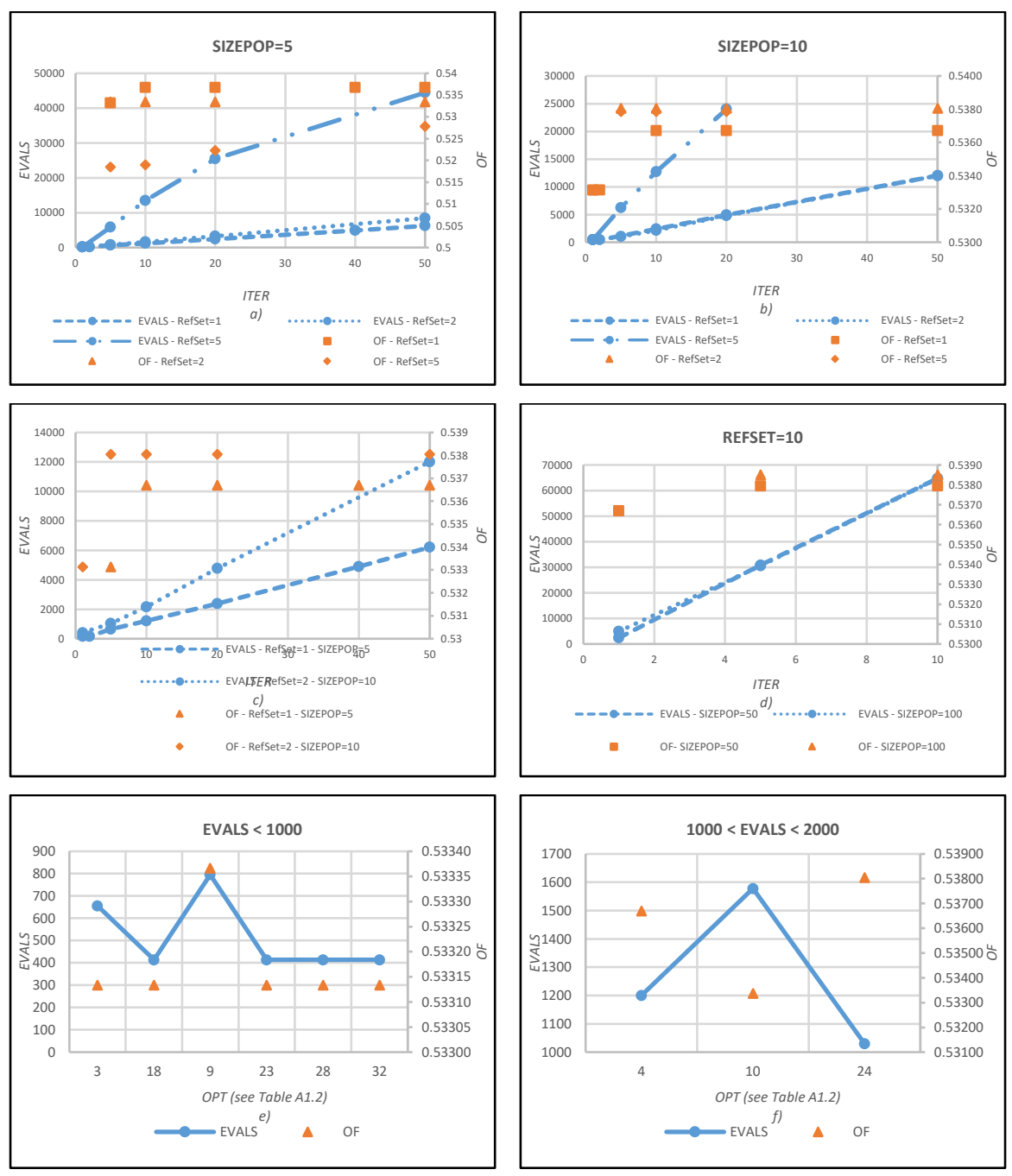

Figure P3. 5: Performed test with Scatter Search algorithm.

To summarise these two groups of OPT, Figure P3. $5 \mathrm{c}$ shows the most optimal solutions of each GROUP. For the first group, SIZEPOP $=5$ and REFSET $=1$ were used, and for the second group, SIZEPOP=10 and REFSET=2. It is clear to see that the proportion SIZEPOP/REFSET is maintained. Considering both solutions, SIZEPOP $=10$ is the one with the best value for OF but requires a higher EVALS value. The optimal solution is obtained with SIZEPOP=10, 
REFSET $=2$ and 5 ITER, requiring 1030 OF evaluations and reaching an OF value of 0.5380 .

Subsequently, we analysed the Scatter Search behaviour for higher values of SIZEPOP, specifically sizes of 50 and 100 . In both cases, a value of 10 has been chosen for REFSET size, a lower value than SIZEPOP to maintain the proportion of SIZEPOP to REFSET that was used in previous OPTs. The result shown in Figure P3. 5d reflects the need for a very high EVALS value (from 2377 to more than 64000). With the lowest EVALS value, an OF value of 0.5367 is reached, which is a worse result than that generated through a previous analysis. An OF value of 0.5385 is obtained only for EVALS values higher than 30000 OF evaluations (the highest registered value in the Scatter Search analysis).

With the Scatter Search study, we check to see if higher values of EVALS are reached in many OPT, which is not desirable because it is related to a higher computation time. To compare to the ranges of EVALS obtained with the SCEUA, Figures $5 e$ and $5 f$ show some OPT conducted with the Scatter Search. Figure P3. 5e shows 6 OPT with fewer than 1000 OF evaluations, with OF values lower than 0.5334 . Figure P3. $5 f$ shows 3 OPT requiring between 1000 and 2000 OF evaluations. In those cases, an OF value of 0.538 is reached, with 1030 OF evaluations, although this is worse than the best result of the SCE-UA (0.5389).

\subsection{Discussion}

The assessment of both algorithms yields some conclusions about the parameters, the stop condition of the algorithm, and which algorithm obtained the best results in this simple case study. Zielinski et al. (2005) provide six convergence/termination criteria for EAs. These EAs use some of these criteria, the SCE-UA uses three of them, and the Scatter Search uses only one.

In the SCE-UA, six parameters have been studied, although MAXN has not been used in the analysis because it was not limiting for the example, as mentioned above. From the other five parameters, two of them affect the 
stopping criteria (KSTOP and PCENTO), one affects the improvements of individuals (NGS), and the last two (ISEED and IFLAG) condition the initial values for the decision variables and generate new values as the individuals evolve.

On the one hand, the NGS parameter has an influence on EVALS and thus on the optimisation time, and on the other hand, it affects the obtained result in certain ways. The results obtained in section 3.1 show that it is not convenient to choose either a low or a high value for NGS in the first case because of worse values for OF and in the second because EVALS increases. Therefore, NGS values between 3 and 8 would be appropriate.

Parameters affecting the convergence/termination criteria (KSTOP and PCENTO) are important. Choosing an incorrect value can make the algorithm end before it is convenient, and sub-optimal results will thus be reached, or, on the contrary, more time will be taken to complete the algorithms than is strictly needed to reach the optimal solution. In the former case, if some slack is introduced to the stop criteria, the process can finish in a shorter time, but it will not be certain if the result is a globally optimised value. However, in the latter case, EVALS will increase because it is quite strict in the termination condition of the SCE-UA, using a higher computation time than would be necessary if these parameters were appropriately defined. PCENTO is the most influential parameter.

Regarding ISEED and IFLAG, they have a certain random nature. A priori, better or worse results can be obtained depending upon the practical case and this randomness.

A more rigorous method has been developed to corroborate the two previous analysis. This method is the ANOVA statistical analysis, which enables us to know the statistical significance of the parameters analysed. The tables below (Table P3. 2 and Table P3. 3) show the results of this analysis, identifying the statistical significance of each parameter analysed (independent variables) versus EVALS and OF value (dependent variables). Low values of this significance indicates a higher probability that the 
dependent variable values (EVALS or OF) are modified when the value of the parameter analysed is changed.

With this aim, SCEUA algorithm has been used in a larger sample than in the previous section, with a total of 180 OPT (which includes OPTs of Table A1.1).

\begin{tabular}{lrllll} 
& EVALS & OF & \\
\hline KSTOP & 0.000 & $* * *$ & 0.011 & $* *$ \\
\hline PCENTO & 0.097 & $*$ & 0.767 & \\
NGS & 0.000 & $* * *$ & 0.000 & $* * *$ \\
ISEED & 0.331 & 0.003 & $* * *$
\end{tabular}

Table P3. 2: Parameter significance of the SCE-UA algorithm. ANOVA results.

Statistical significance displayed in Table P3. 2 shows how the parameters affect in the obtaining process of optimal solutions. KSTOP and NGS are the two parameters most significant, therefore if these parameters are modified the EVALS and OF value will be changed. Similarly, ISEED is statistically significant in OF value. However, the analysis indicates that the variation of PCENTO does not influence much as the previous ones. In contrast to the foregoing analysis (section 3.1), ISEED does not affect to EVALS, maybe due to the ANOVA performed here ignores the interaction between parameters.

In the Scatter Search algorithm, three parameters were analysed, each affecting EVALS in some way and thus affecting the computation time. Increasing the knowledge about this algorithm, the trials that have been carried out have demonstrated that the algorithm is not efficient for higher SIZEPOP values (more than 20 solutions) because a high EVLAS is required, obtaining similar results as when lower population sizes are used (10 or fewer solutions).

The REFSET parameter, for which the size is lower than SIZEPOP, is quite influential in optimised solutions. Considering SIZEPOP values less than or equal to 10 , it is observed that low values of REFSET are most appropriate because, for different SIZEPOP values, optimal solutions are reached with a lower EVALS than in the case of higher REFSET values (as an example, REFSET=5). 
Finally, for ITER values near 10 but lower than 20, the results obtained are reached with low EVALS values and optimal values for OF. This last parameter controls the stop condition of the algorithm. Given the results obtained with the Scatter Search and as Bhandari et al. (2012) have suggested, the statistical variance of the values of the best fitness should be considered as a termination criterion.

The same ANOVA analysis developed with SCE-UA algorithm has been done with Scatter Search algorithm. In this case, the sample used is equal to the analysis carried out in section 3.2.

\begin{tabular}{lrllll} 
& EVALS & OF & \\
\hline REFSET & 0.001 & $* * *$ & 0.004 & $* * *$ \\
SIZEPOP & 0.018 & $* *$ & 0.006 & $* * *$ \\
ITER & 0.402 & & 0.999 &
\end{tabular}

Table P3. 3: Parameter significance of the Scatter Search algorithm. ANOVA results.

Table P3. 3 shows the statistical significance of Scatter Search parameters versus EVALS and OF value. REFSET and SIZEPOP are the most significant parameters that affect to the two dependent variables. This ANOVA analysis indicates how ITER is not significant unlike the descriptive analysis in section 3.2 (maybe for the same reason that ISEED in the SCE-UA statistical analysis).

It should be noted that in the analysis performed in sections 3.1 and 3.2, we have focused on the OF values and have looked for those results whereby OF was improved to the largest number of significant figures (up to the fourth decimal). Nevertheless, those OF values are related to the supply of demand 2, as seen in section 3. If we take 0.538 and 0.5389 as an example of OF values, the annual supply for demand 2 is $77.472 \mathrm{Mm}^{3} /$ year and 77.6016 $\mathrm{Mm}^{3} /$ year, respectively. It can be observed that the difference is not very significant. This fact can be even more important in greater assignment demands, or in other problems with more complex OF, and depends on more variables.

Given this statement and considering the results of this analysis, it can be said that all the results are within the optimal range. This does not 
underestimate the analysis because these differences in the OF can be important in other problems, and, moreover, the conclusions obtained regarding the convergence/termination criteria of the algorithm and EVALS used in analysis are valid for any problem.

Comparing the results of the SCE-UA and the Scatter Search, the latter typically uses a higher EVALS than the former. Moreover, the SCE-UA obtains more optimal values of OF (inside the range considered to be optimal); nevertheless, the Scatter Search approach makes it flexible and able to provide excellent quality solutions, even when there are fewer parameters to vary for the global optimisation. Both algorithms allow the user to obtain optimal ORs combined with network flow SIMGES, noting that the SCE-UA is more efficient. Therefore, decision-makers could rely on both algorithms to determine the best management for the WRS.

\section{Application real case: Tirso-Flumendosa-Campidano}

This section has three objectives: first, to demonstrate the usefulness of both EAs analysed in designing ORs for real WRSs; second, to determine which algorithm is better; and finally, to analyse the influence of decision-makers upon the optimisation pre-process and post-process (using an analysis of the results).

The proposed methodology in section 2 is applied to the Tirso-FlumendosaCampidano system located on the island of Sardinia (Italy). The system has a Mediterranean climate and is characterised by irregular distributions of water resources in time and space and by an irregular distribution of demand in time. All these factors suggest that the system can be considered one of the most complex systems to manage in the region. The average hydrological inflow of water resources to the system is approximately $750 \mathrm{hm}^{3} /$ year. Furthermore, the total system demand is $383.25 \mathrm{hm}^{3} /$ year. The water supply system is mainly characterised by the use of surface water that is stored and regulated by the reservoir. Groundwater is used only for small localised requirements. Figure P3. 6 shows the complexity of the Tirso-FlumendosaCampidano system, with 23 reservoirs, 14 diversion dams, 23 pumps and 44 demands. The main problem of the system is to carry water from areas with 
a high volume of resources to those with less availability. For this reason, the system has many pumping systems and pipelines that facilitate transport of the water to areas that need it, with a consequent economic cost. An important goal is to minimise the management cost of such pumping systems, while meeting as much of the demand as possible.

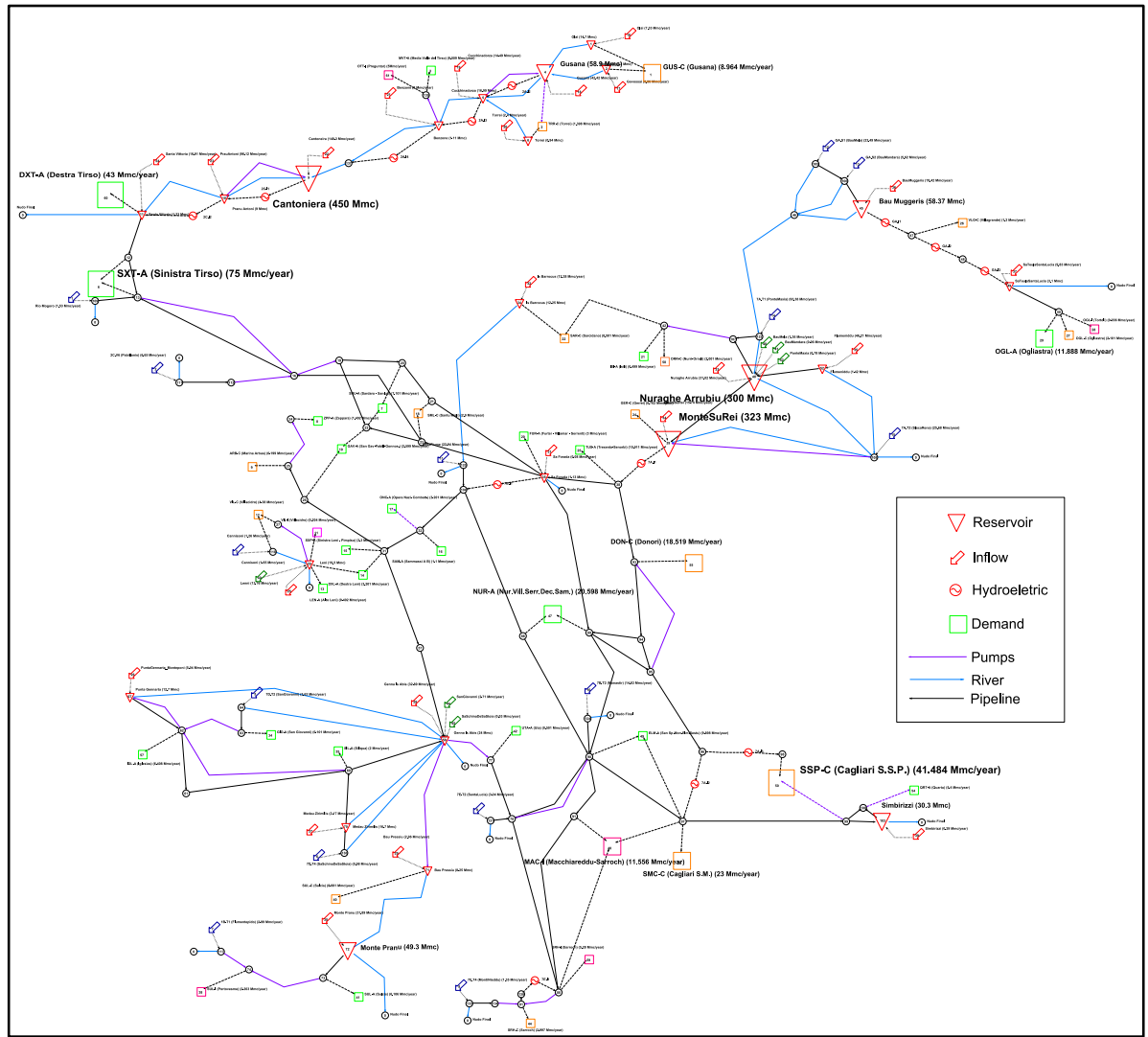

Figure P3. 6: Schematic of Tirso-Flumendosa-Campidano system for SIMGES model.

The Water Management Authority of Sardinia (ENAS) advised the building of the Tirso-Flumendosa-Campidano model. Once the simulation model of the management system was developed with SIMGES, the analysis was conducted, the most representative results of which are shown in Table P3. 4. The results included in this table are the annual maximum deficit, the number of demands with a deficit and the total cost of operating the 
pumping system. These three aspects are considered in the OR optimisation process, given recommendations from ENAS. This demonstrates the participation of decision-makers in the optimisation pre-process because for ENAS, the priority is two-fold: to reduce the pumping costs and to reduce the demand deficits, which are both given the same level of importance.

a)

\begin{tabular}{|c|c|}
\hline Number of demands with deficits & 4 \\
\hline Average annual cost of pumping & $3,675,330.24 €$ \\
\hline
\end{tabular}

b)

\begin{tabular}{|c|c|}
\hline Demand & Maximum annual deficit \\
\hline GIO-A & $86 \%$ \\
\hline GUS-C & $47.04 \%$ \\
\hline LEN-A & $80.2 \%$ \\
\hline IGL-A & $2.9 \%$ \\
\hline
\end{tabular}

Table P3. 4: Results of the current management system for the case study.

Four demands in the system suffer deficits (Table P3. 4a), and one of them is an urban demand (GUS-C). The reason for this demand to suffer deficits is due to its location (in the upper sub-basins) and the lack of hydrological contributions in that area. These circumstances cause that demand to have two periods of several months in which it is not supplied with $100 \%$ of its water requirements. All other demands with deficits are agrarian demands. The average annual cost of pumping is $3,675,330.24 €$, which is calculated using the volume pumped for each pumping system and their unit operating cost, all on an annual basis.

Departing from defined system management protocols, an optimisation problem is proposed to improve it, where the OF (Eq. 6) minimises the weighted sum of the maximum annual deficit, number of demands with a 
deficit and pumping costs. The goal of the optimisation for this case study is to design ORs that obtain the least number of demands with a deficit and, at the same time, the lowest possible value for their maximum annual deficit. On the one hand, this approach is expected to affect the least number of users, considering user priority (urban demands have the highest priority). In contrast, when deficits occur, they are less damaging if they are distributed over a number of years than if significant deficits occur in any single year. Furthermore, the Tirso-Flumendosa-Campidano system has a complex infrastructure consisting of pipelines and pumping systems. The latter have a strong influence on management due to the significant economic costs of pumping. Because of this, the lowest pumping rate is also required to reduce the economic costs of higher operating rates for this pumping system. The problem with these two goals is that typically, in this type of system, the reduction in supply deficit for demands implies an increase in net pumping and, hence, the WRS operating cost. Therefore, the defined OF tries to minimise both quantities for optimal management.

$$
\begin{gathered}
O F=\left(0.3 * N D C D * C_{N D}+0.2 * \frac{\sum D M A}{N D C D} * C_{D M A}\right)+0.5 * \sum C B \\
* C_{C B} \quad(E q .6)
\end{gathered}
$$

NDCD is the number of deficit demands, and $\mathrm{C}_{\mathrm{ND}}$ is a coefficient that makes the term NDCD ${ }^{*} C_{N D}$ be between 0 and 1 . However, it also takes into account the type of deficit demands. In the case where more than one urban demand suffers a deficit (Eq. 7), the term NDCD ${ }^{*} C_{N D}$ has a value of 1000 . This implies that any solution where more than one urban demand suffers a deficit is not acceptable. DMA is the maximum annual deficit of each demand, and $C_{D M A}$ is a similar coefficient to $C_{\mathrm{ND}}$. In this case, it takes into account the vulnerability criteria (MARMA, 2008) used in Spain to verify the compliance of agrarian demands (Eq. 8-10). These criteria are based on the establishment of maximum limits for deficits that may occur over a given time period. Specifically, the time periods considered are 1, 2 and 10 years, and the threshold compliance rates for these periods are $50 \%, 75 \%$, and $100 \%$ of the annual demand, respectively. In this way, the supply to the demand is considered "satisfactory" as long as the maximum annual deficit of the simulated series is less than $50 \%$ of the annual demand, the maximum deficit 
of two consecutive years is less than $75 \%$ of the annual demand, and the maximum deficit of 10 consecutive years is less than $100 \%$ of the annual demand. The last term of Eq. 3 takes into account the economic costs of the pumping systems $(C B)$. The $\mathrm{C}_{C B}$ term is another coefficient that normalises the term $\mathrm{CB}{ }^{*} \mathrm{C}_{\mathrm{CB}}$, and only for cases where the pumping cost exceeds a certain value (considered to be the upper limit) (Eq. 11); this term takes a value of 1000 , designating any solutions above this upper cost limit to be unfeasible. Final values of OF will be between 0 (best solutions) and 1 (worse solutions), but as explained before, it can also take the value of 1000 , indicating undesirable solutions.

\section{Restrictions:}

Deficit in Urban Demands $\leq 1 \quad$ (Eq. 7)

Maximum 1 Year Deficit (\%) < 50\% Annual Demand (Eq. 8)

Maximum 2 Years Deficit (\%) $<75 \%$ Annual Demand (Eq. 9)

Maximum 10 Years Deficit (\%) <

100\% Annual Demand (Eq.10)

Maximum Pumping Cost $(€)<5.000 .000 €($ Eq. 11)

The OR for this real case is defined by six parameters, which represent the thresholds of different reservoirs of the system. These parameters are considered by the experience of the decision makers in the WRS. Based on these thresholds, the supply demands are restricted to a greater or lesser level and, at the same time, this affect to the volume pumped.

Optimisation has been carried out with both EAs previously described, the SCE-UA and the Scatter Search. The combination of parameters used in this real case reflects the best option considered in section 3 . In the case of SCEUA algorithm the OPT number is 20 and for the Scatter Search algorithm OPT number is 24 . The results obtained, by using these parameters for each algorithm, are described below. To be able to compare these results with the current management of the system results, a value of 0.626 is obtained by evaluating the OF (Eq. 6). 
For each EA, a figure with all the ORs analysed is displayed, showing the number of demands with a deficit ( $\mathrm{x}$-axis) and the average annual cost of pumping (y-axis). A decision-maker using this methodology can select between alternatives for what they consider to be the most desirable for the interests of the system in the post-process. For example, in this case, the decision-maker may choose an alternative with a greater number of demands with deficits, but with a lower net pump flow rate and thus lower pumping costs. These figures do not show the maximum annual deficits of demands with deficits because in most solutions, they remain constant. Nevertheless, in other cases, these figures alone would not be sufficient because they do not show all aspects of the WRS management needed for making objective decisions. For those cases, a collection of figures can be created to show all important aspects and relate different solutions across the figures using a colour code (Lerma et al., 2014).

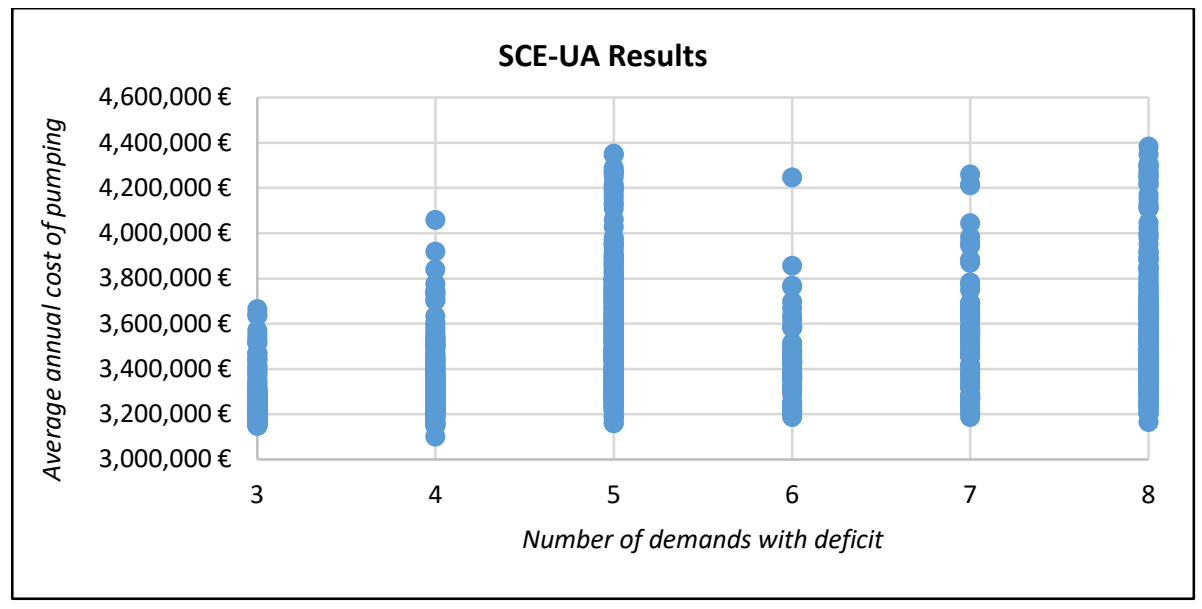

Figure P3. 7: Obtained results using the SCE-UA algorithm.

The optimisation performed with the SCE-UA algorithm employed 1594 iterations to complete the process. The best value for the OF is 0.570 , with an average annual pumping cost of 3,161,191.56 $€$ and a total number of three demands with a water deficit. As shown in Figure P3. 7 (which shows the results of all iterations), this is the solution with the fewest number of demands having a deficit and the lowest average annual cost of pumping; simultaneously, there is a significant reduction in the average annual cost of 
pumping, from $3,675,330.24 €$ to $3,161,191.56 €$, a decrease of approximately half a million euros.

Alternatively, 3989 evaluations of OF were made using the Scatter Search algorithm (Figure P3. 8), and the optimal solution obtained is one with three demands having a deficit and having an average annual cost of pumping of $3,251,280.22 €$. The value of OF reached is 0.579 .

The three demands that have deficits (in the best solution using both algorithms) show the same values of maximum annual deficit that are observed in the current management system (Table P3. 4b).

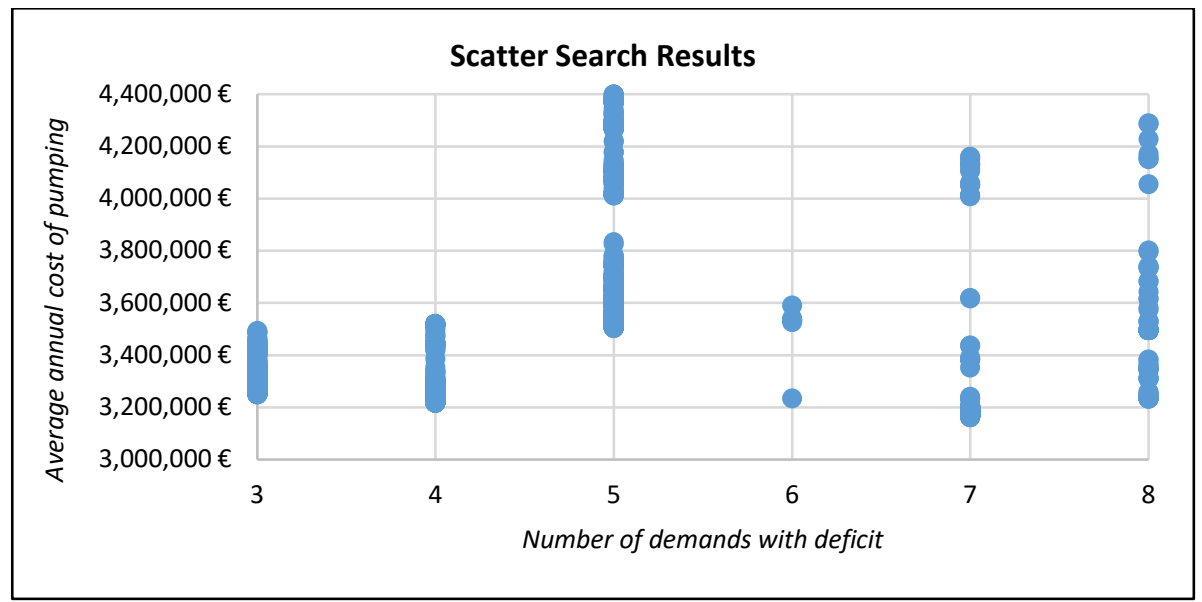

Figure P3. 8: Obtained results using the Scatter Search algorithm.

At this point, we want to show the similarities and differences between the two EAs analysed. First, it can be seen that the number of iterations using the SCE-UA algorithm is smaller than that when using the Scatter Search algorithm, and without looking at any further aspect, one could say that the first algorithm is more efficient. Considering the OF and the results obtained, the best solution obtained by the algorithms is more optimal than the current management system, in terms of water supply deficits and pumping costs. Both algorithms are able to reduce the number of demands suffering a deficit from four to three. However, the SCE-UA obtains an average annual cost of pumping that is lower than that from the Scatter Search alternative, i.e., the 
SCE-UA obtains a better solution, but the Scatter Search nevertheless has fewer parameters, which makes it flexible and able to provide good solutions.

Figure P3. 8 shows that the solutions found by the Scatter Search algorithm are focused on specific values for the average annual cost of pumping, in contrast to the more or less homogeneous distribution that is shown in Figure P3. 7 for the SCE-UA, i.e., there are ranges of the average annual cost of pumping that the Scatter Search does not analyse or does not provide any solutions for.

\section{Conclusions}

In this paper, two EAs have been assessed as optimisation tools to design optimal ORs in a WRS. Several aspects have been considered through analysis of each algorithm's parameters and a real case. The discussed aspects are aimed at a particular study of EAs: which is the best in real case applications, the convergence/termination criteria, and the influence of decision-makers in the optimisation process.

The parameter analysis allows us to better understand the behaviour of the SCE-UA and Scatter Search algorithms, detecting the most relevant parameters for the optimisation process. Simultaneously, their stop condition is also studied, through the parameters defined for that objective. The SCE-UA has three parameters for this purpose, while there is only one parameter for the Scatter Search, which gives SCE-UA more flexibility and therefore greater efficiency because it requires a lower number of OF evaluations in many cases. Regarding the remaining parameters, the NGS is quite important in the SCE-UA, in which neither values lower than 3 nor values higher than 8 are recommended to obtain optimal results in an efficient way. In the Scatter Search approach, to provide good solutions, parameters related to the population size and the Reference Set are most influential during the optimisation process.

When the EAs were applied to a real case study, other aspects related to the decision-makers were considered, apart from checking the methodology to 
design optimal OR using these algorithms. The participation of decisionmakers in the optimisation pre-process is important in correctly addressing this problem, a correct representation of the results is needed for the postprocess, and the decision-makers must have all the information necessary to make the best decisions that yield the most appropriate management protocols for the WRS.

Regarding the comparison of both algorithms, the SCE-UA needs fewer iterations to reach an optimal solution, and the solution obtained is typically better than the one obtained using the Scatter Search algorithm. Therefore, the conclusion is that the SCE-UA algorithm is a more efficient algorithm for realistic problems and obtains better, nearly globally optimised solutions when searching for ORs than does the Scatter Search, even if this second approach could be considered flexible and able to provide quality solutions in an expanded range of real-world applications.

\section{Acknowledgements}

The authors wish to thank the University of Cagliari (Sardinia) and the Basin Agency of Sardinia for the data provided in the development of this study, as well as the Autonomous Region of Sardinia for funding the research project CRP 2_716. Thanks are also due to the Spanish Ministry of Science and Innovation (Comisión Interministerial de Ciencia y Tecnología, CICYT) for funding the projects NUTEGES (VI Plan Nacional de I+D+i 2008-2011, CGL2012-34978) and SCARCE (program Consolider-Ingenio 2010, project CSD2009-00065). The authors also thank the European Commission (Directorate-General for Research and Innovation) for funding the projects DROUGHT-R\&SPI (program FP7-ENV-2011, project 282769), SIRIUS (FP7SPACE-2010-1, project 262902), LIFE ALBUFERA project (LIFE12 ENV/ES/000685) and WAMCD project (EC-DG Environment No. 07.0329/2013/671291/SUB/ENV.C.1). 


\section{References}

- $\quad$ ADENSO-DÍAZ, B., GARCÍA-CARBAJAL, S. and LOZANO, S. An empirical investigation on parallelization strategies for Scatter Search. European Journal of Operational Research. Volume 169, Issue 2, 1 March 2006, Pages 490-507, ISSN 0377-2217, http://dx.doi.org/10.1016/j.ejor.2004.08.011.

- $\quad$ AHMED, J.A. and SARMA, A.K. Genetic algorithm for optimal operating policy of a multipurpose reservoir. Water Resources Management 19, 2005, pp. 145-161.

- $\quad$ AKTER, T. and SIMONOVIC, S.P. Modelling uncertainties in short-term reservoir operation using fuzzy sets and a genetic algorithm, Hydrological Science Journal, 49, 6, 2004, pp. 1079-81.

- ANDREU, J., CAPILLA, J., and SANCHIS, E. Aquatool, a generalized decision support system for water resources planning and operational management, Journal of Hydrology, Vol. 177, pp. 269-291, 1996.

- BHANDARI, D., MURTHY, C. A. and PAL, S. K. Variance as a stopping criterion for genetic algorithms with elitist model. Fundamenta Informaticae, Vol. 120, 2012, pp. 145-164.

- BHASKAR, N. R. and WHITLACH JR., E. E.: Deriving of monthly reservoir release policies, Water Resources Research, 16, 6, 1980, pp. 987-993.

- BOYLE, D. P., GUPTA, H. V. and SOROOSHIAN, S. Toward improved calibration of hydrological models: Combining the strengths of manual and automatic methods, Water Resources Research, 36(12), 3663 3674, 2000.

- CAI, X., MCKINNEY D.C., and LASDON L.S. Solving nonlinear water management models using a combined genetic algorithm and linear programming approach, Advances in water Resources, 24, 2001, pp. 667-676.

- CAMPOS, V., GLOVER, F., LAGUNA, M. and MARTÍ, R. An experimental evaluation of a scatter search for the linear ordering problem. Journal of Global Optimization 21, pp. 397-414, 2001. 
- $\quad$ CHJ (Júcar River Basin Organization). Hydrological Plan of Júcar Basin (in Spanish). Ministry of Environment. Spain, in BOE 191 11/aug/1998, 1998.

- DOUGHERTY, D. E. and MARRYOTT, R. A. Optimal groundwater management 1. Simulated annealing. Water Resour. Res., 27(10), 1991, pp. 2493-2508.

- DUAN, Q., SOROOSHIAN, S. and GUPTA, V. Effective and efficient global optimization for conceptual rainfall-runoff models. Water Resources Research, Vol. 28, No. 4, 1992, pp. 1015-1031.

- DUAN Q., SOOROSHIAN S., GUPTA V.J. Optimal use of the SCE-UA global optimization method for calibrating watershed models. Journal of Hydrology, 158(3-4), 1994, 265-284.

- ElfERCHICHI, A., GHARSALLAH, O., NOUIRI, I., LEBSI, F. and LAMADDALENA, $N$. The genetic algorithm approach for identifying the optimal operation of a multi-reservoirs on-demand irrigation system. Biosystems Engineering, 2009, pp. 334-344.

- GLOVER, F. Heuristics for Integer Programming using surrogate constraints. Decision Sciences 8, 1977, pp. 156-166.

- GOLDBERG, D. E. and KUO, C. H. Genetic algorithms in pipeline optimization. J. Comput. Civ. Eng. 1987.

- GUO, Y.; WALTERS, G. A. and SAVIC, D. A. Optimal design of storm sewer networks: Past, present and future. Proc., 11th Int. Conf. on Urban Drainage (ICUD 2008), IWA Pub., London. 2008.

- GUO, X., HU, T., WU, C., ZHANG, T., AND LV, Y. Multi-Objective Optimization of the Proposed Multi-Reservoir Operating Policy Using Improved NSPSO. Water Resources Management, 27(7), 2013, 21372153.

- HOSSAIN, M. AND EL-SHAFIE, A. Evolutionary techniques versus swarm intelligences: application in reservoir release optimization. Neural Computing and Applications, 24(7-8), 2014, 1583-1594.

- KUCZERA, G., Efficient subspace probabilistic parameter optimization for catchment models, Water Resources Research, 33(1), 177 - 185, 1997. 
- LeRMA, N., PAREDES-ARQUiOlA, J., MOLINA, J. L. and ANDREU, J. Evolutionary network flow models for obtaining operation rules in multi-reservoir water systems. Journal of Hydroinformatics, 16.1, 2014, pp. 33-49 DOI:10.2166/hydro.2013.151.

- $\quad$ LIBERATORE S. and SECHI G.M. Location and Calibration of Valves in Water Distribution Networks Using a Scatter-Search Meta-heuristic Approach. Water Resources Management. 23:1479-1495, 2009. DOI 10.1007/s11269-008-9337-6.

- LOUCKS D. P. and SIGVALDASON O. T. Multiple reservoir operation in North America. In The Operation of Multiple Reservoir Systems, edited by Z. Kaczmarck and J. Kindler, IIASA Collab. Proc. Ser., CP-82-53, 1982, pp. 1-103.

- LUCE, C. H., and CUNDY, T. W. Parameter identification for a runoff model for forest roads, Water Resources Research, 30(4), 1057-1069, 1994.

- LUND, J., and FERREIRA, I. Operating rule optimization for Missouri River reservoir system. J. Water Resour. Plan. Manage, 122, 4, 1996, pp. 287-295.

- MAIER H.R., KAPELAN Z., KASPRZYK J., KOLLAT J., MATOTT L.S., CUNHA M.C., DANDY G.C., GIBBS M.S., KEEDWELL E., MARCHI A., OSTFELD A., SAVIC D., SOLOMATINE D.P., VRUGT J.A., ZECCHIN A.C., MINSKER B.S., BARBOUR E.J., KUCZERA G., PASHA F., CASTELLETTI A., GIULIANI M. AND REED P.M. Evolutionary algorithms and other metaheuristics in water resources: Current status, research challenges and future directions, Environmental Modelling and Software, 62, 271-299, 2014, DOI: 10.1016/j.envsoft.2014.09.013.

- MARMA (Spanish Ministry of Environment, Agriculture and Fishery), IPH (Guidelines for Basin Planning and Management) (in Spanish), in BOE 229 22/SEPT/2008, 2008.

- MARTÍ, R. and LAGUNA, M. Scatter Search: Basic Design and Advanced Strategies. Revista Iberoamericana de Inteligencia Artificial. No.19. 2003. pp. 123-130. 
- MARTí, R. Scatter Search-Wellsprings and Challenges. European Journal of Operational Research. Volume 169, Issue 2, 1 March 2006, Pages 351-358, ISSN 0377-2217, http://dx.doi.org/10.1016/j.ejor.2004.08.003.

- MIMAM (Spanish Ministry of Environment) Water in Spain. (English version), Centro de Publicaciones, Secretaría General Técnica, Ministerio de Medio Ambiente. Spain, 2004.

- MOEINI R., AFSHAR A. and AFSHAR M.H. Fuzzy rule-based model for hydropower reservoirs operation, Int J Electr Power Energy Syst, 33, 2, 2010, pp. 171-178.

- MOMTAHEN, S. and DARIANE, A. Direct Search Approaches Using Genetic Algorithms for Optimization of Water Reservoir Operating Policies. J. Water Resour. Plann. Manage. 133(3), 2007, 202-209.

- MULETA, M. K. and NICKLOW, J. W. Decision support for watershed management using evolutionary algorithms. J. Water Resour. Plann. Manage. 131(1), 2005, pp. 35-44.

- MURTHY, Z. V. P. and VENGAL, J. C. Optimization of a reverse osmosis system using genetic algorithm. Sep. Sci. Technol, 41(4), 2006, pp. 647-663.

- NICKLOW, J., REED, P., SAVIC, D., DESSALEGNE, T., HARRELL, L., CHANHILTON, A., KARAMOUZ, M., MINSKER, B, OSTFELD, A., SINGH, A. and ZECHMAN. State of the Art for Genetic Algorithms and Beyond in water Resources Planning and Management. Journal of Water Resources Planning and Management 136(4), 412-432, 2009.

- OLIVIERA R. and LOUCKS D.P. Operating rules for multireservoir systems, Water Resources Research, 33, 4, 1997, pp. 839-852.

- SAVIC, D.A. and WALTERS, G.A. Genetic algorithms for least-cost design of water distribution networks. Journal of Water Resources Planning and Management, ASCE, Vol. 23, No. 2, pp. 67-77, 1997.

- SCHEUERER, S. and WENDOLSKY, R. A scatter search heuristic for the capacitated clustering problem. European Journal of Operational Research. Volume 169, Issue 2, 1 March 2006, Pages 533-547, ISSN 0377-2217, http://dx.doi.org/10.1016/j.ejor.2004.08.014. 
- YOUNG, G. Finding reservoir operating rules, J. Hydraul. Div. Am. Soc. Civ. Eng., 93, 6, 1967, pp. 297-321.

- ZIELINSKI, K., PETERS, D. and LAUR, R. Stopping criteria for singleobjective optimization. Available on line at: http://citeseerx.ist.psu.edu/viewdoc/summary?doi=10.1.1.142.3511 (accessed December 10 2013), 2005. 


\section{Appendix 1. Test suite.}

The next two tables contain the optimisation groups for SCE-UA and Scatter Search algorithms for the academic case. These tables mainly show the algorithm parameters, the evaluation number of the OF (EVALS) and the normalised OF value.

Table A1.1: Optimisations summary performed in SCE-UA algorithm analysis.

\begin{tabular}{cccccccc} 
OPT & GROUP & KSTOP & PCENTO & NGS & ISEED & EVALS & OF \\
\hline $\mathbf{1}$ & 1 & 10 & 0.1 & 1 & 123456 & 172 & 0.5239 \\
$\mathbf{2}$ & 1 & 10 & 0.1 & 2 & 123456 & 476 & 0.5372 \\
$\mathbf{3}$ & 1 & 10 & 0.1 & 3 & 123456 & 419 & 0.5378 \\
$\mathbf{4}$ & 1 & 10 & 0.1 & 4 & 123456 & 441 & 0.5370 \\
$\mathbf{5}$ & 1 & 10 & 0.1 & 5 & 123456 & 1017 & 0.5382 \\
$\mathbf{6}$ & 1 & 10 & 0.1 & 6 & 123456 & 574 & 0.5378 \\
$\mathbf{7}$ & 1 & 10 & 0.1 & 7 & 123456 & 1531 & 0.5385 \\
$\mathbf{8}$ & 1 & 10 & 0.1 & 8 & 123456 & 1173 & 0.5379 \\
$\mathbf{9}$ & 1 & 10 & 0.1 & 9 & 123456 & 1493 & 0.5382 \\
$\mathbf{1 0}$ & 1 & 10 & 0.1 & 10 & 123456 & 1456 & 0.5382 \\
\hline $\mathbf{1 1}$ & 1 & 10 & 0.1 & 15 & 123456 & 2893 & 0.5385 \\
$\mathbf{1 2}$ & 1 & 10 & 0.1 & 20 & 123456 & 3269 & 0.5383 \\
$\mathbf{1 3}$ & $\mathbf{2}$ & $\mathbf{2}$ & 0.1 & 7 & 123456 & 122 & 0.5333 \\
\hline
\end{tabular}




$\begin{array}{llllllll}14 & 2 & 5 & 0.1 & 7 & 123456 & 722 & 0.5375 \\ 15 & 2 & 15 & 0.1 & 7 & 123456 & 1841 & 0.5385 \\ 16 & 2 & 20 & 0.1 & 7 & 123456 & 2159 & 0.5385 \\ 17 & 3 & 10 & 0.2 & 7 & 123456 & 1043 & 0.5383 \\ 18 & 3 & 10 & 0.5 & 7 & 123456 & 978 & 0.5383 \\ 19 & 3 & 10 & 0.05 & 7 & 123456 & 1531 & 0.5385 \\ 20 & 4 & 10 & 0.1 & 7 & 967217 & 589 & 0.5389 \\ 21 & 4 & 10 & 0.1 & 7 & 583569 & 663 & 0.5369 \\ \mathbf{2 2} & 4 & 10 & 0.1 & 7 & 657424 & 881 & 0.5378 \\ \mathbf{2 3} & 5 & 10 & 0.1 & 7 & 967217 & 616 & 0.5389 \\ \mathbf{2 4} & 5 & 10 & 0.1 & 7 & 967217 & 592 & 0.5389 \\ \mathbf{2 5} & 5 & 10 & 0.1 & 7 & 123456 & 1043 & 0.5379 \\ \mathbf{2 6} & 5 & 10 & 0.1 & 7 & 123456 & 1170 & 0.5381\end{array}$

Table A1.2: Summary of optimisations performed using Scatter Search algorithm analysis.

\begin{tabular}{ccccccc} 
OPT & GROUP & REFSET & SIZEPOP & ITER & EVALS & OF \\
\hline $\mathbf{1}$ & 1 & 1 & 5 & 1 & 164 & 0 \\
$\mathbf{2}$ & 1 & 1 & 5 & 2 & 164 & 0 \\
3 & 1 & 1 & 5 & 5 & 655 & 0.5331
\end{tabular}




\begin{tabular}{|c|c|c|c|c|c|c|}
\hline 4 & 1 & 1 & 5 & 10 & 1200 & 0.5367 \\
\hline 5 & 1 & 1 & 5 & 20 & 2377 & 0.5367 \\
\hline 6 & 1 & 1 & 5 & 40 & 4907 & 0.5367 \\
\hline 7 & 1 & 1 & 5 & 50 & 6212 & 0.5367 \\
\hline 8 & 1 & 2 & 5 & 1 & 164 & 0 \\
\hline 9 & 1 & 2 & 5 & 5 & 795 & 0.5334 \\
\hline 10 & 1 & 2 & 5 & 10 & 1578 & 0.5334 \\
\hline 11 & 1 & 2 & 5 & 20 & 3222 & 0.5334 \\
\hline 12 & 1 & 2 & 5 & 50 & 8430 & 0.5334 \\
\hline 13 & 1 & 5 & 5 & 1 & 164 & 0 \\
\hline 14 & 1 & 5 & 5 & 5 & 5784 & 0.5184 \\
\hline 15 & 1 & 5 & 5 & 10 & 13487 & 0.5190 \\
\hline 16 & 1 & 5 & 5 & 20 & 25444 & 0.5223 \\
\hline 17 & 1 & 5 & 5 & 50 & 44444 & 0.5278 \\
\hline 18 & 2 & 1 & 10 & 1 & 414 & 0.5331 \\
\hline 19 & 2 & 1 & 10 & 2 & 414 & 0.5331 \\
\hline 20 & 2 & 1 & 10 & 10 & 2377 & 0.5367 \\
\hline 21 & 2 & 1 & 10 & 20 & 4907 & 0.5367 \\
\hline 22 & 2 & 1 & 10 & 50 & 12018 & 0.5367 \\
\hline 23 & 2 & 2 & 10 & 1 & 414 & 0.5331 \\
\hline
\end{tabular}




\begin{tabular}{|c|c|c|c|c|c|c|}
\hline 24 & 2 & 2 & 10 & 5 & 1030 & 0.5380 \\
\hline 25 & 2 & 2 & 10 & 10 & 2155 & 0.5380 \\
\hline 26 & 2 & 2 & 10 & 20 & 4788 & 0.5380 \\
\hline 27 & 2 & 2 & 10 & 50 & 12015 & 0.5380 \\
\hline 28 & 2 & 5 & 10 & 1 & 414 & 0.5331 \\
\hline 29 & 2 & 5 & 10 & 5 & 6184 & 0.5378 \\
\hline 30 & 2 & 5 & 10 & 10 & 12717 & 0.5378 \\
\hline 31 & 2 & 5 & 10 & 20 & 23996 & 0.5378 \\
\hline 32 & 2 & 10 & 10 & 1 & 414 & 0.5331 \\
\hline 33 & 2 & 10 & 10 & 5 & 28548 & 0.5380 \\
\hline 34 & 2 & 10 & 10 & 10 & 40700 & 0.5380 \\
\hline 35 & 3 & 10 & 50 & 1 & 2377 & 0.5367 \\
\hline 36 & 3 & 10 & 50 & 5 & 30864 & 0.5379 \\
\hline 37 & 3 & 10 & 50 & 10 & 64761 & 0.5379 \\
\hline 38 & 4 & 10 & 100 & 1 & 4907 & 0.5367 \\
\hline 39 & 4 & 10 & 100 & 5 & 30571 & 0.5385 \\
\hline 40 & 4 & 10 & 100 & 10 & 64630 & 0.5385 \\
\hline
\end{tabular}




\section{A.4. Optimization assessment of hydropower plants during floods in Visp basin (Switzerland) using evolutionary algorithms. ${ }^{4}$}

Néstor Lerma (1), Javier García (2), Javier Paredes-Arquiola (1), Joaquín Andreu (1)

(1) Universitat Politècnica de València. Research Institute of Water and Environmental Engineering, (IIAMA). Ciudad Politécnica de la Innovación, Camino de Vera, 46022 Valencia, Spain. e-mail: nestorlerma@upv.es;

(2) Centre de Recherche sur l'Environnement Alpin, Rue de I'Industrie 45, CH-1951, Sion, Switzerland.

\section{Abstract}

Flood events can exceed the river capacity with important economic costs associated. Sometimes, flood mitigation is a complementary effect when a dam is built. When this is not enough, an optimal management of this type of infrastructures and, usually, of hydropower plants, is necessary. In this research, an optimization approach based on real forecasts and using evolutionary algorithms is assessed with the main purpose of obtaining optimal management rules in Visp basin (Switzerland) during floods. A methodology is developed coupling two evolutionary algorithms (SCE-UA and NSGA-II) and the hydrological-hydraulic tool RS MINERVE. Both algorithms are assessed to know their validity to optimize management rules in flood events and to identify the advantages of each one. The tests carried out indicate the importance of this methodology to save energy losses and reduce significantly the damage in flood areas. The results achieved highlight the algorithms advantages and disadvantages in the optimization process.

Reservoir, Hydropower plant, Water Management, Flood event, Evolutionary algorithms, Optimization

\footnotetext{
${ }^{4}$ In Revision in the Journal of Flood Risk Management.
} 


\section{Introduction}

The study of flood events is necessary to avoid catastrophic damages due to high water flow in risk zones where it could cause important economic costs and could affect human life.

The hydrologic-hydraulic network global analysis is essential in several decision-making situations including water resources management, hydropower plant operations optimization, spillways design and regulation or the appropriate flood protection development (García et al., 2016). Reservoirs are important structures due to the possibilities given to system operators to make decisions about storing and releasing water (Farhangi et al., 2012). Determining an effective reservoir operation strategy minimizing downstream damage, keeping dam safety and maximizing the volume reservoir at the end of the flood event is an essential task of flood management (Malekmohammadi et al., 2010; Uysal et al., 2016). But also, when the system includes hydropower plants, more objectives, like the revenue maximization of these infrastructures, are taken into account.

In this field, the time frame for decision-making is very short, with scarce available information and a very limited forecast of the hydro-meteorological situation (Malekmohammadi et al., 2010). Moreover, in reservoir systems this short-term operation is challenging due to conflicting objectives, constraints and the need for taking firm decisions in real-time (Uysal et al., 2016). Trying to achieve this issue, some studies were carried out using mathematical models for reservoir operations (summarized in Yeh, 1985) or optimizing power generation requirements and flood control in multipurpose reservoir (Dias et al., 1985). Many other optimization methods have been developed to solve the short-term optimal schedule problem with the aid of network flow methods and linear programming (Lian and Jiang, 2005; Needham et al., 2000; Zeng et al., 2003), nonlinear programming (Lyra and Ferreira, 1995; Piekutowski et al., 1994), dynamic programming (Zhang and Zhang, 2003), mathematical decomposition ( $\mathrm{Ni}$ et al., 1999) or artificial neural networks (Naresh and Sharma, 2000). 
An alternative way to conduct a search in a diverse range of optimization problems is successfully provided by genetic algorithms, even in a complex system and in the absence of domain knowledge (Chang and Chen, 1998). In the same field, evolutionary algorithms (EAs) have been applied to solve an optimal multi-objective dispatch of hydroelectric generating units (Villasanti et al., 2004), to optimize a flood control reservoir (Chang and Chen, 1998), to obtain a daily energy demand in an economic and safe way (Hidalgo et al., 2015) or for real-time flood management in river-reservoir system (Malekmohammadi et al., 2010). EAs are based on the theory of evolution making a population of individuals evolves by subjecting it to similar processes than the biological evolution (crosses and mutations). The population is also subjected to a selection process which depends on the fittest individuals who will survive and the less suitable who will be discarded.

Real management problems often involve multiple conflicting objectives that should be optimized simultaneously (Makropoulos et al., 2008). To do so, multi-objective evolutionary algorithms offer a means to find the optimal Pareto front (Abd-Elhamid and Javadi, 2011; Cisty, 2010; Farmani et al., 2005; Zhou et al., 2015). The Pareto Front contains solutions that cannot improve one of its objectives without worsening at least another one. Thus, the decision maker can select a final design solution from a set of non-dominated solutions.

Regarding to the data availability, different approaches to optimize management rules could be developed. For example, when only the observed data is accessible, these data would be used to optimize the management of the system in several history flood events. Optimizations results would be analysed and management rules based on different trigger indicators would be obtained. However, if forecast series are available, these series could be used to obtain optimal management rules and to apply them to the real flood of the forecast period.

This research defines an optimization approach based on real forecasts to get optimal management rules in reservoirs and hydropower plants of Visp basin, in Switzerland, during flood events. In the optimization process two EAs are coupled with the hydrological-hydraulic tool RS MINERVE (García et 
al., 2016). The case study, like a real management problem, involves different objectives and, that is why a multi-objective NSGA-II algorithm (Deb et al., 2002) is analysed. SCE-UA (Duan et al., 1992), as a mono-objective algorithm, is also studied due to its demonstrated efficiency. Both EAs are assessed in this field to optimize the system management during flood events.

This document describes, in the following section, the optimization approach to reduce energy losses in hydropower plant and flood damages, both algorithms and the hydrological-hydraulic tool. In the third section, the case study and its methodology implementation is presented. The results are discussed in the fourth section, and the conclusions are remarked at the end.

\section{Methods and tools}

An optimization approach is presented in this research to acquire optimal management rules in Visp basin during flood events. To reach this target, the EAs are coupled with RS MINERVE freeware software. This software is a hydrological-hydraulic tool to compute the water balance in a water system according to different predefined rules. RS MINERVE is used due to its application for studying basins in several projects and thesis in Switzerland, Spain, Peru, China, Brazil or Mexico (Astorayme et al., 2016, 2015; Deval et al., 2011; Drenkhan et al., 2016; García et al., 2014; Jordan et al., 2012; Perez et al., 2016; Rodrigues et al., 2016).

EAs are responsible for searching optimal definition of these rules testing different combinations. Each defined rule represents an individual in the EAs, who are responsible for creating new rules through processes like crossing, mutation or recombination, with the aim of improve an objective function (OF). In this study, SCE-UA and NSGA-II are used to optimize the water management in reservoirs with hydropower plants. The SCE-UA algorithm is assessed in this study due to its demonstrated efficiency, which has been widely recognized to calibrate hydrological problems with a large number of parameters and high nonlinearity (Boyle et al., 2000; Duan et al., 1992; Kuczera, 1997; Luce and Cundy, 1994). The method was designed for solving problems encountered in conceptual watershed model calibration (Muttil and Liong, 2004), but has also been satisfyingly used in water resources 
management and its optimization (Lerma et al., 2013; Lin et al., 2008; Wang et al., 2010; Zhu et al., 2006). Instead, NSGA-II is one of the most currently used multi-objective algorithms. In the last years, the multi-objective algorithms (including the NSGA-II algorithm) are used in the hydraulic and hydrologic field in real cases (Chang and Chang, 2009; Chen et al., 2007; Lin et al., 2008; Reddy and Kumar, 2006).

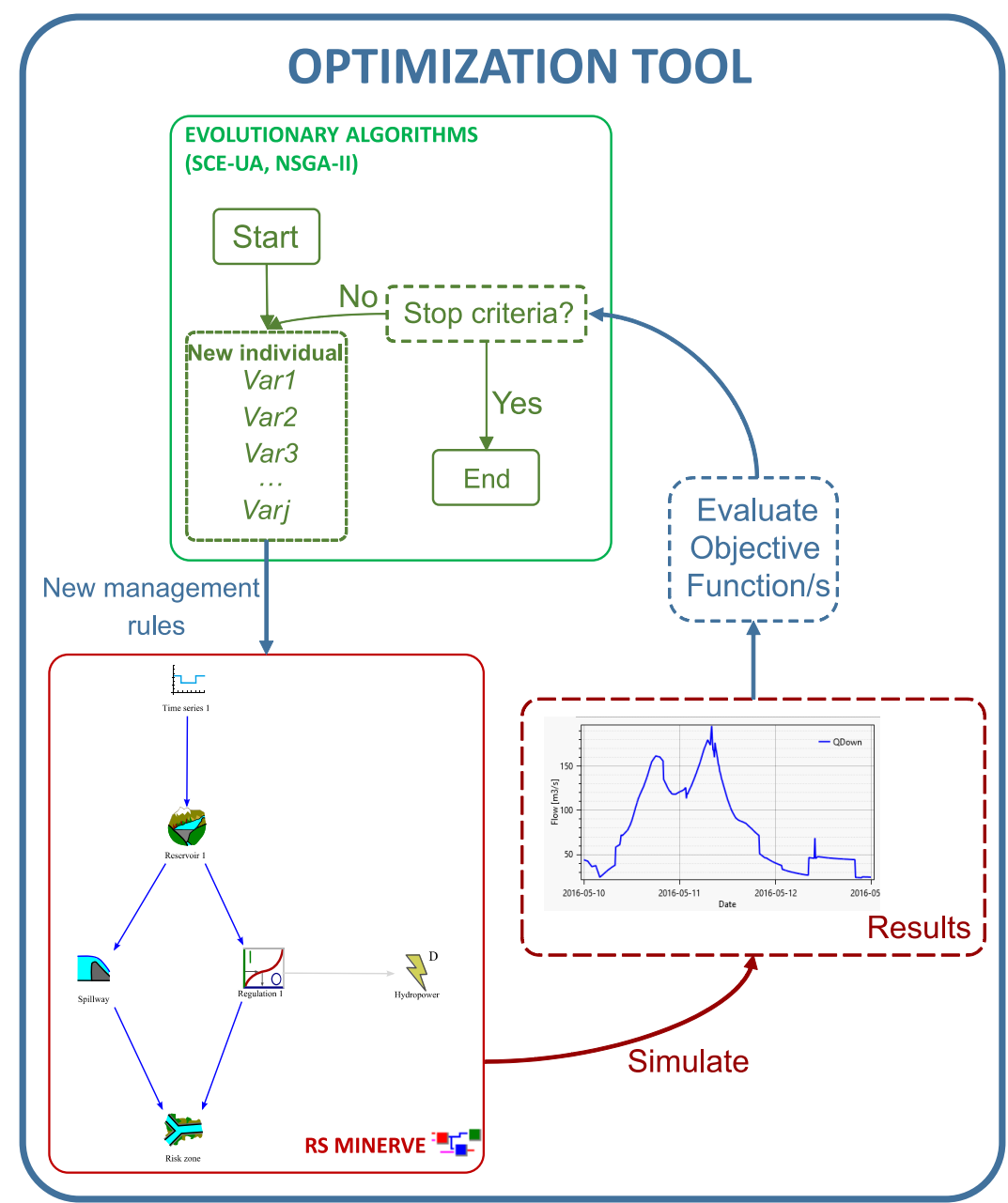

Figure P4. 1: Flowchart approach to optimize water management in flood events.

Figure P4. 1 describes the optimization methodology, which is responsible for obtaining optimal rules for a specific hydrological-hydraulic model. Each 
optimization process uses one EA (like SCE-UA or NSGA-II) included in the Optimization Tool (OT) and a RS MINERVE model with one of the forecast flow event series. When the selected EA starts, a set of individuals is created. Each individual is composed by a set of variables, which defines the management rules of the system. For each individual, the RS MINERVE model is modified applying new rules, and then it is computed to obtain series of results. These results are used to evaluate an OF (single objective algorithm) or different OFs (multi objective algorithm). The values obtained allow the algorithm to generate new individuals (new rules) with the aim of getting new management options better than the previous ones. The process is repeated until one of the EA stop criteria is satisfied.

The required OF in the optimizations depends on the case study. However, the main target in flood events is normally to reduce as much as possible the peak flow in risk areas to reduce the possibilities of occurrence of these events and the costs caused by them. To achieve this objective, it is necessary to implement a proper hydraulic system management. Usually, a preventive turbine program is carried out to create an additional volume in reservoirs allowing to store the flood water. In other occasions when it is not possible to control certain flow that reaches the flood area, it should be necessary to stop regular turbine program to avoid an excessive flow in this zone. However, it is advisable to store the maximum possible water in the reservoirs at the end of the optimization process to accomplish the regular turbine programs after the flood event. In all these situations, the aim is to maximize the revenue in the hydropower plants without increasing the damage costs in flood areas. These aims will define the OFs used by the EAs to optimize the management rules.

\subsection{Hydrological and Hydraulic tool}

As it was mentioned previously, RS MINERVE is used in this approach as a hydrological- hydraulic tool. RS MINERVE (García et al., 2016) is a software for the simulation of free surface run-off flow formation and propagation. This tool is in continuous development since 2007 at the Research Centre on Alpine Environment CREALP and the engineering office HydroCosmos SA 
(Switzerland), in collaboration with the École Polytechnique Fédérale de Lausanne (Switzerland) and Universitat Politècnica de València (Spain).

Complex hydrological and hydraulic networks are modelled according to a semi-distributed conceptual scheme. Snowmelt, glacier melt, surface or underground flow as particular hydrological processes and gates, spillways, diversions, junctions, turbines or pumps as hydraulic control elements are included in the modelling process. RS MINERVE contains different hydrological models for rainfall-runoff, such as SOCONT, SAC-SMA or HBV. Their combination with hydraulic structure models (reservoirs, turbines or spillways) can reproduce complex water resources systems.

The user-friendly interface of RS MINERVE allows carry out different analysis such as the management or planning of water resources, the optimization of hydropower plant operations or the development of flood protection rules.

This software is based on the concept that every simulation keeps the correct balance of water volume in each element of the whole system (reservoirs, junctions or turbines) at each time step. For example, simulations in reservoirs consider the retention equation, as shown in (Eq 1). Due to short time simulation period, evaporation and infiltration may be neglected.

$$
V_{t+1}=V_{t}+Q_{\text {in }, t} \Delta t-Q_{\text {out }, t} \Delta t
$$

with $\mathrm{V}_{\mathrm{t}+1}$ : Volume at time $\mathrm{t}+1\left[\mathrm{~L}^{3}\right] ; \mathrm{V}_{\mathrm{t}}$ : Volume at time $\mathrm{t}\left[\mathrm{L}^{3}\right] ; \Delta \mathrm{t}$ : time step [T]; $Q_{\text {in,t }}$ : total inflow at time $t\left[L^{3} / T\right] ; Q_{\text {out }, t}:$ total outflow at time $t\left[L^{3} / T\right]$.

Particular physical constraints are also considered for adequate and physically-based simulations. The volume cannot be lower than $\mathrm{V}_{\text {min }}$ in any case, assuming that $\mathrm{V}_{\min }$ corresponds to the minimum operational volume for turbines or bottom outlets. When volume exceeds the maximum capacity of the reservoir $\left(V_{\text {max }}\right)$, spillways automatically release water to limit the level in the reservoir.

As other system elements, the hydropower models compute the linear pressure losses and the net height, providing the energy production values 
and the total income based on the turbine performance and on the sale price of energy (more details in García Hernández et al., 2016).

Moreover, a new regulation element, called "Planner", was created to perform this research. It is composed by different rules, where each one can modify one output value to this element (flows, temperature, precipitation or others). The output value could be calculated from a defined series, from the regulation input, from a database or from a specific value. The application of each rule depends on a set of conditions defined for each one. The conditions can be of different types: from the result of other object of the model (e.g. Resevoir1.Qinput $>100 \mathrm{~m}^{3} / \mathrm{s}$ ) or from the state of another rule. Moreover, the rule also has a time schedule limitation and it could be satisfied if the current time step is equal to a specific day, month or if it is between two dates or two different times.

In the field of this research, the new regulation object could be used as a turbine, a spillway or a bottom outlet among others.

\subsection{Evolutionary algorithms}

\subsubsection{SCE-UA algorithm:}

SCE-UA is an optimisation mechanism (the Shuffled Complex Evolution) developed by Duan et al. (1992) at the University of Arizona. This algorithm is inspired by the principles of natural selection and genetics where its basic operation is a combination of deterministic and random processes. The algorithm starts from different points (individuals) organising them by teams (complexes). The globally optimised solution search is designed as an evolutionary process (evolution), based upon reproduction (crossing, mutation, recombination) and team mixing (shuffle).

The SCE-UA process starts with the number of parameters to be optimised (nopt) and the number of complexes (ngs), which allows to calculate the total number of sample points (npt). Knowing the value of $n p t$, a uniform distribution is used by default to generate the sample, taking into account the possible range of parameters. For each individual, the fitness is calculated and then, the EA generates a ranking. At that point, a looped process starts 
until stop criteria are satisfied (Figure P4. 2). During this process, the sample is divided into subgroups (size $n p g=2 * n o p t+1$ ). Individuals are divided in such a way that the first group has all points located in $n g s^{*}(k-1)+1$ (of the ordered sample), the second group has all points located in $n g s^{*}(\mathrm{k}-1)+2$ positions, and so on, where $k=1,2, \ldots, n p g$. Each group evolves independently, taking the allowed number of steps (nspl=npg) or evolutionary stages.

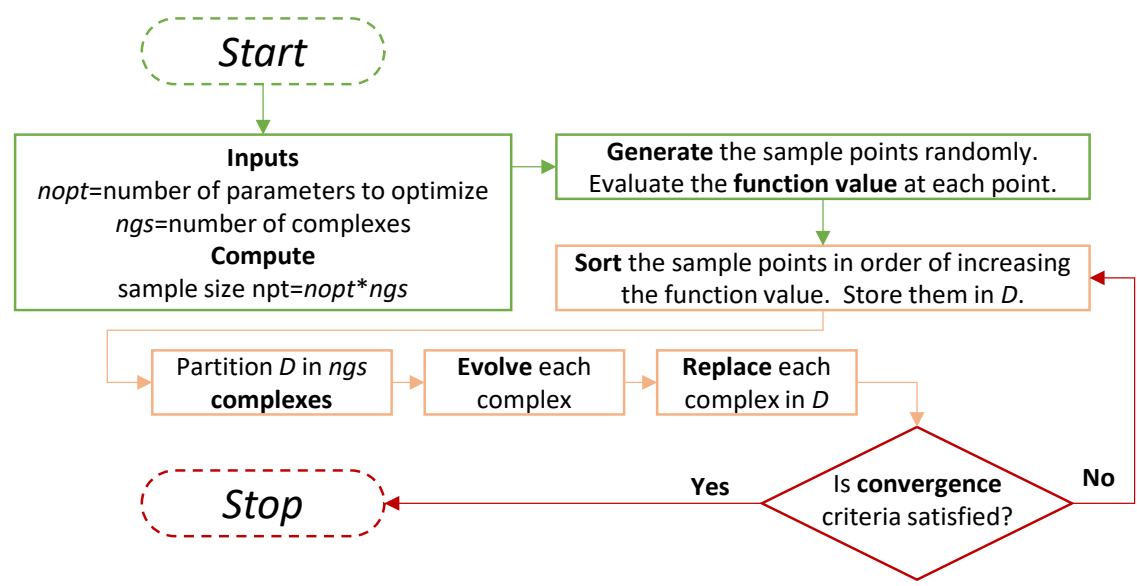

Figure P4. 2: Flowchart of the SCE-UA algorithm (Source: adaptation of Duan et al. (1992)).

This version of the SCE-UA includes three types of evolution methods: reflection, contraction and mutation. In the reflection stage, the worst subgroup point (of three) is reflected through the gravity centre of the other two points. If the reflected point has a lower value than the worst point, the worst point is switched by the new point. If this method does not increase the fitness of the individual, the contraction is implemented, where the new point is in the middle of the worst point and the gravity centre of the other points. If in reflection method the resulting point is out of range of the parameters or, if after reflection and contraction the fitness of the individual is not improved, then a mutation is carried out. This process randomly generates a point in the space of possible parameters. 
If stop criteria (like maximum number of iteration or like fitness level improvement in a percentage in the different loops) are not satisfied, all groups are combined and the process is repeated, sorting the new population in order to increase the fitness value.

\subsubsection{NSGA-Il algorithm:}

NSGA-II (Elitist Non-Dominated Sorting Genetic Algorithm) (Deb et al., 2002) is an evolutionary multi-objective optimization algorithm. This algorithm has a fast and non-dominated sorting approach, with a selection operator, used to create a new population by combining the parent and offspring populations and selecting the best solutions respecting the fitness and the spread (Deb et al., 2002; Dumedah et al., 2010).

This algorithm creates the descendant population $Q_{t}($ size $N$ ) using the parent population $\mathrm{P}_{\mathrm{t}}$ (size $\mathrm{N}$ ) and then, both populations are combined to generate $R_{t}$ with a size of $2 \mathrm{~N}$. After this, by means of non-dominated sorting, the population $R_{t}$ is classified in different Pareto fronts. Although this process requires more effort, it is necessary because dominance testing between the parent and descendant populations is developed. Once the sorting process is over, the new population is generated from the configurations of the nondominated Pareto fronts. This new population is first built with the best nondominated Pareto front $\left(F_{1}\right)$, and then the process continues with the solutions from the second front $\left(F_{2}\right)$, the third front and so on $\left(F_{3}\right)$. Because the population $R_{t}$ has a size of $2 \mathrm{~N}$ and there are only $\mathrm{N}$ configurations that form the descendant population, not all of the front configurations belonging to the $R_{t}$ population will be placed in the new population. The fronts that cannot be placed are rejected.

When the last front is under consideration, the solutions that belong to this front can exceed the descendant population size (Figure P4. 3). In this case, it is useful to use strategies that allow to select those configurations at a scarcely populated area that is far away from the other solutions. This will fill up the rest of the descendant population positions instead of choosing configurations randomly. 


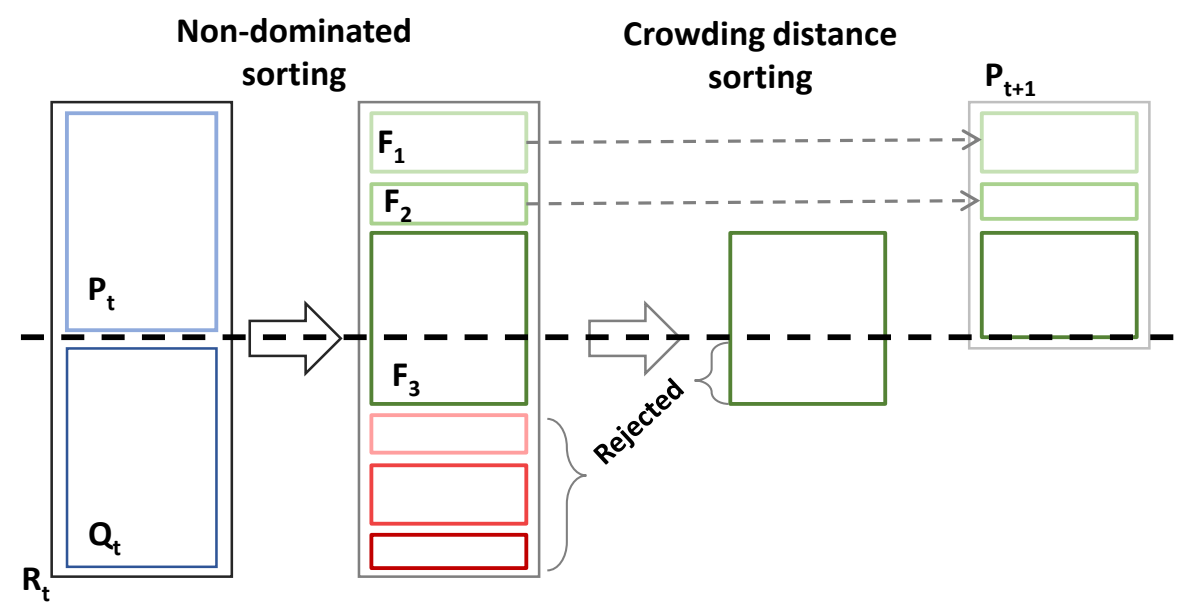

Figure P4. 3: Schematic diagram of the NSGA-II promoting individual's mechanism (Source: adaptation of Correa Flórez et al., 2008).

For the first generational cycles of the algorithm, these strategies are not very relevant because there are many fronts that persist to the next generation. However, in the next generation cycles, several configurations become part of the first generation, and this front may have more than $\mathrm{N}$ genes or individuals. Thus, it is important that the non-rejected configurations are chosen through a methodology that guarantees diversity. When the population as a whole converges to the Pareto front, the algorithm assures that the solutions are separated from each other.

\section{Case Study}

Visp River is located in Upper Rhone River basin, Valais Canton, in Switzerland (Figure P4. 4). Although the system is small $\left(778 \mathrm{~km}^{2}\right)$ compared with the whole basin $\left(5520 \mathrm{~km}^{2}\right)$, it has a real and complex regulation system with two reservoirs and its hydropower plants. The Visp River has a length of around $40 \mathrm{~km}$ and its average discharge is about $17.2 \mathrm{~m}^{3} / \mathrm{s}$. Its basin varies from 450 masl to up to 4000 masl and contains $3 \%$ of glacier surface. 


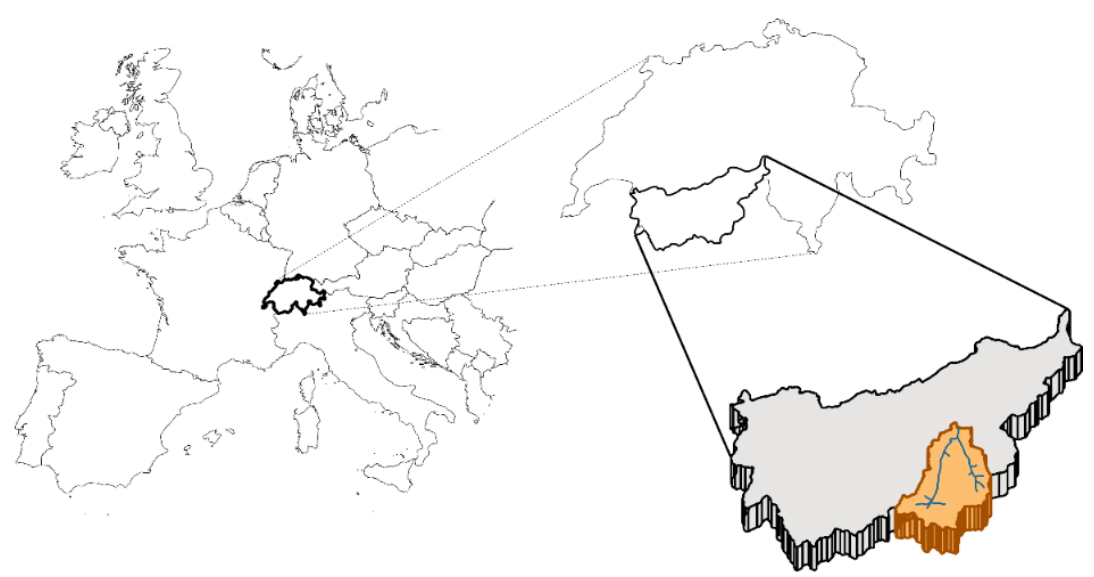

Figure P4. 4: Case Study location. Visp basin in Valais Canton (Switzerland).

The main reservoir is Mattmark with an approximately storage capacity of $100 \mathrm{Hm}^{3}$. However, the system has another tank reservoir, called Zermeiggern, and it is used as compensation basins for short time storage (0.12 $\mathrm{Hm}^{3}$ of capacity). Both reservoirs have a hydropower plant to allow turbine water in regular conditions. Due to the configuration of the system, Zermeiggern hydropower plant generates more energy than Mattmark hydropower plant. For this reason, Zermeiggern reservoir and its hydropower plant are also included in RS MINERVE model. In Visp basin, each reservoir has a spillway, and only Mattmark has a bottom outlet system. As Figure P4. 5 shows, the water from the spillways and the Mattmark bottom outlet goes to the downstream river network, taking into account a fixed transit time between the elements.

There are three model inputs represented as TimeSeries Objects. One for each reservoir and another one in the checkpoint of the flood zone (VISP_OFEV). In Mattmark, this flow series represents the natural inflow to the basin. In Zermeiggern reservoir, the values consider natural inflows and the inflows from intakes. The last one, in the checkpoint, collects the water from a part of subbasin not represented in this model, but that goes to this point, downstream of the reservoirs. For each input, seven forecast series are available every 12 hours, with a duration of 3 days for each one. 


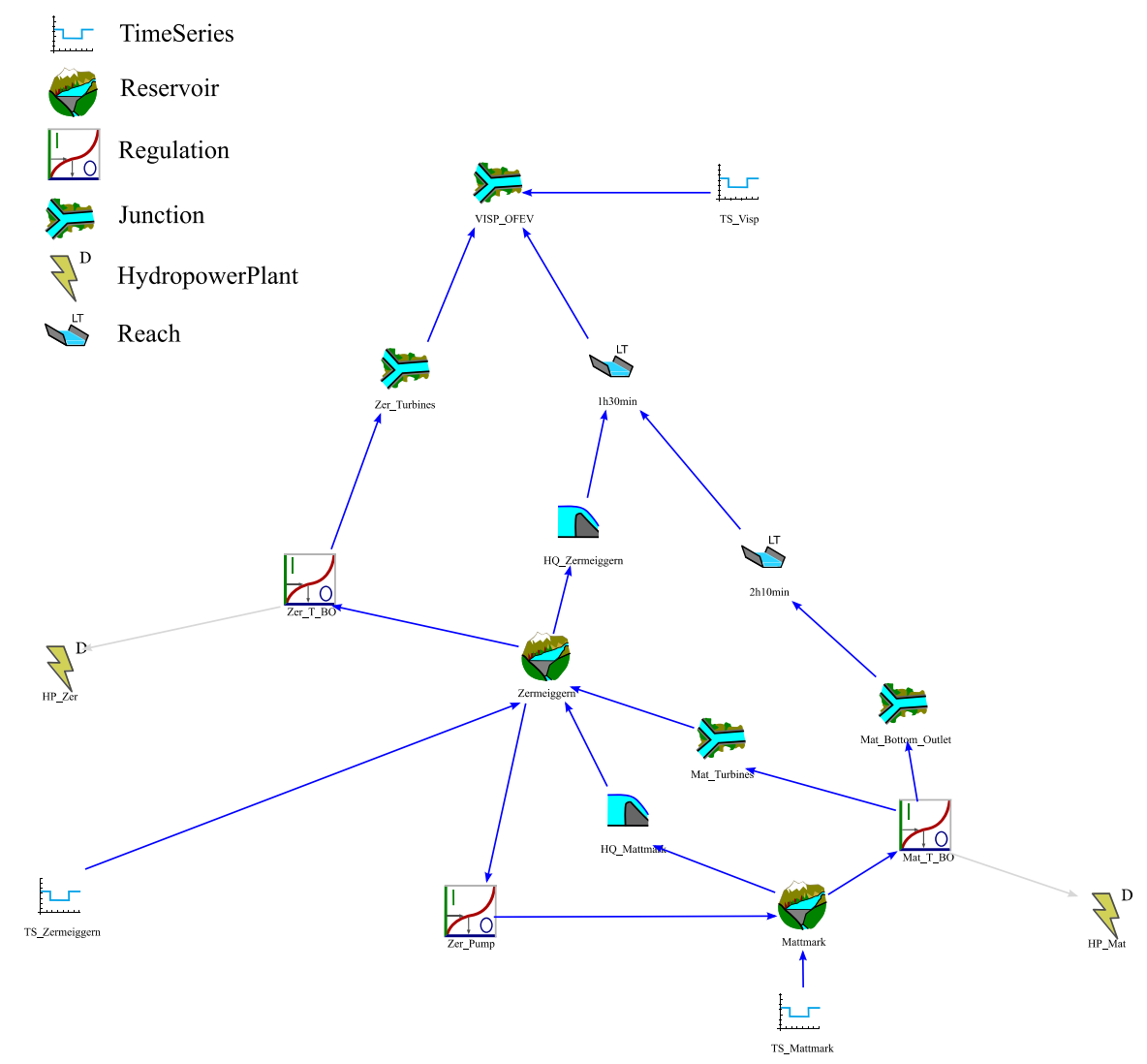

Figure P4. 5: Case study model in RS MINERVE software.

The regulation element is an important item in this model and in this research because it is responsible for the system management in regular episodes and specifically in flood events. Regarding to the characteristics of the Visp basin, the model includes three regulation elements. Mat_T_BO manages the turbine system and the bottom outlet of Mattmark reservoir. Zer_T only regulates the turbines in Zermeiggern reservoir. The last one, Zer_Pump, manages the pumping between Zermeiggern and Mattmark reservoirs. Table P4. 1 summarizes the different rules and conditions that define each regulation system. Some of the conditions depend on values (Var1 to Var12) that should be optimized and they represent the decision variables of the EA selected to this process, i.e., the algorithm would define 
the values for these variables in order to obtain an optimal management of the system.

Table P4. 1: Rules and conditions definition (with the decision variables of the EAs) in the 3 regulation elements.

\begin{tabular}{|c|c|c|c|c|}
\hline $\begin{array}{l}\text { Name } \\
\text { Regulation }\end{array}$ & $\begin{array}{l}\text { Code } \\
\text { Rule }\end{array}$ & Name Rule & Output & Conditions \\
\hline Mat_T_BO & $\mathrm{R} 1$ & $\begin{array}{l}\text { Regular Turbine } \\
\text { Program }\end{array}$ & $\begin{array}{l}Q_{\text {tur }}=19 \\
\mathrm{~m}^{3} / \mathrm{s}\end{array}$ & 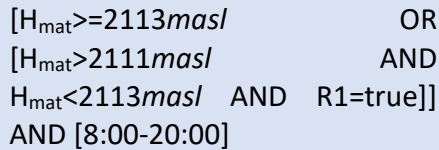 \\
\hline Mat_T_BO & R2 & $\begin{array}{l}\text { Preventive } \\
\text { Turbine } \\
\text { Program }\end{array}$ & $\begin{array}{l}\mathrm{Q}_{\text {tur }}=19 \\
\mathrm{~m}^{3} / \mathrm{s}\end{array}$ & $\begin{array}{l}\mathrm{H}_{\text {mat }}>\operatorname{Var1masl} \text { AND } \\
\text { TS_Mattmark. } \mathrm{Q}_{\mathrm{ln}}>\operatorname{Var} 2 \mathrm{~m}^{3} / \mathrm{s}\end{array}$ \\
\hline Mat_T_BO & R3 & $\begin{array}{l}\text { Stop Regular } \\
\text { Turbine } \\
\text { Program }\end{array}$ & $\begin{array}{ll}Q_{\text {tur }}= & 0 \\
\mathrm{~m}^{3} / \mathrm{s} & \end{array}$ & $\mathrm{H}_{\mathrm{mat}}<=2111$ masl \\
\hline Mat_T_BO & R4 & $\begin{array}{l}\text { Stop Turbine } \\
\text { Program }\end{array}$ & $\begin{array}{l}\mathrm{Q}_{\text {tur }}=0 \\
\mathrm{~m}^{3} / \mathrm{s}\end{array}$ & $\begin{array}{l}\text { Visp.Q }>>\operatorname{Var} 3 \mathrm{~m}^{3} / \mathrm{s} \\
\text { [Visp. } Q>\operatorname{Var} 4 \mathrm{~m}^{3} / \mathrm{s} \text { AND R4=true] }\end{array}$ \\
\hline Mat_T_BO & R5 & Bottom Outlet & $\begin{array}{l}\mathrm{Q}_{\mathrm{bo}}=58 \\
\mathrm{~m}^{3} / \mathrm{s}\end{array}$ & $\begin{array}{l}\mathrm{H}_{\text {mat }}>\text { Var5masl } \\
\text { TS_Mattmark. } Q_{1 n}>\operatorname{Var} 6 \mathrm{~m}^{3} / \mathrm{s}\end{array}$ \\
\hline Mat_T_BO & R6 & $\begin{array}{l}\text { Stop Bottom } \\
\text { Outlet }\end{array}$ & $\begin{array}{l}\mathrm{Q}_{\mathrm{bo}}=0 \\
\mathrm{~m}^{3} / \mathrm{s}\end{array}$ & $\begin{array}{l}\text { Visp. } Q>\operatorname{Var} 7 m^{3} / s \quad \text { OR } \\
\text { [Visp. } Q>\operatorname{Var} 8 m^{3} / s \text { AND R6=true] }\end{array}$ \\
\hline Zer_T & R1 & $\begin{array}{l}\text { Regular Turbine } \\
\text { Program }\end{array}$ & $\begin{array}{l}\mathrm{Q}_{\text {tur }}=20 \\
\mathrm{~m}^{3} / \mathrm{s}\end{array}$ & $\begin{array}{lr}{\left[\mathrm{H}_{\text {zer }}>=1738 \mathrm{masl}\right.} & \text { OR } \\
{\left[\mathrm{H}_{\text {zer }}>1736.5 \mathrm{masl}\right.} & \text { AND } \\
\mathrm{H}_{\text {zer }}<1738 \mathrm{masl} \text { AND } & \mathrm{R} 1=\text { true }]] \\
\text { AND }[8: 00-20: 00] & \end{array}$ \\
\hline Zer_T & R2 & $\begin{array}{l}\text { Preventive } \\
\text { Turbine } \\
\text { Program }\end{array}$ & $\begin{array}{l}Q_{\text {tur }}=20 \\
\mathrm{~m}^{3} / \mathrm{s}\end{array}$ & $\begin{array}{l}\mathrm{H}_{\text {zer }}>\text { Var9masl } \\
\text { TS_Zermeiggern. } Q_{1 \mathrm{n}}>\operatorname{Var} 10 \mathrm{~m}^{3} / \mathrm{s}\end{array}$ \\
\hline Zer_T & R3 & $\begin{array}{l}\text { Stop Regular } \\
\text { Turbine } \\
\text { Program }\end{array}$ & $\begin{array}{ll}Q_{\text {tur }}= & 0 \\
m^{3} / s & \end{array}$ & $\mathrm{H}_{\mathrm{zer}}<=1736.5 \mathrm{mas} /$ \\
\hline Zer_T & R4 & $\begin{array}{l}\text { Stop Turbine } \\
\text { Program }\end{array}$ & $\begin{array}{ll}Q_{\text {tur }}= & 0 \\
\mathrm{~m}^{3} / \mathrm{s} & \end{array}$ & $\begin{array}{lr}{\left[\text { Visp.Q>Var11 } \mathrm{m}^{3} / \mathrm{s}\right.} & \text { OR } \\
{\left[\text { Visp.Q>Var12 } \mathrm{m}^{3} / \mathrm{s}\right.} & \text { AND } \\
\text { R4=true]] } & \text { AND } \\
\text { Mat_T_BO.Q. Q Down1 }=0 \mathrm{~m}^{3} / \mathrm{s} & \end{array}$ \\
\hline Zer_Pump & R1 & $\begin{array}{l}\text { Normal } \\
\text { Pumping }\end{array}$ & $\begin{array}{l}Q_{\text {pump }}=9 \\
\mathrm{~m}^{3} / \mathrm{s}\end{array}$ & $\begin{array}{l}{\left[\left[\mathrm{H}_{\mathrm{zer}}>1733 \mathrm{masl} \text { AND }\right.\right.} \\
\left.\mathrm{H}_{\mathrm{zer}}<=1736 \mathrm{mas} / \mathrm{AND} \mathrm{R} 1=\text { true }\right] \text { OR } \\
\left.\mathrm{H}_{\mathrm{zer}}>1736 \mathrm{mas} /\right] \quad \text { AND } \quad\left[\mathrm{V}_{\mathrm{mat}}<\right. \\
\left.\left.88.139 \mathrm{hm}^{3}\right] \text { AND [00:00 }-06: 00\right]\end{array}$ \\
\hline Zer_Pump & R2 & Stop Pumping & $\begin{array}{l}Q_{\text {pump }}=0 \\
\mathrm{~m}^{3} / \mathrm{s}\end{array}$ & $\begin{array}{l}\mathrm{H}_{\text {zer }}<1733 \mathrm{mas} / \\
\mathrm{V}_{\text {mat }}>=88.139 \mathrm{hm}^{3} \\
\text { Zer_T. Q } \text { Down } 1>0 \mathrm{~m}^{3} / \mathrm{s}\end{array}$ \\
\hline
\end{tabular}




\subsection{Optimization methodology implementation}

To reach an optimal solution, the EAs need one or more OFs. With the monoobjective SCE-UA algorithm and for Visp basin, the OF to minimize (Eq 2) is composed of three different objectives as they are described below.

$$
\text { Minimize } O F=O F_{1}+O F_{2}+O F_{3}
$$

The first objective $(\mathrm{Eq} 3)$ is related to the flood damage in the risk zone.

$$
O F_{1}=\left\{\begin{array}{c}
Q_{\max } \leq Q_{f l} \rightarrow 0 \\
Q_{f l}<Q_{\max }<Q_{e x} \rightarrow E D_{\max }\left[\delta+(1-\delta)\left(\frac{Q_{\max }-Q_{f l}}{Q_{e x}-Q_{f l}}\right)^{(1-\varphi)}\right] \\
Q_{\max }>Q_{e x} \rightarrow E D_{\max }
\end{array}\right\}(3)
$$

Where $Q_{f l}$ is the theoretical discharge for flooding $\left(190 \mathrm{~m}^{3} / \mathrm{s}\right), Q_{e x}$ is the probable maximum flood discharge $\left(590 \mathrm{~m}^{3} / \mathrm{s}\right), Q_{\max }$ is the maximum predicted discharge, $\mathrm{ED}_{\max }$ is a theoretical maximum expected damages in VISP area (CHF 441,000,000.00), $\delta$ is the initial damage parameter $(0.2)$ and $\varphi$ is a power function parameter (0.5).

The second OF (Eq 4) considers the revenue in the hydropower plants and the pumping cost.

$$
O F_{2}=\sum_{i=1}^{2}\left(\text { Revenue }_{\text {max }, i}-\text { Revenue }_{C, i}\right)+\text { Cost }_{\text {Pump }}
$$

Where Revenue $e_{c, i}$ is the cumulated revenue in the full optimization period for reservoir $i$; Revenue max, $_{i}$ is the revenue obtained if the height of the reservoir $i$ was always $H_{\max }$ and the turbinated flow was the maximum; and Cost $_{\text {pump }}$ is the cost of pumping from Zermeiggern to Mattmark. A cost of 0.1 $€ /$ KWh for peak hours and $0.01 € / K W h$ for off-peak hours are used to compute the revenue in the hydropower plants.

The last $\mathrm{OF}(\mathrm{Eq} 5$ ) is defined to take in account the potential revenue of future uses of the stored water.

$$
O F_{3}=\sum_{i=1}^{2}\left(A B S\left(V_{\max , i}-V_{\text {end }, i}\right) * C_{P R, i}\right)
$$


Where $\mathrm{V}_{\mathrm{max}, \mathrm{i}}$ is the maximum admissible volume in the reservoir $i ; \mathrm{V}_{\text {end, }}$ is the volume stored at the end of the optimization period; and $\mathrm{C}_{\mathrm{PR}, \mathrm{i}}$ is the unitary cost per cubic meter associated to this potential revenue.

The final target is to reduce the peak flow in the risk zone to minimize the cost computed with $\mathrm{OF}_{1}$. However, sometimes it will be necessary to stop the turbine process. For this reason, $\mathrm{OF}_{2}$ is defined to minimize the difference between the maximum revenue in normal conditions and the revenue obtained in the optimization. In other situations, it will be necessary to make preventive turbine programs providing enough space in the reservoirs to be able to store the flood water when it arrives. To avoid turbine all the time, the $\mathrm{OF}_{3}$ is defined in order to get more benefit storing the water in the reservoir at the end of the optimization period for future turbines.

Besides the OFs, two restrictions are considered in that optimization problem. Due to the time step of the simulation, defined in ten minutes, a non-valid operation in turbines could occur, i.e., the turbines could be activated and deactivated each ten minutes and this situation does not occur in the real cases. For this reason, a restriction is added to prevent this behaviour, remaining at least one hour in the same state (on or off). The other restriction is related to the maximum level in the reservoirs before the dam failure. In this case, the restriction is not included directly in the optimization process, but in the model. The spillways curve is modified to consider that if the level of the reservoir is bigger than a certain maximum level, the output flow thrown by the spillway is so big that the damage cost in the risk zone is not acceptable and the EA will discard this solution.

A combined OF is not needed in a multi-objective algorithm like NSGA-II, instead, the individual OFs (Eq 3, 4 and 5) are used to optimize the problem.

\section{Results and analysis}

The methodology previously exposed in Figure P4. 1 is applied to Visp basin with the goal of obtaining optimal management rules to minimize damages in flood zones and losses in hydropower plants. Both EAs detailed in this research are assessed to validate them as optimization tools in this field and to identify the best one. In this point, the set of tests is detailed and the 
general results are presented. Following this, the comparison between the algorithms and some techniques to select the system management by decision makers are shown.

A set of optimizations was conducted for each flood forecast available series. Furthermore, for each algorithm (SCE-UA and NSGA-II), the OT runs an optimization. Therefore, 14 optimization processes were carried out. Figure P4. 6 summarizes the results achieved with both algorithms ( $b$ and $c$ ) and the results obtained without a specific flood management (a). In order to compare the results, the NSGA-II results represent the solution with the minimum sum of three individual functions ( $\mathrm{Eq} 3,4$ and 5). This figure shows the four most representative forecast optimizations out of seven available forecasts.

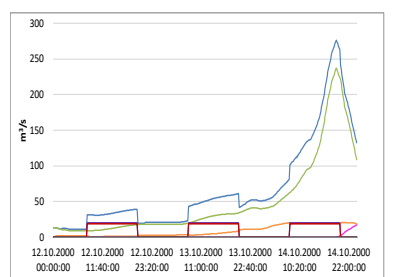

a1)

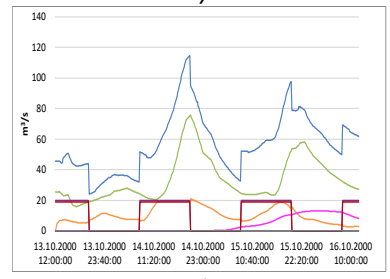

a4)

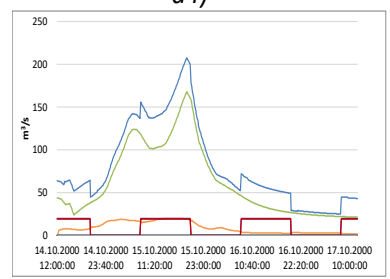

a6)

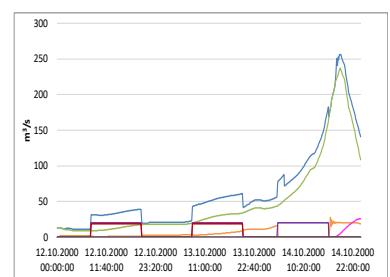

b1)

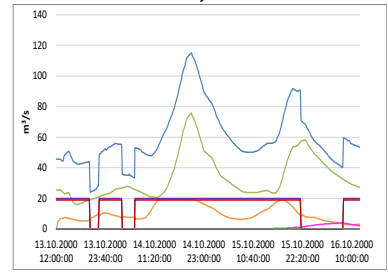

b4)

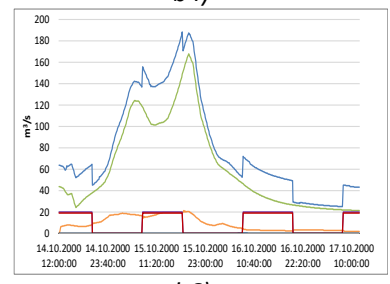

b6)

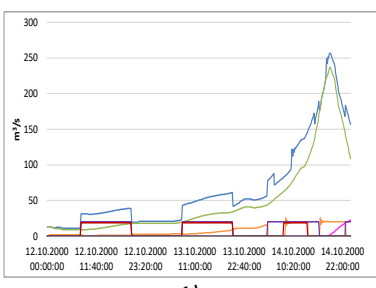

c1)

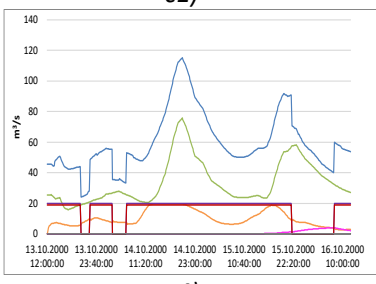

c4)

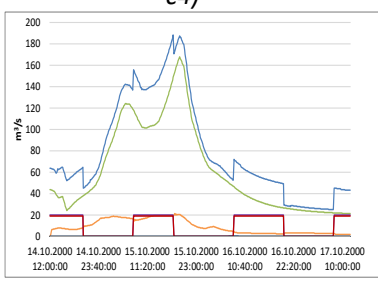

c6) 


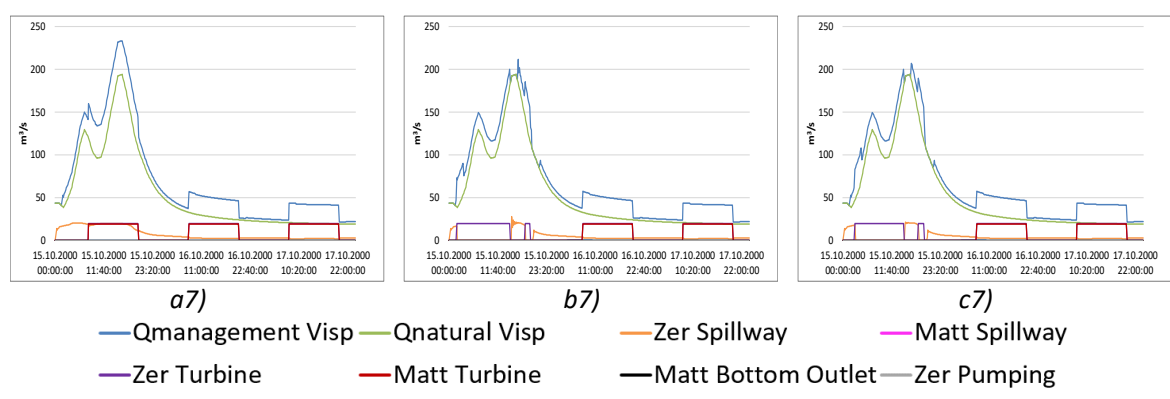

Figure P4. 6: Result comparative of four different forecasts using SCE-UA (b), NSGA-II (c) and without optimization (a). Where [Qmanagement Visp] = [Qnatural Visp]+[Upper river flow of Visp]+[Zer Turbine].

With Figure P4. 6 and Table P4. 2 the optimization process effectivity is demonstrated. In the four scenarios, the EA optimizations acquire an optimal management, saving a significant amount of money compared to the situation without a specific flood management. The saving range is from approximately CHF 15,000 (forecast 4) to CHF 160 million (forecast 6).

Table P4. 2: OF values for the analysed forecasts without optimization (a) and with SCE-UA (b) and NSGA-II (c) algorithms.

\begin{tabular}{|c|c|c|c|c|c|}
\hline & $\mathrm{OF}_{1}$ & $\mathrm{OF}_{2}$ & $\mathrm{OF}_{3}$ & & $O F_{k}$ \\
\hline a1) & CHF $252,100,947$ & 3,143 & CHF 160,626 & CHF & $252,264,717$ \\
\hline b1) & CHF $231,792,308$ & CHF 155,438 & CHF 122,491 & CHF & $232,070,238$ \\
\hline c1) & CHF $231,819,935$ & CHF 104,665 & CHF 141,751 & CHF & $232,066,352$ \\
\hline a4) & $\mathrm{CHF}$ & CHF $\quad-1,967$ & CHF 204,731 & CHF & 202,764 \\
\hline B4) & $\mathrm{CHF}$ & CHF $-54,097$ & CHF 241,608 & CHF & 187,510 \\
\hline c4) & $\mathrm{CHF}$ & CHF $-53,266$ & CHF 240,784 & CHF & 187,517 \\
\hline a6) & CHF $161,922,749$ & CHF $\quad-1,774$ & CHF 323,423 & CHF & $162,244,397$ \\
\hline b6) & $\mathrm{CHF}$ & CHF 56,841 & CHF 314,389 & CHF & 371,230 \\
\hline c6) & $\mathrm{CHF}$ & CHF $\quad 56,841$ & CHF 314,389 & CHF & 371,230 \\
\hline a7) & CHF $204,299,345$ & CHF $\quad 2,337$ & CHF 381,429 & CHF & $204,683,112$ \\
\hline b7) & CHF $170,256,342$ & CHF 156,194 & CHF 334,484 & CHF & $170,747,021$ \\
\hline c7) & CHF $160,473,643$ & CHF 154,984 & CHF 334,484 & CHF & $160,963,112$ \\
\hline
\end{tabular}


In forecast 1 , the peak of the flood is reached at the end of the optimized period and its value is $276 \mathrm{~m}^{3} / \mathrm{s}$ without a specific flood management (a). This value is reduced to $256 \mathrm{~m}^{3} / \mathrm{s}$ with both optimizations ( $b$ and $c$ ). This difference in the peak flood generates about CHF 20 Million of reduction in the damage costs $\left(\mathrm{OF}_{1}\right)$. However, the lost costs of hydropower plants $\left(\mathrm{OF}_{2}\right)$ are increased in only between $\mathrm{CHF} 100,000$ (c) and CHF 150,000 (b). The $\mathrm{OF}_{3}$ is reduced between CHF 20,000 (c) and $\mathrm{CHF} 40,000$ (b) because the reservoir level is higher than the situation without flood management (a). In case 4, both algorithms obtain the same solution, with a saving of CHF 15,000. This small reduction is due to the fact that the flood forecast is not very important, and without a specific flood management the flood does not cause any damage in the risk zone. Even so, this forecast is optimized because it is between two flood forecasts. In this situation, the improvement in the total OF is due to the reduction of the hydropower plant costs although the $\mathrm{OF}_{3}$ is increased. The $\mathrm{OF}_{2}$ negative value represents a preventive turbine program in addition to the normal turbine. Forecast 6 is the situation where the optimization tool demonstrates the importance of its use. In this case, without the optimization, the cost amounts to CHF 162 Million. However, both algorithms obtain the same reduction of the cost, around CHF 161 Million. Since the peak flood goes from more than $200 \mathrm{~m}^{3} / \mathrm{s}$ to less than 190 $\mathrm{m}^{3} / \mathrm{s}$, disappearing the damage cost in the flood zone, the previously mentioned reduction of costs is achieved. The behaviour of the $\mathrm{OF}_{2}$ and $\mathrm{OF}_{3}$ is similar to forecast 1 . The last forecast (7) is also similar to case 1 , but the peak is reached now at the beginning of the optimization period and there is a difference of CHF 10 Million between NSGA-II and SCE-UA solutions. This difference is focused in the damages reduction in the flood risk area.

Table P4. 3: Values for each optimized variable (b: SCE-UA; c:NSGA-II) in the four analysed forecast.

\begin{tabular}{|l|c|c|c|c|c|c|c|c|}
\hline & $\mathbf{1 b}$ & $\mathbf{1 c}$ & $\mathbf{4 b}$ & $\mathbf{4 c}$ & $\mathbf{6 b}$ & $\mathbf{6 c}$ & $\mathbf{7 b}$ & $\mathbf{7 c}$ \\
\hline Var1 (masl) & 2112.3 & 2209.4 & 2179.3 & 2118 & 2212.2 & 2212.2 & 2208.4 & 2113.1 \\
\hline Var2 (m3/s) & 36.5 & 40.1 & 23.2 & 23.4 & 37 & 65 & 2.9 & 83.4 \\
\hline Var3 (m3/s) & 69.6 & 142.7 & 144.5 & 170.4 & 186.4 & 186.2 & 128.2 & 61.1 \\
\hline Var4 (m3)s) & 22.9 & 26.6 & 15.4 & 47.9 & 39.3 & 48.7 & 29 & 14.9 \\
\hline Var5 (masl) & 2123.5 & 2121.7 & 2217 & 2218.3 & 2198.8 & 2210.9 & 2152.7 & 2174.2 \\
\hline
\end{tabular}




\begin{tabular}{|l|c|c|c|c|c|c|c|c|}
\hline Var6 $\left(\mathrm{m}^{3} / \mathrm{s}\right)$ & 66.9 & 40.5 & 4.8 & 67.8 & 37.7 & 55.1 & 74.9 & 69.2 \\
\hline $\operatorname{Var7}\left(\mathrm{m}^{3} / \mathrm{s}\right)$ & 88.9 & 55.3 & 175.2 & 102.2 & 87.7 & 126.1 & 145.5 & 67.5 \\
\hline $\operatorname{Var} 8\left(\mathrm{~m}^{3} / \mathrm{s}\right)$ & 7.5 & 43.7 & 40.6 & 13.8 & 18.6 & 17.3 & 40.7 & 37.6 \\
\hline $\operatorname{Var9}(\mathrm{mas})$ & 1730.5 & 1732.1 & 1729.9 & 1735.1 & 1735.2 & 1736.1 & 1729.1 & 1735.4 \\
\hline Var10 $\left(\mathrm{m}^{3} / \mathrm{s}\right)$ & 16.6 & 16.5 & 18.5 & 15.3 & 5.7 & 20.5 & 16.9 & 18 \\
\hline $\operatorname{Var11}\left(\mathrm{m}^{3} / \mathrm{s}\right)$ & 177.3 & 187.7 & 137.1 & 170.6 & 60.2 & 144.9 & 198.2 & 197.7 \\
\hline $\operatorname{Var12}\left(\mathrm{m}^{3} / \mathrm{s}\right)$ & 49.7 & 17.7 & 2.7 & 21.7 & 39.5 & 45.7 & 24.5 & 23.4 \\
\hline
\end{tabular}

Table P4. 3 shows the values for each decision variable (Var1-Var12) for SCEUA (b) and NSGA-II (c) algorithms. Although these values are different between both algorithms for the same forecast $(1,4,6$ or 7$)$, in turbines or bottom outlets on/off criteria represents almost the same. Only in forecast 4 , the results of both algorithms are different (as shown in Figure P4. 6, graphs b7 and c7).

\subsection{Algorithms assessment}

As it has been previously mentioned, both EAs optimize the management of the system in flood events. In some cases, the solution of the two algorithms is the same (just in terms of final cost; the decision variables could be different as Table P4. 3 shows) and in other cases NSGA-II results are better than SCE-UA.

SCE-UA has different stop criteria (e.g. maximum number of iterations or variation percentage of the OF) and the range of its time computation is between 18 and 35 minutes. However, NSGA-II computation time is the same in the different optimizations (30 minutes) because the number of individuals and the generations is equal in all of them. The value of these two parameters is fixed in order to the computation time will be similar for both algorithms. All optimizations are run with an Intel(R) Core(TM) i7-4790 CPU @ 3.60Ghz computer with 8 Gb of RAM.

In Table P4. 4 the iterations needed for each algorithm are represented. In all of the four forecast analysed in this section, SCE-UA algorithm takes less iterations than NSGA-II algorithms. However, in some other optimizations 
carried out in the research, SCE-UA requires more iterations to stop the optimization process, it sometimes reaches until 3242 iterations.

Table P4. 4: Optimization iterations for both algorithms in the four analysed forecasts.

\begin{tabular}{|l|l|l|}
\hline & SCE-UA & NSGA-II \\
\hline 1) & 2239 & 2500 \\
\hline 4) & 2151 & 2500 \\
\hline 6) & 1447 & 2500 \\
\hline 7) & 1764 & 2500 \\
\hline
\end{tabular}

Comparing the results of both algorithms on Table P4. 2, NSGA-II obtains better solutions than SCE-UA algorithm (only with NSGA-II result as sum of the different OFs). In forecast 1, NSGA-II reaches a bigger reduction of the hydropower plants $\left(\mathrm{OF}_{2}\right)$ at the expense of an increment of damage costs $\left(\mathrm{OF}_{1}\right)$. The Pareto front could contain other solutions with less damage costs. However, in forecast 4, NSGA-II gets best results in $\mathrm{OF}_{2}$ and $\mathrm{OF}_{3}\left(\mathrm{OF}_{1}\right.$ is equal to $\mathrm{CHF} 0$ in both cases), in forecast 6 has the same results for both algorithms and in forecast 7, the $\mathrm{OF}_{1}$ and $\mathrm{OF}_{2}$ are better with NSGA-II, where $\mathrm{OF}_{3}$ is equal in both of them.

The evolution of the individuals of both algorithms is shown in Figure P4. 7 for the four forecast series analysed. For each one, the figure contains one $3 \mathrm{D}$ plot and their corresponding $2 \mathrm{D}$ projections $\left(\mathrm{OF}_{1} \mathrm{vs}_{\mathrm{OF}}, \mathrm{OF}_{1} \mathrm{vs}_{\mathrm{OF}} \mathrm{OF}\right.$ and $\mathrm{OF}_{2}$ vs $\mathrm{OF}_{3}$ ). In all plots, the SCE-UA individuals are represented with blue points and NSGA-II individuals with orange triangles. Only the solutions that satisfy all restrictions are represented.

Figure P4. 71 and 4 manifest how management rules tested by SCE-UA cover more space than NSGA-II. It could be an advantage of this algorithm because, that way, it could obtain a better solution in some points of the search space. However, in Visp basin is not applicable because NSGA-II found the same or best solution without testing in a larger space. 


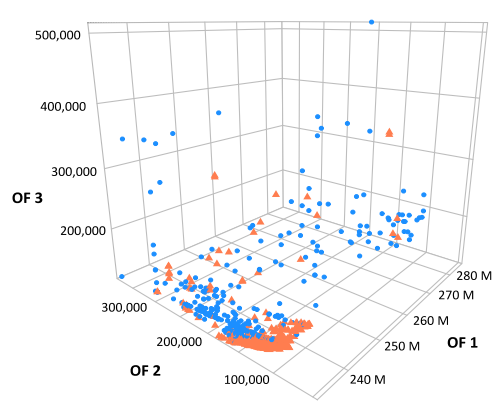

$1-\mathrm{i})$

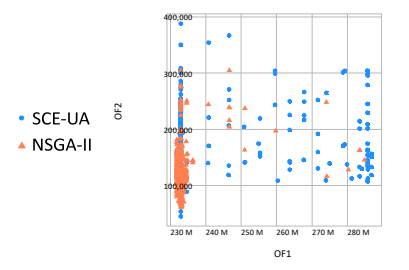

1-ii)

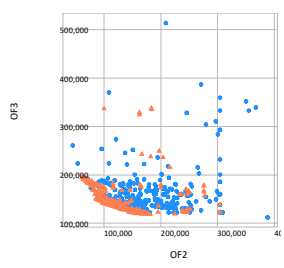

1-iv)

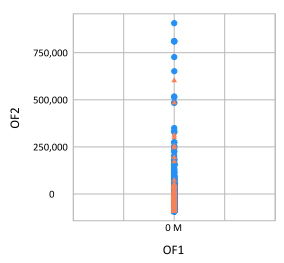

4-ii)

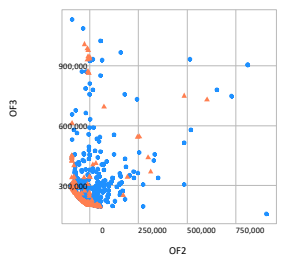

4-iv)

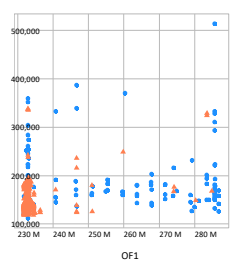

1-iii)

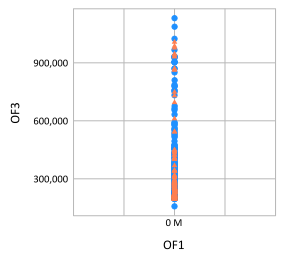

4-iii) 


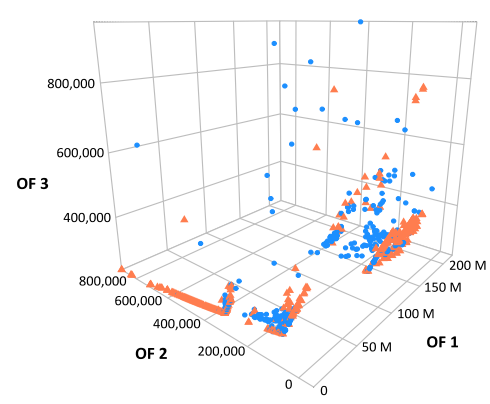

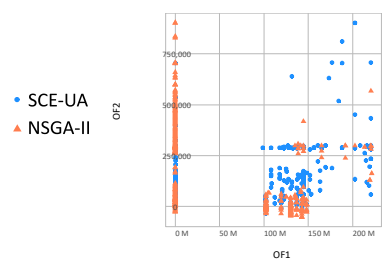

6-ii)

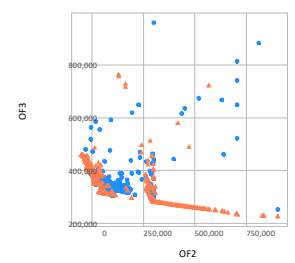

6-iv)

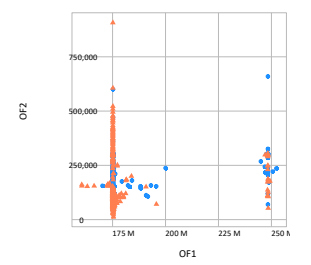

7-ii)

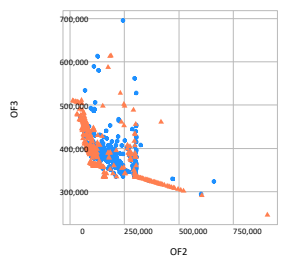

7-iv)

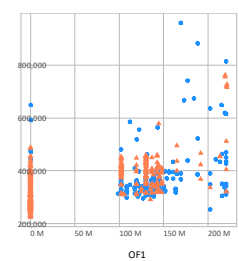

6-iii)

$6-i)$

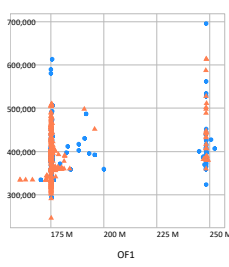

7-iii)

Figure P4. 7: NSGA-II (orange) vs SCE-UA (blue) search space for four different forecast. 3D view (i), OF1 vs OF2 (ii), OF1 vs OF3 (iii) and OF2 vs OF3 (iv).

In forecast 4 all the solutions demonstrate that a cost free management in risk zone $\left(O F_{1}\right)$ is possible. For this reason, analysing this situation is easier because only 4-iv projection $\left(\mathrm{OF}_{2}\right.$ vs $\left.\mathrm{OF}_{3}\right)$ contains points. Actually, this forecast does not cause any flood in the risk zone. However, the optimization is carried out because it is between two forecasts that cause floods. Moreover, depending on the levels of the reservoirs, the OT is useful to 
optimize the hydropower plants turbines and therefore, optimize the revenue.

In forecast 6 plots it is not easy to see the previous behaviour. In this case, there is a part of the space where there are more SCE-UA points and other space section where NSGA-II solutions are predominant. Even so, both algorithms reach the same best solution. Finally, in the last forecast of Figure P4. 7, solutions of both algorithms are grouped into two significant space zones regarding to $\mathrm{OF}_{1}$. There is a range in this $\mathrm{OF}$ in which any algorithm could find a valid solution. The reason of this issue is because of its own definition. The difference between the cost when the flow is higher or lower than $190 \mathrm{~m}^{3} / \mathrm{s}$, is reasonably significant. Moreover, in the NSGA-II optimization, it is possible to see how the best solution (less than CHF $175 \mathrm{M}$

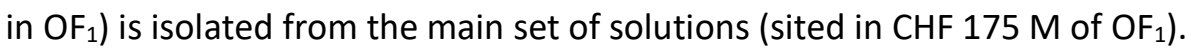
It could indicate that this solution was reached at the end of the process.

As it has been explained previously, NSGA-II is defined to find solutions that represent a Pareto front. This front contains all the rules that, in the solution space, individually satisfy the following: one rule gives a better value for one objective without also degrading the performance of at least another objective. For this reason, orange triangle points try to represent a Pareto front in all 3D plots (in forecast 6 is less noticeable). In this sense, it seems that the optimal search of NSGA-II, as a multi-objective algorithm, is better and more effective than SCE-UA algorithm.

\subsection{Management decision}

Once finished the optimization process, decision makers are responsible for selecting the best management to the system according to the different objectives and priorities. To facilitate this task, Pareto fronts could be the best tool because they only contain non-dominated solutions. When a management rule of the Pareto front is selected based on a specific OF (e.g. cost in flood zone), the two other OF values will be the minimum possible. If the solution set does not contain a defined Pareto front, Figure P4. 8 shows another alternative. This figure contains four plots whose points are coloured according to the global OF value. These plots allow to quickly identify the 
best rules obtained in the optimization process (considering that the best rule is obtained by minimizing all individual functions). In this case, only solutions achieved by NSGA-II algorithm, which provides better solutions, are represented.

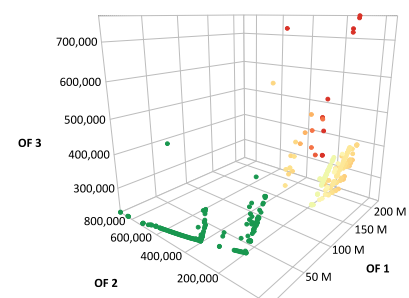

i)

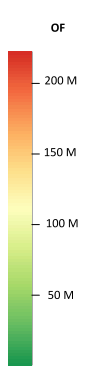

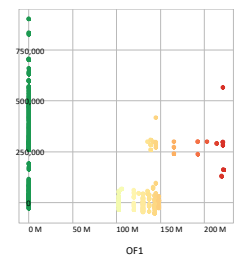

ii)

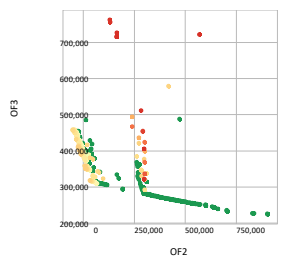

iv)

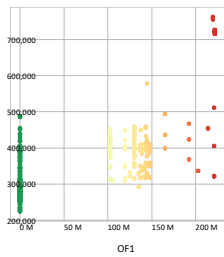

iii)

Figure P4. 8: Coloured plots of the NSGA-Il solutions for the forecast 6. 3D view (i), OF1 vs OF2 (ii), OF1 vs OF3 (iii) and OF2 vs OF3 (iv). From the worst solutions (red) to the best ones (green).

In this case, decision makers could have a look to the green points, which represent better solutions, and, from this set of points, select the best management for the system according to the three different OFs.

\section{Conclusions}

This research presents an approach to optimize the management in hydropower plants and reservoirs during flood events in Visp basin (Switzerland). A set of optimization processes is computed combining EAs with RS MINERVE tool. SCE-UA and NSGA-II algorithms were assessed as EAs to optimize this problem. Seven forecast series were available in Visp basin to apply the proposed methodology. 
Results of the optimization methodology show the effectivity of both algorithms to find optimal solutions and to reduce the final cost of the flood. In some cases, the two EAs obtained the same results (in terms of final cost) and in other cases, NSGA-II achieves better solutions than SCE-UA. Focusing on the individual OFs, when both algorithms found the same final OF, NSGAII usually gets better values for hydropower plants costs $\left(\mathrm{OF}_{2}\right)$ than SCE-UA which gets some more reduction of damages in the risk zone $\left(\mathrm{OF}_{1}\right)$. The advantage of the SCE-UA version used is its different stop criteria. They allow the algorithm, for example, to stop the optimization when the solution is not improved in consecutives steps without waiting to reach a specific number of iterations. This fact reduces the compute time of this algorithm. Meanwhile, NSGA-II always uses the same time because it has predefined the number of iterations based on the number of individuals and generations. Besides the advantage of reaching better solutions than SCE-UA in this research, it tries to find a Pareto front as 3D plots show. This Pareto front and its $3 \mathrm{D}$ view and $2 \mathrm{D}$ projections could help to the decision maker to select the best management rule for the system according to the different objectives.

The proposed approach is applied with forecast series, and the optimal management rules obtained are valid for these flood events. Normally, the forecast series does not represent perfectly the reality. For this reason, in our following research, a comparison between forecast series and real flow will be developed. We will try to identify if the optimization tool is useful when the management rules obtained with forecasts are applied in the system with real flood events.

\section{Acknowledgements}

The authors wish to thank the Spanish Ministry of Economy and Competitiveness for its financial support through the NUTEGES project (CGL2012-34978), the FPI fellowship (BES-2013-062954), and for the FPI stay (EEBB-I-16-10731). Additionally, we also value the support provided by the European Community's in financing the projects ENHANCE (FP7-ENV-2012, 308438), AGUAMOD (Interreg V-B Sudoe 2016), SWICCA (ECMRWFCopernicus-FA 2015/C3S_441-LOT1/SMHI) and IMPREX (H2020-WATER2014-2015, 641811). 


\section{References}

- Abd-Elhamid, H.F., Javadi, A.A., 2011. A Cost-Effective Method to Control Seawater Intrusion in Coastal Aquifers. Water Resour. Manag. 25, 2755-2780. doi:10.1007/s11269-011-9837-7

- Astorayme, M.A., García, J., Felipe, O., Suarez, W., Huggel, C., Molina, W., Sarango, D., 2016. Análisis comparativo de los modelos hidrológicos GR4J-SOCONT-HBV-SAC en la cuenca del río Chillón, Perú, in: XXVII Congreso Latinoamericano de Hidráulica -LADHI. International Association of Hydraulic Engineering and Research, IAHR. Lima, Perú, pp. 227-237.

- Astorayme, M.A., García, J., Suarez, W., Felipe, O., Huggel, C., Molina, W., 2015. Hydrological modeling with a semi-distributed approach in the Chillon River Basin, Peru. RPGA 4, 109-124.

- Boyle, D.P., Gupta, H. V., Sorooshian, S., 2000. Toward improved calibration of hydrologic models: Combining the strengths of manual and automatic methods. Water Resour. Res. 36, 3663-3674. doi:10.1029/2000WR900207

- Chang, F.-J., Chen, L., 1998. Real-Coded Genetic Algorithm for RuleBased Flood Control Reservoir Management. Water Resour. Manag. 12, 185-198. doi:10.1023/A:1007900110595

- Chang, L.-C., Chang, F.-J., 2009. Multi-objective evolutionary algorithm for operating parallel reservoir system. J. Hydrol. 377, 12-20. doi:10.1016/j.jhydrol.2009.07.061

- Chen, L., McPhee, J., Yeh, W.W.-G., 2007. A diversified multiobjective GA for optimizing reservoir rule curves. Adv. Water Resour. 30, 10821093. doi:10.1016/j.advwatres.2006.10.001

- Cisty, M., 2010. Hybrid Genetic Algorithm and Linear Programming Method for Least-Cost Design of Water Distribution Systems. Water Resour. Manag. 24, 1-24. doi:10.1007/s11269-009-9434-1

- Correa Flórez, C.A., Andrés Bolaños, R., Molina Cabrera, A., 2008. Algoritmo multiobjetivo NSGA-II aplicado al problema de la mochila. Sci. Tech. 2. 
- Deb, K., Pratap, A., Agarwal, S., Meyarivan, T., 2002. A fast and elitist multiobjective genetic algorithm: NSGA-II. IEEE Trans. Evol. Comput. 6, 182-197. doi:10.1109/4235.996017

- Deval, J., Luengo, J.A., Lorenzo, J.L., García, J., de Paz, M., 2011. Módulo nival en los modelos hidrológicos de la Confederación Hidrográfica del Cantábrico. Calibración y validación en Picos de Europa, Jornada Internacional del Agua. ISBN-13: 978-84-615-4023-5, Barcelona, Spain.

- Dias, N.L.C., Pereira, M.V.F., Kelman, J., 1985. Optimization of flood control and power generation requirements in a multi-purpose reservoir. In Proceedings of the IFAC symposium on planning and operation of electric energy systems, Rio de Janeiro, Brazil, pp. 121124.

- Drenkhan, F., Huggel, C., García, J., Seidel, J., 2016. Objetivos del modelamiento hidrológico integrado bajo cambios hidroclimáticos y socioeconómicos en la Cordillera Blanca, Perú. XXVII Congreso Latinoamericano de Hidráulica -LADHI. International Association of Hydraulic Engineering and Research, Lima, Perú, pp. 4259-4268.

- Duan, Q., Sorooshian, S., Gupta, V., 1992. Effective and efficient global optimization for conceptual rainfall-runoff models. Water Resour. Res. 28, 1015-1031. doi:10.1029/91WR02985

- Dumedah, G., Berg, A.A., Wineberg, M., Collier, R., 2010. Selecting Model Parameter Sets from a Trade-off Surface Generated from the Non-Dominated Sorting Genetic Algorithm-II. Water Resour. Manag. 24, 4469-4489. doi:10.1007/s11269-010-9668-y

- Farhangi, M., Bozorg-Haddad, O., Mariño, M.A., 2012. Evaluation of simulation and optimisation models for WRP with PIs. Proc. Inst. Civ. Eng. - Water Manag. 165, 265-276. doi:10.1680/wama.10.00046

- Farmani, R., Savic, D.A., Walters, G.A., 2005. Evolutionary multiobjective optimization in water distribution network design. Eng. Optim. 37, 167-183. doi:10.1080/03052150512331303436

- García, J., Claude, A., Paredes, J., Roquier, B., Boillat, J.-L., 2014. Integrated flood forecasting and management system in a complex catchment area in the Alps - Implementation of the MINERVE project in the canton of Valais, in: Schleiss, S.\& P. (Ed.), Swiss Competences in 
River Engineerig and Restoration. Taylor \& Francis Group, London, pp. 87-97. doi:doi:10.1201/b17134-12

- García, J., Paredes, J., Foehn, A., Roquier, B., 2016. RS MINERVE Technical manual v2.4.

- Hidalgo, I.G., Barros, R.S. De, Fernandes, J.P.T., Estrócio, J.P.F., Correia, P.B., 2015. Metaheuristic Approaches for Hydropower System Scheduling. J. Appl. Math. 2015, 6 pages. doi:doi:10.1155/2015/701851

- Jordan, F., García, J., Boillat, J.-L., Bieri, M., De Cesare, G., Schleiss, A., 2012. Prévision des crues sur le Yangtsé - Application du concept MINERVE, in: Wasser Energie Luft. Wasser Energie Luft, pp. 282-288.

- Kuczera, G., 1997. Efficient subspace probabilistic parameter optimization for catchment models. Water Resour. Res. 33, 177-185. doi:10.1029/96WR02671

- Lerma, N., Paredes-Arquiola, J., Andreu, J., Solera, A., 2013. Development of operating rules for a complex multi-reservoir system by coupling genetic algorithms and network optimization. Hydrol. Sci. J. 58, 797-812. doi:10.1080/02626667.2013.779777

- Lian, X., Jiang, T., 2005. Daily scheduling model and implementation in three gorges cascaded hydroelectric system. Adv. Syst. Sci. Appl. 5, 313-319.

- Lin, J.-Y., Cheng, C.-T., Lin, T., 2008. A Pareto Strength SCE-UA Algorithm for Reservoir Optimization Operation, in: 2008 Fourth International Conference on Natural Computation. IEEE, pp. 406-412. doi:10.1109/ICNC.2008.84

- Luce, C.H., Cundy, T.W., 1994. Parameter identification for a runoff model for forest roads. Water Resour. Res. 30, 1057-1069. doi:10.1029/93WR03348

- Lyra, C., Ferreira, L.R.M., 1995. A multiobjective approach to the shortterm scheduling of a hydroelectric power system. IEEE Trans. Power Syst. 10, 1750-1755. doi:10.1109/59.476038

- Makropoulos, C.K., Natsis, K., Liu, S., Mittas, K., Butler, D., 2008. Decision support for sustainable option selection in integrated urban water management. Environ. Model. Softw. 23, 1448-1460. doi:10.1016/j.envsoft.2008.04.010 
- Malekmohammadi, B., Zahraie, B., Kerachian, R., 2010. A real-time operation optimization model for flood management in river-reservoir systems. Nat. Hazards 53, 459-482. doi:10.1007/s11069-009-9442-8

- Muttil, N., Liong, S.-Y., 2004. Superior Exploration-Exploitation Balance in Shuffled Complex Evolution. J. Hydraul. Eng. 130, 12021205. doi:10.1061/(ASCE)0733-9429(2004)130:12(1202)

- Naresh, R., Sharma, J., 2000. Hydro system scheduling using ANN approach. IEEE Trans. Power Syst. 15, 388-395.

- Needham, J.T., Jr., D.W.W., Lund, J.R., Nanda, S.K., 2000. Linear Programming for Flood Control in the lowa and Des Moines Rivers. http://dx.doi.org/10.1061/(ASCE)0733-9496(2000)126:3(118). doi:10.1061/(ASCE)0733-9496(2000)126:3(118)

- $\quad \mathrm{Ni}, \mathrm{E}$., Guan, X., Li, R., 1999. Scheduling hydrothermal power systems with cascaded and head-dependent reservoirs. IEEE Trans. Power Syst. 14, 1127-1132.

- Perez, G., García, J., Rubio, H., Fluixá, J., 2016. Gestión de recursos hídricos con un modelo semi-distribuido en la cuenca del río Fuerte, México. XXVII Congreso Latinoamericano de Hidráulica -LADHI. International Association of Hydraulic Engineering and Research, IAHR, Lima, Perú, pp. 2931-2940.

- Piekutowski, M.R., Litwinowicz, T., Frowd, R.J., 1994. Optimal shortterm scheduling for a large-scale cascaded hydro system. IEEE Trans. Power Syst. 9, 805-811. doi:10.1109/PICA.1993.291004

- Reddy, M.J., Kumar, D.N., 2006. Optimal Reservoir Operation Using Multi-Objective Evolutionary Algorithm. Water Resour. Manag. 20, 861-878. doi:10.1007/s11269-005-9011-1

- Rodrigues, V.A., Lucas, M.E., García, J., Fluixá, J., Timoteo, M., Ranzini, M., 2016. Evaluación de los procesos hidrológicos y ciclo del agua en bosques tropicales con un modelo semi-distribuido. XXVII Congreso Latinoamericano de Hidráulica -LADHI. International Association of Hydraulic Engineering and Research, IAHR, Lima, Perú, pp. 2582-2589.

- Uysal, G., Akkol, B., Topcu, M.I., Sensoy, A., Schwanenberg, D., 2016. Comparison of Different Reservoir Models for Short Term Operation of Flood Management. 12th Int. Conf. Hydroinformatics 154, 13851392. doi:10.1016/j.proeng.2016.07.506 
- Villasanti, C.M., von Lucken, C., Baran, B., 2004. Dispatch of hydroelectric generating units using multiobjective evolutionary algorithms, in: IEEE/PES Transmision and Distribution Conference and Exposition: Latin America (IEEE Cat. No. 04EX956). IEEE, pp. 929-934. doi:10.1109/TDC.2004.1432507

- Wang, L., Nyunt, C.T., Koike, T., Saavedra, O., Nguyen, L.C., van Sap, T., 2010. Development of an integrated modeling system for improved multi-objective reservoir operation. Front. Archit. Civ. Eng. China 4, 47-55. doi:10.1007/s11709-010-0001-x

- Yeh, W.W.-G., 1985. Reservoir Management and Operations Models: A State-of-the-Art Review. Water Resour. Res. 21, 1797-1818. doi:10.1029/WR021i012p01797

- Zeng, Y., Lu, Z., Jiang, T., 2003. The model and application of daily optimal operation in three gorges cascaded hydroelectric systems. Adv. Syst. Sci. Appl. 3, 417-422.

- Zhang, G., Zhang, Y., 2003. Hydrothermal generation scheduling with a stochastic dual dynamic programming algorithm. Adv. Syst. Sci. Appl. 3, 383-389.

- Zhou, J., Zhang, Y., Zhang, R., Ouyang, S., Wang, X., Liao, X., 2015. Integrated optimization of hydroelectric energy in the upper and middle Yangtze River. Renew. Sustain. Energy Rev. 45, 481-512. doi:10.1016/j.rser.2015.01.022

- Zhu, X., Wu, J., Wu, J., 2006. Application of SCE-UA to Optimize the Management Model of Groundwater Resources in Deep Aquifers of the Yangtze Delta, in: First International Multi-Symposiums on Computer and Computational Sciences (IMSCCS'06). IEEE, pp. 303308. doi:10.1109/IMSCCS.2006.192 



\title{
A.5. Comparativa de herramientas para el desarrollo de Sistemas Soporte a la Decisión para los sistemas de recursos hídricos de Cerdeña, Italia. ${ }^{5}$
}

\author{
N. Lerma Elvira, A. Solera Solera, J. Andreu Álvarez, J. Paredes Arquiola
}

Instituto de Ingeniería del Agua y del Medio Ambiente (IIAMA). Área de Recursos Hídricos. Universitat Politècnica de València. Cno. de Vera $s / n$, 46022, Valencia.

G. Sechi, R. Zucca

Dipartimento di Ingegneria Civile, Ambientale e Architettura (DICAAR). Universidad de Cagliari. Via Marengo 2, 09131 Cagliari, Italia.

\section{Introducción}

Para el análisis y la planificación de sistemas de recursos hídricos se suele emplear habitualmente los modelos de simulación como herramienta de trabajo. Estos modelos se caracterizan por su flexibilidad y por su capacidad para contener elementos muy complejos en la modelización. Además, permiten una representación más detallada de los sistemas que los modelos de optimización (Loucks y Sigvaldason, 1982).

En general, la gestión de las cuencas se realiza mediante el apoyo de modelos de simulación. Esto no impide que para un paso de la simulación (por ejemplo

\footnotetext{
5 Lerma Elvira, Néstor; Solera Solera, Abel; Andreu Álvarez, Joaquín, Paredes Arquiola, Javier; Sechi, Giovanni M. y Zucca, Riccardo (2014). Comparativa de herramientas para el desarrollo de Sistemas Soporte a la Decisión para los sistemas de recursos hídricos de Cerdeña, Italia. Aplicaciones de Sistemas Soporte a la Decisión en Planificación y Gestión Integradas de Cuencas Hidrográficas (ed. Solera Solera A. et al.), pp. 85-94, Ed. Marcombo, Barcelona.
}

"Marcombo Técnicas Unidas" offered the reuse of its content for this thesis. 
el mes), se empleen técnicas de optimización (como las redes de flujo) para optimizar el reparto del recurso entre los distintos usuarios, y la procedencia del recurso entre las distintas fuentes o masas de agua. Labadie (2004) y Rani \& Moreira (2010) revisaron el estado del arte respecto a las técnicas de optimización utilizadas para sistemas multi-embalse, que representan la mayoría de los problemas de asignación de agua. En ambos artículos se indica que la técnica más favorable para los modelos de asignación de recursos hídricos ha sido la programación lineal. Sin embargo, la programación de redes de flujo es un método más eficiente computacionalmente en la programación lineal y, como demostró Kuczera (1989 y 1993), es más adecuado para resolver grandes sistemas multi-embalse.

En el proyecto RAS (RAS, 2013) se han analizado distintos Sistemas Soporte a la Decisión (SSD) con el fin de estudiar el sistema Tirso-FlumendosaCampidano. Para ello se ha desarrollado un modelo que describe su estado actual. A parte de este modelo, se han definido distintos escenarios que permiten tener en cuenta aspectos como la influencia de diferentes valores de caudales ecológicos, el posible fallo de infraestructuras, o también nuevas demandas e infraestructuras actualmente en construcción. Además, se han analizado una serie de nueve escenarios que permiten evaluar el comportamiento del sistema al aumentar la dotación de las demandas agrarias. Todos estos escenarios, incluyendo el modelo de la situación actual, se desarrollan con el fin de conocer en detalle el funcionamiento del sistema $y$ analizar los distintos SSD.

\section{Datos y Herramientas disponibles}

\subsection{Caso de estudio}

Cerdeña se encuentra en el mar Mediterráneo, entre la península Ibérica y la Italiana, y cubre un área aproximada de $24.000 \mathrm{~km}^{2}$ con una población de 1.648.000 habitantes. Comparándola con la Comunidad Valenciana, ésta tiene una superficie de $23.000 \mathrm{~km}^{2}$, prácticamente iguales, sin embargo, su población es de casi 5.000 .000 de habitantes. El clima de Cerdeña se clasifica generalmente como mediterráneo, con inviernos suaves y relativamente húmedos y veranos secos y cálidos. 
En Cerdeña, el sistema de suministro de agua se caracteriza principalmente por el uso de agua superficial almacenada y regulada por los embalses. El agua subterránea se utiliza únicamente para pequeños requerimientos locales. La zona presenta un gran número de sistemas de bombeo y conducciones para transportar el agua desde los embalses hasta los puntos de suministro. Un objetivo importante en su gestión consiste en reducir el coste de dichos bombeos, minimizando al mismo tiempo los déficits de las demandas.

\subsection{Herramientas}

Las herramientas estudiadas para analizar el sistema de recursos hídrico Tirso-Flumendosa-Campidano han sido: WARGI, AQUATOOL y AQUATOR.

WARGI (Water Resources System Optimization Aided by Graphical Interface) (Sechi \& Zuddas, 2000) fue desarrollado por CRIFOR-CINSA (Centro di Ricerca e Formazione delle Reti del Centro Interdipartimentale CINSA) de la Universidad de Cagliari y básicamente consta de tres módulos: uno para la simulación (WARGI-SIM), uno para la optimización (WARGI -OPT) y uno para el análisis de la calidad del recurso (WARGI -QUAL). EI SSD WARGI está dirigido principalmente para aplicarlo a los sistemas de suministro de recursos hídricos superficiales de varios embalses y multiusuario.

AQUATOOL (Andreu et al., 1996) es un entorno de desarrollo de SSD para planificación y gestión de cuencas o de sistemas de recursos hídricos. Como SSD proporciona recursos para ayudar al análisis de diversos problemas relacionados con la gestión del agua. La interfaz de usuario (AQUATOOLDMA) facilita el diseño de esquemas de trabajo y la gestión de datos y resultados. Dentro de esta interfaz se incluyen diversos módulos que ayudan a la planificación y gestión de sistemas de recursos hídricos como SIMGES, GESCAL, OPTIGES o SIMRISK. El módulo SIMGES (Andreu et al., 1992) es un modelo general para la Simulación de la Gestión de cuencas, o sistemas de recursos hidráulicos complejos, en los que se dispone de elementos de regulación o almacenamiento tanto superficiales como subterráneos, de captación, de transporte, de utilización y/o consumo, y de dispositivos de recarga artificial. 
AQUATOR es un software dedicado a la simulación de sistemas complejos de gestión del agua, desarrollado por Oxford Scientific Software desde 2001 y continuamente actualizado. Al igual que en los otros dos software, AQUATOR también permite la definición gráfica del sistema mediante la técnica de arrastrar y soltar los elementos (embalses, tuberías, equipos de bombeo, plantas de agua potable, pozos, etc.). El conjunto de componentes disponibles es, por supuesto, muy similar a la de otro software, pero con algunas diferencias debido al hecho de que AQUATOR ha sido concebido y diseñado para realizar la simulación de sistemas de agua en escala de tiempo corto, típicamente los días, con una gestión del flujo predominantemente controlada por la infraestructura, pero también tratando de modelar las interacciones con áreas de captación natural en el sistema.

Cada software y modelo de simulación tienen sus características únicas. No obstante, hay que señalar un aspecto que diferencia a los modelos de simulación considerados: AQUATOOL y AQUATOR utilizan módulos internos de optimización, algoritmos basados en out-of-kilter y programación lineal. Sin embargo, WARGI-SIM utiliza una técnica de simulación pura fundamentalmente sobre la base de un enfoque lógico "si-entonces". Aun así, dentro de WARGI-SIM hay una forma de definir el flujo óptimo, la cual se basa en la identificación del camino de menor coste entre un nudo y el nudo de aplicación del recurso empleando el algoritmo de Dijkstra (1959).

\section{Desarrollo del modelo}

Para analizar la gestión del sistema Tirso-Flumendosa-Campidano se ha desarrollado un modelo de simulación que representa el estado actual del sistema en términos de infraestructuras y dotación de las distintas demandas. Además de este modelo, se han implementado una serie de escenarios que contemplan distintas circunstancias: diferentes caudales ecológicos, fallo de infraestructuras, etc.

Tanto para el modelo que representa la situación actual como para los distintos escenarios desarrollados, el sistema completo Tirso-FlumendosaCampidano se divide en seis zonas: Taloro, Tirso (Oristanese), Ogliastra, Flumendosa-Campidano, Cixerri y Sulcis (Figura C1. 1). 


\subsection{Situación Actual}

Los aportes hidrológicos aplicados al sistema hidráulico se han obtenido a partir del documento regional de Cerdeña "Piano Stralcio di Utilizzo delle Risorse Idriche". En dicho documento se calculan series evaluadas a partir de las series temporales de precipitación. Concretamente series comprendidas entre los periodos 1922-1975 y 1986-2002. Estas series tienen en cuenta los efectos de las sequías producidas por la disminución de las aportaciones. Constituyen un período de 53 años y están asociadas a los embalses y azudes del sistema.

\begin{tabular}{|c|c|}
\hline & Aportación media (hm $\mathbf{3}$ /año) \\
\hline Taloro & 83.5 \\
\hline Tirso & 289.63 \\
\hline Ogliastra & 59.78 \\
\hline Flum-Camp & 356.22 \\
\hline Cixerri & 14.56 \\
\hline Sulcis & 39.55 \\
\hline
\end{tabular}

Tabla C1. 1: Valores medios de las aportaciones al sistema en las distintas zonas del sistema.

El sistema consta de 23 embalses cuyas capacidades varían entre los 0.94 $\mathrm{hm}^{3}$ y los $450 \mathrm{hm}^{3}$. Los más importantes son los embalses de Cantoneira (450 $\left.\mathrm{hm}^{3}\right)$, Monte Su Rei $\left(323 \mathrm{hm}^{3}\right)$ y Nuraghe Arrubiu $\left(300 \mathrm{hm}^{3}\right)$. El primero de estos tres embalses se encuentra en el río Tirso, en la zona de Oristanese y los otros dos en la zona Flumendosa-Campidano. 


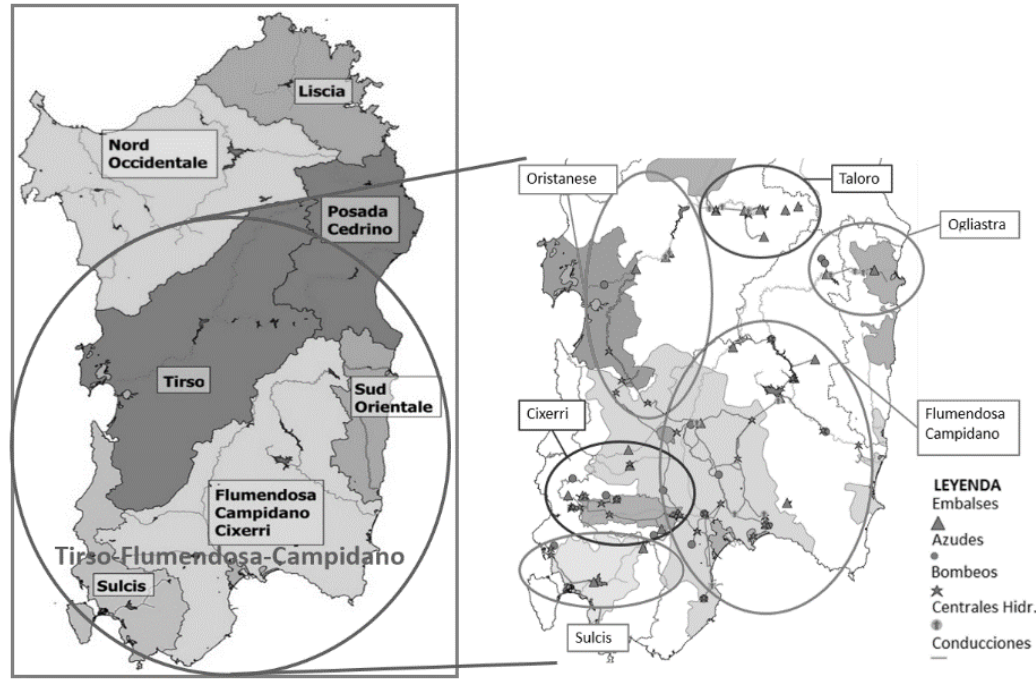

Figura C1. 1: Esquema del sistema Tirso-Flumendosa-Campidano.

En cuanto a los azudes, el sistema presenta un total de 14 infraestructuras con distintos caudales de extracción de agua. Estos caudales varían entre 0.2 y $36 \mathrm{~m}^{3} / \mathrm{s}$. Los más importantes son los de la cabecera del río Flumendosa, en la zona de Ogliastra (Bau Mela y Bau Mandara), al este de los embalse de Monte Su Rei y Nuraghe Arrubiu (Ponte Maxia), y al oeste de éstos (Casa Fiume).

El número total de centrales hidroeléctricas es de 14, donde sus caudales turbinados varían entre los 0.5 y $95 \mathrm{~m}^{3} / \mathrm{s}$. La más importante es la que se encuentra aguas abajo del embalse de Gusana, en la zona de Taloro.

Los sistemas de bombeo son obras de infraestructuras a las cuales se les da gran importancia debido al coste económico que suponen. El sistema consta de 23 bombeos cuyo caudal máximo está comprendido entre los 0.07 y los 6 $\mathrm{m}^{3} / \mathrm{s}$. Sus coste unitarios varían entre los 0.005 y los $0.11 € / \mathrm{m}^{3}$.

El sistema tiene un total de 15 demandas urbanas, 6 industriales y 23 agrarias. Las demandas urbanas tienen dotaciones comprendidas entre los 0.2 y los $41.4 \mathrm{hm}^{3} / a n ̃ o$, siendo la más importante la de la ciudad de Cagliari. Las demandas industriales varían entre 0.04 y $11.6 \mathrm{hm}^{3} / a n ̃ o$ y las agrarias 
entre 0.1 y $75 \mathrm{hm}^{3} /$ año. Como se puede observar, los valores de las dotaciones son muy dispares. Respecto a las demandas agrarias, las dos demandas más importantes son las de Oristanese con 43 y $75 \mathrm{hm}^{3} /$ año.

La gestión de las demandas conlleva dar más prioridad a las urbanas, seguidas de las industriales y por último las agrarias. En el caso de los bombeos, se tiene en cuenta el coste económico unitario de cada sistema de bombeo. En el caso de AQUATOOL, en algunos bombeos se han impuesto unos costes en función del valor económico asociado a cada uno de ellos, y en otros casos se han definido otros costes en AQUATOOL con el objetivo de minimizar al máximo el coste económico producido por los sistemas de bombeos. Además de esta gestión, en AQUATOOL se introducen prioridades entre las demandas, entre los embalses, reglas de operación, etc.

\subsection{Escenarios}

Como se ha comentado anteriormente, se han simulado una serie de escenarios para introducir distintas casuísticas, además de permitir entender con más detalle el comportamiento del sistema.

Los dos primeros escenarios tienen en cuenta la influencia de los caudales ecológicos. Cada escenario introduce un caudal distinto en 17 tramos de río aguas abajo de algunos de los embalses del sistema. La diferencia entre los dos escenarios es la obtención de dichos caudales ecológicos. Uno se obtiene a partir de la repartición espacial (según la superficie de los embalses) de una cantidad teórica de $42 \mathrm{hm}^{3}$ distribuidos en los meses de verano. En el segundo caso, el caudal ecológico se considera el $5 \%$ de las aportaciones que entran a los embalses. En estos escenarios se le ha dado mayor prioridad al suministro a las demandas que al propio caudal ecológico, debido a que en Cerdeña no se le da la misma importancia que en España.

El primer escenario es el que más se acerca a la gestión actual del caudal ecológico. Por esto, ha sido definido como "modelo base" y utilizado para la primera comparación entre los tres SSD. Además, los valores de caudal ecológico de este primer escenario han sido utilizados en el resto de escenarios (fallo de infraestructuras y escenarios futuros). 
Los siguientes escenarios analizan el posible fallo de infraestructuras. Tratan de analizar qué podría ocurrir y a qué demandas afectaría el fallo de alguna infraestructura durante un periodo determinado de la simulación. En concreto, se han desarrollado tres escenarios de este tipo. En el primero se ven afectados una serie de bombeos de la zona sur del sistema durante un periodo de 6 meses. En el segundo escenario, un embalse sufre filtraciones y debe estar un periodo de dos años reparándose $y$, por tanto, sin poder almacenar agua. El tercer y último escenario de este tipo afecta a una central hidroeléctrica, aguas abajo de uno de los embalses principales del sistema, la cual está 6 meses fuera de servicio.

Otro escenario permite tener en cuenta la aparición de nuevas demandas e infraestructuras, actualmente en construcción. Este escenario define la situación futura del sistema. Se introducen nuevos sistemas de bombeo, nuevas demandas (suministradas por dichos bombeos), un nuevo azud (con su aportación) y una conducción desde un embalse que evitará el uso de un bombeo que se emplea actualmente.

Los últimos nueve escenarios definidos permiten evaluar el comportamiento del sistema al aumentar la dotación de las demandas agrarias. En cada escenario se va incrementando dicha dotación en distintas zonas del sistema, llegando al quinto escenario en el que empiezan a aumentarse todas las demandas agrarias del sistema al mismo tiempo. En el último escenario, todas estas demandas alcanzan la dotación que históricamente les correspondería tener, y que actualmente se ve reducida por la falta de recursos en el sistema.

Para cada uno de los distintos escenarios se ha ido ajustando la gestión para adaptarse a los nuevos cambios, evitando que las demandas sufran más déficits (en la medida de lo posible).

\section{Resultados}

Los resultados obtenidos en los distintos SSD se resumen en este punto. En primer lugar, se muestran los correspondientes al modelo base que 
representa el estado actual con la primera hipótesis de caudal ecológico y, seguidamente, los proporcionados por los otros escenarios diseñados.

\subsection{Modelo base}

Una vez simulada la gestión del sistema mediante los distintos módulos de cálculo se obtienen una serie de resultados. De todos estos resultados, aquí se comentan únicamente resultados de déficits en las demandas, volúmenes almacenados y caudales bombeados, los cuales proporcionan una buena descripción del estado del sistema.

\begin{tabular}{|c|c|c|c|c|c|c|}
\cline { 2 - 7 } \multicolumn{1}{c|}{} & \multicolumn{2}{c|}{ WARGI } & \multicolumn{2}{c|}{ AQUATOR } & \multicolumn{2}{c|}{ AQUATOOL } \\
\cline { 2 - 7 } & $\begin{array}{c}\text { Déficit } \\
\text { Promedio } \\
(\%)\end{array}$ & $\begin{array}{c}\text { Máximo } \\
\text { déficit } \\
\text { anual } \\
(\%)\end{array}$ & $\begin{array}{c}\text { Déficit } \\
\text { Promedio } \\
(\%)\end{array}$ & $\begin{array}{c}\text { Máximo } \\
\text { déficit } \\
\text { anual } \\
(\%)\end{array}$ & $\begin{array}{c}\text { Déficit } \\
\text { Promedio } \\
(\%)\end{array}$ & $\begin{array}{c}\text { Máximo } \\
\text { déficit } \\
\text { anual } \\
(\%)\end{array}$ \\
\hline Urbano & 0.29 & 4.97 & 0.34 & 5.29 & 0.15 & 3.30 \\
\hline Industrial & 0 & 0 & 0.03 & 0.21 & 0 & 0 \\
\hline Agrario & 0.60 & 5.92 & 0.29 & 4.33 & 0.41 & 3.30 \\
\hline Total & $\mathbf{0 . 4 6}$ & $\mathbf{5 . 2 3}$ & $\mathbf{0 . 2 9}$ & $\mathbf{4 . 3 9}$ & $\mathbf{0 . 3 0}$ & $\mathbf{3 . 1 0}$ \\
\hline
\end{tabular}

Tabla C1. 2: Déficits por tipo de demanda para los distintos SSD (modelo base).

En la Tabla C1. 2 se muestra para cada SSD el déficit promedio y el máximo déficit anual de las demandas urbanas, industriales y agrarias. Para todos los SSD las demandas que menos déficit deberían sufrir son las urbanas (debido a la prioridad que tienen frente al resto). Principalmente el déficit que se muestra es debido a una demanda de la zona de Taloro que debido a su ubicación en la cabecera del sistema y a la falta de aportaciones en dicha zona, no puede ser suministrada al $100 \%$. Las industriales tienen menos déficits que las urbanas debido a que el número de demandas de este tipo es mucho menor y debido a su localización pueden ser suministradas en WARGI y AQUATOOL al $100 \%$ y en AQUATOR prácticamente al máximo. Por último, las demandas agrarias son las que mayor déficit tienen (déficit promedio), siendo AQUATOR el que consigue reducir más el déficit de estas demandas. Si se atiende al déficit de todas las demandas, es en AQUATOOL 
donde se consigue reducir más el máximo déficit anual. AQUATOR consigue reducir el déficit promedio total, aunque obtiene los déficits más altos (promedio y máximo anual) para las dos demandas prioritarias (urbanas e industriales).

En relación al caudal ecológico, de los 17 tramos de río con éste, el número de tramos que sufren déficits en su suministro son: 7 en WARGI, 5 en AQUATOR y 4 en AQUATOOL.

En la Tabla C1. 3 se observa un resumen de los volúmenes almacenados en todos los embalses del sistema y el caudal bombeado por todos los sistemas de bombeo. Fijándose en el primer aspecto, el SSD que más volumen almacena es AQUATOOL, seguido de AQUATOR y por último WARGI. En el caso del caudal bombeado ocurre algo similar, en este caso también es AQUATOOL el SSD que menos caudal bombea, seguido de AQUATOR.

\begin{tabular}{|c|c|c|c|}
\cline { 2 - 4 } \multicolumn{1}{c|}{} & WARGI & AQUATOR & AQUATOOL \\
\hline Volumen almacenado (\%) & 63 & 68 & 77 \\
\hline Bombeo (Hm³/año) & 76.91 & 70.57 & 67.07 \\
\hline
\end{tabular}

Tabla C1. 3: Volúmenes almacenados en los embalses y caudales bombeados en los distintos SSD.

En general se puede ver cómo los resultados de AQUATOOL son más óptimos en términos de déficits, volúmenes almacenados y caudales bombeados que los obtenidos con WARGI y AQUATOR. Pero también habría que estudiar otros aspectos como el coste económico del bombeo (puesto que no todos los sistemas de bombeo tienen el mismo precio) o las centrales hidroeléctricas. Aún con ello, estos resultados pueden deberse al hecho que se ha comentado anteriormente de que AQUATOR y AQUATOOL emplean técnicas de optimización en cada uno de los pasos de tiempo de la simulación.

\subsection{Escenarios}

En el otro escenario que incluye diferentes valores de caudal ecológico se obtienen los mismos resultados mostrados para el "modelo base" de déficits 
en las demandas (debido a la prioridad más alta de suministro a las demandas) y pequeñas modificaciones en los volúmenes almacenados y en los caudales bombeados.

En el caso de los escenarios desarrollados para analizar el posible fallo de infraestructuras se observa como durante el periodo de fallo, y según la infraestructura que tiene el problema, afecta a un mayor o menor número de demandas. En el caso de aquellas infraestructuras que están al sur del sistema, afectan a un número reducido de demandas (1-2); sin embargo, si se encuentran en un punto estratégico de suministro, afectan a gran parte de las demandas de la zona de Flumendosa-Campidano. En este caso los tres SSD han proporcionado resultados similares.

Gracias a la nueva aportación y los nuevos bombeos introducidos en el escenario que representa la situación futura del sistema, se consigue disminuir el número de demandas con déficit, aumentando el coste económico de los bombeos, ya que para suministrar a las nuevas demandas se requiere su funcionamiento. Los resultados obtenidos reflejan las mismas diferencias entre los tres SSD que en el "modelo base".

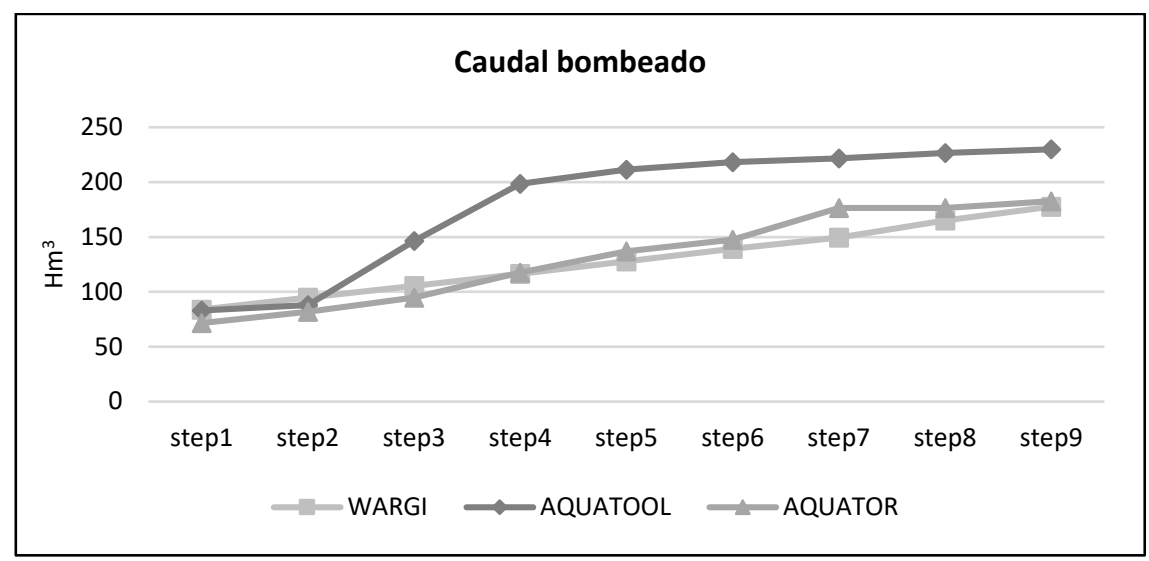

Figura C1. 2: Caudal bombeado en los escenarios futuros.

Para terminar, los escenarios de incremento de la dotación de las demandas agrarias. En los cuatro primeros escenarios de este tipo sólo se ve afectada la zona de Cixerri que ya sufría déficits en el "modelo base". A partir del quinto escenario, en que se aumentan todas las dotaciones de las demandas 
agrarias del sistema a la vez, el déficit y los caudales bombeados se ven incrementados alcanzando valores más elevados a los actuales.

En la Figura C1. 2 se observa la evolución del caudal bombeado en los nueve escenarios (step 1-9) de incremento de dotaciones agrarias. Respecto al déficit, la Tabla C1. 4 muestra los valores de tres escenarios (tercero, sexto y noveno) representativos del análisis.

\begin{tabular}{|c|c|c|c|c|c|c|c|c|c|}
\cline { 2 - 11 } \multicolumn{1}{c|}{} & \multicolumn{3}{c|}{ Déficit Promedio (\%) } \\
\cline { 2 - 11 } \multicolumn{1}{c|}{} & \multicolumn{3}{c|}{ Step 3 } & \multicolumn{3}{c|}{ Step 6 } & \multicolumn{3}{c|}{ Step 9 } \\
\cline { 2 - 11 } & WARGI & AQUATOR & AQUATOOL & WARGI & AQUATOR & AQUATOOL & WARGI & AQUATOR & AQUATOOL \\
\hline Urb. & 0.3 & 3.3 & 0.1 & 0.3 & 12.1 & 0.2 & 0.3 & 18.9 & 0.2 \\
\hline Ind. & 0 & 1.1 & 0 & 0 & 5.6 & 0 & 0 & 8.4 & 0 \\
\hline Agr. & 5.9 & 4.0 & 2.3 & 21.3 & 14.0 & 17.0 & 39.5 & 28.3 & 35.1 \\
\hline Tot. & $\mathbf{4 . 0}$ & $\mathbf{3 . 5}$ & $\mathbf{1 . 6}$ & $\mathbf{1 6 . 2}$ & $\mathbf{1 3 . 3}$ & $\mathbf{1 2 . 9}$ & $\mathbf{3 2 . 3}$ & $\mathbf{2 6 . 5}$ & $\mathbf{2 8 . 7}$ \\
\hline
\end{tabular}

Tabla C1. 4: Déficits promedio por tipo de demanda para los distintos SSD en los escenarios futuros.

La Figura C1. 2 muestra como AQUATOOL es el que más caudal bombea (buscando reducir los déficits), frente a valores similares entre WARGI y AQUATOR. Atendiendo a los déficits, WARGI y AQUATOOL mantienen valores similares al escenario actual (modelo base) para las demandas urbanas e industriales, al contrario que AQUATOR que no consigue mantener la prioridad de los usuarios.

En general, se puede afirmar que AQUATOR es lo que proporciona resultados menos apropiados, AQUATOOL obtiene déficits menores en las demandas frente a un uso mayor de los bombeos, al contrario que WARGI que proporciona más déficit frente a un ahorro de caudal bombeado.

\section{Optimización}

Tras el análisis de los distintos escenarios, se plantea la aplicación de una metodología que permita optimizar las reglas de gestión que se han definido en el modelo con el fin de minimizar los déficits obtenidos en las demandas, así como reducir el coste económico de los sistemas de bombeo. Con este 
fin, se ha empleado, por un lado, el módulo SIMGES para la simulación de la gestión del SSD AQUATOOL, y por otro lado, algoritmos evolutivos, como herramientas que permiten controlar las sucesivas simulaciones de SIMGES. Los algoritmos empleados son el SCE-UA y el Scatter Search.

El mecanismo de optimización SCE-UA (The Shuffled Complex Evolution) (Duan et al. 1992) tiene una eficiencia que ha sido ampliamente reconocida ante problemas de calibración de modelos hidrológicos con un elevado número de parámetros y una alta no linealidad. El funcionamiento básico del algoritmo está inspirado en los principios de selección natural y la genética y es una combinación de procedimientos deterministas y aleatorios. Se parte de diferentes puntos de búsqueda (individuos) que se organizan por equipos. De esta manera, la búsqueda de la solución global óptima se plantea como un proceso evolutivo basado en la reproducción (cruce, mutación, recombinación) existiendo, además, mezcla de equipos.

Por otro lado, el Scatter Search (Glover, F. 1997), también conocido en castellano como Búsqueda Dispersa, es un procedimiento metaheurístico. Los conceptos y principios fundamentales del método están basados en las estrategias para combinar reglas de decisión. Scatter Search opera sobre un conjunto de soluciones, llamado conjunto de referencia, combinando éstas para crear nuevas soluciones de modo que mejoren a las que las originaron. En este sentido se dice que es un método evolutivo. Sin embargo, a diferencia de otros métodos evolutivos, como los algoritmos genéticos, Scatter Search no está fundamentado en la aleatorización sobre un conjunto relativamente grande de soluciones sino en elecciones sistemáticas y estratégicas sobre un conjunto pequeño.

La metodología a emplear se lleva a cabo a través de una aplicación en MS Excel, en la que se incluye los códigos de los algoritmos evolutivos, así como distintas hojas de cálculo con los resultados de la simulación con SIMGES. Lo primero que el usuario debe hacer es imponer los parámetros con los que se quiere lanzar el algoritmo (semillas, probabilidad de cruce, tipo de mutación, número de complejos, etc.). A continuación se definen las variables que el algoritmo ha de ir modificando (variables de decisión), en este caso las reglas de decisión que se pretendan optimizar, así como los límites inferiores y 
superiores de estas variables. Llegados a este punto, se ejecuta el algoritmo de optimización, el cual va generando esas variables de decisión. Para cada generación (o iteración) se escribe el archivo de datos necesario para la simulación y, una vez escrito se lanza SIMGES, que simula la gestión propuesta guardando los resultados en un archivo. Este archivo permite obtener entre otras cosas los déficits de las distintas zonas y los bombeos, y así poder evaluar una función objetivo. Ésta es utilizada por los algoritmos evolutivos para buscar el resultado más óptimo. Una vez evaluada, si no se cumple el criterio de parada, se repite el mismo proceso a partir de la generación de las variables de decisión, buscando la optimización de la gestión.

Finalizado el proceso realizado por la aplicación, es el turno del usuario para analizar los resultados y tomar decisiones. Los resultados obtenidos en este trabajo, para el modelo que representa el estado actual del sistema, muestran un descenso en el número de demandas con déficit y en su máximo déficit anual. Además, también se consigue reducir el coste económico producido por el empleo de los sistemas de bombeos.

\section{Conclusiones}

En este trabajo se han examinado distintos SSD (WARGI, AQUATOR y AQUATOOL) para analizar la gestión en el sistema Tirso-FlumendosaCampidano, en la isla de Cerdeña (Italia), a través de un modelo de simulación. Junto con este modelo, se han desarrollado también una serie de escenarios que han permitido tener en cuenta y analizar distintos aspectos como los caudales ecológicos, el fallo de infraestructuras, escenarios futuros e incrementos en las demandas.

Los tres SSD analizados proporcionan resultados semejantes en términos de déficits de demandas, volúmenes almacenados en los embalses y caudales bombeados, sin embargo, AQUATOOL parece proporcionar resultados algo más óptimos, en términos de minimización de déficits. Este hecho puede ser debido a que AQUATOOL emplea técnicas de optimización para cada intervalo de tiempo de la simulación, pero además, hay que tener en cuenta 
que en AQUATOOL se puede definir más aspectos para regular la gestión del sistema.

Respecto a la optimización llevada a cabo, se ha demostrado una mejora en la gestión del sistema con menos déficits y costes de bombeo. Esta técnica se pretende emplear en los distintos escenarios desarrollados, con el fin de obtener en cada uno de ellos una gestión más óptima de la alcanzada.

\section{Agradecimientos}

Los autores desean dar las gracias a la Universidad de Cagliari (Cerdeña) y a la Agencia de Cuenca de Cerdeña (Ente acque della Sardegna - ENAS) por los datos proporcionados en el desarrollo de este estudio. Al Ministerio de Ciencia e Innovación de España (Comisión Interministerial de Ciencia y Tecnología, CICYT) por la financiación de los proyectos NUTEGES (VI Plan Nacional de I+D+i 2008-2011, CGL2012-34978) y SCARCE (programa Consolider-Ingenio 2010, proyecto CSD2009-00065). Los autores también quieren dar las gracias a la Comisión Europea (Directorate-General for Research \& Innovation) por la financiación del proyecto DROUGHT-R\&SPI (programa FP7-ENV-2011, proyecto 282769), al séptimo programa marco de la Comisión Europea por financiar el proyecto SIRIUS (FP7-SPACE-2010-1, proyecto 262902) y al proyecto ENHANCE (FP7-ENV-2012, proyecto 308438).

\section{Referencias}

- Andreu, J., Solera, A., Capilla, J. y Ferrer, J. (1992): “Modelo SIMGES de simulación de la gestión de recursos hídricos, incluyendo utilización conjunta". Manual de usuario. Universidad Politécnica de Valencia.

- Andreu, J., Solera, A., Paredes, J. (1996): "AQUATOOL SSD para Planificación de Cuencas. Manual de usuario v1.0". DIHMA, Universidad Politécnica de Valencia.

- Dijkstra, E. (1959): "A note of two problem in connexion with graph", Numeriche Mathematik 1, 269-271.

- Duan, Q., Sorooshian, S., Gupta, V. (1992). "Effective and efficient global optimization for conceptual rainfall-runoff models". Water Resources Research, Vol. 28, No. 4, pp. 1015-1031. 
- Glover, F. (1977): “Heuristics for Integer Programming using surrogate constraints". Decision Sciences 8, 156-166

- Kuczera, G., (1989): “Fast Multireservoir Mulltiperiod Linear Programming Models". Water Resources Research 25:169- 176.

- Kuczera, G., (1993): "Network linear programming codes for watersupply headworks modeling". Journal of Water Resources Planning and Management 119:412-417.

- Labadie, J., (2004): "Optimal Operation of Multireservoirs Systems: State-of-the-Art Review" Journal of Water Resources Planning and Management 130 N2 March 1.

- Loucks, D. P., y Sigvaldason, O.T. (1982): “Multiple reservoir operation in North America. In The Operation of Multiple Reservoir Systems". Edited by Z. Kaczmarck and J. Kindler, IIASA Collab. Proc. Ser., CP-8253, pp. 1-103.

- Rani, D. and Moreira, M., (2010): "Simulation-optimization modeling: a survey and potential application in reservoir systems operation". Water Resources Management 24:1107-1138.

- RAS, (2013): Final Report of the RAS Project: "Decision support system models development for multi-use water resource systems in water scarcity conditions using mixed simulation-optimization techniques" In press.

- Sechi G.M. y Zuddas P. (2000): “WARGI: Water Resources System Optimization Aided by Graphical Interface". In W.R. Blain \& C.A. Brebbia: Hydraulic Engineering Software. WIT-PRESS, pp 109-120. 